TÂMIRA TÁCITA MAIA RODRIGUES

ESTUDO DA PIRÓLISE DA MICROALGA Chlorella vulgaris:

DETERMINAÇÃO DAS CLASSES DE PRODUTOS E DOS

PARÂMETROS CINÉTICOS

São Paulo 
TÂMIRA TÁCITA MAIA RODRIGUES

ESTUDO DA PIRÓLISE DA MICROALGA Chlorella vulgaris:

DETERMINAÇÃO DAS CLASSES DE PRODUTOS E DOS

PARÂMETROS CINÉTICOS

\author{
Tese apresentada à Escola Politécnica \\ da Universidade de São Paulo para \\ obtenção do título de Doutora em \\ Ciências.
}

São Paulo 


\section{ESTUDO DA PIRÓLISE DA MICROALGA Chlorella vulgaris: DETERMINAÇÃO DAS CLASSES DE PRODUTOS E DOS PARÂMETROS CINÉTICOS}

Tese apresentada à Escola Politécnica da Universidade de São Paulo para obtenção do título de Doutora em Ciências.

Área de Concentração: Engenharia Química

Orientador: Prof. Dr. Marcelo Martins Seckler

São Paulo 
Este exemplar foi revisado e alterado em relação à versão original, sob responsabilidade única do autor e com a anuência de seu orientador.

São Paulo, 05 de junho de 2017.

Assinatura do autor

Assinatura do orientador

Rodrigues, Tâmira Tácita Maia

Estudo da pirólise da microalga Chlorella vulgaris: Determinação das classes de produtos e dos parâmetros cinéticos / T. T. M. Rodrigues -- versão corr. -- São Paulo, 2017.

$133 \mathrm{p}$.

Tese (Doutorado) - Escola Politécnica da Universidade de São Paulo. Departamento de Engenharia Química.

1.Pirólise 2.Microalga 3.Parâmetros cinéticos I.Universidade de São Paulo. Escola Politécnica. Departamento de Engenharia Química II.t. 


\section{AGRADECIMENTOS}

Agradeço ao meu orientador, Prof. Marcelo M. Seckler, pela paciência, pela generosidade em transmitir parte do que aprendeu ao longo de sua carreira acadêmica, por não desistir, pela visão crítica e até pelos comentários duros que me movimentaram a buscar sempre melhorar.

Ao Prof. Claudio Oller pela proposta de um projeto diferenciado, pela visão entusiasmada da vida e por todo incentivo para realização deste estudo.

Ao Prof. Jorge Tenório pelo acesso aos laboratórios do CEPEMA e pelos comentários para melhoria da tese.

A minha querida professora de graduação e orientadora de iniciação científica, Prof. Regina Jorge, que me introduziu na carreira científica e mais tarde me conduziu ao doutorado na USP.

À CAPES pela concessão da bolsa de doutorado.

Aos meus queridos companheiros de grupo de estudo, Dr. Silveira e Dra. Lidiane, pelas contribuições técnicas, pela amizade e pela generosidade em dividir suas experiências de vida comigo.

Ao corpo técnico do CEPEMA, especialmente aos senhores Osmar, Nilson e Rafaela pela amizade e todo o suporte oferecido para realização dos experimentos de cromatografia e termogravimetria.

A todos os amigos do CEPEMA, especialmente para Mauro, Marcela, Renata, Ingrid, Bruno, Ellen, Luciana, Jefferson, Louise, Helena, Luciano, Gustavo, Diego, Mirian, Daniele, Palmira, Priscila e Alex, pela amizade, por tornar mais leve a jornada, pelos inúmeros ensinamentos em assuntos aleatórios que tornaram minha vida melhor.

Aos professores do departamento de engenharia química, especialmente aos Prof. Ardson, Galo, Reinaldo, Rita, Guardani, Gil, Song, Paiva, Camacho, Antunha e Pedro, pelo conhecimento adquirido através das disciplinas cursadas 
durante o doutorado. É realmente um privilégio ter acesso a um corpo docente de tão alto nível como o da USP.

A Dra. Anita e a Ma. Mariana, pelas dicas e pela generosidade em compartilhar seu conhecimento em espectrometria de massas.

Ao Sr. Roberto Harakawa e toda equipe da Radchrom pelos ensinamentos e suporte técnico para utilização do pirolisador.

A querida Prof. Silvia, do Instituto de Química da USP, pela orientação no estágio de docência, pelo carinho e toda atenção que me foi dedicada.

A minha querida família, especialmente a minha mãe e meu marido, por estarem presentes nos momentos de maior dificuldade e por todo o suporte provido para que este projeto se tornasse viável. Ao meu amado filho, Filipe, por aceitar todos os momentos em que não pude dar a atenção requerida e por trazer tanta alegria a minha vida. 
"O pessimista reclama do vento, o otimista espera que ele mude, o realista ajusta as velas" 


\section{RESUMO}

A crescente necessidade de se obter fontes de energia e materiais mais sustentáveis tem aumentado o interesse em processos baseados na conversão de biomassa. Microalgas são particularmente interessantes por não competirem com alimentos e serem facilmente adaptáveis ao meio de crescimento. Além disso, microalgas podem ser processadas termicamente para geração tanto de biocombustíveis quanto de produtos químicos úteis. Estudos de conversão térmica de microalgas tem aparecido apenas em anos recentes, endereçando principalmente temperaturas entre 350 e $500^{\circ} \mathrm{C}$. Neste estudo, a pirólise em temperaturas entre 500 e $900^{\circ} \mathrm{C}$ foi avaliada pelo interesse em se obter biocombustíveis e produtos químicos úteis. As classes de compostos obtidos a partir da pirólise isotérmica da microalga da espécie Chlorella vulgaris foram investigadas através de um sistema composto por um pirolisador conectado a um CG/MS. Dentre as classes identificadas, houve uma predominância de compostos aromáticos e nitrogenados, principalmente derivados de proteínas. Além disso, a maioria dos compostos identificados na corrente de produtos voláteis está presente em todas as temperaturas de reação estudadas. Os parâmetros cinéticos de energia de ativação aparente, constante de reação e ordem de reação foram determinados através de três modelos cinéticos conhecidos como K-A-S, Osawa e Freeman-Carroll, a partir de dados termogravimétricos. A energia de ativação determinada para Chlorella apresentou valores entre 60 e $206 \mathrm{~kJ} / \mathrm{mol}$, enquanto a ordem de reação teve como resultado valores entre segunda e décima ordem, de acordo com o modelo cinético

Palavras-chave: Pirólise, Microalga, Chlorella, Termogravimetria, Parâmetros cinéticos. 


\begin{abstract}
The increasing need to obtain more sustainable sources of energy and raw materials has attracted attention to processes based on biomass conversion. Microalgae are particularly interesting because they do not compete with human food and they are easily adaptable to the growth medium. Besides, microalgae can be thermally processed to produce both biofuels and useful chemicals. Studies on thermal conversion of microalgae have appeared only in recent years, addressing mainly reaction temperatures between 350 and $500{ }^{\circ} \mathrm{C}$. In this study, pyrolysis in temperatures ranging from 500 to $900{ }^{\circ} \mathrm{C}$ have been investigated considering the interest in producing biofuels and useful chemical compounds. The classes of products obtained by isothermal pyrolysis of the Chlorella vulgaris microalgae have been investigated using a pyrolyzer directly connected to a GC/MS system. Among the classes identified, there was a predominance of aromatic and nitrogenous compounds, mainly protein derived compounds. In addition, most products identified in the volatile products stream are present in all reaction temperatures investigated. The kinetic parameters of apparent activation energy, reaction constant and order of reaction were determined through three kinetic models known as K-A-S, Osawa and Freeman-Carroll, calculated from thermogravimetric data. The activation energy for Chlorella presented values within the range of 60 and $206 \mathrm{~kJ} / \mathrm{mole}$, while the order of reaction resulted in values between second and tenth order, from the different methods.
\end{abstract}

Keywords: Pyrolysis, Microalgae, Chlorella, Thermogravimetric analysis, Kinetic parameters. 


\section{SUMÁRIO}

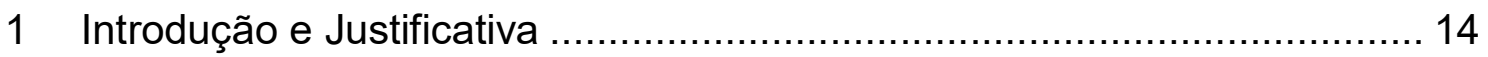

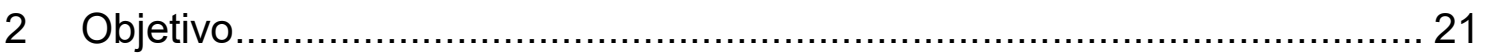

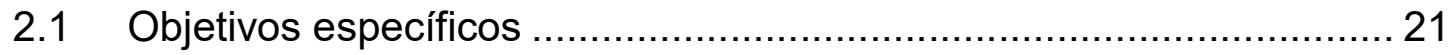

3 Revisão Bibliográfica .................................................................. 22

3.1 Fontes geradoras de energia no mundo: Cenário atual .................... 22

3.2 Processamento de Biomassa................................................. 30

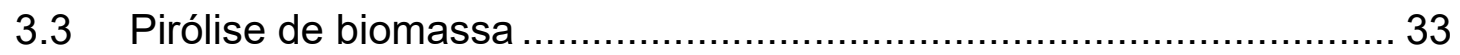

3.4 Parâmetros cinéticos da reação de pirólise ................................... 40

3.5 Cromatografia Gasosa e Espectrometria de Massas ....................... 49

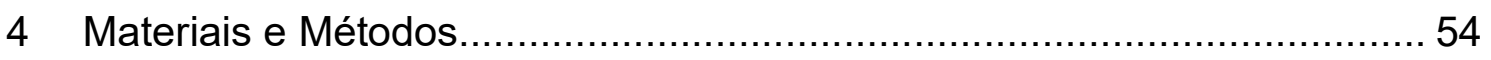

4.1 Identificação de Classes de Compostos Produzidos......................... 54

4.2 Determinação dos Parâmetros da Cinética de Reação.......................63

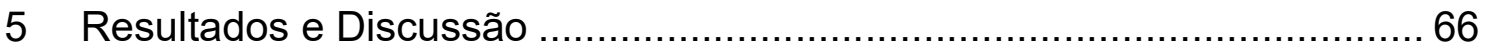

5.1 Produtos de Pirólise - Método 1 ................................................ 66

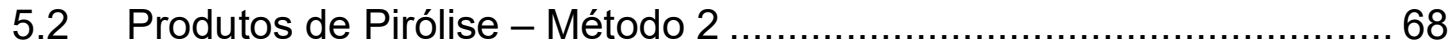

5.3 Avaliação das classes dos produtos em diferentes temperaturas....... 85

5.4 Avaliação da taxa de reação - reator de bancada .......................... 89

5.5 Determinação do teor de cinzas ........................................... 92

5.6 Parâmetros cinéticos da reação de pirólise ................................... 93

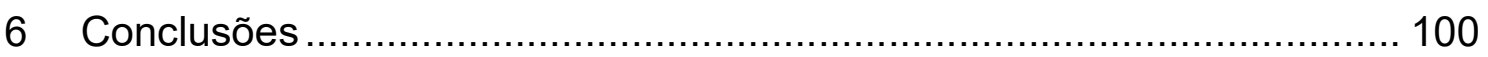

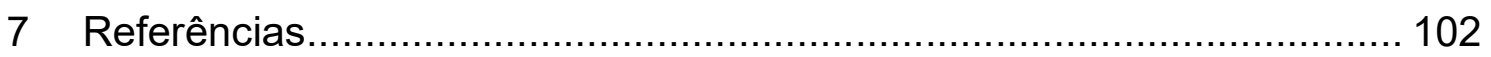

APÊNDICE A - Análise detalhada dos espectros de massa com maior nível de

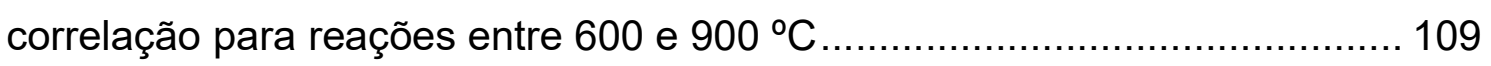




\section{ÍNDICE DE TABELAS}

Tabela 1 - Composição geral de diferentes espécies de microalgas. 16

Tabela 2 - Propriedades típicas do bio-óleo produzido a partir da pirólise e liquefação de biomassa derivada da madeira 18

Tabela 3 - Principais fontes de energia renovável e suas formas de uso........ 25

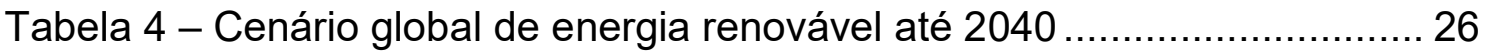

Tabela 5 - Composição dos gases da destilação seca e lenta de madeira ..... 31

Tabela 6 - Reações exotérmicas da pirólise de celulose................................. 35

Tabela 7 - Rendimento de vários produtos a partir da decomposição térmica da madeira de Bétula, Pinho e Pinheiro, aquecidos por um período de 8 horas até

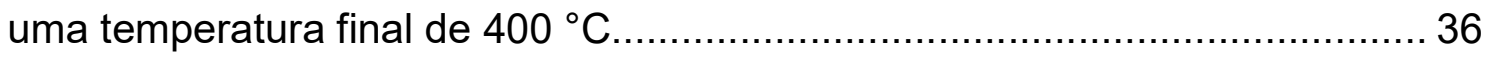

Tabela 8 - Efeito da temperatura sobre a produtividade de gases, líquidos e carvão, e composição dos gases e carvão obtidos a partir da pirólise da fração orgânica de RSM

Tabela 9 - Tecnologias típicas de pirólise de Biomassa, condições e principais produtos 38

Tabela 10 - Valores para Energia de ativação apresentados na literatura para

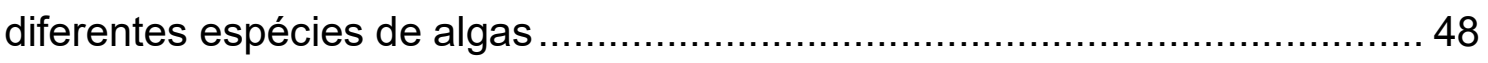

Tabela 11 - Parâmetros de temperatura utilizados nos ensaios de pirólise .... 56

Tabela 12 - Métodos de análise gravimétrica: taxas de aquecimento ............. 65

Tabela 13 - Parâmetros utilizados nas análises termogravimétricas ............... 65

Tabela 14 - Classes de compostos sugeridos através do método 1 de cromatografia 68

Tabela 15 - Lista de compostos com maior compatibilidade entre os espectros pesquisados e os de referência analisados a partir dos produtos de pirólise a $500{ }^{\circ} \mathrm{C}$ - Método 2 69

Tabela 16 - Lista de compostos com maior compatibilidade entre os espectros pesquisados e os de referência analisados a partir dos produtos de pirólise a $600{ }^{\circ} \mathrm{C}$ - Método 2

Tabela 17 - Lista de compostos com maior compatibilidade entre os espectros pesquisados e os de referência analisados a partir dos produtos de pirólise a $700{ }^{\circ} \mathrm{C}$ 
Tabela 18 - Lista de compostos com maior compatibilidade entre os espectros pesquisados e os de referência analisados a partir dos produtos de pirólise a $800{ }^{\circ} \mathrm{C}$ - Método 2

Tabela 19 - Lista de compostos com maior compatibilidade entre os espectros pesquisados e os de referência analisados a partir dos produtos de pirólise a $900{ }^{\circ} \mathrm{C}$ - Método 2

Tabela 20 - Classes de compostos presentes em diferentes temperaturas Método 2 86

Tabela 21 - Teor de cinzas .

Tabela 22 - Energia de ativação determinada através dos modelos K-A-S e Osawa

Tabela 23 - Ordem de reação e fator pré-exponencial determinados através dos modelos K-A-S e Osawa 96 Tabela 24 - Parâmetros cinéticos determinados pelo modelo Freeman-Carroll adaptado para diferentes taxas de aquecimento. 97 Tabela 25 - Comparação dos valores experimentais e da literatura 97 


\section{ÍNDICE DE FIGURAS}

Figura 1 - Chlorella vulgaris (com aumento de 400x) 16

Figura 2 - Suprimento de energia primária total por tipo de recurso em 2011, computado em megatonelada equivalente em petróleo (Mtep)....................... 22

Figura 3 - Célula Fotovoltaica de Silício Cristalizado..................................... 27 Figura 4 - Esquema de geração de eletricidade por turbinas movidas por energia eólica.

Figura 5 - Esquema simplificado das etapas básicas de um processo de pirólise e regime contínuo.

Figura 6 - Efeito da temperatura na separação de uma mistura por cromatografia gasosa: (a) análise isotérmica a $40^{\circ} \mathrm{C}$, (b) análise isotérmica a $200{ }^{\circ} \mathrm{C}$ e (c) análise com rampa de temperatura de 40 a $200{ }^{\circ} \mathrm{C}$ 51

Figura 7 - Arranjo Py-GC/MS: Pirolisador(a) interligado por uma linha de transferência aquecida ${ }^{(b)}$ a um cromatógrafo(c) acoplado a um espectrometro de

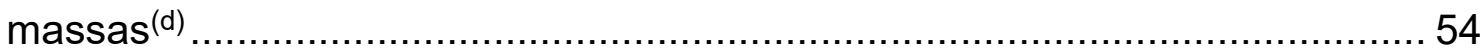

Figura 8 - Imagem da serpentina de platina aquecida.................................. 55

Figura 9 - Esquema da montagem interna do pirolisador ............................... 55

Figura 10 - Medidas da câmara onde ocorre a reação................................... 56

Figura 11 - Exemplo de cromatograma após integração.................................. 62

Figura 12 - Exemplo de gráfico comparativo entre espectro de massa experimental e o de catalogado na biblioteca NIST

Figura 13 - Balança termogravimétrica modelo Q600 SDT (TA Instruments) . 64 Figura 14 - Pirogramas a $500^{(\text {a) }}, 600^{(\text {b) }}, 700^{(\mathrm{c})}, 800^{(\mathrm{d})}$ e $900^{\circ} \mathrm{C}$ (e) - Método 1.67 Figura 15 - Pirogramas obtidos a partir da reação a $500{ }^{\circ} \mathrm{C}$ - Método 2..........70

Figura 16 - Pirogramas obtidos a partir da reação a $600{ }^{\circ} \mathrm{C}$ - Método 2......... 71

Figura 17 - Pirogramas obtidos a partir da reação a $700{ }^{\circ} \mathrm{C}$ - Método 2......... 72

Figura 18 - Pirogramas obtidos a partir da reação a $800{ }^{\circ} \mathrm{C}$ - Método 2......... 73

Figura 19 - Pirogramas obtidos a partir da reação a $900{ }^{\circ} \mathrm{C}$ - Método 2......... 74

Figura 20 - Espectro pesquisado(a) ${ }^{(a)}$ Espectro catalogado ${ }^{(b)}$ - Tempos de

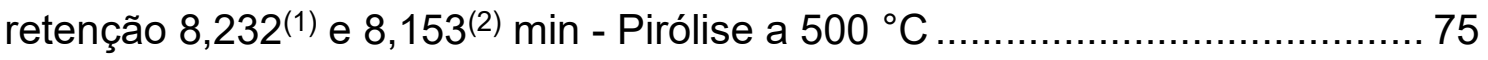

Figura 21 - Espectro pesquisado (a) $\times$ Espectro catalogado ${ }^{(b)}$ - Tempos de retenção $12,376^{(1)}$ e $12,113^{(2)}$ min - Pirólise a $500{ }^{\circ} \mathrm{C}$..................................... 77 
Figura 22 - Espectro pesquisado(a) $\times$ Espectro catalogado(b) - Tempos de retenção $15,346^{(1)}$ e $15,166^{(2)}$ min - Pirólise a $500^{\circ} \mathrm{C}$.................................. 78

Figura 23 - Espectro pesquisado(a) $\times$ Espectro catalogado(b) - Tempos de retenção $17,106^{(1)}$ e $16,953^{(2)}$ min - Pirólise a $500^{\circ} \mathrm{C}$.................................... 79 Figura 24 - Espectro pesquisado(a) $\times$ Espectro catalogado(b) - Tempos de retenção $18,637^{(1)}$ e $18,490^{(2)}$ min - Pirólise a $500^{\circ} \mathrm{C}$.................................... 80 Figura 25 - Espectro pesquisado ${ }^{(a)} \times$ Espectro catalogado(b) - Tempos de

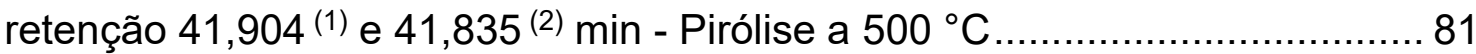
Figura 26 - Espectro pesquisado(a) ${ }^{(a)}$ Espectro catalogado ${ }^{(b)}$ - Tempos de retenção $70,943^{(1)}$ e $70,941^{(2)}$ min - Pirólise a $500^{\circ} \mathrm{C}$.................................... 82 Figura 27 - Comparativo dos cromatogramas obtidos a $500^{(\text {a) }}, 700^{(\text {b) }}$ e $900^{(\text {c) }}{ }^{\circ} \mathrm{C}$

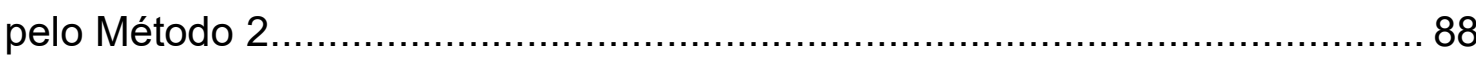

Figura 28 - Fração dos produtos voláteis de pirólise em diferentes temperaturas para pirólise rápida após 20 segundos de reação 89

Figura 29 - Taxa de variação da massa no tempo obtida em diferentes temperaturas 90

Figura 30 - Valores médios da taxa de variação da massa no tempo obtida versus a vazão do gás de arraste em diferentes temperaturas 91

Figura 31 - Avaliação da fração volatilizada variando o tempo de reação a $500^{\circ} \mathrm{C}$ 91

Figura 32 - Teor de cinzas: Produto a $600{ }^{\circ} \mathrm{C}^{(\mathrm{a})}$ e $800{ }^{\circ} \mathrm{C}^{(\mathrm{b})} \ldots \ldots \ldots \ldots \ldots \ldots \ldots \ldots . . . . . . . . . . . . . .92$

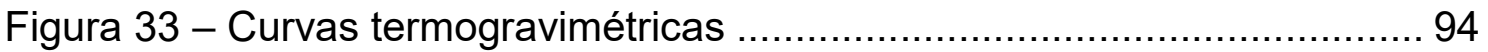

Figura 34 - Curva termogravimétrica diferencial por temperatura ${ }^{(a)}$ e por tempo ${ }^{(b)}$

Figura 35 - Gráfico para cálculo da energia de ativação aparente pelo Método K-A-S. 95

Figura 36 - Gráfico para cálculo da energia de ativação aparente pelo Método Osawa 95

Figura 37 - Espectro pesquisado(a) x Espectro catalogado(b) - Tempos de retenção 8,237(1) e 8,333 ${ }^{(2)}$ min - Pirólise a $600^{\circ} \mathrm{C}$..................................... 109 Figura 38 - Espectro pesquisado(a) x Espectro catalogado(b) - Tempos de retenção $12,391^{(1)}$ e $11,943^{(2)} \mathrm{min}$ - Pirólise a $600^{\circ} \mathrm{C}$ 110 Figura 39 - Espectro pesquisado(a) ${ }^{(a)}$ Espectro catalogado ${ }^{(b)}$ - Tempos de retenção $17,265^{(1)}$ e $16,759^{(2)} \mathrm{min}$ - Pirólise a $600^{\circ} \mathrm{C}$ 
Figura 40 - Espectro pesquisado(a) $x$ Espectro catalogado(b) - Tempos de

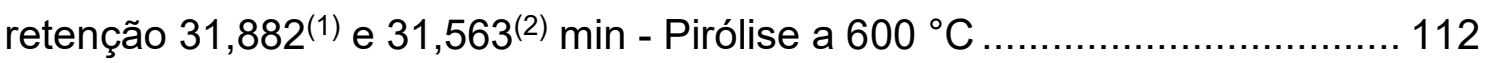
Figura 41 - Espectro pesquisado(a) x Espectro catalogado(b) - Tempos de retenção $34,486^{(1)}$ e $34,226^{(2)}$ min - Pirólise a $600{ }^{\circ} \mathrm{C}$ 113 Figura 42 - Espectro pesquisado ${ }^{(a)}$ x Espectro catalogado(b) - Tempos de

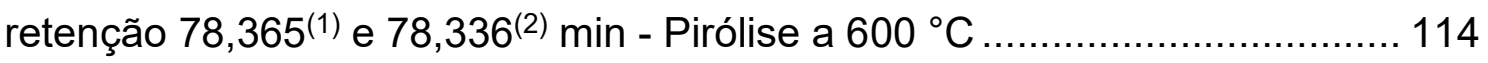
Figura 43 - Espectro pesquisado(a) $x$ Espectro catalogado(b) - Tempos de

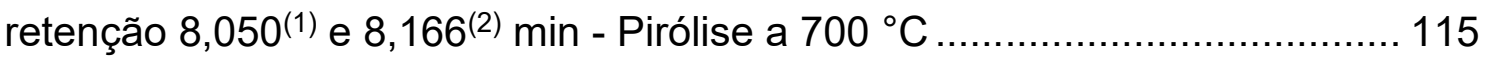
Figura 44 - Espectro pesquisado(a) $x$ Espectro catalogado $^{(b)}$ - Tempos de

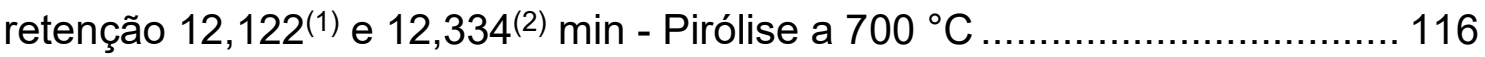
Figura 45 - Espectro pesquisado(a) $x$ Espectro catalogado(b) - Tempos de retenção $16,975^{(1)}$ e $17,192^{(2)} \min$ - Pirólise a $700{ }^{\circ} \mathrm{C}$ 117 Figura 46 - Espectro pesquisado(a) $x$ Espectro catalogado(b) - Tempos de retenção $25,016^{(1)}$ e $25,191^{(2)} \min$ - Pirólise a $700{ }^{\circ} \mathrm{C}$ 118 Figura 47 - Espectro pesquisado(a) x Espectro catalogado(b) - Tempos de

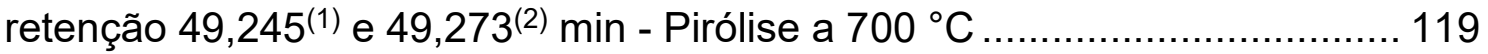

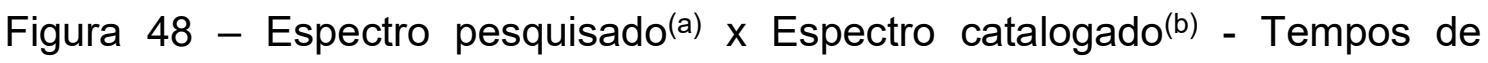
retenção $71,058^{(1)}$ e $71,026^{(2)} \min$ - Pirólise a $700{ }^{\circ} \mathrm{C}$ 120 Figura 49 - Espectro pesquisado(a) x Espectro catalogado(b) - Tempos de retenção $8,031^{(1)}$ e $8,359^{(2)} \min$ - Pirólise a $800{ }^{\circ} \mathrm{C}$ 121

Figura 50 - Espectro pesquisado(a) x Espectro catalogado(b) - Tempos de retenção $12,099^{(1)}$ e $12,651^{(2)} \min$ - Pirólise a $800{ }^{\circ} \mathrm{C}$ 122 Figura 51 - Espectro pesquisado(a) $x$ Espectro catalogado(b) - Tempos de retenção $16,915^{(1)}$ e $17,532^{(2)} \min$ - Pirólise a $800^{\circ} \mathrm{C}$ 123 Figura 52 - Espectro pesquisado ${ }^{(a)}$ x Espectro catalogado(b) - Tempos de retenção $24,960^{(1)}$ e $25,471^{(2)} \min$ - Pirólise a $800{ }^{\circ} \mathrm{C}$ 124 Figura 53 - Espectro pesquisado(a) $x$ Espectro catalogado(b) - Tempos de retenção $47,438^{(1)}$ e $47,630^{(2)} \min$ - Pirólise a $800{ }^{\circ} \mathrm{C}$ 125 Figura 54 - Espectro pesquisado ${ }^{(a)}$ x Espectro catalogado(b) - Tempos de

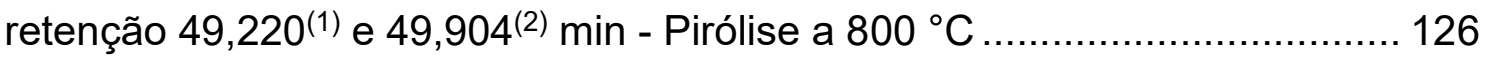
Figura 55 - Espectro pesquisado(a) x Espectro catalogado(b) - Tempos de retenção $78,365^{(1)}$ e $78,423^{(2)} \min$ - Pirólise a $800{ }^{\circ} \mathrm{C}$ 127 Figura 56 - Espectro pesquisado(a) $x$ Espectro catalogado(b) - Tempos de retenção $8,480^{(1)}$ e $8,464^{(2)} \min$ - Pirólise a $900{ }^{\circ} \mathrm{C}$ 128 
Figura 57 - Espectro pesquisado(a) ${ }^{(a)}$ Espectro catalogado ${ }^{(b)}$ - Tempos de retenção $12,827^{(1)}$ e $12,822^{(2)}$ min - Pirólise a $900{ }^{\circ} \mathrm{C}$................................... 129

Figura 58 - Espectro pesquisado(a) ${ }^{(a)}$ Espectro catalogado(b) - Tempos de retenção $17,705^{(1)}$ e $17,698^{(2)} \mathrm{min}$ - Pirólise a $900^{\circ} \mathrm{C}$.................................. 130 Figura 59 - Espectro pesquisado(a) ${ }^{(a)}$ Espectro catalogado(b) - Tempos de retenção $25,605^{(1)}$ e $25,592^{(2)} \mathrm{min}$ - Pirólise a $900{ }^{\circ} \mathrm{C}$................................... 131 Figura 60 - Espectro pesquisado(a) ${ }^{(a)}$ Espectro catalogado ${ }^{(b)}$ - Tempos de retenção $71,076^{(1)}$ e $71,051^{(2)} \mathrm{min}$ - Pirólise a $900{ }^{\circ} \mathrm{C}$................................... 132 Figura 61 - Espectro pesquisado(a) x Espectro catalogado(b) - Tempos de retenção $78,409^{(1)}$ e $78,380^{(2)}$ min - Pirólise a $900^{\circ} \mathrm{C}$................................... 133 


\section{INTRODUÇÃO E JUSTIFICATIVA}

Diante de um cenário com recursos naturais cada vez mais escassos, da dificuldade para se alocar resíduos oriundos das atividades humanas e das concentrações mais elevadas de poluentes no ar, faz-se necessário buscar alternativas para geração de energia e produtos químicos necessários para subsistência humana.

Desde 1750 tem-se notado, como resultado das atividades humanas, um aumento acentuado das concentrações atmosféricas globais de dióxido de carbono, metano e óxido nitroso, as quais agora excedem em muito os valores pré-industriais determinados a partir de amostras de gelo proveniente do polo Antártico.

Com a Convenção das Nações Unidas sobre Alterações Climáticas, realizada no Rio de Janeiro em 1992, o protocolo de Kyoto, firmado em 1997 e mais recentemente o Acordo de Paris em 2015, ficou evidenciada a importância em minimizar a emissão desses gases responsáveis pelo efeito estufa. Por isso cresce em importância a utilização de biomassa para produção de combustíveis, commodities químicas e para geração de energia, a qual é capaz de provocar reduções significativas nas emissões de $\mathrm{CO}_{2}$, é o que afirmam Ross et al. (2009).

A maior parte das pesquisas se concentra na conversão de biomassa terrestre, sendo um conceito relativamente novo a utilização de biomassa marinha. Os oceanos e mares cobrem mais de $70 \%$ da superfície terrestre, sendo a maior parte sub explorada, o que resulta em um grande potencial para a produção deste tipo de biomassa, particularmente algas. Além disso, as algas não são usadas extensivamente para alimentação humana (ANASTASAKIS et al., 2011), o que traz uma grande possibilidade de serem uma matéria prima para obtenção de energia e produtos químicos no futuro.

Algumas vantagens podem ser observadas na utilização de algas (principalmente microalgas) para produção de biocombustíveis, entre elas estão:

1. Elevada taxa de crescimento (até $20 \mathrm{~g}$ de algas seca por $\mathrm{m}^{2}$ por dia) (BABICH et al., 2011); 
2. Não há competição com a agricultura alimentar, podendo ser cultivadas em águas abertas (águas do mar, lagoas) ou em foto-bioreatores sobre terras não aráveis (BABICH et al., 2011);

3. O conteúdo de lipídio pode ser ajustado através da composição do meio de cultivo (PHUKAN et al., 2011);

4. A cultura de microalgas pode ser realizada em águas salgadas ou de esgoto (PHUKAN et al., 2011);

5. A geração de biocombustíveis a partir de algas pode ser acoplada a mitigação da emissão de $\mathrm{CO}_{2}$, tratamento de água e produção de insumos químicos de alto valor agregado (PHUKAN et al., 2011).

Cerca de 40.000 espécies de microalgas são conhecidas atualmente, dentre as principais cultivadas comercialmente podemos citar Dunaliella salina, fonte de $\beta$ caroteno que se tornou a terceira maior indústria de microalga, Haematococcus pluvialis, fonte de astaxantina, os gêneros Chlorella e Anthospira, utilizado comumente para adição em alimentos (SPOLAORE et al., 2006; ANDRADE, 2014).

As biomassas aquáticas, como as algas e microalgas, são compostas majoritariamente por lipídeos, proteínas e carboidratos (BROWN, 1991). Os principais usos das microalgas estão associados à sua composição. Uma visão geral dos principais constituintes de várias espécies de microalgas está apresentada na Tabela 1. Podemos verificar que as espécies que apresentam conjuntamente elevados teores de proteína e lipídeos são Chlorella vulgaris e Euglena gracilis.

A biomassa escolhida para estudo foi a Chlorella vulgaris, alga verde unicelular, com diâmetro variando entre 2 e $12 \mu \mathrm{m}$ (KEBELMANN, 2013), esférica, globular ou elipsoidal em relação à forma, como pode ser visto através da Figura 1. Pode ser encontrada em águas doces ou marinhas. Esse gênero de microalgas possui grande importância econômica em aplicações para alimentação humana e animal, devido ao elevado teor de proteínas, além disso, é utilizada para renovação da atmosfera em viagens espaciais (PHUKAN et al., 2011), produção de $\beta-1,3$-glucano, que é um imunoestimulante, além de outros usos medicinais, e produção de cosméticos com efeito anti-idade (SPOLAORE et al., 2006). Sendo o gênero Chlorella o mais cultivado comercialmente (DA SILVEIRA, 2015). 
Tabela 1 - Composição geral de diferentes espécies de microalgas

(BECKER, 2007)

\begin{tabular}{cccc}
\hline Alga & $\begin{array}{c}\text { Proteína } \\
\text { (\% em massa seca) }\end{array}$ & $\begin{array}{c}\text { Carboidrato } \\
\text { (\% em massa seca) }\end{array}$ & $\begin{array}{c}\text { Lipídio } \\
\text { (\% em massa seca) }\end{array}$ \\
\hline Anabaena cylindrica & $43-56$ & $25-30$ & $4-7$ \\
Aphanizomenon flos-aquae & 62 & 23 & 3 \\
Chlamydomonas rheinhardii & 48 & 17 & 21 \\
Chlorella pyrenoidosa & 57 & 26 & 2 \\
Chlorella vulgaris & $51-58$ & $12-17$ & $14-22$ \\
Dunaliella salina & 57 & 32 & 6 \\
Euglena gracilis & $39-61$ & $14-18$ & $14-20$ \\
Porphyridium cruentum & $28-39$ & $40-57$ & $9-14$ \\
Scenedesmus obliquus & $50-56$ & $10-17$ & $12-14$ \\
Spirogyra sp. & $6-20$ & $33-64$ & $11-21$ \\
Arthrospira maxima & $60-71$ & $13-16$ & $6-7$ \\
Spirulina platensis & $46-63$ & $8-14$ & $4-9$ \\
Synechococcus sp. & 63 & 15 & 11 \\
\hline
\end{tabular}

Figura 1 - Chlorella vulgaris (com aumento de 400x)

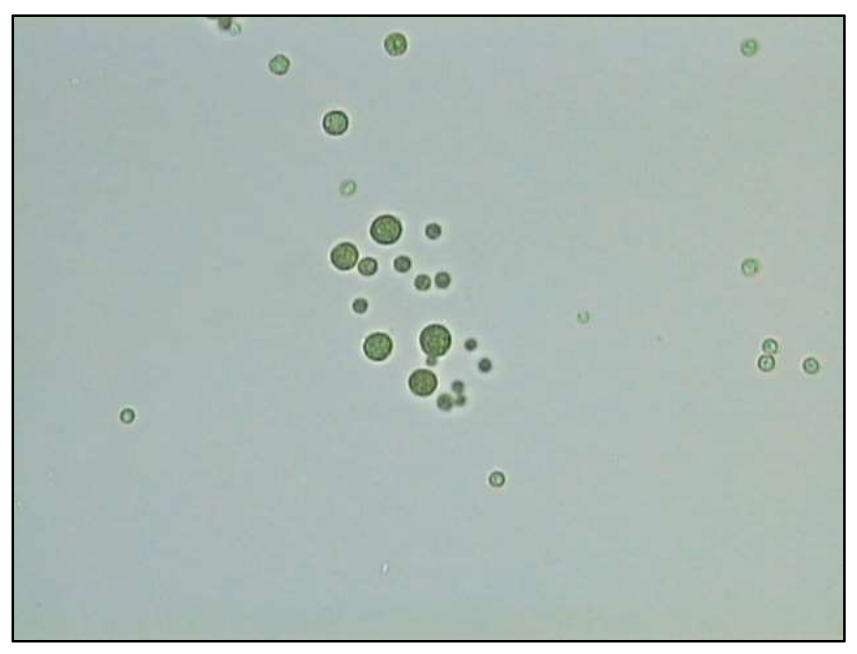

Fonte: Dra. Lidiane M. Andrade 
A obtenção de compostos orgânicos a partir de biomassa pode ser atingida por processos térmicos e não térmicos. Dentre os processos não térmicos podemos citar a fermentação e as extrações física e química. Segundo Fatih Dermibas (2011), os principais processos termoquímicos para processamento de algas são a pirólise, a liquefação e a gaseificação.

Tanto a pirólise quanto a gaseificação consistem na decomposição térmica da biomassa na ausência de oxigênio, a principal diferença entre os dois processos é a temperatura de reação, que no caso da pirólise comumente varia entre 300 e $600{ }^{\circ} \mathrm{C}$, enquanto os processos de gaseificação possuem temperaturas superiores a $700{ }^{\circ} \mathrm{C}$. O principal foco dos processos de gaseificação é a produção de gás de síntese, já a pirólise é empregada para a obtenção de carvão, líquidos voláteis e gases, variandose a produtividade de cada um deles de acordo com a temperatura e o tempo de processamento.

Lee et al. (2007) afirmam que a pirólise é uma das técnicas mais promissoras para a recuperação de energia a partir de biomassa, além da geração de produtos químicos. Liquefação de biomassa produz bio-óleo pelo tratamento em altas pressões (50 a $200 \mathrm{~atm})$ e baixas temperaturas $\left(250\right.$ a $\left.450{ }^{\circ} \mathrm{C}\right)$, o principal objetivo deste processo é controlar a taxa e o mecanismo de reação, de forma a obter um óleo de melhor qualidade, a partir de uma pasta composta pela biomassa e um solvente e/ou um catalisador (HUBER et al., 2006).

A Tabela 2 mostra algumas propriedades dos óleos obtidos a partir da pirólise e da liquefação. Comparando-se os produtos obtidos, podemos observar que o óleo gerado a partir da liquefação possui menor umidade e teor de oxigênio, e maior poder calorífico do que o produzido através da pirólise, porém possui alta viscosidade, o que pode atrapalhar sua comercialização.

O bio-óleo produzido a partir da pirólise de biomassa possui tipicamente uma coloração marrom, odor de fumo e contem centenas de produtos, variando em tamanho de cadeia e abundância, que resultam da decomposição dos biopolímeros presentes na biomassa (MOHAN et al., 2006).

Biomassas terrestres são compostas principalmente por celulose, hemicelulose e lignina. Hemicelulose é um polissacarídeo amorfo composto por unidades de variados 
açucares e a celulose é um polissacarídeo de unidades de $\beta$-glicose. Lignina é um polímero amorfo composto por monômeros de fenilpropanóide e monolignóis, derivados de álcoois cumarílico, coniferílico e sinapílico. Enquanto a pirólise de hemicelulose e celulose normalmente gera açucares, furanos e pequenos compostos oxigenados, como, por exemplo, hidroxipropanona e ácido acético (PATWARDHAN et al., 2011), a lignina produz fenóis e outros compostos aromáticos durante a sua pirólise (SAIZ-JIMENES; DE LEEUW, 1985).

Tabela 2 - Propriedades típicas do bio-óleo produzido a partir da pirólise e liquefação de biomassa derivada da madeira

(CZERNIK; BRIDGWATER, 2004; ELLIOT; SCHIEFELBEIN, 1989)

\begin{tabular}{ccc}
\hline Propriedade & Pirólise & Liquefação \\
\hline Umidade (\% em massa) & $15-30$ & 5,1 \\
pH & 2,5 & - \\
Densidade específica & 1,2 & 1,1 \\
Composição elementar (\% em massa) & & \\
Carbono & $54-58$ & 73 \\
Hidrogênio & $5,5-7,0$ & 8 \\
Oxigênio & $35-40$ & 16 \\
Nitrogênio & $0-0,2$ & - \\
Cinzas & $0-0,02$ & - \\
Poder calorífico (MJ/kg) & $16-19$ & 34 \\
Viscosidade (cP) & $40-100\left(a 50{ }^{\circ} \mathrm{C}\right)$ & $15.000\left(\mathrm{a} 61^{\circ} \mathrm{C}\right)$ \\
Sólidos (\% em massa) & $0,2-1$ & \\
\hline
\end{tabular}

Como citado anteriormente, os principais componentes das biomassas aquáticas são lipídeos, proteínas e carboidratos. A pirólise de lipídeos produz ácidos graxos de cadeia longa, ésteres, aldeídos, álcoois, alcanos e alcenos (NICHOLS; HOMAN,1972), além de compostos aromáticos, que normalmente resultam de lipídeos insaturados (MAHER; BRESSLER, 2007). As proteínas geram uma grande variedade de compostos nitrogenados, tais como indole, pirolidonas, aminas e amidas (RATCLIFF et al., 1974; SMITH et al., 1974). Carboidratos costumam gerar anidro açúcares, furanos e compostos carbonílicos (SCHULTEN; GLEIXNER, 1999). A literatura apresenta poucos estudos sobre a caracterização dos produtos diretamente da biomassa, uma vez que este é um dos maiores desafios, tendo em vista a 
complexidade tanto da matéria prima quanto dos produtos de pirólise, os quais são constituídos por uma mistura de um grande número de compostos, muitos dos quais pouco conhecidos. Os estudos existentes, na sua maioria, avaliam a composição da corrente de produtos voláteis em temperaturas que variam de 350 a $500{ }^{\circ} \mathrm{C}$, de tal forma que existe um campo aberto para estudos de pirólise em temperaturas superiores a $500{ }^{\circ} \mathrm{C}$.

Entre as técnicas tradicionais para análise de microalgas estão as técnicas gravimétricas e espectrofotométricas. Experimentos de centrifugação gradiente podem ser usados para uma análise rápida (BARUPAL et al., 2010). Tecnologias mais seletivas e sensíveis como a cromatografia gasosa (GC) e líquida (LC) acopladas a detectores de espectrometria de massa fornecem dados quantitativos e qualitativos sobre constituintes do biocombustível da microalga, conforme exposto por Barupal et al. (2010). Ainda segundo este autor, a decomposição térmica de macromoléculas biológicas produz compostos voláteis que são facilmente detectados por GC/MS quadrupolo para a caracterização quantitativa e qualitativa.

Além da busca pelo conhecimento dos compostos que podem ser obtidos através da pirólise, também é importante o conhecimento da cinética das reações de pirólise, isto é, da conversão da biomassa em produtos. A análise termogravimétrica (TGA) tem sido extensivamente utilizada para o entendimento das características da pirólise e a determinação de seus parâmetros cinéticos (WILLIAMS; BESLER, 1993; MANSARAY; GHALY, 1998), sendo considerada como uma boa ferramenta para elucidar a taxa de decomposição de vários tipos de biomassa (HU et al., 2007). A literatura apresenta uma faixa de energia de ativação para amostras de biomassa entre 30 e 200 kJ/mol (WEBER, 2008), porém estudos mais recentes com biomassas aquáticas apresentam valores superiores a $200 \mathrm{~kJ} / \mathrm{mol}$, demonstrando a necessidade de estudos para consolidar o conhecimento sobre os parâmetros ligados à velocidade da reação de pirólise.

Neste estudo optou-se por investigar a pirólise da microalga Chlorella vulgaris (CV) por meio de um pirolisador de bancada, o qual reproduz as condições de processo em microescala. O reator analítico (Py) é conectado diretamente a um cromatógrafo gasoso (GC) acoplado a um espectrômetro de massas (MS) para identificar as principais classes de compostos formadas em cinco diferentes temperaturas de 
síntese $\left(500,600,700,800\right.$ e $\left.900^{\circ} \mathrm{C}\right)$. Tem-se como finalidade avaliar a ocorrência de alterações significativas com a variação da temperatura de reação. Além disso, propõe-se determinar os parâmetros cinéticos da reação através de dados experimentais obtidos por termogravimetria, utilizando-se três métodos matemáticos. 


\section{OBJETIVO}

O objetivo deste trabalho é avaliar as principais classes orgânicas dos produtos, em uma faixa de temperaturas de 500 a $900^{\circ} \mathrm{C}$, e os parâmetros cinéticos das reações de pirólise, tendo como matéria prima a microalga da espécie Chlorella vulgaris.

\subsection{Objetivos específicos}

\subsubsection{Produtos de pirólise}

Identificar as principais classes de compostos produzidas a partir da pirólise rápida de microalgas em diferentes temperaturas, utilizando as técnicas analíticas de cromatografia e espectrometria de massas.

\subsubsection{Parâmetros de reação}

Determinar, através da técnica analítica de termogravimetria e modelos matemáticos disponíveis na literatura, os parâmetros cinéticos (energia de ativação, ordem de reação e fator pré-exponencial) das reações de pirólise. 


\section{REVISÃO BIBLIOGRÁFICA}

\subsection{Fontes geradoras de energia no mundo: Cenário atual}

A maior parte da energia utilizada no mundo vem de fontes não renováveis, principalmente dos combustíveis fósseis (carvão, petróleo, gás natural). Outra importante fonte é a energia nuclear. Porém, devido à natureza limitada do ponto de vista de reservas desses tipos de fonte, muitas pesquisas têm sido desenvolvidas na busca de fontes mais sustentáveis, como as renováveis. A Figura 2 apresenta um panorama das fontes de energia utilizadas no mundo.

Figura 2 - Suprimento de energia primária total por tipo de recurso em 2011, computado em megatonelada equivalente em petróleo (Mtep)

\section{1 - 14.092 Mtep}

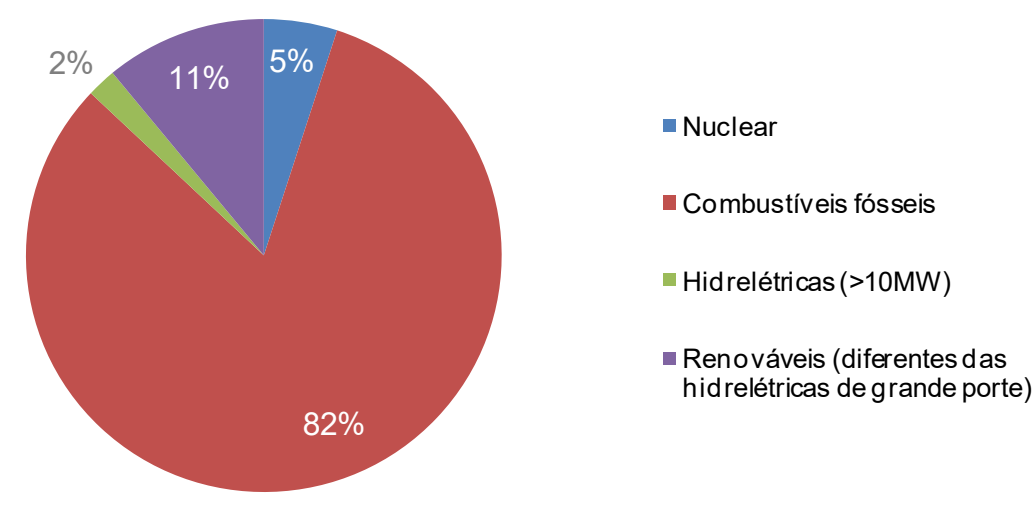

Fonte: WEC, 2013

\subsubsection{Fontes não renováveis}

Fontes de energia não renováveis são aquelas apresentadas na natureza em reservas limitadas e que não podem ser regeneradas uma vez que tenham sido utilizadas. Entre as principais fontes de energia não renováveis pode-se citar o petróleo, o carvão mineral, o gás natural e o urânio.

As fontes de energia não renováveis têm a sua sustentabilidade questionada uma vez que as reservas são finitas. Além disso, a maior parte destas fontes gera emissão de 
gases de efeito estufa quando utilizadas como combustíveis. Já no caso do urânio existe um grave problema quanto à disposição final do resíduo gerado pelo processo nuclear.

\subsubsection{Petróleo}

O petróleo é um óleo mineral composto prioritariamente por hidrocarbonetos aromáticos e alifáticos, associado a pequenas quantidades de nitrogênio, enxofre e oxigênio. Atualmente é uma das fontes de energia mais utilizadas no mundo, sendo importante fonte para produção de insumos químicos. As maiores reservas do mundo estão localizadas em 5 países, sendo eles: Venezuela, Arábia Saudita, Canadá, Iran e Iraque. As reservas mundiais foram estimadas em 2011 em 223.454 Mt, enquanto a extração de petróleo neste ano estava na faixa de $3.973 \mathrm{Mt}$, o que significa que ainda existem reservas no mundo para aproximadamente 56 anos (WEC, 2013).

Uma das grandes vantagens da utilização de petróleo como fonte de energia é a facilidade de transporte e armazenamento, além do alto nível de maturidade das tecnologias para seu processamento. Como desvantagem se pode salientar a grande poluição gerada pela combustão dos seus derivados, sobretudo $\mathrm{O} \mathrm{CO}_{2}$, a alta volatilidade dos preços, a concentração geográfica de jazidas e o mercado dominado e manipulado pelos produtores líderes.

\subsubsection{Carvão mineral}

O carvão mineral é uma rocha sedimentar, formada a partir dos restos soterrados de florestas tropicais e subtropicais, principalmente nos períodos carbonífero e permiano. A reserva global estimada em 2011 era de 891.530 Mt e a extração de 7.520 Mt, o que significaria que o mundo possui reservas para mais de 100 anos de exploração no ritmo atual (WEC, 2013).

Uma das grandes desvantagens do uso de carvão é a alta emissão de poluentes, como $\mathrm{CO}_{2}$ e material particulado, além de não haver tecnologia de ponta para seu processamento. Apesar disso ele é largamente empregado no mundo para a produção de energia. Um dos fatores que favorece seu uso é a larga distribuição geográfica das 
suas reservas, além disso, seus custos são estáveis e previsíveis e novas tecnologias estão sendo aplicadas para aumentar sua eficiência e desempenho ambiental.

\subsubsection{Nuclear}

A energia nuclear é produzida a partir da fissão de átomos de urânio. As reservas de urânio cresceram 12,5 \% desde 2008 e são suficientes para suprir a atual demanda por mais de 100 anos. Os cinco países com a maior capacidade instalada para geração de energia nuclear são Estados Unidos, França, Japão, Rússia e Coréia do Sul. (WEC, 2013)

A produção de energia nuclear traz alguns benefícios como alta eficiência, custos da eletricidade moderados e previsíveis ao longo da vida útil da planta e não emissão de gases de efeito estufa. Porém, apresenta alto investimento inicial, dificuldades para disposição final do resíduo, além do passivo gerado em caso de um acidente, o que, em geral, traz certa oposição da opinião pública em relação â utilização deste tipo de energia.

\subsubsection{Gás Natural}

O gás natural é composto basicamente por metano. É uma importante fonte de energia para o mundo atualmente, pois além de ser o combustível fóssil mais limpo, em geral, é mais fácil e flexível para ser processado. Nas duas últimas décadas as reservas de gás natural cresceram em 36 \% e sua exploração em 61 \%, segundo o World Energy Council (WEC, 2013). As maiores reservas do mundo estão localizadas nos seguintes países: Rússia, Iran, Qatar, Turcomenistão e Arábia Saudita. As reservas globais em 2011 eram estimadas em 209.742 bcm (bilhão de metros cúbicos) e a exploração neste mesmo ano foi de $3.518 \mathrm{bcm}$, de tal forma que a exploração neste patamar de consumo seria viável por mais 55 anos aproximadamente. (WEC, 2013)

Pontos negativos para a utilização do gás natural são a localização de reservas, que em geral estão fora da região continental terrestre e em áreas remotas, o alto investimento inicial necessário para a instalação de um sistema de transporte e 
distribuição, além do alto custo da infraestrutura das longas rotas de suprimento (WEC, 2013).

\subsubsection{Fontes renováveis}

O aumento da população mundial gera a necessidade de maior produção de bens e alimentos, além do consequente aumento na demanda de energia. Desde aproximadamente 1850, o consumo global de combustíveis fósseis (carvão mineral, petróleo e gás) cresceu para dominar o suprimento de energia, levando a um rápido crescimento nas emissões de dióxido de carbono, e a concentração de $\mathrm{CO}_{2}$ na atmosfera aumentou para um patamar superior a 390 ppm ou $39 \%$ entre a era préindustrial e 2010 (IPCC, 2011).

Segundo o IPCC (2011), as fontes de energia renováveis têm um alto potencial para mitigar o dano gerado pelas emissões de gases de efeito estufa (GEE). A Tabela 3 apresenta as principais fontes de energia renovável.

Tabela 3 - Principais fontes de energia renovável e suas formas de uso

(PANWAR et al., 2011)

\begin{tabular}{|c|c|}
\hline Fonte de energia & Opções para conversão de energia e outros usos \\
\hline Hidroelétrica & Geração de eletricidade \\
\hline Biomassa moderna & Geração de calor e eletricidade, pirólise, gaseificação, digestão. \\
\hline Geotérmica & $\begin{array}{l}\text { Aquecimento urbano, geração de eletricidade, hidrotérmica, "Hot dry } \\
\text { rock" (HDR) }\end{array}$ \\
\hline Solar & Sistemas de aquecimento doméstico, secadores e fogões solares \\
\hline Solar direta & Célula fotovoltaica, geração de energia térmica, aquecedores de água \\
\hline Eólica & $\begin{array}{c}\text { Geração de eletricidade, geradores de vento, moinhos de vento, } \\
\text { bombas de água }\end{array}$ \\
\hline Ondas & Numerosos projetos \\
\hline Marítima & Barragens, correntes marítimas \\
\hline
\end{tabular}

A crescente preocupação com as questões relativas às mudanças climáticas e sustentabilidade faz com que a comunidade científica e a indústria invistam em desenvolvimento de fontes de energia que minimizem a emissão de gases de efeito estufa. Isso torna provável uma mudança no cenário mundial de consumo de recursos 
para geração de energia nos próximos anos, o que pode ser observado na Tabela 4, na qual a projeção para o consumo de recursos visando a geração de energia é apresentado por década até 2040. A expectativa projetada é que a contribuição das fontes de energia renovável no mundo passe de 16,6 \% (valor reportado em 2010) para $47,7 \%$ em 2040.

Dentre as principais fontes de energia renováveis pode-se citar a hidroelétrica, solar, eólica, geotérmica e a biomassa.

Tabela 4 - Cenário global de energia renovável até 2040

(PANWAR et al., 2011)

\begin{tabular}{cccccc}
\hline Ano de referência & $\mathbf{2 0 0 1}$ & $\mathbf{2 0 1 0}$ & $\mathbf{2 0 2 0}$ & $\mathbf{2 0 3 0}$ & $\mathbf{2 0 4 0}$ \\
\hline Consumo total (milhões de ton equivalentes) & $\mathbf{1 0 . 0 3 8}$ & $\mathbf{1 0 . 5 4 9}$ & $\mathbf{1 1 . 4 2 5}$ & $\mathbf{1 2 . 3 5 2}$ & $\mathbf{1 3 . 3 1 0}$ \\
Biomassa & 1.080 & 1.313 & 1.791 & 2.483 & 3.271 \\
Hidro larga escala & 22,7 & 266 & 309 & 341 & 358 \\
Geotérmica & 43,2 & 86 & 186 & 333 & 493 \\
Hidro pequena escala & 9,5 & 19 & 49 & 106 & 189 \\
Eólica & 4,7 & 44 & 266 & 542 & 688 \\
Térmica-solar & 4,1 & 15 & 66 & 244 & 480 \\
Fotovoltaica & 0,1 & 2 & 24 & 221 & 784 \\
Eletricidade térmica solar & 0,1 & 0,4 & 3 & 16 & 68 \\
Marítima (maré/ondas/oceano) & 0,05 & 0,1 & 0,4 & 3 & 20 \\
Total de Fontes de energia renovável & $\mathbf{1 . 3 6 5 , 5}$ & $\mathbf{1 . 7 4 5 , 5}$ & $\mathbf{2 . 9 6 4 , 4}$ & $\mathbf{4 . 2 8 9}$ & $\mathbf{6 . 3 5 1}$ \\
Contribuição das fontes de energia renovável & $\mathbf{1 3 , 6}$ & $\mathbf{1 6 , 6}$ & $\mathbf{2 3 , 6}$ & $\mathbf{3 4 , 7}$ & $\mathbf{4 7 , 7}$ \\
(\%) & & & &
\end{tabular}

\subsubsection{Hidroelétrica}

A energia elétrica gerada a partir do movimento da água passando por uma turbina conectada a um gerador de energia é conhecida como hidrelétrica. É uma fonte de energia significativa, presente em mais de 100 países, contribuindo por aproximadamente $15 \%$ da produção global de eletricidade. Os países com maior capacidade instalada em hidrelétricas são China, Brasil, Estados Unidos, Canadá e Rússia. (WEC, 2013) 
As usinas hidrelétricas apresentam grande investimento inicial, além do impacto ambiental e social gerado para se construir as represas. Porém possuem um baixo custo operacional, não há produção de resíduo ou gases de efeito estufa e possuem uma tecnologia bastante simples para geração de energia.

\subsubsection{Solar}

A conversão direta de energia solar em eletricidade é convencionalmente feita através de células fotovoltaicas, tendo como uma de suas grandes vantagens ser livre de emissão de $\mathrm{CO}_{2}$ e outros poluentes. Apesar da energia solar ser gratuita, há um alto custo de produção, já que as células fotovoltaicas requerem uma grande superfície para uma pequena produção de energia (PANWAR et al., 2011). O esquema para geração de energia elétrica pela célula fotovoltaica pode ser melhor ilustrado pela Figura 3. Atualmente, o mundo conta com uma potência instalada de energia solar equivalente a 234 GW, e a produção total em 2014 foi de 253 TWh. Os principais produtores de energia solar são China, Estados Unidos, Alemanha, Japão e Itália, sendo que dentre os maiores produtores, a Itália foi que apresentou em 2014 o maior percentual de geração solar em relação a sua geração total, equivalendo a 9,3 \% (MME, 2016).

Figura 3 - Célula Fotovoltaica de Silício Cristalizado

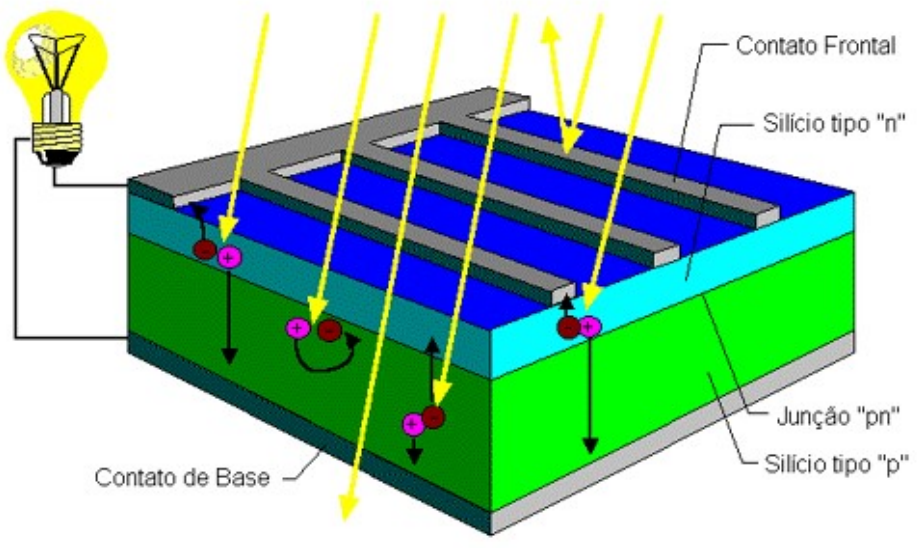

Fonte: CRECESB 


\subsubsection{Eólica}

O potencial mundial para geração de energia elétrica a partir de usinas eólicas é estimado em 26.000 TWh/ano. Atualmente a produção de energia eólica é madura e competitiva. A principal tecnologia empregada é virtualmente livre de poluição. Esta tecnologia converte a energia disponível nos ventos em eletricidade ou força mecânica através de turbinas eólicas (PANWAR et al., 2011). A Figura 4 abaixo ilustra como é gerada a energia em usinas eólicas a partir de turbinas de eixo horizontal, as quais são largamente empregadas atualmente.

Figura 4 - Esquema de geração de eletricidade por turbinas movidas por energia eólica

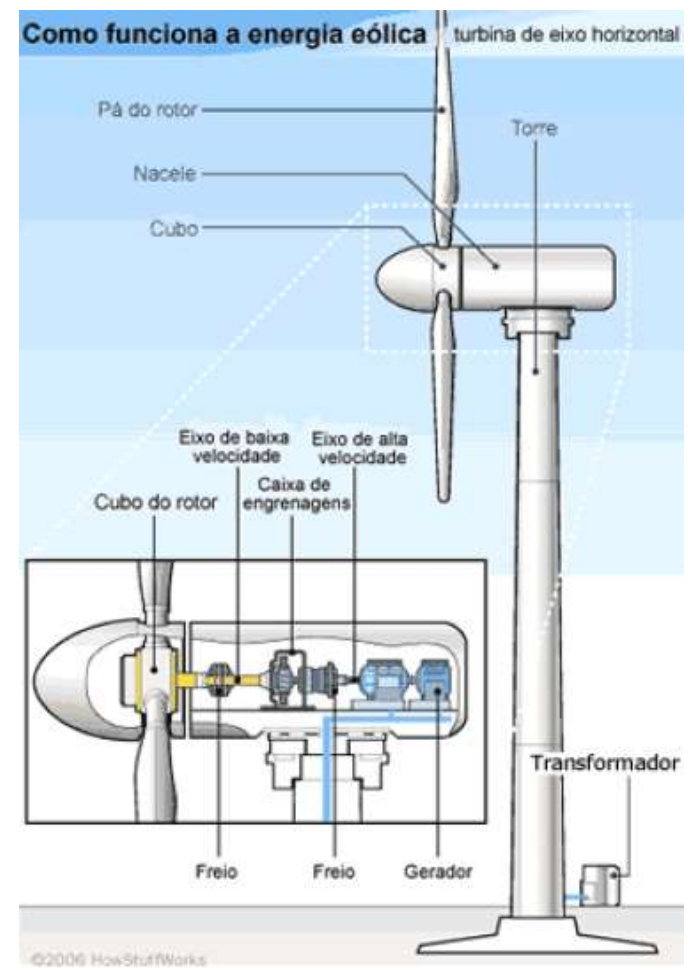

Fonte: EBAH

\subsubsection{Geotérmica}

A energia geotérmica é obtida através do calor proveniente do interior da Terra. Essa energia é trazida até a superfície por um veículo, normalmente água na forma líquida ou vapor. Quando extraída na forma líquida, a água precisa ser vaporizada através de um "flash" para, ser utilizada na geração de eletricidade. Esse vapor é utilizado para movimentar uma turbina acoplada a um gerador de energia elétrica. Outras formas de 
utilização de energia geotérmica são as bombas de aquecimento geotérmicas e a utilização direta do fluido para aquecimento (WEC, 2013).

\subsubsection{Biogás}

A produção de biogás através de digestão anaeróbica tem sido avaliada como uma das formas mais eficientes e ambientalmente benéficas para a produção de bioenergia (PANWAR et al., 2011).

O Biogás é uma mistura de gases composta principalmente por metano (40-70 \%), $\mathrm{CO}_{2}(30-60 \%)$ e outros gases (1-5\%). Quando comparado com outras fontes de geração de energia, o biogás apresenta algumas vantagens como o fato que poder ser produzido sempre que necessário e ser facilmente estocável, pode ser distribuído através da infraestrutura já existente para o transporte do gás natural e utilizado nas mesmas aplicações deste, podendo ser utilizado em cozinhas domésticas e como combustível para automóveis (PANWAR et al., 2011).

\subsubsection{Biomassa}

A biomassa é a maior fonte de carbono fixo que pode ser renovada em uma velocidade capaz de suprir e manter as reservas necessárias para produção de energia (KLASS, 1998), uma vez que os combustíveis fósseis levam milhares de anos para serem formados.

Atualmente, a biomassa supre cerca de 50 EJ por ano mundialmente, o que representa $10 \%$ do consumo primário de energia do mundo (WEC, 2013).

Segundo Ross et al. (2009), a biomassa oferece reduções nas emissões de $\mathrm{CO}_{2}$ e é mais sustentável do que combustíveis fósseis. A produção e o uso de combustíveis de primeira geração como o biodiesel e o bio-etanol já estão bem estabelecidos, entretanto, as consequências ambientais e sócio econômicas de se utilizar culturas alimentícias para produzir combustíveis está estimulando o desenvolvimento de uma segunda geração de biocombustíveis, isto é, aqueles produzidos a partir de fontes de biomassa não alimentícias. 
Uma alternativa às biomassas terrestres, que em geral competem com a produção de alimentos, é a biomassa aquática, principalmente as macro e microalgas. A eficiência fotossintética média da biomassa aquática é de 6 a $8 \%$, o que é muito acima do observado para a biomassa terrestre, que está em torno de 1,8 a 2,2 \%, como afirmam Ross et al. (2009) e Anastasakis et al. (2011).

Por outro lado, uma das grandes desvantagens das biomassas aquáticas para produção de biocombustível é a sua baixa concentração no meio de cultura devido ao limite de penetração de luz. No caso de microalgas, há uma dificuldade adicional relacionada a pequeno tamanho de células, que faz com que a sua colheita e secagem se tornem relativamente dispendiosas, conforme exposto por Fatih Dermibas (2011).

\subsection{Processamento de Biomassa}

\subsubsection{Processos não térmicos}

Dentre os principais processos não térmicos utilizados para biomassa pode-se citar a fermentação, a extração física e a química.

A fermentação consiste em um processo bioquímico em meio anaeróbio, no qual se utiliza um microrganismo para metabolizar uma matéria prima. Desse processo se obtém substratos metabólicos como álcoois, ácidos e ésteres orgânicos, hidrogênio, metano e outros hidrocarbonetos.

A extração física é um processo de separação que ocorre através de uma ação mecânica, geralmente provocando o esmagamento ou prensagem da matéria prima sólida para liberação do produto líquido. Alguns produtos obtidos através deste processo são: sucos, óleos alimentícios e óleos essenciais. Uma das vantagens deste tipo de processamento é a alta pureza do produto obtido.

A extração química se caracteriza pela adição de um solvente com a finalidade de separar um determinado composto de uma mistura e requer a formação de um sistema com mais de uma fase, podendo ser um sistema líquido-líquido, líquido-sólido ou líquido-gasoso. A biomassa geralmente se apresenta em fase sólida e o solvente em fase líquida. Através do contato entre as fases, o composto de interesse é 
transferido de uma fase para outra, de tal forma que ao final do processo seja obtida uma fase mais rica (com maior concentração) do produto de interesse. Um dos inconvenientes deste tipo de processo é que, de forma geral, ele exige mais uma etapa de separação para retirar o solvente. Apesar disso, é um processo largamente utilizado para obtenção de uma série de produtos, entre eles agentes ativos para fármacos, álcool anidro e óleos vegetais.

\subsubsection{Processos térmicos}

Um dos principais métodos térmicos para processamento de biomassa é a combustão, cujo objetivo é a obtenção de energia. Esse processo pode ser definido como a oxidação completa de uma matéria orgânica, na presença de oxigênio, com a liberação de calor e formação de dióxido de carbono e água (KLASS, 1998).

Quando a celulose é lentamente aquecida até aproximadamente 250 a $270{ }^{\circ} \mathrm{C}$, uma grande quantidade de gases é produzida contendo prioritariamente monóxido e dióxido de carbono (KLASS, 1998). A Tabela 5 ilustra como a fração de alguns produtos voláteis varia com a temperatura em uma destilação lenta e seca de madeira. Através dela podemos observar que a produção de hidrocarbonetos é maximizada entre 380 e $500{ }^{\circ} \mathrm{C}$, já a produção de hidrogênio tem seu máximo entre 700 e $900{ }^{\circ} \mathrm{C}$.

Tabela 5 - Composição dos gases da destilação seca e lenta de madeira

(NIKITIN et al., 1962 apud KLASS, 1998)

\begin{tabular}{|c|c|c|c|c|c|}
\hline Processo & $\begin{array}{c}\text { Temperatura } \\
\left({ }^{\circ} \mathrm{C}\right)\end{array}$ & $\begin{array}{c}\mathrm{H}_{2} \\
(\% \mathrm{~mol})\end{array}$ & $\begin{array}{c}\mathrm{CO} \\
(\% \mathrm{~mol})\end{array}$ & $\begin{array}{c}\mathrm{CO}_{2} \\
(\% \mathrm{~mol})\end{array}$ & $\begin{array}{l}\mathrm{HCs}^{(1)} \\
(\% \mathrm{~mol})\end{array}$ \\
\hline Eliminação de água & $155-200$ & 0 & 30,5 & 68,0 & 2,0 \\
\hline $\begin{array}{l}\text { Liberação dos Óxidos de } \\
\text { Carbono }\end{array}$ & $200-280$ & 0,2 & 3,5 & 66,5 & 3,3 \\
\hline $\begin{array}{l}\text { Início da liberação de } \\
\text { hidrocarbonetos }\end{array}$ & $280-380$ & 5,5 & 20,5 & 35,5 & 36,6 \\
\hline Liberação de hidrocarbonetos & $380-500$ & 7,5 & 12,3 & 31,5 & 48,7 \\
\hline Dissociação & $500-700$ & 48,7 & 24,5 & 12,2 & 20,4 \\
\hline Liberação de Hidrogênio & $700-900$ & 80,7 & 9,6 & 0,4 & 8,7 \\
\hline
\end{tabular}

(1) Hidrocarbonetos. 
A pirólise é um processo que visa à obtenção de produtos químicos orgânicos e carvão. Uma das principais diferenças entre os processos de combustão e de pirólise é que o primeiro ocorre na presença de oxigênio e o segundo ocorre m uma atmosfera inerte, como, por exemplo, o nitrogênio. Na seção subsequente será apresentada uma descrição mais detalhada sobre processo de pirólise.

Os processos de pirólise e gaseificação possuem algumas semelhanças, ambos ocorrem em uma atmosfera inerte, em que se fornece calor para a quebra das cadeias orgânicas mais complexas. Porém, o termo gaseificação é geralmente utilizado para uma reação que ocorre em temperaturas mais altas (acima de $700{ }^{\circ} \mathrm{C}$ ) do que as usuais para pirólise, desta forma existe mais energia no meio reacional e consequentemente podem ocorrer várias quebras consecutivas, de tal forma que é mais comum se obter uma fração maior de produtos líquidos em uma reação de pirólise do que em um reator de gaseificação. De um modo geral, a principal finalidade de um processo de gaseificação de matéria orgânica é a obtenção de gás de síntese, que consiste de uma mistura de gás hidrogênio e monóxido de carbono. Essa diferenciação de nomenclatura nem sempre é utilizada e alguns autores utilizam o termo pirólise mesmo para reações acima de $700{ }^{\circ} \mathrm{C}$.

A gaseificação é um termo que pode ser utilizado também para processos de oxidação parcial e reforma. O processo de oxidação parcial é aquele que utiliza uma quantidade de oxigênio inferior à requerida estequiometricamente para uma oxidação completa, assim são obtidos produtos parcialmente oxidados (KLASS, 1998).

O termo reforma foi usado originalmente para descrever a conversão térmica de frações de petróleo a produtos mais voláteis de maior octanagem, e representava o efeito total de muitas reações simultâneas como quebra, desidrogenação e isomerização. Para biomassa o termo refere-se à gaseificação na presença de outro reagente (KLASS, 1998), sendo um dos processos mais comuns a reforma a vapor.

Sob condições ideais, os produtos da gaseificação, seja por pirólise, oxidação parcial ou reforma, são essencialmente os mesmos: óxidos de carbono e hidrogênio (KLASS, 1998). As principais reações de biomassas derivadas de celulose podem ser descritas pelas equações químicas a seguir (RAHEEM et al.,2015). 


$$
\begin{aligned}
& \text { Reação de oxidação: } \quad \mathrm{C}+\mathrm{O}_{2} \rightarrow \mathrm{CO}_{2} \\
& \text { Reação de Boudouard: } \mathrm{C}+\mathrm{CO}_{2} \rightarrow 2 \mathrm{CO} \\
& \text { Reação gás-água: } \mathrm{C}+\mathrm{H}_{2} \mathrm{O} \rightarrow \mathrm{CO}+\mathrm{H}_{2} \\
& \text { Reação de metanação: } \mathrm{C}+2 \mathrm{H}_{2} \rightarrow \mathrm{CH}_{4} \\
& \text { Reação de shift: } \mathrm{CO}+\mathrm{H}_{2} \mathrm{O} \rightarrow \mathrm{CO}_{2}+\mathrm{H}_{2} \\
& \text { Reforma a vapor de metano: } \mathrm{CH}_{4}+\mathrm{H}_{2} \mathrm{O} \rightarrow \mathrm{CO}+3 \mathrm{H}_{2} \\
& \text { Reforma seca de metano: } \mathrm{CH}_{4}+\mathrm{CO}_{2} \rightarrow \mathrm{CO}+2 \mathrm{H}_{2}
\end{aligned}
$$

\subsection{Pirólise de biomassa}

A pirólise de biomassa é definida por Klass (1998) como a decomposição térmica direta de componentes orgânicos da biomassa na ausência de oxigênio para produzir uma série de produtos úteis - derivados líquidos, sólidos e combustíveis gasosos. $\mathrm{O}$ processo de pirólise é utilizado para produção comercial de um largo espectro de combustíveis, solventes, químicos, e outros produtos obtidos a partir da biomassa.

O processo de pirólise pode ser divido em três operações básicas: pirólise, separação de sólidos/voláteis e resfriamento de voláteis. Dependendo da matéria prima a ser processada, é usual a utilização de uma etapa de secagem prévia à reação com o objetivo de retirar a umidade externa da biomassa.

A primeira etapa da pirólise corresponde à reação propriamente dita, na qual a biomassa será submetida a temperaturas que variam entre 250 e $900{ }^{\circ} \mathrm{C}$ em atmosfera livre de oxigênio, para que suas cadeias de polímeros naturais sejam fracionadas em cadeias menores, gerando gases, líquidos voláteis e carvão.

A segunda etapa consiste na separação da fração sólida, a qual dá origem ao carvão, e a fração volátil. No caso de um processo em batelada, a fração volátil é carregada por um gás de arraste, usualmente o nitrogênio, para a etapa seguinte e a fração sólida permanece no reator, para ser retirada ao final da batelada. No caso de um processo contínuo, tanto o produto sólido quanto o volátil são conduzidos para um 
vaso separador, como por exemplo ciclones, em que a fração sólida é retirada pela parte inferior e os produtos voláteis saem pelo topo.

A terceira etapa consiste no resfriamento da fração volátil, esta etapa é comumente denominada de "quenching". Através desse resfriamento, o líquido formado é retirado pela base, enquanto os gases são retirados pelo topo. A Figura 5 mostra esquematicamente as etapas básicas citadas para um processo de pirólise de biomassa.

Figura 5 - Esquema simplificado das etapas básicas de um processo de pirólise e regime contínuo

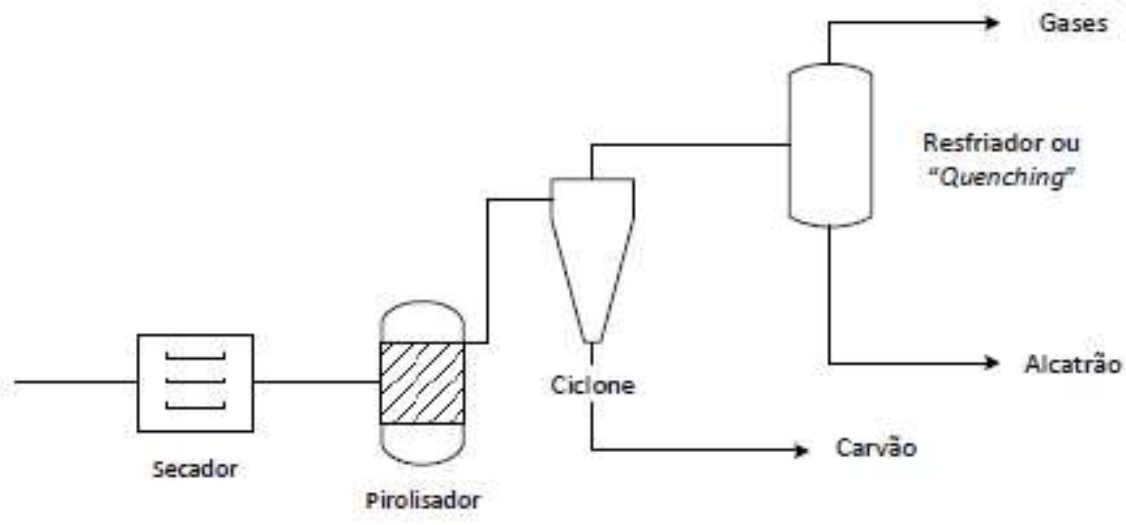

O Carvão pode ser utilizado diretamente como combustível, como matéria prima em gaseificadores para a produção de gás de síntese ou como fonte de carbono em processos como o siderúrgico. A fração de líquidos voláteis corresponde ao alcatrão ou óleo pirolenhoso, que é de onde se retira o bio-óleo e outros compostos orgânicos de interesse comercial, como, por exemplo, ácido acético, metanol e acetona. A fração gasosa é rica em hidrogênio, óxidos de carbono e hidrocarbonetos de baixo peso molecular ( $\mathrm{C} 1$ e C2). A mistura de hidrogênio, monóxido e dióxido de carbono é conhecida como gás de síntese, o qual pode ser utilizado diretamente para a produção de energia, para síntese de outros combustíveis, como etanol e metanol, ou variados compostos orgânicos.

Variáveis como tipo e composição da biomassa, temperatura e pressão da reação, tempo de residência, dimensão das partículas alimentadas e uso de catalisadores têm influência sobre os produtos que serão obtidos. 
Os principais processos de pirólise podem ser descritos como (KLASS, 1998):

- Lenta: baixas taxas de aquecimento e relativamente baixas temperaturas, cerca de 250 a $300{ }^{\circ} \mathrm{C}$, nas quais carvão, alcatrão e produtos da desidratação são os produtos principais, além disso alguns líquidos voláteis e gases são formados.

- Convencional: com taxas de aquecimento intermediárias e temperaturas entre 300 e $600^{\circ} \mathrm{C}$, nas quais carvão, alcatrão, líquidos voláteis e gases são formados.

- Rápida ou "Flash": com rápidas taxas de aquecimento e temperatura entre 450 e $600{ }^{\circ} \mathrm{C}$, nas quais líquidos voláteis são o produto principal, mas alguns produtos como carvão, alcatrão e gases também são formados.

- Altas temperaturas: ocorre a temperaturas superiores a $600{ }^{\circ} \mathrm{C}$ onde as reações de gaseificação começam a predominar.

A Tabela 6 mostra as principais reações exotérmicas presentes na pirólise de celulose. Nessas reações está incluída a redução de óxidos de carbono a metano e metanol, a reação de "shift" e a carbonização da celulose. Grande quantidade de hidrogênio é necessária para as reações de metanação e formação de metanol, esse hidrogênio é obtido a partir da reação de "shift". A água necessária para produção de hidrogênio pode ser obtida através da reação de formação de carvão e da vaporização da umidade presente na própria biomassa. O rendimento na produção de carvão a partir da pirólise convencional é de até $35 \%$ em massa (KLASS, 1998).

Tabela 6 - Reações exotérmicas da pirólise de celulose

(KLASS, 1998)

\begin{tabular}{|c|c|c|c|}
\hline \multirow{2}{*}{ Processo } & \multirow{2}{*}{ Reação } & \multicolumn{2}{|c|}{$\begin{array}{l}\text { Entalpia (kJ/gmol), } \\
\text { Carbono convertido a }\end{array}$} \\
\hline & & $300 \mathrm{~K}$ & $1000 \mathrm{~K}$ \\
\hline \multirow{2}{*}{ Metanação } & $\mathrm{CO}+3 \mathrm{H}_{2} \rightarrow \mathrm{CH}_{4}+\mathrm{H}_{2} \mathrm{O}$ & -205 & -226 \\
\hline & $\mathrm{CO}_{2}+4 \mathrm{H}_{2} \rightarrow \mathrm{CH}_{4}+2 \mathrm{H}_{2} \mathrm{O}$ & -167 & -192 \\
\hline \multirow{2}{*}{ Formação de Metanol } & $\mathrm{CO}+2 \mathrm{H}_{2} \rightarrow \mathrm{CH}_{3} \mathrm{OH}$ & -92 & -105 \\
\hline & $\mathrm{CO}_{2}+3 \mathrm{H}_{2} \rightarrow \mathrm{CH}_{3} \mathrm{OH}+\mathrm{H}_{2} \mathrm{O}$ & -50 & -71 \\
\hline Formação de carvão & $1 / 6 \mathrm{C}_{6} \mathrm{H}_{10} \mathrm{O}_{5}{ }^{(3)} \rightarrow \mathrm{C}+5 / 6 \mathrm{H}_{2} \mathrm{O}$ & -81 & -80 \\
\hline Reação de "Shift" & $\mathrm{CO}+\mathrm{H}_{2} \mathrm{O} \rightarrow \mathrm{CO}_{2}+\mathrm{H}_{2}$ & -42 & -33 \\
\hline
\end{tabular}


Uma distribuição mais detalhada dos produtos obtidos a partir de uma pirólise lenta, com temperatura final de $400^{\circ} \mathrm{C}$, de três espécies diferentes de biomassas baseadas em celulose pode ser visualizada na Tabela 7. Pode-se observar que as produtividades tanto das substâncias gasosas, quanto dos líquidos orgânicos e de carvão é muito próxima independentemente das matérias primas, e que existe uma preponderância na produção de carvão e do óleo pirolenhoso, o que de certa forma é esperado, considerando que a temperatura final é relativamente baixa e a taxa de aquecimento é lenta, se aproximando de $50^{\circ} \mathrm{C} / \mathrm{h}$.

Tabela 7 - Rendimento de vários produtos a partir da decomposição térmica da madeira de Bétula, Pinho e Pinheiro, aquecidos por um período de 8 horas até uma temperatura final de $400{ }^{\circ} \mathrm{C}$

(KLASS, 1998)

\begin{tabular}{cccc}
\hline Produto & $\begin{array}{c}\text { Bétula } \\
\text { (\% massa) }\end{array}$ & $\begin{array}{c}\text { Pinho } \\
\text { (\% massa) }\end{array}$ & $\begin{array}{c}\text { Pinheiro } \\
\text { (\% massa) }\end{array}$ \\
\hline Gases & & & \\
$\mathrm{H}_{2}$ & 0,03 & 0,03 & 0,03 \\
$\mathrm{CO}$ & 4,12 & 4,10 & 4,07 \\
$\mathrm{CO}_{2}$ & 11,19 & 11,17 & 10,95 \\
$\mathrm{CH}_{4}$ & 1,51 & 1,49 & 1,59 \\
$\mathrm{C}_{2} \mathrm{H}_{4}$ & 0,21 & 0,14 & 0,15 \\
Subtotal & 17,06 & 16,93 & 16,79 \\
Carvão & 33,66 & 36,40 & 37,43 \\
Óleo pirolenhoso & & & \\
Água & 21,42 & 22,61 & 23,44 \\
Alcatrão insolúvel & 3,75 & 10,81 & 10,19 \\
Alcatrão solúvel & 10,42 & 5,90 & 5,13 \\
Ácidos voláteis & 7,66 & 3,70 & 3,95 \\
Álcoois & 1,83 & 0,89 & 0,88 \\
Aldeídos & 0,50 & 0,19 & 0,22 \\
Ésteres & 1,63 & 1,22 & 1,30 \\
Cetonas & 1,13 & 0,26 & 0,29 \\
Subtotal & 48,34 & 45,58 & 45,40 \\
Perdas & 0,94 & 1,09 & 0,38 \\
\hline
\end{tabular}

À medida que a temperatura de pirólise aumenta, na faixa de 500 a $900{ }^{\circ} \mathrm{C}$, a produtividade dos gases aumenta, enquanto a produção de líquidos e carvão diminui. Esse comportamento pode ser verificado para os produtos de pirólise da fração 
orgânica de Resíduo Sólido Municipal (RSM) através da Tabela 8. De acordo com a taxa de aquecimento e a temperatura de processamento, podemos observar que há uma grande variação no tipo de produto obtido, conforme mostra a Tabela 9. Quando mencionamos baixas taxas de aquecimento, estamos nos referindo a uma variação de temperatura na ordem de dezenas de graus Celsius por hora, uma taxa de aquecimento média significa dezenas de graus Celsius por minuto e alta taxa de aquecimento significa um aumento de dezenas de graus Celsius por segundo ou frações de segundo.

Muitos trabalhos já foram realizados na área de pirólise envolvendo biomassas derivadas da celulose. Porém, como já foi dito, existe um grande potencial para utilização de biomassa de origem aquática, principalmente as algas. Ross et al. (2009) realizaram um mapeamento dos produtos gerados a partir da pirólise da (macro) alga parda, seus resultados indicaram uma gama de cetonas, pentosanas, compostos nitrogenados e fenóis.

Tabela 8 - Efeito da temperatura sobre a produtividade de gases, líquidos e carvão, e composição dos gases e carvão obtidos a partir da pirólise da fração orgânica de RSM

(KLASS, 1998)

\begin{tabular}{ccccc}
\hline \multirow{2}{*}{ Parâmetro } & \multicolumn{4}{c}{ Temperatura de Pirólise $\left({ }^{\circ} \mathbf{C}\right.$ ) } \\
& $\mathbf{5 0 0}$ & $\mathbf{6 5 0}$ & $\mathbf{8 0 0}$ & $\mathbf{9 0 0}$ \\
\hline Gases (\% em massa) & 12,3 & 18,6 & 23,7 & 24,4 \\
Líquidos (\% em massa) & 61,1 & 59,2 & 59,7 & 58,7 \\
Carvão (\% em massa) & 24,7 & 21,8 & 17,2 & 17,7 \\
Composição dos gases (\% molar) & & & & \\
$\mathrm{H}_{2}$ & 5,56 & 16,6 & 28,6 & 32,5 \\
$\mathrm{CO}$ & 33,5 & 30,5 & 34,1 & 35,3 \\
$\mathrm{CO}_{2}$ & 44,8 & 31,8 & 20,6 & 18,3 \\
$\mathrm{CH}_{4}$ & 12,4 & 15,9 & 13,7 & 10,5 \\
$\mathrm{C}_{2} \mathrm{H}_{6}$ & 3,03 & 3,06 & 0,77 & 1,07 \\
$\mathrm{C}_{2} \mathrm{H}_{4}$ & 0,45 & 2,18 & 2,24 & 2,43 \\
Composição dos gases & & & & \\
(\% em massa) & & & & \\
Carbono fixo & 70,5 & 70,7 & 79,1 & 77,2 \\
Material volátil & 21,8 & 15,1 & 8,13 & 8,30 \\
Cinzas & 7,71 & 14,3 & 12,8 & 14,5 \\
\hline
\end{tabular}


Tabela 9 - Tecnologias típicas de pirólise de Biomassa, condições e principais produtos (KLASS, 1998)

\begin{tabular}{|c|c|c|c|c|}
\hline Tecnologia & $\begin{array}{l}\text { Tempo de } \\
\text { residência }\end{array}$ & $\begin{array}{c}\text { Taxa de } \\
\text { aquecimen } \\
\text { to }\end{array}$ & $\begin{array}{c}\text { Temperatura } \\
\left({ }^{\circ} \mathrm{C}\right)\end{array}$ & $\begin{array}{l}\text { Principais } \\
\text { produtos }\end{array}$ \\
\hline $\begin{array}{l}\text { Carbonização } \\
\text { convencional }\end{array}$ & Horas/dias & Muito baixa & $300-500$ & Carvão \\
\hline $\begin{array}{l}\text { Carbonização } \\
\text { pressurizada }\end{array}$ & $15 \min -2 h$ & Média & 450 & Carvão \\
\hline Pirólise convencional & Horas & Baixa & $400-600$ & $\begin{array}{c}\text { Carvão, líquidos } \\
\text { e gases }\end{array}$ \\
\hline Pirólise convencional & $5-30 \mathrm{~min}$ & Média & $700-900$ & Carvão e gases \\
\hline Pirólise rápida (“Flash”) & $0,1-2 \mathrm{~s}$ & Alta & $400-650$ & Líquidos \\
\hline Pirólise rápida (“Flash”) & $<1 \mathrm{~s}$ & Alta & $650-900$ & Líquidos e gases \\
\hline Pirólise rápida (“Flash”) & $<1 \mathrm{~s}$ & Muito alta & $1000-3000$ & Gases \\
\hline Pirólise a vácuo & $2-30 s$ & Média & $350-450$ & Líquidos \\
\hline $\begin{array}{l}\text { Pirólise hidro } \\
\text { pressurizada }\end{array}$ & $<10 \mathrm{~s}$ & Alta & $<500$ & Líquidos \\
\hline
\end{tabular}

Ainda seguindo a linha da identificação dos compostos obtidos através da pirólise de biomassa aquática, Babich et al. (2011) investigaram a diferença entre os produtos obtidos pela pirólise da Chlorella pura e com a adição de $\mathrm{Na}_{2} \mathrm{CO}_{3}$ como catalisador. Seus resultados a $450^{\circ} \mathrm{C}$ demonstraram um aumento significativo na quantidade de compostos aromáticos, em que o percentual da área total do cromatograma aumenta de 16,5 para $25 \%$ após a adição do catalisador. Diminui consideravelmente a acidez da mistura formada, não estando presentes na mistura de produtos os ácidos crotónico, pentanóico e hexadecanóico quando a pirólise é conduzida com a adição de $\mathrm{Na}_{2} \mathrm{CO}_{3}$, em termos de percentual da área total do cromatograma o resultado da fração de ácidos diminui de 11,5 (sem catalisador) para 3,6 \% quando se utiliza o catalisador. Os autores concluem que o uso $\mathrm{Na}_{2} \mathrm{CO}_{3}$ como catalisador pode ser benéfico para a produção de bio-óleo de melhor qualidade.

Kebelmann et al. (2013) estudaram os produtos de pirólise de duas espécies de microalgas, Chlamydomonas reinhardtii e Chlorella vulgaris, utilizando 
termogravimetria e o sistema pirolisador acoplado a um CG/MS (Py-GC/MS) reagindo a $500^{\circ} \mathrm{C}$. Os resultados revelaram uma quantidade significativa de compostos derivados de proteínas, incluindo tolueno, fenol, 4-metil-fenol, $1 \mathrm{H}$-indol e 3-metil-indol. Os principais produtos identificados foram fitol e seus derivados formados a partir da cadeia terpenóide de clorofila, além de derivados de alquil ésteres de ácido benzóico, ácido benzenodicarboxílico e esqualeno. Adicionalmente, foram detectados éster octílico do ácido octadecanóico, éster metílico do ácido hexadecanóico e hidrocarbonetos incluindo heptadecano, 1-nonadeceno e heneicosano obtidos a partir da pirólise da C. vulgaris.

Peng et al. (2000) estudaram o efeito da temperatura e do tempo de residência na pirólise de Chlorella protothecoides (CP) através do processo em batelada em uma autoclave e constataram que a máxima produção de óleo (52 \%) foi obtida após o aquecimento a $500{ }^{\circ} \mathrm{C}$ durante $5 \mathrm{~min}$. A produtividade dos hidrocarbonetos voláteis se mostrou 8,5 vezes maior para amostras de CP que receberam degradação por bactérias quando comparadas as células autotróficas (WU et al., 1996). Mais recentemente, examinaram a produção de bio-óleo a partir de CP e Microcystis aeruginosa utilizando a pirólise rápida. Por este estudo ficou evidenciado que o rendimento de bio-óleo produzido a partir da CP cultivada heterotroficamente foi 3,4 vezes maior do que o rendimento obtido a partir da mesma biomassa cultivada autotroficamente, enquanto o bio-óleo obtido a partir da primeira tinha teor de oxigênio inferior e poder calorífico mais elevado do que a última. Estes resultados poderiam ser atribuídos ao teor de lipídio maior das algas heterotróficas $(55,2 \%$ contra $14,6 \%)$ (MIAO; WU, 2004; MIAO et al., 2004).

O cultivo autotrófico, em que o micro-organismo produz seu próprio alimento através de fotossíntese ou quimiossíntese, é geralmente utilizado para microalgas, principalmente se considerarmos a produção em larga escala. Porém, como já demonstrado por Miao et al. (2004), é possível alterar a composição de certas espécies de microalgas através do cultivo heterotrófico, no qual uma fonte de carbono é adicionada ao meio tornando o cultivo independente da presença de luz, de tal forma que a produção de bio-óleo seja otimizada. Cunha et al. (2012) avaliaram o cultivo heterotrófico da Chlorella vulgaris através da adição de glicerol ao meio em diferentes 
proporções e concluíram que para essa espécie o cultivo autotrófico se mostrou mais adequado para o crescimento celular em termos de densidade de células no meio.

O uso de catálise heterogênea vem sendo largamente aplicado com a intenção de melhorar as propriedades físico-químicas das frações líquidas (CONTI et al., 2016). Estudos com a Chlorella vulgaris demonstraram que a utilização da zeólita HZSM-5 na proporção de 5:1 aumenta significativamente a produtividade de aromáticos (DU et al., 2013) e o aumento da proporção catalisador/biomassa para razão 9:1 de ZSM-5 resulta em $25 \%$ em massa do carbono presente na biomassa como hidrocarboneto aromático (THANGALAZHY-GOPAKUMAR et al., 2012), além da pirólise catalítica de microalgas produzir uma quantidade maior de aromáticos monocíclicos (WANG; BROWN, 2013). No caso da microalga Spirulina platensis, o aumento na proporção do catalisador de 2:1 para 50:1 em massa provocou um aumento significativo na produção de monoaromáticos, poliaromáticos, cicloalcanos e nitrilas (ANAND et al., 2016). Estudos com a Desmodesmus communis demonstraram que o aumento da carga da zeólita HZSM-5 de 5:1 para 20:1 provoca a denitrogenação/desoxigenação dos produtos (CONTI et al., 2016). A pirólise da alga Rhizoclonium $s p$. conduzida a $400^{\circ} \mathrm{C}$ resulta em uma produtividade de $35 \%$ de bioóleo rico em fitol (CASONI et al., 2016).

\subsection{Parâmetros cinéticos da reação de pirólise}

Uma vez que a pirólise é a primeira etapa de vários processos para conversão de biomassa, como gaseificação, liquefação, carbonização e combustão, parece compreensível que um entendimento satisfatório da pirólise de biomassa traz um desenvolvimento considerável ao processo de conversão de biomassa. Para aplicações em engenharia, o conhecimento da cinética é essencial para prever o comportamento da pirólise de biomassa, assim como para o projeto de reatores (SONOBE et al., 2008) e melhoria de processos.

Uma das formas de se conhecer a cinética de uma reação é através de parâmetros como energia de ativação e constantes cinéticas. A seguir estão apresentados modelos matemáticos para obtenção destes parâmetros. 


\subsubsection{Modelos matemáticos para cinética de pirólise}

\subsubsection{Método K-A-S}

A pirólise é considerada um processo que converte a biomassa (B) em uma mistura sólida (S) e uma mistura volátil (V) conforme a eq. (1) (HASHIMOTO et al., 2011).

$$
B \rightarrow s S+v V
$$

O grau de conversão de biomassa $(\alpha)$ pode ser definido pela eq. (2), onde $m_{0}$ é a massa inicial da biomassa seca, $m_{t}$ é a massa sólida em um determinado tempo $(t)$ e mash é a massa de cinzas da biomassa.

$$
\alpha=\left(m_{0}-m_{t}\right) /\left(m_{0}-m_{a s h}\right)
$$

A taxa de reação $(r)$ depende do grau de conversão $(\alpha)$ e da temperatura absoluta $(T)$ conforme a eq. (3) a seguir.

$$
r=\frac{d \alpha}{d t}=g(T) \cdot f(\alpha)
$$

Considerando que a taxa de reação seja expressa por uma reação de ordem $n$ em relação ao grau de conversão $(\alpha)$ e assumindo que a dependência com a temperatura segue a lei de Arrhenius, em que $K_{0}$ é o fator pré-exponencial e $E_{a}$ é a energia de ativação aparente da reação, a taxa de reação pode ser expressa através da eq. (4).

$$
r=\frac{d \alpha}{d t}=K_{0} \cdot \exp \left[\frac{-E_{a}}{R \cdot T}\right] \cdot(1-a)^{n}
$$

Como a proposta deste estudo é obter os parâmetros cinéticos calculados a partir de dados gerados por análise termogravimétrica, definiremos a taxa de aquecimento constante $(\beta)$ pela eq. (5).

$$
\beta=\frac{d T}{d t}
$$


Dividindo os dois lados da eq. (4) pela taxa de aquecimento definida pela eq. (5), obtemos a eq. (6) que define a variação do grau de conversão pela variação da temperatura.

$$
\frac{d \alpha}{d T}=\frac{K_{0}}{\beta} \cdot \exp \left[\frac{-E_{a}}{R \cdot T}\right] \cdot(1-a)^{n}
$$

A eq. (6) é uma equação diferencial separável que pode ser rearranjada e integrada resultando na eq. (7).

$$
\int_{o}^{\alpha} \frac{d \alpha}{(1-\alpha)^{n}}=\frac{K_{0}}{\beta} \int_{0}^{T} e^{-E_{a} / R \cdot T} \cdot d T
$$

O lado esquerdo da eq. (7) depende do valor da ordem de reação $n$ e será definido como $\mathrm{G}(\alpha)$. O lado direito da equação pode ser integrado analiticamente, de tal forma que obtemos a eq. (8).

$$
-G(\alpha)=-\frac{K_{0} \cdot R}{E_{a}} \cdot \frac{T^{2}}{\beta} \cdot e^{-E_{a} / R \cdot T}
$$

Rearranjando:

$$
\frac{\beta}{T^{2}}=\frac{K_{0} \cdot R}{E_{a} \cdot G(\mathrm{z})} \cdot e^{-E_{a} / R \cdot T}
$$

Aplicando In aos dois lados da eq. (9), obtemos a eq. (10) que corresponde à equação de uma reta.

$$
\ln \left(\frac{\beta}{T^{2}}\right)=\left[\ln \left(\frac{K_{0} \cdot R}{E_{a}}\right)-\ln G(\alpha)\right]-\frac{E_{a}}{R} \cdot \frac{1}{T}=b-a \cdot x
$$

Onde o coeficiente linear (b) desta reta é definido pela eq. (11) e o coeficiente angular (a) é definido pela eq. (12).

$$
\begin{aligned}
& b=\left[\ln \left(\frac{K_{0} \cdot R}{E_{a}}\right)-\ln (\alpha)\right] \\
& a=\frac{E_{a}}{R}
\end{aligned}
$$

Desta forma, plotando In $\left(\beta / T^{2}\right)$ versus $(1 / T)$, para um determinado grau de conversão $\alpha$, consegue-se calcular a energia de ativação aparente através do coeficiente 
angular. Para isso é importante fazer as curvas com pelo menos três diferentes taxas de aquecimento.

\subsubsection{Método Osawa}

A conversão da biomassa pela reação de pirólise pode ser descrita pela seguinte equação (HU et al., 2011):

$$
\frac{d \alpha}{d t}=K_{0} \cdot \exp \left[\frac{-E_{a}}{R \cdot T}\right] \cdot f(\alpha)
$$

Onde $\alpha$ é a fração convertida da biomassa ou grau de conversão, previamente definida pela eq. (2), $E_{a}$ é a energia de ativação aparente, $K_{0}$ é o fator pré-exponencial, $R$ corresponde a constante universal dos gases e $T$ é a temperatura absoluta.

A divisão de ambos os lados da eq. (13) pela taxa de aquecimento ( $\beta$ ), previamente definido pela eq. (5), e a integração fornece a eq. (14).

$$
\int_{o}^{\alpha} \frac{d \alpha}{f(\alpha)}=\frac{K_{0}}{\beta} \int_{0}^{T} e^{-E_{a} / R \cdot T} \cdot d T
$$

Segundo Hu et al. (2007), a função $f(\alpha)$ depende do mecanismo de reação da pirólise. Muitos métodos para determinação da cinética de reação estão disponíveis na literatura, porém apenas o método conhecido como Osawa não requer informação sobre o mecanismo de reação para se calcular a energia de ativação.

Osawa (1965) utilizou uma abordagem empírica, que não considera o efeito da taxa de aquecimento para determinar a energia de ativação. Para resolução da eq. (14), ele propõe a seguinte igualdade utilizando a função $p$. 


$$
\frac{\Delta E_{a}}{R} p\left(\frac{\Delta E_{a}}{R T}\right)=\int_{0}^{T} e^{-E_{a} / R \cdot T} \cdot d T
$$

Se $\Delta E_{a} / R T$ é maior do que $20, p\left(\Delta E_{a} / R T\right)$ pode ser aproximada pela eq. (16) (OSAWA, 1965).

$$
\log p\left(\frac{\Delta E_{a}}{R T}\right)=-2,315-0,4567 \frac{E_{a}}{R . T}
$$

A partir da eq. (16), Osawa (1965) trabalha com séries polinomiais e estabelece uma relação matemática linear entre a taxa de aquecimento $(\beta)$ e a energia de ativação $\left(E_{a}\right)$, descrita pela eq. (17).

$$
\log (\beta)=C_{1}-0,4567 \frac{E_{a}}{R \cdot T}
$$

Para $\alpha$ e $\mathrm{C}_{1}$ constantes. A energia de ativação pode ser calculada pela inclinação da reta obtida no gráfico log $(\beta)$ versus $(1 / T)$, onde a inclinação da reta é $\left(-0,4567 E_{a} / R\right)$.

\subsubsection{Cálculo da ordem de reação (n) e o fator pré-exponencial (Ko) a partir da energia de ativação $\left(E_{a}\right)$ previamente determinada}

Uma vez que a energia de ativação tenha sido determinada por K-A-S, Osawa ou qualquer outro método, os demais parâmetros podem ser determinados conforme o método proposto a seguir.

Dividindo a eq. (6) por exp (-E/RT) e aplicando logaritmo natural aos dois lados da equação, chegamos a eq. (18) que corresponde a equação de uma reta.

$$
\ln \left[\beta \cdot\left(\frac{d \alpha}{d T}\right) \cdot \frac{1}{e^{-E_{a} / R T}}\right]=\ln \left(K_{0}\right)+n \cdot \ln (1-\alpha)
$$

Definindo uma nova variável $Y$ como:

$$
Y=\beta \cdot\left(\frac{d \alpha}{d T}\right) \cdot \frac{1}{e^{-E a / R \cdot T}}
$$


$\ln Y=\ln K_{0}+n \cdot \ln (1-\alpha)$

Assim, plotando In ( $Y$ ) versus In (1- $\alpha)$ obtemos uma reta cujo coeficiente angular corresponde a ordem de reação $n$ e o coeficiente linear corresponde a $\ln \left(K_{0}\right)$. Os valores obtidos graficamente podem ser utilizados como chute inicial para calcular os parâmetros por meio de mínimos quadrados.

\subsubsection{Método Freeman-Carroll adaptado}

Conforme exposto por Freeman e Carroll (1958), a reação química que segue a eq. (1) poderia ter sua taxa de reação em função da concentração do reagente $(z)$ e do tempo $(t)$ expressa pela eq. (21). Essa equação parte da premissa que a reação é de ordem $n$ e segue a lei de Arrhenius, onde $K_{0}$ é o fator pré-exponencial, $E_{a}$ é a energia de ativação, $R$ é a constante universal dos gases e $T$ é a temperatura absoluta.

$$
-\left(\frac{d z}{d t}\right)=K_{0} \cdot \exp \left[\frac{-E_{a}}{R \cdot T}\right] \cdot z^{n}
$$

Rearranjando chegamos a seguinte igualdade:

$$
\frac{-\left(\frac{d z}{d t}\right)}{z^{n}}=K_{0} \cdot \exp \left[\frac{-E_{a}}{R \cdot T}\right]
$$

Aplicando logaritmo natural aos dois lados da equação e diferenciando em relação à $d z / d t$, z e $T$, obtemos como resultado a eq. (23).

$$
\frac{E_{a}}{R} \cdot \frac{1}{T^{2}} d T=d \ln \left(-\frac{d z}{d t}\right)-n \cdot d \ln z
$$

Integrando a eq. (23) chegamos à seguinte relação:

$$
-\frac{E_{a}}{R} \cdot \Delta\left(\frac{1}{T}\right)=\Delta \ln \left(-\frac{d z}{d t}\right)-n \cdot \Delta \ln z
$$


No estudo de Rizzo et al. (2013), a eq. (24) foi adaptada, partindo-se do método proposto por Freeman e Carroll (1958) para o cálculo da energia de ativação $\left(E_{a}\right)$, fator pré-exponencial $\left(K_{0}\right)$ e ordem de reação $(n)$, considerando o grau de conversão $\alpha^{\prime}$ e a taxa de aquecimento $\beta$.

Neste método foi utilizada uma definição de grau de conversão $\alpha^{\prime}$ conforme a eq. (25), onde $m_{t}$ é a massa da amostra em um determinado tempo $t, m_{0}$ é a massa inicial e $m_{F}$ é a massa final, que considera tanto o teor de cinzas quanto o carbono fixo que resta na amostra de biomassa após a degradação térmica.

$$
\alpha^{\prime}=\frac{\left(m_{0}-m_{t}\right)}{\left(m_{0}-m_{F}\right)}=(1-z)
$$

Fazendo a alteração de variáveis na eq. (24), de forma a utilizar o grau de conversão $\left(\alpha^{\prime}\right)$ no lugar da concentração (z), obtemos a eq. (26).

$$
-\frac{E_{a}}{R} \cdot \Delta\left(\frac{1}{T}\right)=\Delta \ln \left(\frac{d \alpha^{\prime}}{d T}\right)-n \cdot \Delta \ln \left(1-\alpha^{\prime}\right)
$$

Dividindo os dois lados da eq. (26) por $\Delta \ln \left(1-\alpha^{\prime}\right)$ e rearranjando, obtemos a eq. (27).

$$
\frac{\Delta \ln \left(d \alpha^{\prime} / d T\right)}{\Delta \ln \left(1-\alpha^{\prime}\right)}=n-\frac{E_{a}}{R} \cdot \frac{\Delta(1 / T)}{\Delta \ln \left(1-\alpha^{\prime}\right)}
$$

Considerando $\Delta$ como a diferença entre duas medidas, para $\alpha^{\prime}$ e $T$ correspondentes é possível calcular $E_{a}$ e $\mathrm{n}$ através da plotagem de $\Delta \ln \left(d \alpha^{\prime} / d T\right) / \Delta \ln \left(1-\alpha^{\prime}\right)$ versus $\Delta\left(T^{-1}\right) / \Delta \ln \left(1-\alpha^{\prime}\right)$, que resulta em uma reta cujo coeficiente angular é igual a $-E_{a} / R$ e o coeficiente linear é igual a $n$. Através da substituição de $E_{a}$ e $n$ na eq. (6) é possível se calcular $K_{0}$. 


\subsubsection{Modelo com reações paralelas independentes}

Baseia-se na ideia que a biomassa terrestre é composta por basicamente 3 componentes (HU et al., 2011):

- Celulose;

- Hemicelulose e

- Lignina.

Assim, a taxa de conversão poderia ser expressa pela eq. (28), partindo-se da premissa de que cada pseudo-reação é de ordem $n$ e sua relação com a temperatura segue a lei de Arrhenius, onde $\alpha$ corresponde ao grau de conversão, $t$ é o tempo, $C_{i}$ é a fração mássica do componente, $K_{0}$ é o fator pré-exponencial, $E_{a}$ é a energia de ativação, $R$ é a constante universal dos gases e $T$ é a temperatura absoluta.

$$
\frac{d \alpha}{d t}=\sum_{i=1}^{3} C_{i} \frac{d \alpha_{i}}{d t}=\sum_{i=1}^{3} C_{i} \cdot K_{0_{i}} \cdot \exp \left[\frac{-E_{a_{i}}}{R \cdot T}\right] \cdot f\left(\alpha_{i}\right)^{n_{i}}
$$

Para cada pseudo-componentes são usadas as seguintes equações:

$$
\frac{d \alpha_{i}}{d t}=K_{0_{i}} \cdot \exp \left[\frac{-E a_{i}}{R \cdot T}\right] \cdot\left(1-\alpha_{i}\right)^{n_{i}}
$$

Este quarto método para análise da cinética da reação de pirólise foi desenvolvido para biomassas que tem a celulose como base. No entanto, sua base empírica sugere ser possível também ser possível aplicá-lo para biomassa aquática, desde que se tenha informações para decompô-la em componentes apropriados.

\subsubsection{Valores reportados na literatura para Energia de Ativação}

Segundo Weber (2008), as reações de pirólise de biomassa possuem energia de ativação entre 30 e $200 \mathrm{~kJ} / \mathrm{mol}$. Estudos mais recentes apresentam valores maiores 
do que o valor máximo apresentado por essa faixa, de tal forma que atualmente podemos associar ao limite superior o valor de $300 \mathrm{~kJ} / \mathrm{mol}$ (KASSIM et al., 2014). A Tabela 10 apresenta uma série de valores reportados na literatura para energia de ativação relativa ao processamento térmico de alguns tipos de microalgas. A espécie Chlorella vulgaris apresenta uma variação de 44 a $243 \mathrm{~kJ} / \mathrm{mol}$ considerando processos de pirólise, gaseificação e combustão (AGRAWAL; CHAKRABORTY, 2013; CHEN et al., 2011). A Chlorella protothecoides apresenta o valor de energia de ativação mais baixo para o processo de pirólise, avaliado em $42 \mathrm{~kJ} / \mathrm{mol}$ e o valor mais alto, dentre as microalgas analisadas, está associado a pirólise do gênero Chlorella sp. e equivale a $301 \mathrm{~kJ} / \mathrm{mol}$.

Tabela 10 - Valores para Energia de ativação apresentados na literatura para diferentes espécies de algas

\begin{tabular}{|c|c|c|c|c|c|}
\hline Espécie & $\begin{array}{c}\text { Taxa de } \\
\text { aquecimento } \\
\left({ }^{\circ} \mathrm{C} / \mathrm{min}\right)\end{array}$ & $\begin{array}{l}\text { Gás de arraste } \\
\text { (fluxo } \mathrm{mL} / \mathrm{min} \text { ) }\end{array}$ & $\begin{array}{c}\text { Processo - } \\
\text { Método }\end{array}$ & $\begin{array}{c}E_{a} \\
(\mathrm{~kJ} / \mathrm{mol})\end{array}$ & Referência \\
\hline \multirow{8}{*}{ Chlorella vulgaris } & 10,20 e 40 & $20 \% \mathrm{O}_{2} / 80 \% \mathrm{~N}_{2}$ & Combustão - K-A-S & $134-243$ & $\begin{array}{c}\text { Chen et al., } 2011 \\
\text { Thangalazhy- }\end{array}$ \\
\hline & $10,20,30$ e 40 & $\mathrm{~N}_{2}(100)$ & Pirólise - K-A-S & 107 & $\begin{array}{l}\text { Gopakumar } \\
\text { et al., } 2012\end{array}$ \\
\hline & $10,20,30$ e 40 & $\mathrm{~N}_{2}(100)$ & Pirólise - Osawa & 110 & $\begin{array}{l}\text { Thangalazhy- } \\
\text { Gopakumar } \\
\text { et al., } 2012\end{array}$ \\
\hline & $5,10,20,30$ e 40 & $\mathrm{~N}_{2} / \operatorname{ar}(100)$ & $\begin{array}{c}\text { Pirólise/Combustão - } \\
\text { K-A-S }\end{array}$ & $44-62$ & $\begin{array}{c}\text { Agrawal e } \\
\text { Chakraborty, } \\
2013\end{array}$ \\
\hline & 5,10 e 20 & $\mathrm{~N}_{2} / \operatorname{ar}(25)$ & $\begin{array}{c}\text { Pirólise/Gaseificação } \\
\text { - K-A-S }\end{array}$ & $45,38-97,22$ & $\begin{array}{l}\text { Raheem et al., } \\
2015\end{array}$ \\
\hline & $10,20,30$ e 40 & $\operatorname{Ar}(200) / \mathrm{H}_{2} \mathrm{O}$ & Gaseificação - K-A-S & 198 & $\begin{array}{l}\text { Figueira et al., } \\
\qquad 2015\end{array}$ \\
\hline & $10,20,30$ e 40 & $\operatorname{Ar}(200) / \mathrm{H}_{2} \mathrm{O}$ & $\begin{array}{c}\text { Gaseificação - } \\
\text { Osawa }\end{array}$ & 187 & $\begin{array}{l}\text { Figueira et al., } \\
2015\end{array}$ \\
\hline & $10,20,30$ e 40 & $\operatorname{Ar}(200) / \mathrm{H}_{2} \mathrm{O}$ & Gaseificação - IPR & $79,8-124,8$ & $\begin{array}{l}\text { Figueira et al., } \\
\qquad 2015\end{array}$ \\
\hline \multirow[b]{2}{*}{$\begin{array}{c}\text { Chlorella } \\
\text { pyrenoidosa }\end{array}$} & $10,20,40$ e 80 & $\mathrm{~N}_{2}(60)$ & Pirólise - K-A-S & 77 & Gai et al., 2013 \\
\hline & 20,40 e 60 & $\mathrm{~N}_{2}(100)$ & $\begin{array}{l}\text { Pirólise - Single- } \\
\text { step-global-model } \\
\text { (SSGM) }\end{array}$ & 144 & Hu et al., 2015 \\
\hline $\begin{array}{c}\text { Chlorella } \\
\text { protothecoides }\end{array}$ & $15,40,60$ e 80 & $\mathrm{~N}_{2}(60)$ & $\begin{array}{c}\text { Pirólise - Freeman- } \\
\text { Carroll }\end{array}$ & $42-52$ & Peng et al., 2001 \\
\hline
\end{tabular}




\begin{tabular}{|c|c|c|c|c|c|}
\hline Espécie & $\begin{array}{c}\text { Taxa de } \\
\text { aquecimento } \\
\left({ }^{\circ} \mathrm{C} / \mathrm{min}\right)\end{array}$ & $\begin{array}{l}\text { Gás de arraste } \\
\text { (fluxo } \mathrm{mL} / \mathrm{min} \text { ) }\end{array}$ & $\begin{array}{c}\text { Processo - } \\
\text { Método }\end{array}$ & $\begin{array}{c}E_{a} \\
(\mathrm{~kJ} / \mathrm{mol})\end{array}$ & Referência \\
\hline \multirow{3}{*}{ Chlorella sp. } & 15 & $\mathrm{~N}_{2}(8,5)$ & $\begin{array}{c}\text { Pirólise - Freeman- } \\
\text { Carroll }\end{array}$ & $71-79$ & $\begin{array}{l}\text { Rizzo et al., } \\
2013\end{array}$ \\
\hline & 5,10 e 15 & $\mathrm{~N}_{2}(100)$ & Pirólise - K-A-S & 301 & $\begin{array}{l}\text { Kassim et al., } \\
2014\end{array}$ \\
\hline & 5,10 e 15 & $\mathrm{~N}_{2}(100)$ & Pirólise - Osawa & 298 & $\begin{array}{l}\text { Kassim et al., } \\
2014\end{array}$ \\
\hline \multirow{2}{*}{$\begin{array}{l}\text { Dunaliella } \\
\text { tertiolecta }\end{array}$} & $5,10,20$ e 40 & $\mathrm{~N}_{2}(50)$ & Pirólise - K-A-S & 146 & $\begin{array}{l}\text { Shuping et al., } \\
2010\end{array}$ \\
\hline & $5,10,20$ e 40 & $\mathrm{~N}_{2}(50)$ & Pirólise - Osawa & 146 & $\begin{array}{l}\text { Shuping et al., } \\
\qquad 2010\end{array}$ \\
\hline \multirow[t]{2}{*}{ Spirulina platensis } & $15,40,60$ e 80 & $\mathrm{~N}_{2}(60)$ & $\begin{array}{c}\text { Pirólise - Freeman- } \\
\text { Carroll }\end{array}$ & $76-97$ & Peng et al., 2001 \\
\hline & $10,20,40$ e 80 & $\mathrm{~N}_{2}(60)$ & Pirólise - K-A-S & 92 & Gai et al., 2013 \\
\hline Tetraselmis suecica & 5,10 e 15 & $\mathrm{O}_{2} / \mathrm{N}_{2}(100)$ & Combustão - K-A-S & $30-70$ & $\begin{array}{l}\text { Tahmasebi } \\
\text { et al., } 2013\end{array}$ \\
\hline Corallina pilulifera & 10,30 e 50 & $\mathrm{~N}_{2}(80)$ & Pirólise - K-A-S & 251 & Li et al., 2011 \\
\hline $\begin{array}{l}\text { Nannochloropsis } \\
\text { gaditana }\end{array}$ & 5,15 e 40 & $\mathrm{He}(200)$ & Pirólise - IPR & 83 & $\begin{array}{c}\text { Sanchez-Silva et } \\
\text { al., } 2012\end{array}$ \\
\hline $\begin{array}{l}\text { bloom-forming } \\
\text { cyanobacteria }\end{array}$ & 5,15 e 20 & $\mathrm{~N}_{2}(100)$ & Pirólise - SSGM & 173 & Hu et al., 2015 \\
\hline Pophyra yezoensis & 10,30 e 50 & $\mathrm{~N}_{2}(80)$ & Pirólise - K-A-S & 154 & Li et al., 2011 \\
\hline $\begin{array}{l}\text { Plocamium } \\
\text { telfairiae }\end{array}$ & 10,30 e 50 & $\mathrm{~N}_{2}(80)$ & Pirólise - K-A-S & 245 & Li et al., 2011 \\
\hline \multirow[t]{2}{*}{ T. suecica } & 5,10 e 15 & $\mathrm{~N}_{2}(100)$ & Pirólise - K-A-S & 95 & $\begin{array}{l}\text { Kassim et al., } \\
2014\end{array}$ \\
\hline & 5,10 e 15 & $\mathrm{~N}_{2}(100)$ & Pirólise - Osawa & 100 & $\begin{array}{l}\text { Kassim et al., } \\
2014\end{array}$ \\
\hline $\begin{array}{l}\text { Chlorococcum } \\
\text { humicola }\end{array}$ & 5,10 e 20 & - & Pirólise - DAEM & 190 & $\begin{array}{c}\text { Kirtania e } \\
\text { Bhattacharya, } \\
2012 .\end{array}$ \\
\hline
\end{tabular}

\subsection{Cromatografia Gasosa e Espectrometria de Massas}

Cromatografia é um método físico de separação, no qual os componentes a serem separados são distribuídos entre duas fases: uma fase auxiliar fixa de grande área superficial denominada fase estacionária, e a fase principal, constituída por um fluido que percola através dela, sendo por isso, denominada fase móvel (LANÇAS; 
MCNAIR, 1983). A fase estacionária pode ser apresentada como enchimento de um tubo inerte ou recobrindo a parede interna de um tubo de diâmetro relativamente pequeno $(0,10-0,52 \mathrm{~mm})$, podendo ser um sólido ou um líquido. Se for um líquido pode estar depositado sobre a superfície de um suporte sólido inerte (PESSOA, 1993). A fase móvel pode ser um líquido ou um gás inerte. No caso de a fase móvel ser um líquido o método é conhecido como cromatografia líquida, analogamente para a cromatografia gasosa a fase móvel é constituída por um gás que percorre a coluna cromatográfica.

O princípio de separação na cromatografia gasosa é a diferença entre os pontos de ebulição entre os componentes da mistura e a polaridade dos mesmos. As fases estacionárias normalmente diferem em relação a sua polaridade, de tal forma que além da volatilidade, a afinidade da substância com a fase estacionária se torna mais um parâmetro para determinar o tempo de residência na coluna cromatográfica.

Uma substância será identificada utilizando-se cromatografia através do tempo de retenção, ou seja, o tempo que ela permanece na coluna, para uma determinada condição de análise. $\mathrm{Na}$ cromatografia gasosa essas condições incluem a pressão e a vazão do gás de arraste, e a temperatura da coluna de separação (DUNNIVANT; GINSBACH, 2011).

A temperatura da coluna é um dos parâmetros mais importantes para a separação. A Figura 6 ilustra o resultado obtido através da análise de uma mistura de 6 analitos em diferentes temperaturas. Podemos perceber que quando a separação ocorre isotermicamente em uma temperatura muito baixa $\left(40^{\circ} \mathrm{C}\right)$, a separação das substâncias ocorre de forma limitada, pois alguns picos contêm mais de um analito. A análise isotérmica em uma temperatura mais alta $\left(200^{\circ} \mathrm{C}\right)$ foi mais favorável para analitos com maior ponto de ebulição, porém causa uma perda de resolução para os analitos mais voláteis, que acabam se aglomerando no início do gráfico. A utilização de uma rampa de temperaturas torna a separação adequada, de tal forma que cada analito possui um pico no gráfico (DUNNIVANT; GINSBACH, 2011).

O tempo de retenção de um analito é o principal parâmetro utilizado para identificá-lo através da cromatografia, porém, para tal, precisamos de um padrão para cada 
substância pesquisada com a finalidade de se confirmar o tempo de retenção a partir de uma amostra conhecida.

Figura 6 - Efeito da temperatura na separação de uma mistura por cromatografia gasosa: (a) análise isotérmica a $40^{\circ} \mathrm{C}$, (b) análise isotérmica a $200^{\circ} \mathrm{C}$ e (c) análise com rampa de temperatura de 40 a $200{ }^{\circ} \mathrm{C}$
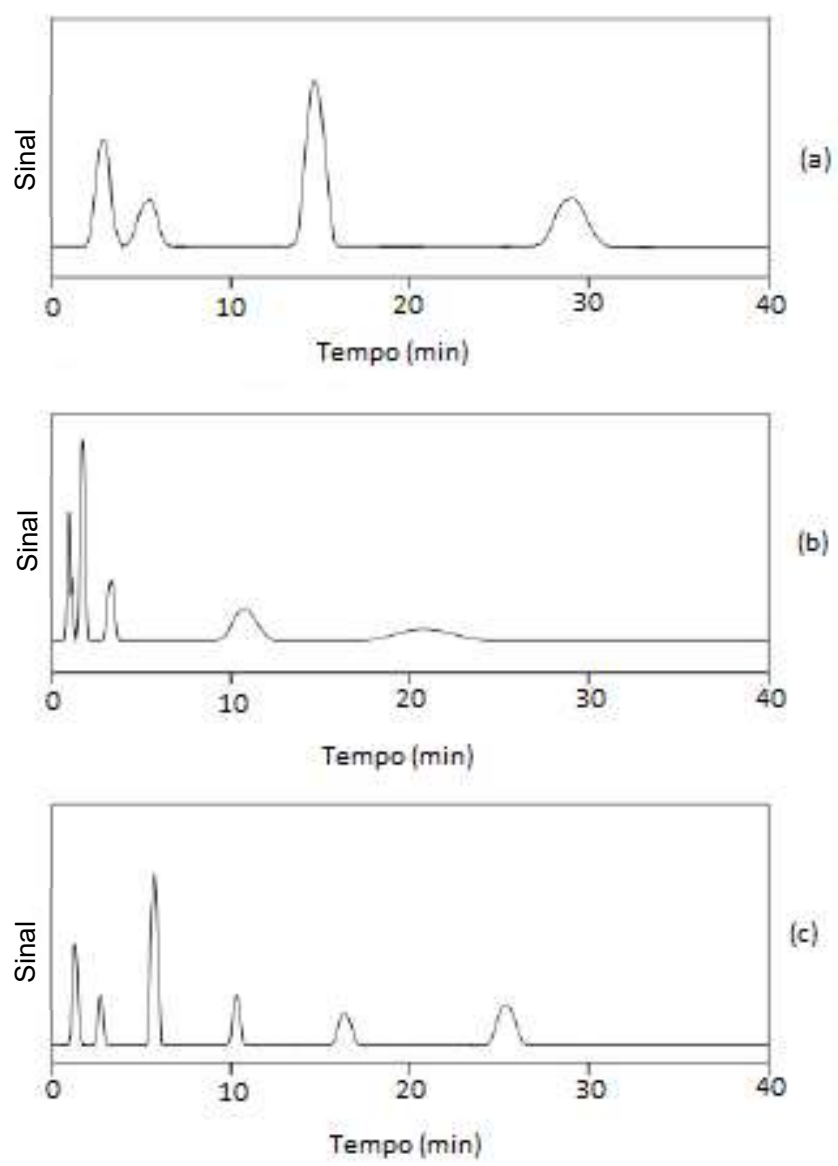

Fonte: Dunnivant e Ginsbach (2011)

Uma alternativa é a utilização de índices de retenção presentes em bases de dados. Os índices de retenção mais utilizados são conhecidos como índices de Kovats, que são obtidos através de cromatografia isotérmica, e índices de retenção com programação linear de temperatura (LTPRI). Esses índices são calculados a partir da razão entre a diferença entre os tempos de retenção do analito e dos n-alcanos com tempo de retenção imediatamente anterior e posterior ao analito. Este índice é expresso em "index units" (iu) (AREY et al., 2005).

$$
\text { LTPRI }=100 n+100 \frac{\left(t_{R(i)}-t_{R(n)}\right)}{\left(t_{R(n+1)}-t_{R(n)}\right)}
$$

Onde $t_{R}$ é o tempo de retenção ajustado (tempo de retenção do pico menos o tempo de eluição do pico de um composto não retido pela coluna cromatográfica), o índice 
“i” corresponde ao analito, "n" ao número de carbonos do padrão adjacente menos retido e "n + 1" é o número de carbonos do padrão adjacente mais retido. Com o valor de LPTRI determinado experimentalmente, ele pode ser comparado com índices de retenção tabelados. Quando a série homóloga utilizada é de n-alcanos, o valor de LTPRI igual a 1.638 já explicita que o composto está eluindo entre C16 e C17, pelo valor de 1.600, e os algarismos 38 indicam que o composto elui mais próximo do C16 do que do C17, em uma escala de 0 a 99 (MUHLEN, 2009).

A coluna cromatográfica em si é responsável pela separação dos componentes da mistura, mas o gráfico resultante da análise é gerado por um detector. Existem alguns tipos de detectores comumente utilizados em cromatógrafos gasosos, dentre os principais podemos citar o detector de condutividade térmica, detector por ionização em chama, detector de captura eletrônica. Além dos detectores previamente citados, existe a possibilidade de se acoplar a outro equipamento, um espectrômetro de massas (MS), ao cromatógrafo gasoso (GC). A grande vantagem de um sistema GCMS é o fato da espectrometria de massas ter caráter confirmatório na análise de uma substância, dispensando a realização de várias análises cromatográficas com mais de uma coluna para identificar um determinado analito.

A análise por espectrometria de massas consiste em basicamente quatro etapas: (1) ionizar cada analito que deixa a coluna cromatográfica, (2) acelerar e focar os compostos e fragmentos ionizados para um analisador de massas, (3) separar os fragmentos no analisador de massas baseado nas razões massa/carga (m/z), e (4) detectar os fragmentos à medida em que eles deixam o analisador (DUNNIVANT; GINSBACH, 2011).

A ionização dos analitos proveniente de um GC é feita de forma eletrônica ou química. A ionização eletrônica é obtida através de um feixe de elétrons gerado a partir do aquecimento de um filamento metálico, usualmente o Tungstênio, que através do "choque" com as moléculas do analito transfere energia (70 eV) para molécula provocando sua fragmentação e o aparecimento de cátions. A ionização química é realizada através do "choque" do analito com um cátion proveniente de um gás reagente, como o metano, propano, isobutano ou amônia, sendo o mais comum o metano, envolve uma energia relativamente menor se comparado ao método de elétrons (de 20 a 40 eV) e um dos seus maiores propósitos é observar o íon molecular. 
Íons precisam ser acelerados no analisador de massas com a finalidade de separar os fragmentos de diferentes massas. Como a maior parte dos fragmentos gerados possui carga positiva, uma forma comum de acelerar os íons é posicionar uma placa carregada positivamente a montante do sistema, de modo a repelir os cátions e enviálos na direção do analisador, além disso, uma outra placa carregada negativamente é posicionada a jusante do sistema para atrair os cátions naquela direção. Os fragmentos de diferentes massas passam por um filtro, de tal forma que os fragmentos de diferentes massas atinjam o detector em momentos distintos.

Existem alguns tipos de analisadores de massas, que funcionam como um filtro de massas que serão posteriormente enviadas ao detector, dentre os mais comuns podemos citar o analisador de setor magnético, filtro de massa quadrupolo, filtro de massa "ion trap" (armadilha de íons), filtro de massa por tempo de voo. Os analisadores de setor magnético utilizam um imã permanente ou um eletroímã para movimentar os íons da fonte em uma trajetória semicircular e separam os íons baseando-se em seus momentos e energia cinética. Um filtro de massas quadrupolo consiste em quatro hastes igualmente afastadas uma da outra de forma paralela, cada haste possui menos de $1 \mathrm{~cm}$ de diâmetro e normalmente menos de $15 \mathrm{~cm}$ de comprimento, através da aplicação de campos elétricos nestas hastes, a cada fração de tempo, fragmentos de uma determinada massa mantem-se ionizados e seguem para o detector e as demais massas são neutralizadas e eliminadas. $O$ analisador do tipo "ion trap" é composto por um eletrodo anelar posicionado em um plano entre dois eletrodos com pontas arredondadas, um campo elétrico, que varia ao longo do tempo, é criado no sistema, de tal forma que gradualmente os fragmentos de uma determinada massa são conduzidos ao detector, enquanto os demais são neutralizados e eliminados, e a medida que o campo elétrico varia, a massa enviada ao detector também varia. Os filtros de tempo de voo medem o tempo para os íns atravessarem um tubo livre de campo (elétrico ou magnético) até atingir o detector, íons com diferentes razões massa/carga terão velocidades variando inversamente a suas massas, quanto menor a massa maior a velocidade.

Uma vez que os fragmentos de massa atingem o detector, este emite um sinal relativo ao número de fragmentos que o atingiram, gerando os dados necessários para a construção dos espectros de massa e dos cromatogramas. 


\section{MATERIAIS E MÉTODOS}

\subsection{Identificação de Classes de Compostos Produzidos}

A identificação das classes de compostos obtidos através da reação de pirólise da microalga de estudo foi realizada através de um pirolisador (Py) de bancada conectado por uma linha de transferência aquecida a um cromatógrafo gasoso (GC) acoplado a um espectrômetro de massas (MS) conforme apresenta a Figura 7 abaixo.

Figura 7 - Arranjo Py-GC/MS: Pirolisador ${ }^{(a)}$ interligado por uma linha de transferência aquecida $^{(b)}$ a um cromatógrafo ${ }^{(c)}$ acoplado a um espectrometro de massas ${ }^{(d)}$

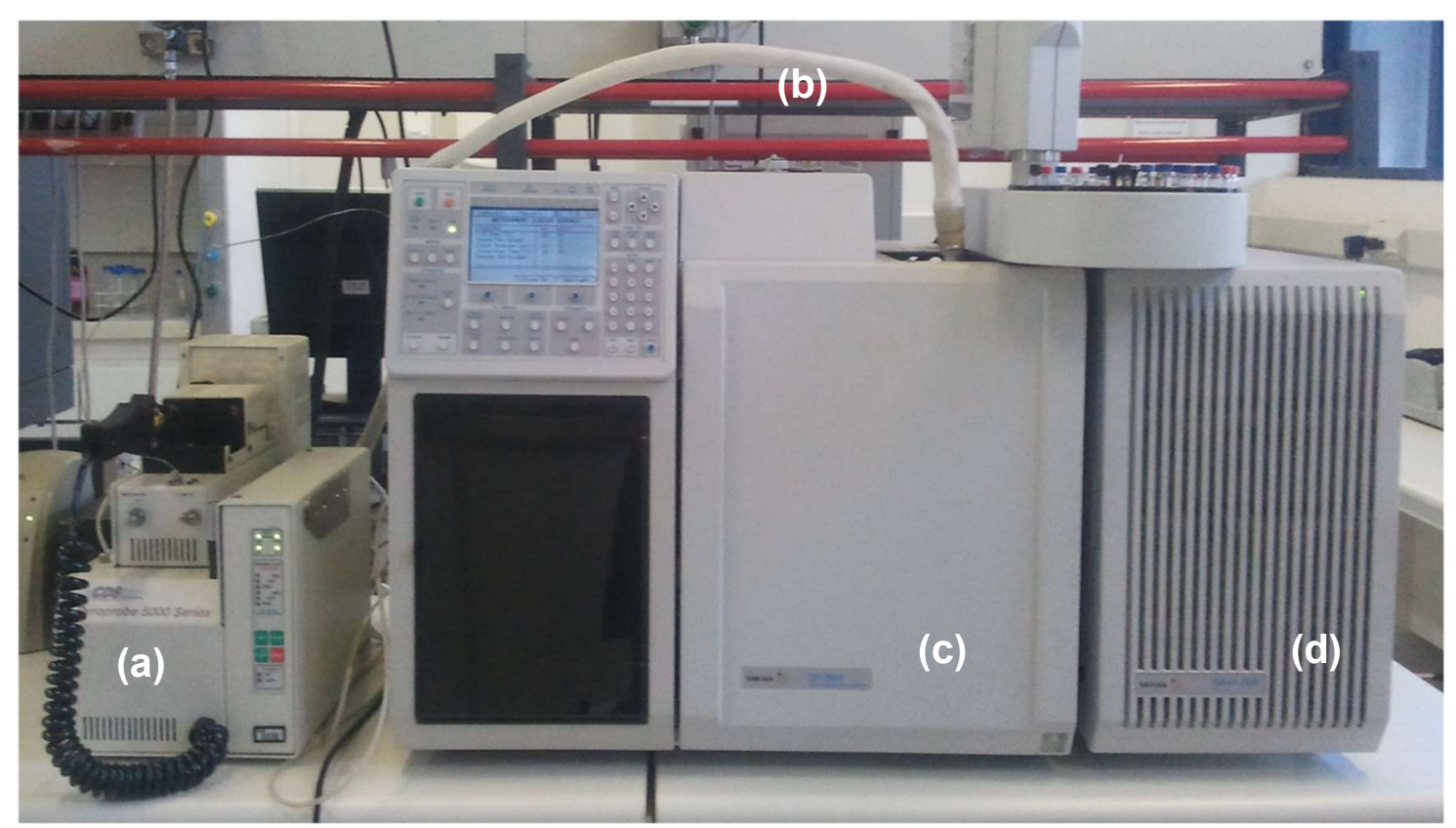

\subsubsection{Pirólise}

Esta etapa é constituída pela reação em si, através da qual a biomassa tem seus componentes básicos (proteínas, lipídeos, etc.) decompostos devido à energia the fornecida. Neste estudo foi realizada a pirólise rápida da espécie de microalga Chlorella vulgaris. Foram utilizadas amostras liofilizadas da microalga de estudo, com massa variando entre 1 e $2 \mathrm{mg}$, cuja composição elementar corresponde a 48,3 \% de carbono, 7,3 \% de hidrogênio e 3,0 \% de nitrogênio (DA SILVEIRA, 2015). 


\subsubsection{Equipamento para reação}

O equipamento utilizado nos ensaios de pirólise foi um pirolisador da marca CDS modelo 5150. Este equipamento é apropriado para ensaios em escala laboratorial, com capacidade de elevar a temperatura do meio reacional através da passagem de corrente elétrica por uma serpentina de platina (Figura 8), chegando a uma taxa de aquecimento extremamente elevada de $20^{\circ} \mathrm{C} / \mathrm{ms}$. São utilizadas amostras na ordem de miligramas e o processamento é feito em bateladas. O arranjo interno do reator durante a pirólise da amostra pode ser mais facilmente visualizado através da Figura 9. As dimensões da câmara de reação estão representadas na Figura 10. Considerando que a câmara de reação possui um formato cilíndrico, o volume da câmara do reator de bancada é de aproximadamente $2,8 \mathrm{~cm}^{3}$.

Figura 8 - Imagem da serpentina de platina aquecida

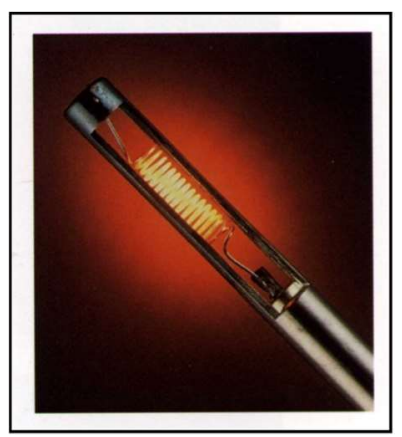

Fonte: CDS

Figura 9 - Esquema da montagem interna do pirolisador

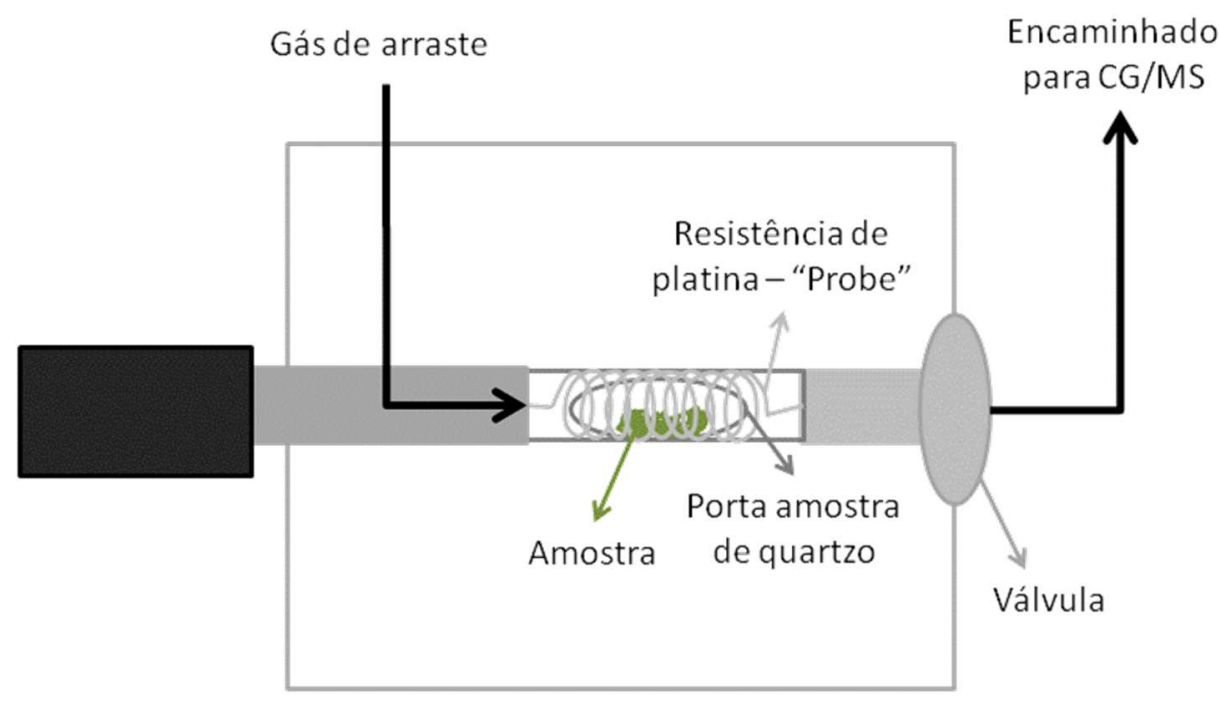


Figura 10 - Medidas da câmara onde ocorre a reação

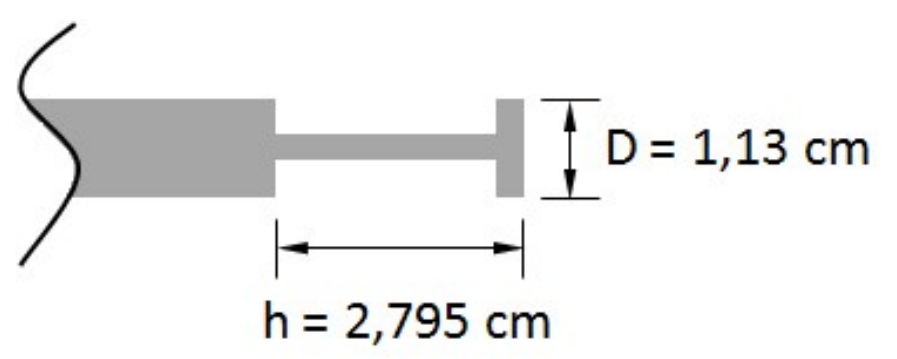

\subsubsection{Método analítico para reação}

A taxa de aquecimento utilizada neste estudo foi de $20{ }^{\circ} \mathrm{C} / \mathrm{ms}$, tendo a temperatura ambiente como inicial e a temperatura final variando entre 500 e $900{ }^{\circ} \mathrm{C}$. Após atingida a temperatura final, esta era mantida durante 20 segundos (fase isotérmica). $O$ gás de arraste utilizado durante a reação de pirólise foi o hélio e a purga do sistema foi efetuada com nitrogênio. As temperaturas da válvula direcionadora e da linha de transferência dos produtos para o sistema GC/MS variava de acordo com a tabela 6 , a qual apresenta os valores das temperaturas obtidas experimentalmente de forma a minimizar a possível deposição de produtos e contaminação das amostras das análises subsequentes.

Tabela 11 - Parâmetros de temperatura utilizados nos ensaios de pirólise

\begin{tabular}{ccc}
\hline $\begin{array}{c}\text { Temperatura de Pirólise }- \text { fase } \\
\text { isotérmica }\left({ }^{\circ} \mathbf{C}\right)\end{array}$ & $\begin{array}{c}\text { Temperatura da } \\
\text { válvula }\left({ }^{\circ} \mathbf{C}\right)\end{array}$ & $\begin{array}{c}\text { Temperatura da linha de } \\
\text { transferência }\left({ }^{\circ} \mathbf{C}\right)\end{array}$ \\
\hline 500 & 270 & 270 \\
600 & 280 & 280 \\
700 & 290 & 290 \\
800 & 290 & 290 \\
900 & 300 & 300 \\
\hline
\end{tabular}




\subsubsection{Procedimento operacional para reação}

- Pesar o porta amostra;

- Tarar a balança mantendo o porta amostra na mesma e pesar em torno de 1 a 2 mg da amostra de microalga;

- Encaixar o porta amostra, já com a amostra pesada, na serpentina de platina e introduzir o conjunto no pirolisador.

- Executar a reação conforme método analítico, acionando o sistema via software;

- Após a reação ser finalizada, retirar a "Probe" do pirolisador e retirar o porta amostra da serpentina;

- Pesar em uma balança analítica o porta amostra com o resíduo sólido da reação.

Os produtos voláteis são direcionados para o sistema GC/MS através da linha de transferência. O método analítico para a cromatografia está descrito a seguir.

\subsubsection{Cromatografia gasosa e espectrometria de massas}

Esta etapa corresponde à separação dos componentes da amostra proveniente do Pirolisador através de uma coluna cromatográfica e a identificação dos compostos através da espectrometria de massas.

\subsubsection{Equipamento para identificação de produtos}

O equipamento utilizado para separação e identificação dos produtos voláteis foi um cromatógrafo gasoso (modelo 450-GC) acoplado a um espectrômetro de massas (modelo 240-MS) do tipo "ion trap". A coluna utilizada para os ensaios de cromatografia foi uma Varian DB-1701 que é de média polaridade, cuja fase estacionária é composta por (14\% cianopropilfenil)-dimetilpolisiloxano, possui $60 \mathrm{~m}$ de comprimento, $0,25 \mathrm{~mm}$ de diâmetro interno e $0,25 \mu \mathrm{m}$ de espessura de filme. 


\subsubsection{Método analítico para identificação de produtos}

\subsection{Método 1}

- Temperatura inicial: $60^{\circ} \mathrm{C}$ por 1 minuto;

- Taxa de aquecimento: $0,8^{\circ} \mathrm{C} /$ minuto;

- Temperatura final: $250{ }^{\circ} \mathrm{C}$ por 7 minutos.

- "Split" de 1:1 com fluxo Hélio mantido em 2,2 mL/min.

O termo "Split" refere-se à razão entre a corrente de gás total que entra no GC contendo a amostra e a corrente que de fato é direcionada para a coluna cromatográfica. Por exemplo, um "Split" de 1:50 significa que a amostra original foi dividida em 50 partes e apenas uma foi direcionada à coluna para a separação de seus componentes.

\subsection{Método 2}

- Temperatura inicial: $60^{\circ} \mathrm{C}$ por 1 minuto;

- Taxa de aquecimento: $1,2^{\circ} \mathrm{C} /$ minuto;

- Temperatura final: $250{ }^{\circ} \mathrm{C}$ por 7 minutos.

- Split de 1:50 com fluxo Hélio mantido em 1,0 mL/min.

Para o segundo método de cromatografia, as análises foram realizadas em duplicata, desta forma, sempre que houver uma referência à primeira análise realizada em uma determinada temperatura de reação ela vai estar identificada como C1 e a segunda análise como C2.

\subsubsection{Experimentos exploratórios e adequação de parâmetros de análise}

Foram realizados experimentos com leveduras (fermento orgânico) com o intuito de entender o funcionamento do pirolisador. Com a Chlorella vulgaris foram iniciados os experimentos exploratórios para investigação dos produtos de pirólise em diferentes temperaturas numa faixa entre 400 e $600{ }^{\circ} \mathrm{C}$. 
O pirolisador de laboratório permite que se escolha uma rampa de aquecimento, a taxa máxima de aquecimento permitida pelo equipamento é de $20^{\circ} \mathrm{C} / \mathrm{ms}$, o que permite elevar a temperatura de 0 a $500{ }^{\circ} \mathrm{C}$, por exemplo, em uma fração de segundo. Como o objetivo deste estudo é avaliar os produtos de pirólise através de uma reação isotérmica, desde o início foi utilizada a taxa máxima de aquecimento possível. Inicialmente foi estabelecido um tempo de 5 segundos para a fase isotérmica ou final, porém após vários ensaios, verificou-se que a massa restante no porta amostra não possuía em sua totalidade o aspecto de carbonizada, o que era um indício de que parte da amostra não tinha sequer iniciado o processo de pirólise. Desta forma, 0 tempo que o reator de laboratório se mantinha na temperatura final foi alterado de 5 para 20 segundos nos experimentos subsequentes.

Após cada corrida contendo amostra eram realizadas corridas em branco, as quais frequentemente apresentavam uma quantidade considerável de picos, o que era um indício de que material de ensaio prévio ficava retido na linha de transferência entre o pirolisador e cromatógrafo ou na coluna de cromatografia. Para minimizar esse efeito na coluna, o tempo total da corrida cromatográfica foi estendido de 35 para 40 minutos. Os picos de alta intensidade continuavam presentes no ensaio em branco, assim para identificar onde exatamente esse material estava sendo retido, foi realizada uma corrida em branco logo após o ensaio com amostra, sem que o pirolisador fizesse parte do circuito, de forma a verificar apenas a coluna cromatográfica. O resultado obtido foi a ausência dos picos, o que é um forte indício de que o material estava sendo retido na linha de transferência e não na coluna. Para solucionar esse problema, as temperaturas da válvula e da linha de transferência do pirolisador foram gradativamente aumentadas até que a retenção de produtos pudesse ser considerada insignificante.

Ainda assim, os resultados apontavam para a necessidade de uma alteração no método de análise, pois o cromatograma apresentava uma quantidade considerável de picos de baixa definição, principalmente no início da corrida, indicando uma separação cromatográfica deficiente. Nos primeiros ensaios a temperatura inicial foi determinada em $90^{\circ} \mathrm{C}$, assim, a primeira alteração realizada foi a diminuição da temperatura inicial de análise de 90 para $40{ }^{\circ} \mathrm{C}$. Os resultados dessa alteração foram positivos, porém o cromatograma resultante da análise não demonstrava um bom 
nível de separação dos compostos. Posteriormente, essa temperatura inicial foi aumentada para $60^{\circ} \mathrm{C}$, devido à dificuldade de estabilizar a coluna em uma temperatura muito próxima à temperatura ambiente. Com a finalidade de melhorar a separação, a coluna de $30 \mathrm{~m}$ que estava sendo utilizada desde o início do estudo, foi substituída por uma coluna de 60 m e o método foi alterado conforme descrito no item 4.1.2.2.1.

\subsubsection{Análise dos espectros de massa}

O primeiro passo para identificação dos produtos obtidos é feito através do "software" de análise dos cromatogramas e espectros de massa que acompanha o instrumento (fornecido pelo próprio fabricante). Nesta primeira etapa do processamento dos dados é realizada a integração dos picos da cromatografia, através da qual, a partir de parâmetros conhecidos como largura, "slope" e tangente, o software identifica e integra os picos do gráfico que devem ser considerados como correspondentes a uma substância. Através desta integração é possível determinar quão representativa é a área de um pico específico em relação à área total integrada. Após esta etapa o programa gera um arquivo conhecido como "spectrum list", o qual contém as informações dos espectros de massa relacionados a cada um dos picos integrados. Essa lista de espectros obtidos experimentalmente é comparada pelo mesmo programa com os espectros de massa catalogados na biblioteca do NIST (National Institute of Standards and Technology).

A comparação dos espectros medidos com os da biblioteca é realizada através da similaridade entre picos de massa (massa do fragmento e intensidade ou abundância) da amostra e da referência contida na biblioteca, essa similaridade é um parâmetro conhecido como "match", que pode variar em uma escala de 0 a 1 ou de 0 a 1000, dependendo do software utilizado, e quanto maior o valor associado ao "match", maior é a chance do componente da amostra analisa ser a substância sugerida. De forma prática, quando o valor de "match" é inferior a 0,7 ou 700, não é feita uma análise mais aprofundada para verificação se os compostos realmente podem ser coincidentes ou similares, parte-se do princípio que as substâncias não são coincidentes. Quando se trata da mesma substância ou uma substância muito similar, o valor associado a esse parâmetro se torna mais próximo de 1 ou 1000, sendo frequentemente superior a 0,85 
ou 850. A Figura 11 apresenta um cromatograma com os picos já integrados, os quais podem ser identificados pelo preenchimento com a coloração vermelha e a Figura 12 ilustra a comparação entre o espectro do componente da amostra e a substância sugerida. Neste gráfico o eixo vertical apresenta a medida de abundância relativa em percentual, de tal forma que o pico mais abundante tem seu valor associado a $100 \%$ e se torna referência para os demais, e o eixo horizontal mostra a massa do fragmento em m/z (massa por carga). O espectro de massas da substância que se deseja identificar está localizado na parte superior da figura e o espectro do composto químico sugerido pelo software como o mais provável está na parte inferior da Figura 12.

A análise realizada automaticamente pelo software serve como base para análise mais aprofundada dos espectros de massa através da comparação dos fragmentos mais abundantes presentes no espectro pesquisado, proveniente da amostra, e o espectro sugerido como mais provável, catalogado na biblioteca. A coincidência entre os picos mais abundantes no espectro de massas é um forte indicativo da presença da substância sugerida pelo software na amostra. Existe um cuidado especial quando se quer determinar uma substância especifica através deste método, pois comumente isômeros possuem picos mais abundantes presentes em um mesmo fragmento de massa, porém, quando se quer determinar a classe orgânica presente, esse é um método interessante, partindo-se da premissa que os isômeros fazem parte da mesma classe funcional. Além desta forma de análise, pode-se identificar grupos funcionais orgânicos através da presença de certos fragmentos de massa ou a diferença da massa entre fragmentos mais abundantes. Por exemplo, a presença de um pico intenso em m/z 91 indica a presença de um anel aromático com cadeia lateral alquila. Quando se faz a diferença entre valores de fragmentos de massa é possível identificar a perda de fragmentos de massa que podem identificar a presença de certos grupos funcionais, por exemplo, quando a diferença entre picos de massa resulta em um valor igual a m/z 17 isso pode ser associado a perda de um radical ${ }^{\circ} \mathrm{OH}$, proveniente da estrutura de um álcool ou de um ácido carboxílico, já uma diferença que resulte em $\mathrm{m} / \mathrm{z} 30$ pode ser associado a perda de um radical $\mathrm{NO}$ que caracteriza um nitro composto. 
Figura 11 - Exemplo de cromatograma após integração

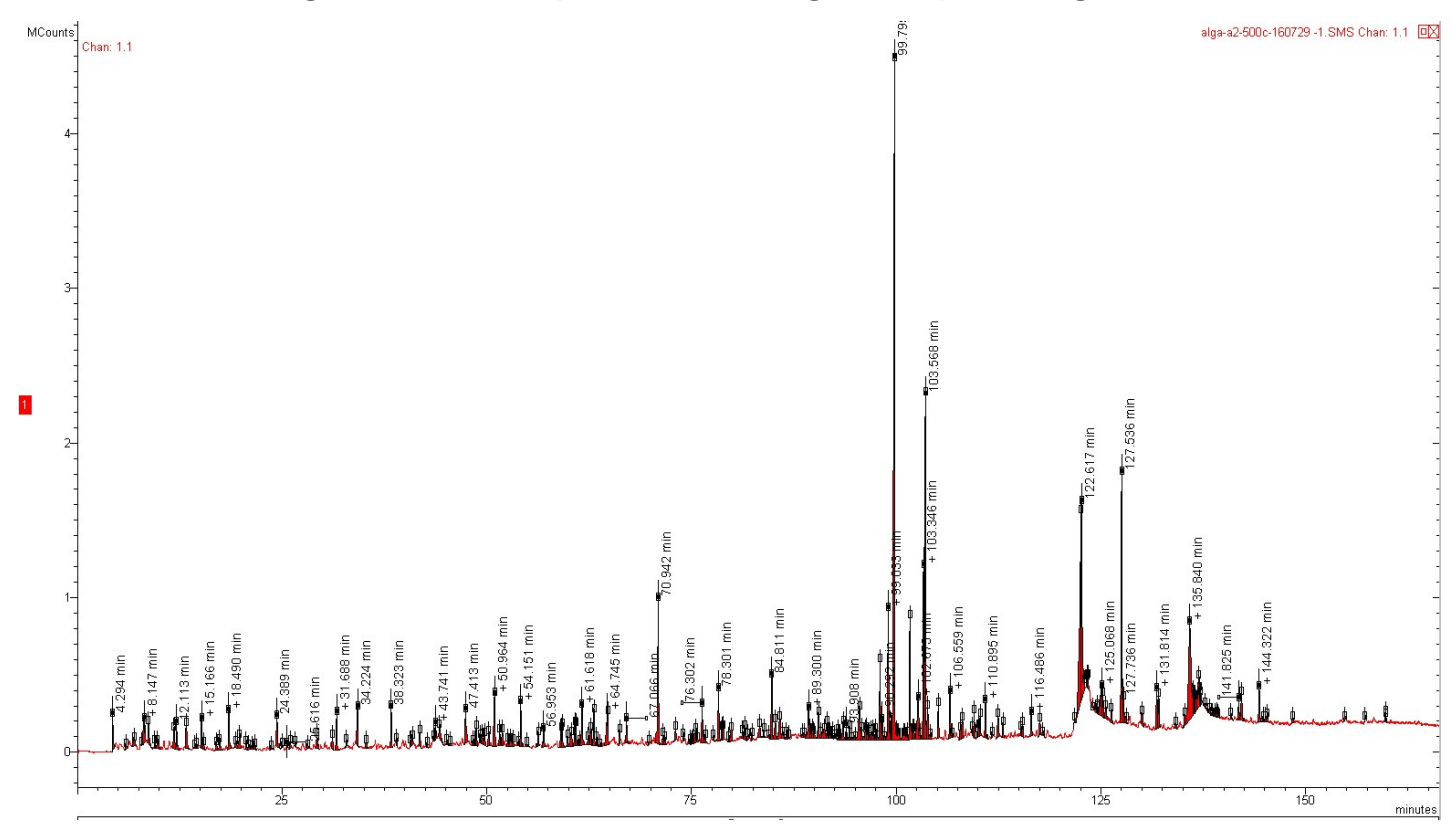

Figura 12 - Exemplo de gráfico comparativo entre espectro de massa experimental e o de catalogado na biblioteca NIST

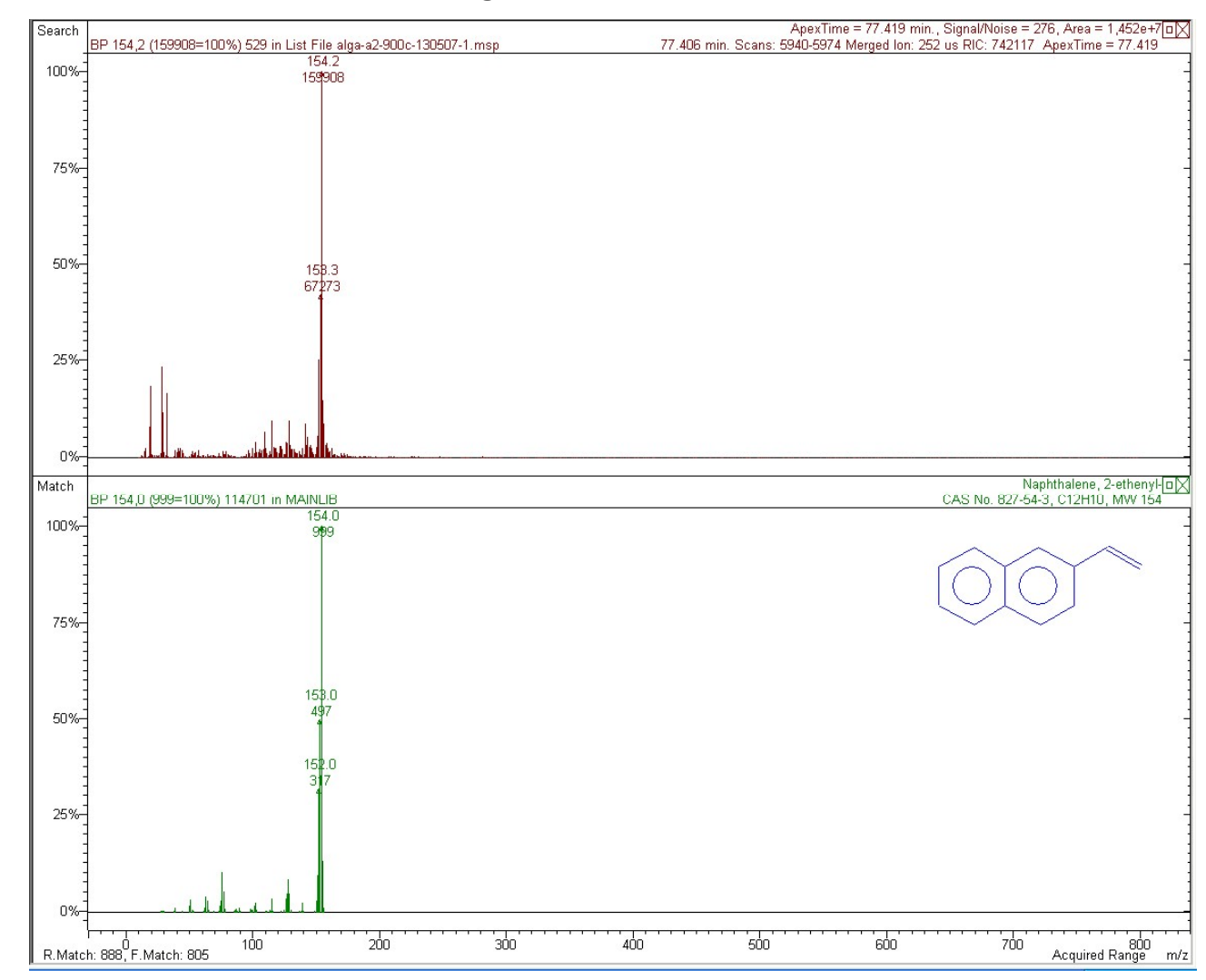

Neste trabalho, uma análise mais aprofundada sobre os espectros de massa foi apresentada no texto para compostos que apresentaram um valor de "R.match" superior a 900, como forma de ilustrar a análise feita para a determinação das classes de compostos apresentadas como resultado deste estudo. 


\subsection{Determinação dos Parâmetros da Cinética de Reação}

\subsubsection{Determinação do teor de cinzas}

\subsubsection{Equipamento}

Para determinação do teor de cinzas da amostra de estudo foi utilizada uma balança termogravimétrica da marca TA Instruments modelo Q600 SDT.

\subsubsection{Método analítico para determinação do teor de cinzas}

Estudos anteriores comprovaram que a taxa de aquecimento não tem influência significativa no resultado final (ARAÚJO et al., 2006), desta forma, por razões práticas a taxa de aquecimento foi estabelecida em $20^{\circ} \mathrm{C} / \mathrm{min}$.

\subsection{Método I}

- Temperatura inicial: ambiente;

- Taxa de aquecimento: $20^{\circ} \mathrm{C} /$ minuto;

- Temperatura final: $600{ }^{\circ} \mathrm{C}$ por 30 minutos;

- Gás de arraste: ar sintético;

- Vazão do gás arraste: 50 mL/minuto.

\subsection{Método II}

- Temperatura inicial: ambiente;

- Taxa de aquecimento: $20^{\circ} \mathrm{C} /$ minuto;

- Temperatura final: $800{ }^{\circ} \mathrm{C}$ por 20 minutos;

- Gás de arraste: ar sintético;

- Vazão do gás arraste: 50 mL/minuto.

Para cada um dos métodos, os testes foram realizados em triplicata. 


\subsubsection{Determinação dos parâmetros cinéticos}

\subsubsection{Equipamento}

Para o estudo dos parâmetros cinéticos da reação de pirólise foi utilizada uma balança termogravimétrica da marca TA Instruments modelo Q600 SDT (Figura 13).

Figura 13 - Balança termogravimétrica modelo Q600 SDT (TA Instruments)

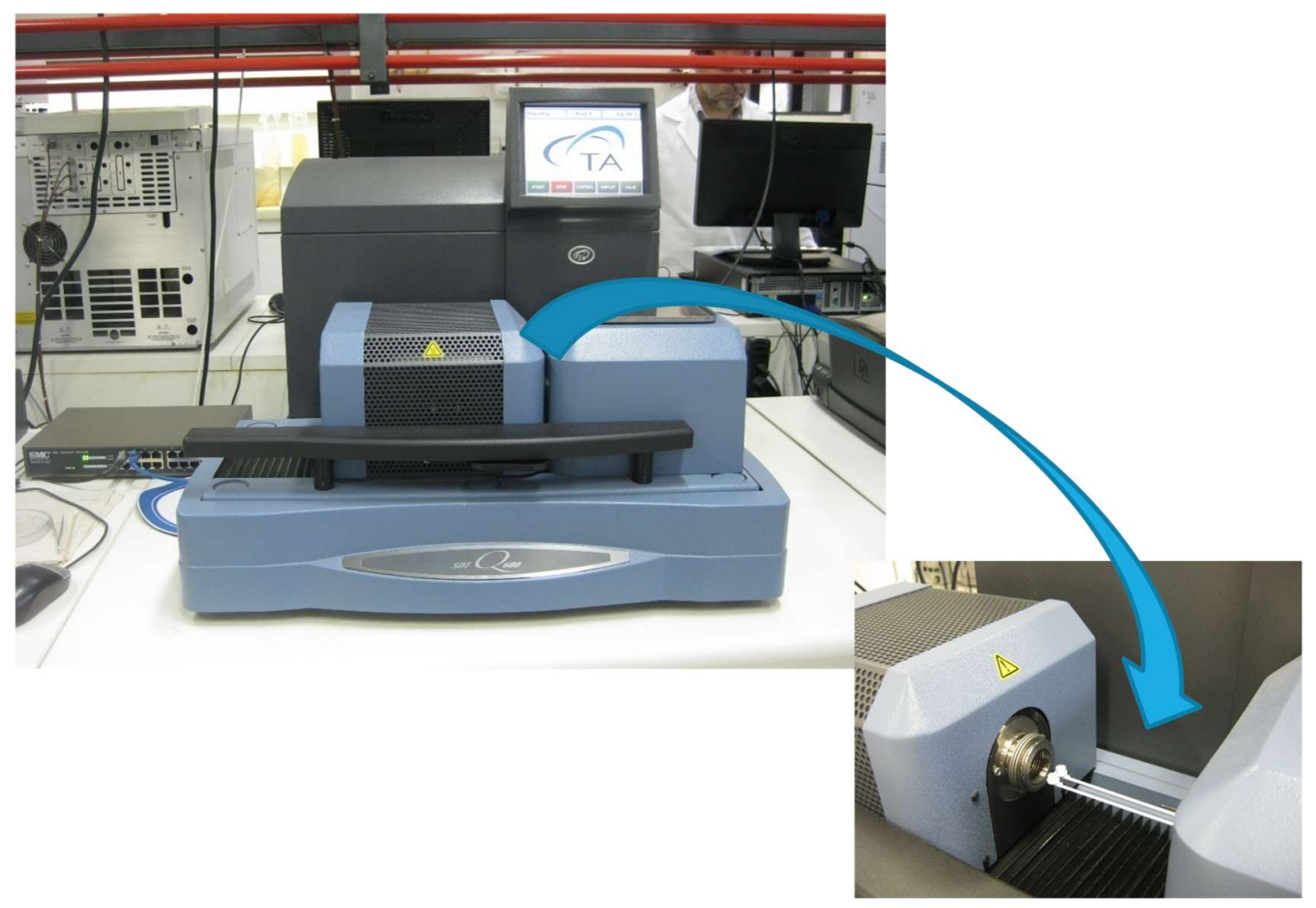

\subsubsection{Método analítico para ensaios termogravimétricos}

- Temperatura inicial: ambiente;

- Temperatura final: $1200^{\circ} \mathrm{C}$;

- Gás de arraste: Nitrogênio;

- Vazão do gás arraste: $50 \mathrm{~mL} /$ minuto.

Foram feitas análises com quatro taxas de aquecimento, as quais estão apresentadas na Tabela 12 a seguir. Para cada um dos métodos, os testes foram realizados em 
triplicata. As massas utilizadas em cada ensaio experimental estão apresentadas na Tabela 13.

Tabela 12 - Métodos de análise gravimétrica: taxas de aquecimento

\begin{tabular}{cc}
\hline Método & Taxa de aquecimento $\left({ }^{\circ} \mathrm{C} / \mathrm{min}\right)$ \\
\hline A & 5 \\
B & 10 \\
C & 20 \\
D & 25 \\
\hline
\end{tabular}

Tabela 13 - Parâmetros utilizados nas análises termogravimétricas

\begin{tabular}{ccc}
\hline Ensaio - \# & Taxa de aquecimento $(\mathbf{K} / \mathbf{m i n})$ & Massa inicial $(\mathbf{m g})$ \\
\hline 1 & 5 & 5,17 \\
2 & 5 & 6,99 \\
3 & 5 & 5,205 \\
4 & 10 & 4,468 \\
5 & 10 & 5,862 \\
6 & 10 & 4,893 \\
7 & 20 & 4,77 \\
8 & 20 & 6,547 \\
9 & 20 & 5,47 \\
10 & 25 & 4,667 \\
11 & 25 & 4,647 \\
12 & 25 & 5,679 \\
\hline
\end{tabular}




\section{RESULTADOS E DISCUSSÃO}

\subsection{Produtos de Pirólise - Método 1}

Os cromatogramas gerados a partir de um pirolisador de bancada acoplado diretamente ao sistema CG/MS são denominados pirogramas. A Figura 14 apresenta uma série de pirogramas que foram gerados a partir da pirólise isotérmica da microalga com a temperatura de reação variando entre 500 e $900{ }^{\circ} \mathrm{C}$, o eixo horizontal do gráfico corresponde ao tempo de retenção em minutos e o eixo vertical a intensidade do sinal em MCount, que é uma medida relativa ao número de partículas que atingem o detector.

Pela grande quantidade de picos obtidos através das análises cromatográficas, fica claro que a corrente de saída do reator de pirólise é uma mistura complexa de compostos orgânicos em todas as temperaturas de reação avaliadas.

A complexidade da amostra analisada, tanto em termos de quantidade de produtos quanto em relação às estruturas encontradas pelos fragmentos de massa, é um dos fatores que gera grande dificuldade na determinação exata do composto produzido. De Waart et al. (1991) apontam para a dificuldade em se analisar produtos de pirólise destas macromoléculas biológicas, citando como um dos fatores que contribuem para esta complexidade, o grande número de possíveis isômeros resultantes das diferenças estruturais de aminoácidos, as estabilidades variáveis das ligações peptídicas e as diferenças nas estruturas tridimensionais de proteínas. Poucos compostos foram identificados com um nível razoável de compatibilidade. As classes de compostos obtidos através da análise com o método 1 de cromatografia revelou uma presença relevante de compostos aromáticos e nitrogenados em diferentes temperaturas, como pode ser visto na Tabela 14, sendo preponderante a ocorrência de compostos de alto peso molecular. Segundo Babich et al. (2011), a presença de compostos aromáticos como produto de pirólise é um indicativo promissor para a utilização da fração líquida como bio-óleo. A determinação dessas classes orgânicas foi feita conforme metodologia para análise dos espectros exposta no item "materiais e métodos". Uma análise mais aprofundada para ilustrar a metodologia está apresentada no item 5.2.1. 
Figura 14 - Pirogramas a $500^{(a)}, 600^{(b)}, 700^{(\mathrm{c})}, 800^{(\mathrm{d})}$ e $900^{\circ} \mathrm{C}^{(\mathrm{e})}-$ Método 1

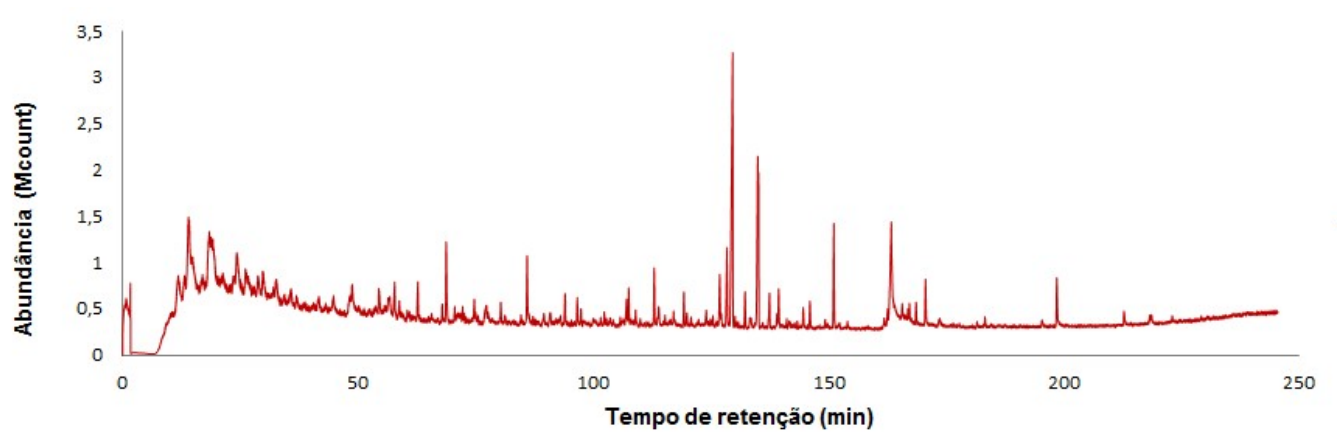

$-500^{\circ} \mathrm{C}$

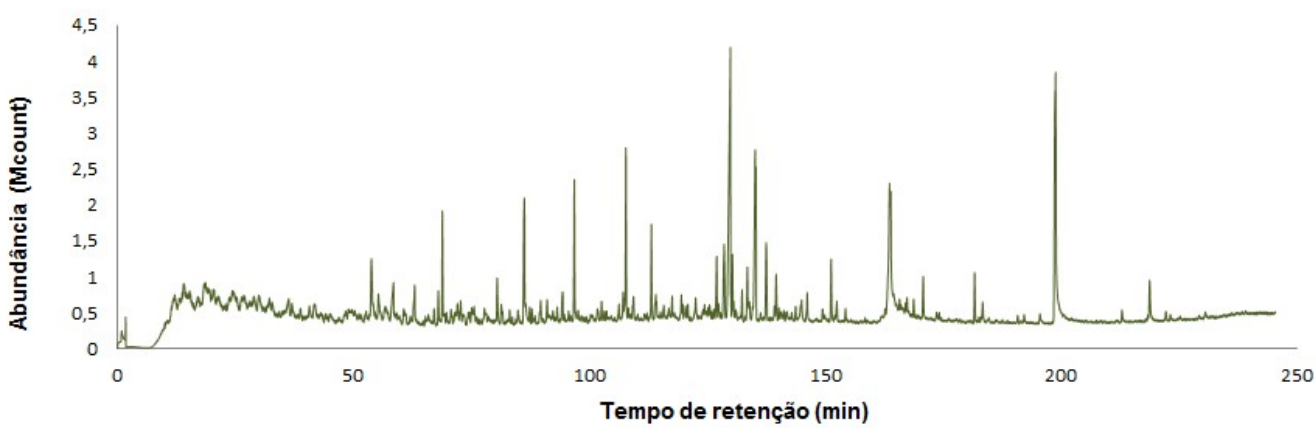

(b)
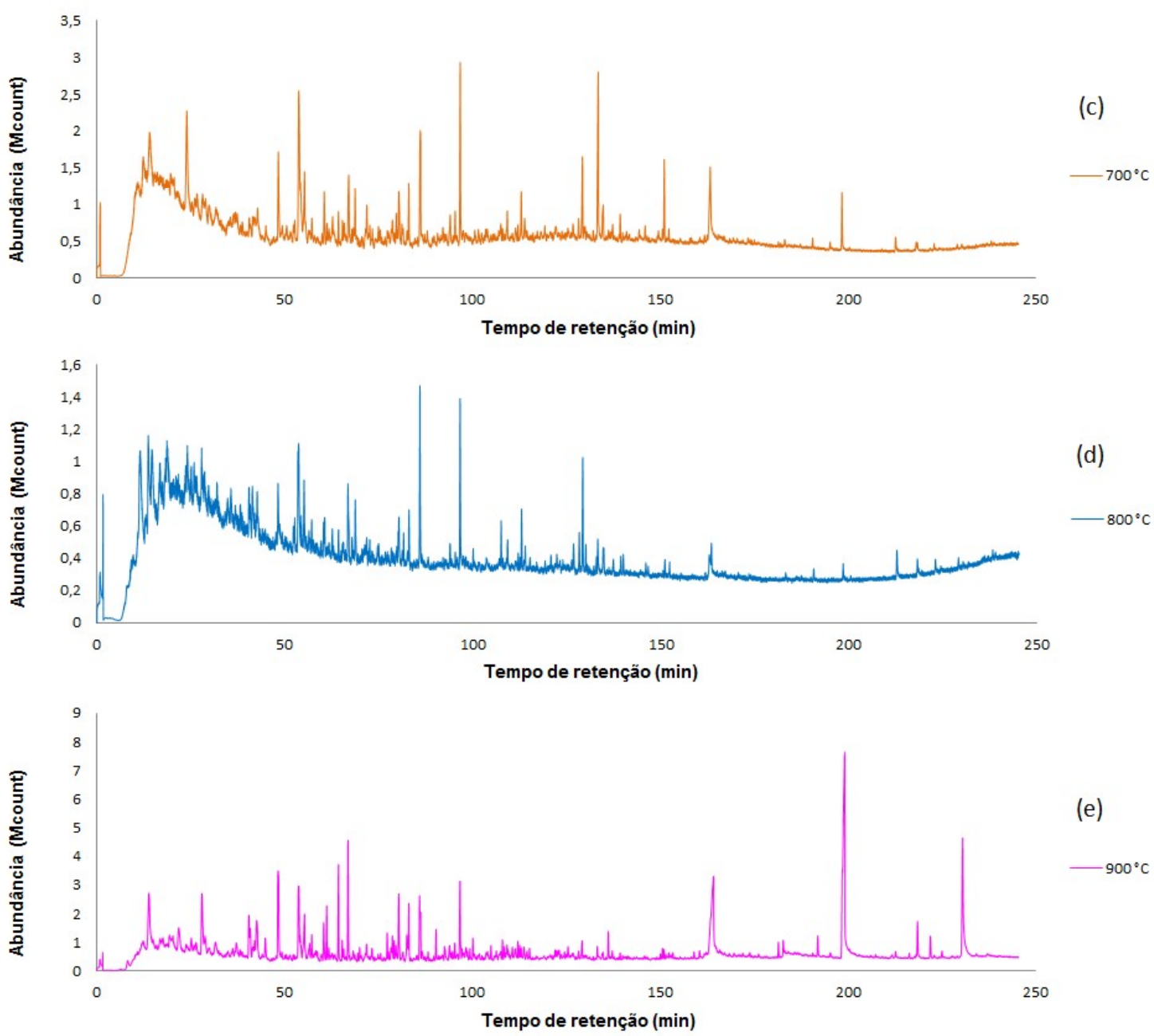
Tabela 14 - Classes de compostos sugeridos através do método 1 de cromatografia

\begin{tabular}{cccc}
\hline $\begin{array}{c}\text { Temperatura } \\
\text { da pirólise } \\
\left({ }^{\circ} \mathbf{C}\right)\end{array}$ & $\begin{array}{c}\text { Tempo de } \\
\text { retenção } \\
(\mathbf{m i n})\end{array}$ & Composto sugerido & $\begin{array}{c}\text { Classe/composto } \\
\text { provável }\end{array}$ \\
\hline 500 & 68,859 & 1,1,6-trimetil-1,2-dihidro-naftaleno (ou isômeros) & $\begin{array}{c}\text { Hidrocarboneto } \\
\text { aromático }\end{array}$ \\
600 & 96,902 & 3-metil-indolizina (ou isômeros) & Amina \\
700 & 68,903 & 1,1,6-trimetil-1,2-dihidro-naftaleno (ou isômeros) & $\begin{array}{c}\text { Hidrocarboneto } \\
\text { aromático }\end{array}$ \\
700 & 96,872 & 5-metil-indolizina (ou isômeros) & Amina \\
800 & 83,104 & 1,4-dimetil-naftaleno (ou isômeros) & $\begin{array}{c}\text { Hidrocarboneto } \\
\text { aromático }\end{array}$ \\
800 & 96,691 & 3-metil-indolizina (ou isômeros) & Amina \\
900 & 77,420 & 2-etenil-naftaleno (ou isômeros) & Hidrocarboneto \\
aromático
\end{tabular}

\subsection{Produtos de Pirólise - Método 2}

Para o segundo método de análise cromatográfica, foram realizadas duas análises para cada uma das temperaturas de reação. O método demonstrou que as análises para cada temperatura de reação são reprodutíveis, o que pode ser visualizado através das Figuras 15 a 19.

Através da análise visual dos cromatogramas é possível verificar que à medida que a temperatura de reação aumenta, a intensidade relativa dos picos com maior tempo de retenção diminui, assim como os picos com menor tempo de retenção tendem a ter sua intensidade majorada à medida que aumenta a temperatura de reação.

\subsubsection{Reação a $500^{\circ} \mathrm{C}$}

A primeira análise cromatográfica dos produtos da pirólise conduzida a $500{ }^{\circ} \mathrm{C}$ apresentou 185 picos integrados, dos quais 134 apresentaram algum nível de correlação com a biblioteca utilizada como referência. A segunda análise apresentou 233 picos integrados, através dos quais foram registradas 162 correlações. Apesar do 
grande número de compostos correlacionados, poucos apresentam nível de similaridade superior a 900 , de tal forma que possam ser considerados para uma análise mais aprofundada com o intuito de identificar a classe orgânica da substância presente na amostra dos produtos de pirólise. A Tabela 15 apresenta os compostos que apresentaram maior compatibilidade com os espectros de massa da biblioteca de referência.

Tabela 15 - Lista de compostos com maior compatibilidade entre os espectros pesquisados e os de referência analisados a partir dos produtos de pirólise a $500^{\circ} \mathrm{C}$ - Método 2

\begin{tabular}{cccc}
\hline Corrida & $\begin{array}{c}\text { Tempo de } \\
\text { retenção (mim) }\end{array}$ & Composto compatível & Fórmula \\
\hline C1 & 8,232 & 1,3,5-cicloheptatrieno & $\mathrm{C}_{7} \mathrm{H}_{8}$ \\
C2 & 8,153 & tolueno & $\mathrm{C}_{7} \mathrm{H}_{8}$ \\
C1 - C2 & $12,376-12,113$ & p-xileno & $\mathrm{C}_{8} \mathrm{H}_{10}$ \\
C1 - C2 & $15,346-15,166$ & 3-furaldeido & $\mathrm{C}_{5} \mathrm{H}_{4} \mathrm{O}_{2}$ \\
C1 - C2 & $17,115-16,953$ & 3-metil-1H-pirrol, & $\mathrm{C}_{5} \mathrm{H}_{7} \mathrm{~N}$ \\
C1 & 18,756 & 3-furanometanol & $\mathrm{C}_{5} \mathrm{H}_{6} \mathrm{O}_{2}$ \\
C1 - C2 & $41,904-41,835$ & furil-hidroximetil-cetona & $\mathrm{C}_{6} \mathrm{H}_{6} \mathrm{O}_{3}$ \\
C1 - C2 & $70,943-70,941$ & indol & $\mathrm{C}_{8} \mathrm{H}_{7} \mathrm{~N}$ \\
\hline
\end{tabular}

De uma forma geral, a análise dos espectros gerados a partir dos produtos de pirólise (espectros pesquisados) demonstra bom nível de reprodutibilidade entre os ensaios de pirólise com mesma temperatura de reação.

A Figura 20 apresenta os espectros de massa de duas corridas a $500{ }^{\circ} \mathrm{C}$ após aproximadamente 8,2 minutos de análise, espectros "a1" e "b1". Apesar dos espectros serem similares, para cada uma das corridas foi sugerido um tipo de composto diferente, conforme mostram os espectros "b1" e "b2". Ambos os espectros "a1" e "a2" apresentam dois picos característicos de compostos aromáticos, sendo eles o m/z 91, que está relacionado ao íon tropílio e o m/z 65 que corresponde à perda de uma molécula de acetileno pelo íon tropílio. Estes dois picos com intensidade relevante no espectro de massas indicam que se trata de um hidrocarboneto aromático com cadeia lateral alifática. A semelhança com o espectro obtido a partir da fragmentação do cicloheptatrieno indica que o composto também pode ser associado a um hidrocarboneto cíclico insaturado com estrutura um pouco diferente do anel benzênico. 
Figura 15 - Pirogramas obtidos a partir da reação a $500{ }^{\circ} \mathrm{C}$ - Método 2

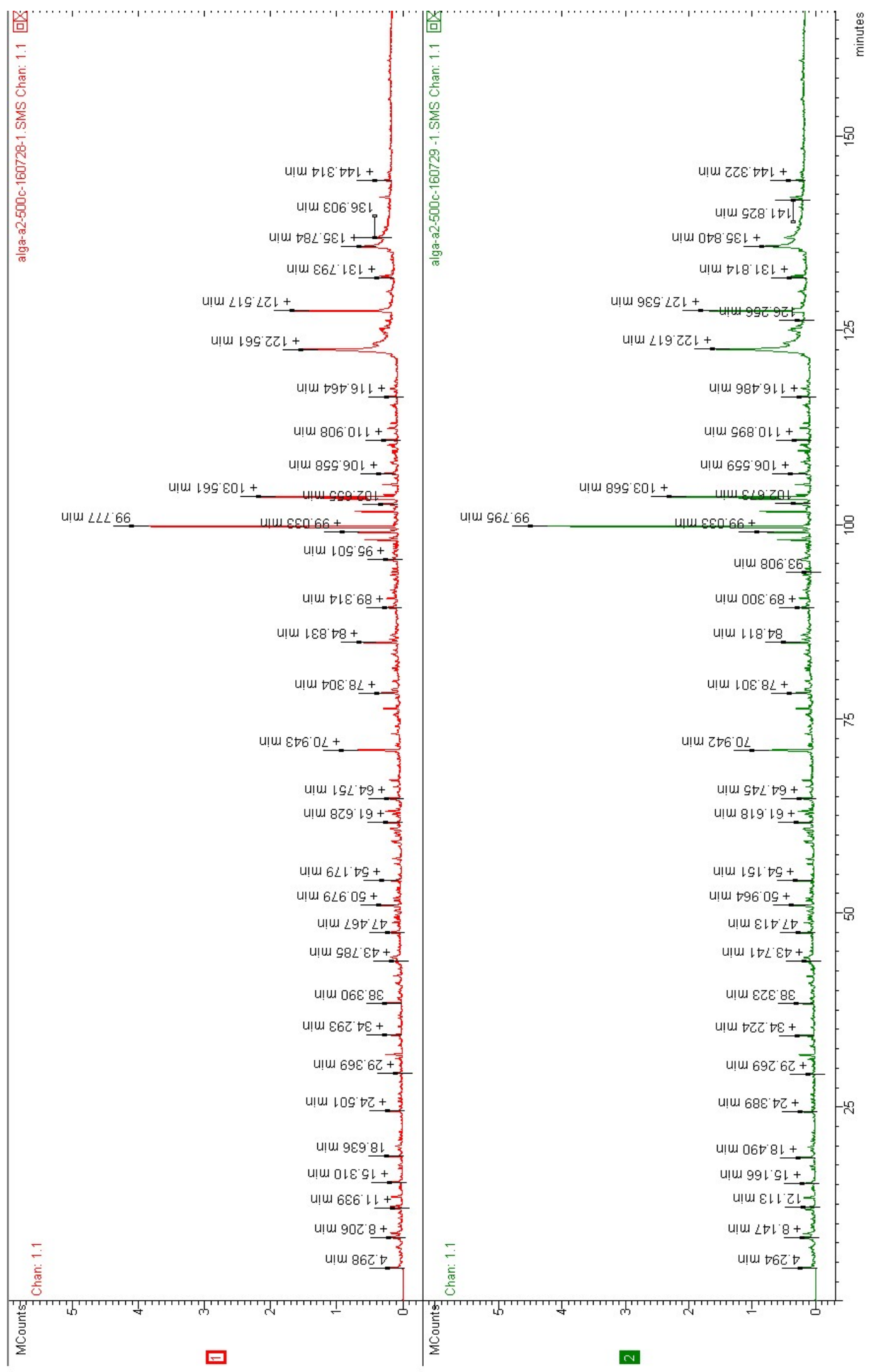


Figura 16 - Pirogramas obtidos a partir da reação a $600{ }^{\circ} \mathrm{C}$ - Método 2

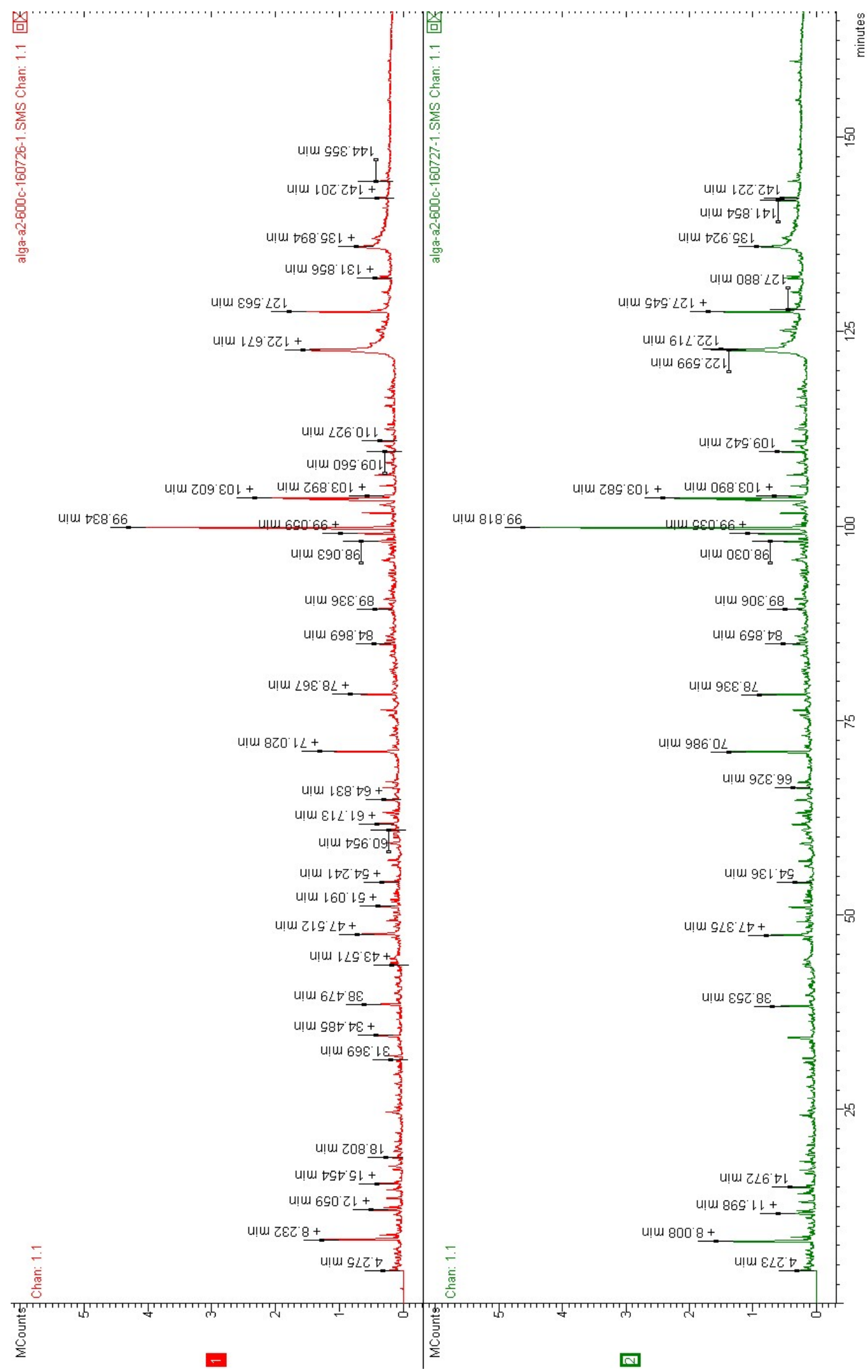


Figura 17 - Pirogramas obtidos a partir da reação a $700{ }^{\circ} \mathrm{C}$ - Método 2

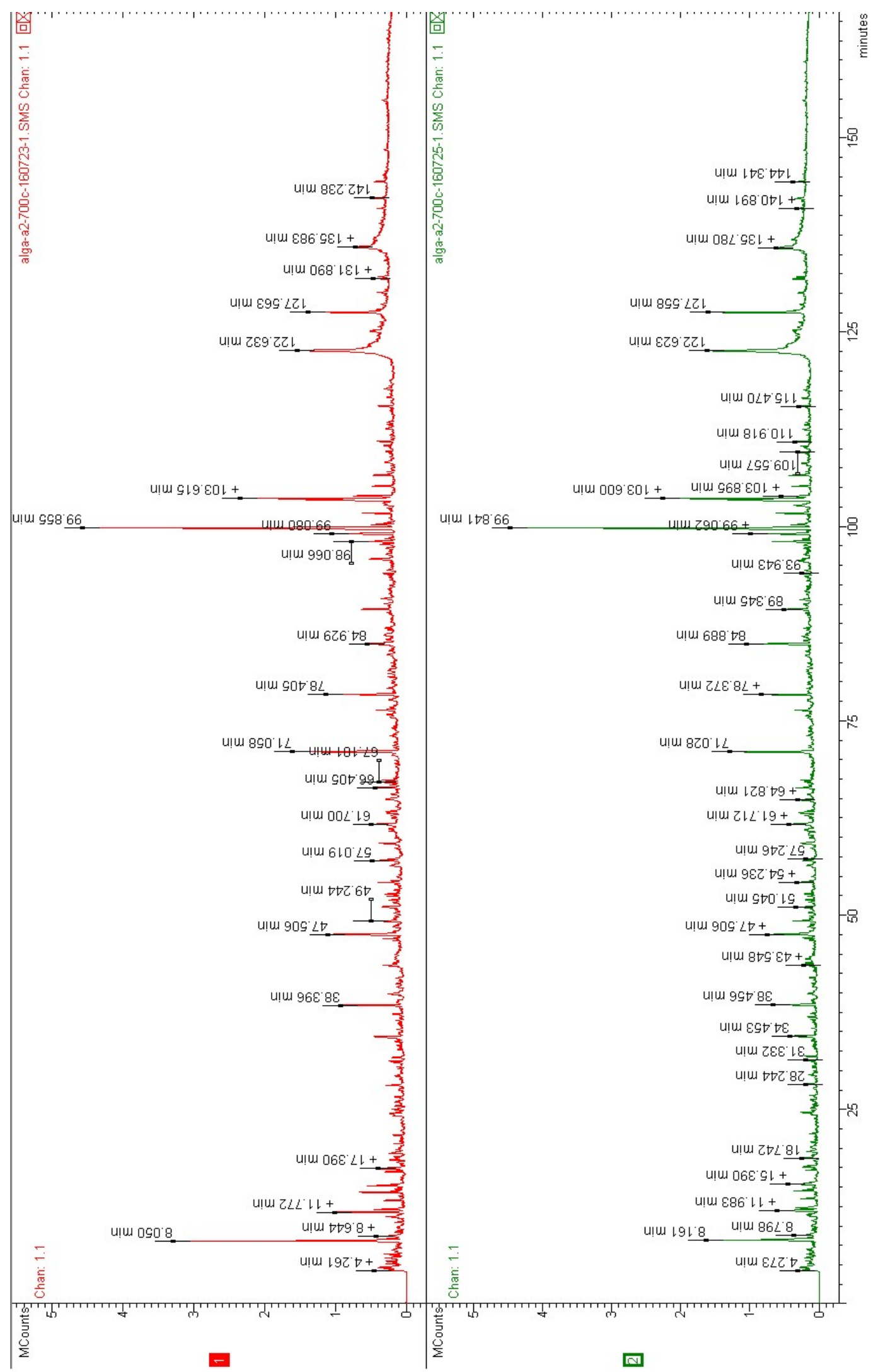


Figura 18 - Pirogramas obtidos a partir da reação a $800{ }^{\circ} \mathrm{C}$ - Método 2

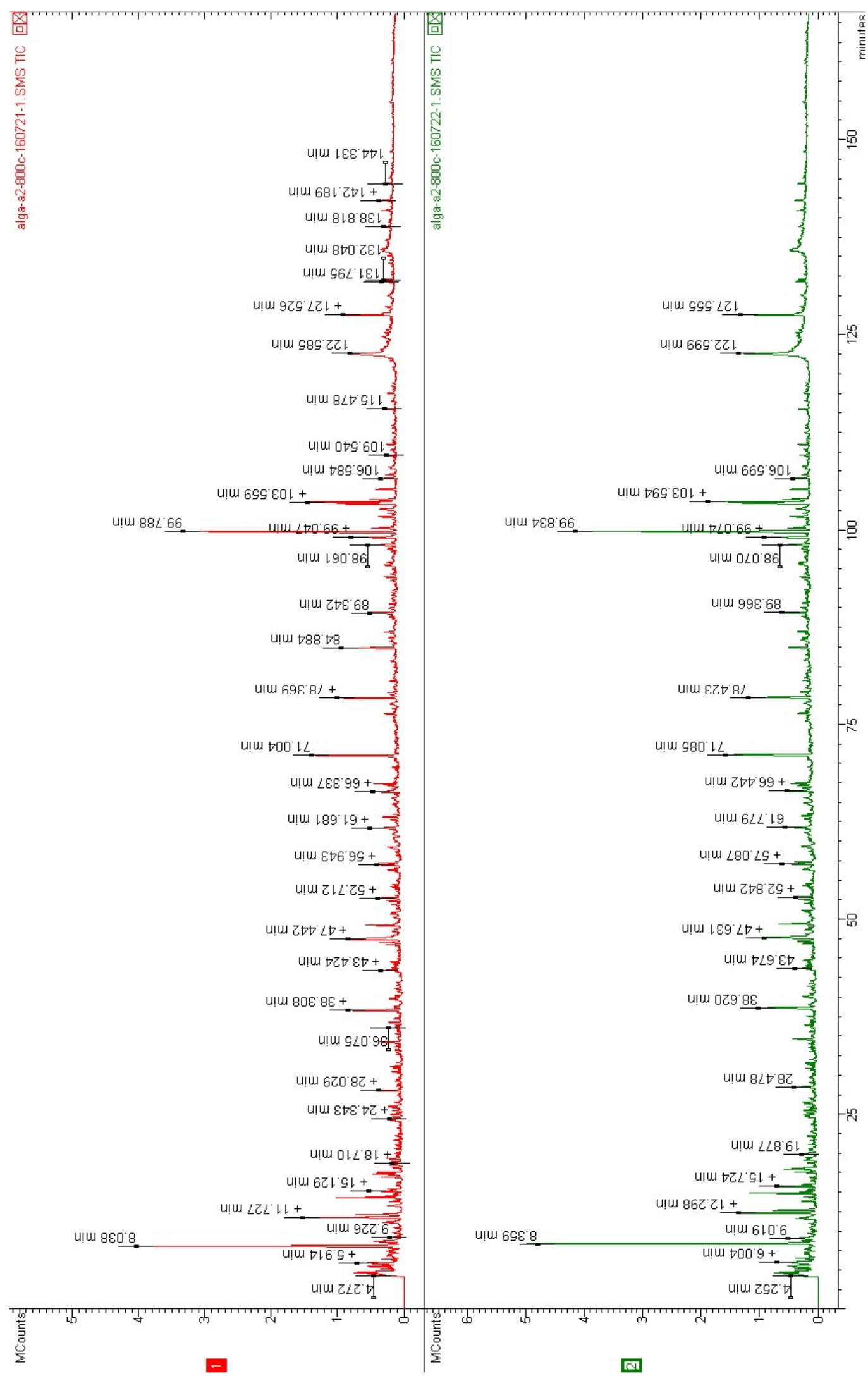


Figura 19 - Pirogramas obtidos a partir da reação a $900^{\circ} \mathrm{C}$ - Método 2

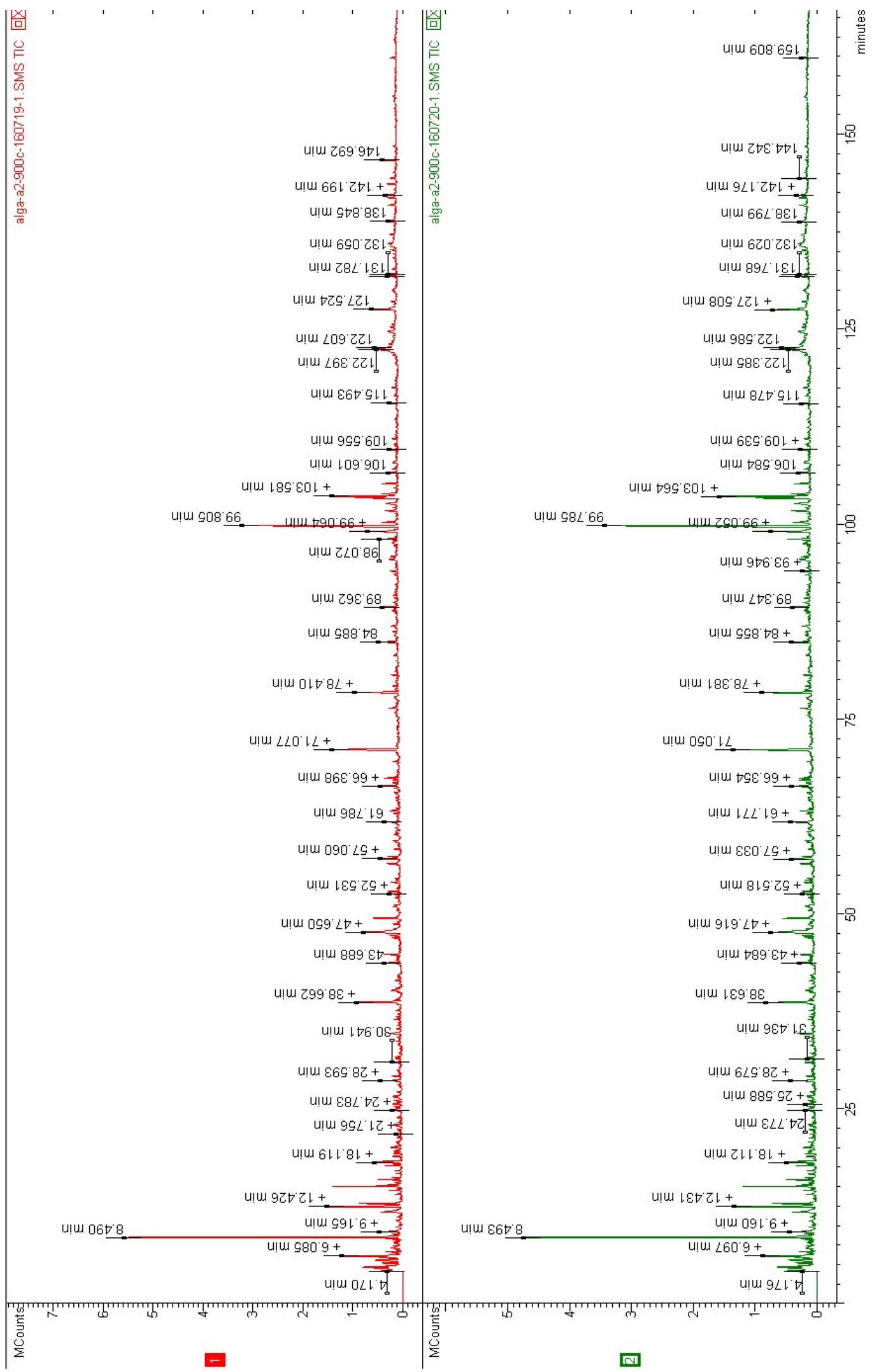


Figura 20 - Espectro pesquisado (a) $x$ Espectro catalogado(b) - Tempos de retenção 8,232 $^{(1)}$ e $8,153^{(2)} \mathrm{min}$ - Pirólise a $500^{\circ} \mathrm{C}$

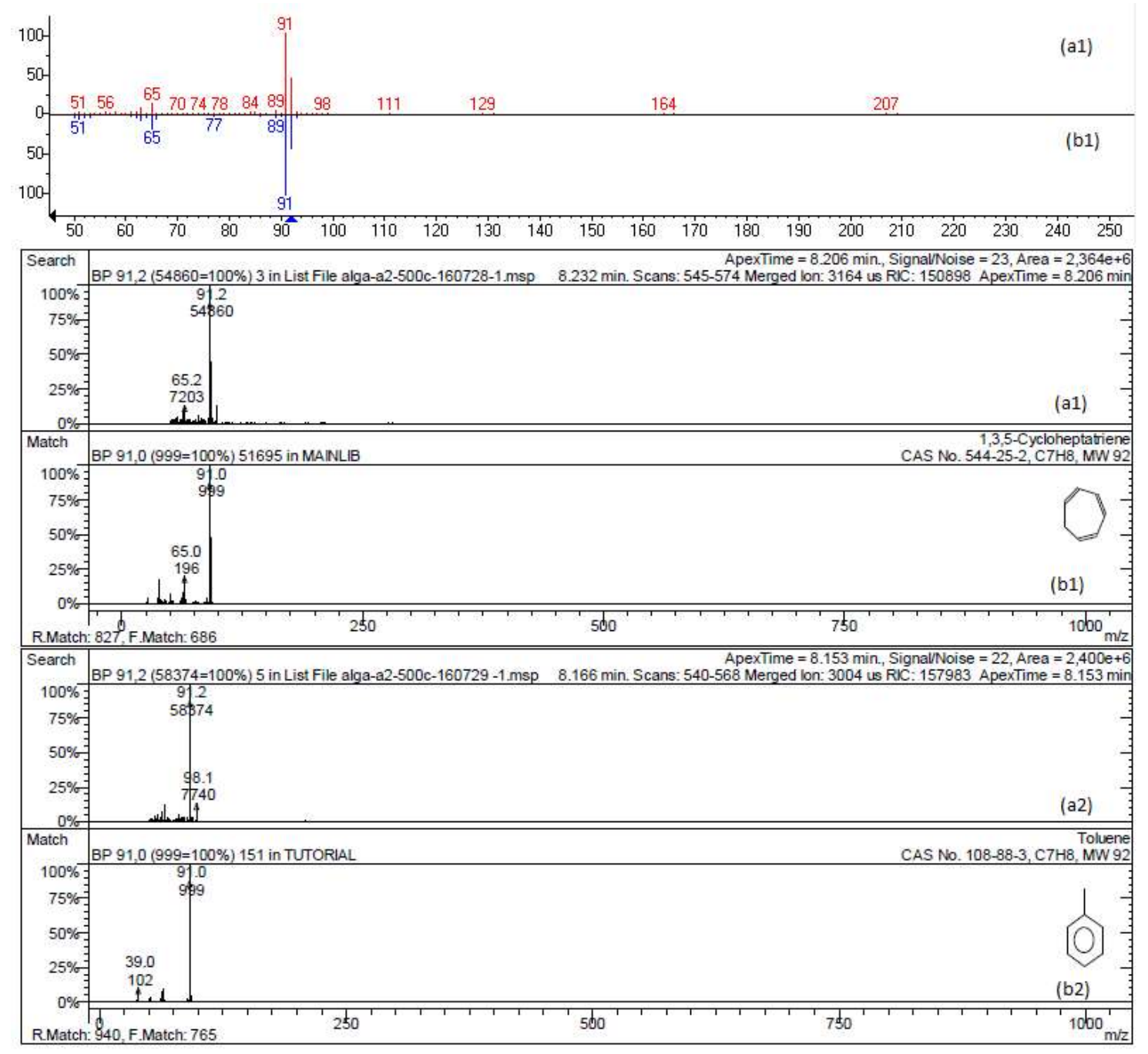


Também em um tempo mais longo de cerca de 12 minutos, observa-se a presença relevante dos fragmentos de massa em m/z 91 e 65 na Figura 21, o que indica a presença de um anel aromático no composto. A diferença de m/z 14 (m/z 91 - 77) está associada à perda de um grupo $\mathrm{CH}_{2}$, o que significa a provável presença deste grupo ligada ao anel aromático. Esses fragmentos indicam a compatibilidade entre o composto pesquisado e o p-xileno ou um isômero de posição.

A Figura 22 apresenta o espectro de massa obtido após um tempo de retenção de aproximadamente 15 minutos. O composto sugerido apresenta uma estrutura que possui um oxigênio inserido em um ciclo, caracterizando um éter, e um grupo aldeído $\left(\mathrm{COH}^{+}\right)$anexo ao ciclo. O composto pesquisado apresenta vários dos fragmentos que caracterizam o composto 3-furaldeido, porém apresenta outros fragmentos de massa, indicando que a estrutura sugerida é parte da molécula do composto pesquisado. A diferença entre os fragmentos m/z 109 e 95, que não aparece no composto de referência, é igual a $\mathrm{m} / \mathrm{z} 14$, o que indica que o composto pesquisado possui em sua estrutura, pelo menos, mais um grupo $\mathrm{CH}_{2}$.

O espectro obtido para o composto cujo tempo de retenção se aproxima de 17 minutos (Figura 23), mais uma vez apresenta um caso em que o composto sugerido pode ser parte da estrutura do composto procurado, pois a presença de picos com valores de $\mathrm{m} / \mathrm{z}$ maiores do que o pico íon molecular do composto sugerido indica que a substância procurada possui massa total superior à substância presente na biblioteca. A diferença entre os fragmentos $\mathrm{m} / \mathrm{z} 108$ e 78 resulta em $\mathrm{m} / \mathrm{z} 30$, o que é um indicativo da perda de um grupo $\mathrm{CH}_{2}=\mathrm{NH}_{2}{ }^{+}$, o que sugere a presença de um grupo amina no composto analisado, porém esse fragmento também pode ser obtido através da clivagem de uma amida. Isto significa que a substância analisada provavelmente é um composto nitrogenado.

A Figura 24 apresenta o espectro obtido em um tempo de retenção de aproximadamente 18,5 minutos. A perda obtida pela diferença entre os fragmentos $\mathrm{m} / \mathrm{z} 98$ e 81 que corresponde a um fragmento de $\mathrm{m} / \mathrm{z} 17$ pode ser associada a um grupo $\mathrm{OH}^{-}$. A diferença entre os picos $\mathrm{m} / \mathrm{z} 98$ e 53 gera um fragmento de $\mathrm{m} / \mathrm{z} 45$, compatível com a perda de um radical $\mathrm{C}_{2} \mathrm{H}_{5} \mathrm{O}^{\bullet}$, que faz referência à existência de um grupo funcional de um éter. 
Figura 21 - Espectro pesquisado ${ }^{(a)} \times$ Espectro catalogado ${ }^{(b)}$ - Tempos de retenção $12,376^{(1)}$ e $12,113^{(2)} \mathrm{min}$ - Pirólise a $500{ }^{\circ} \mathrm{C}$

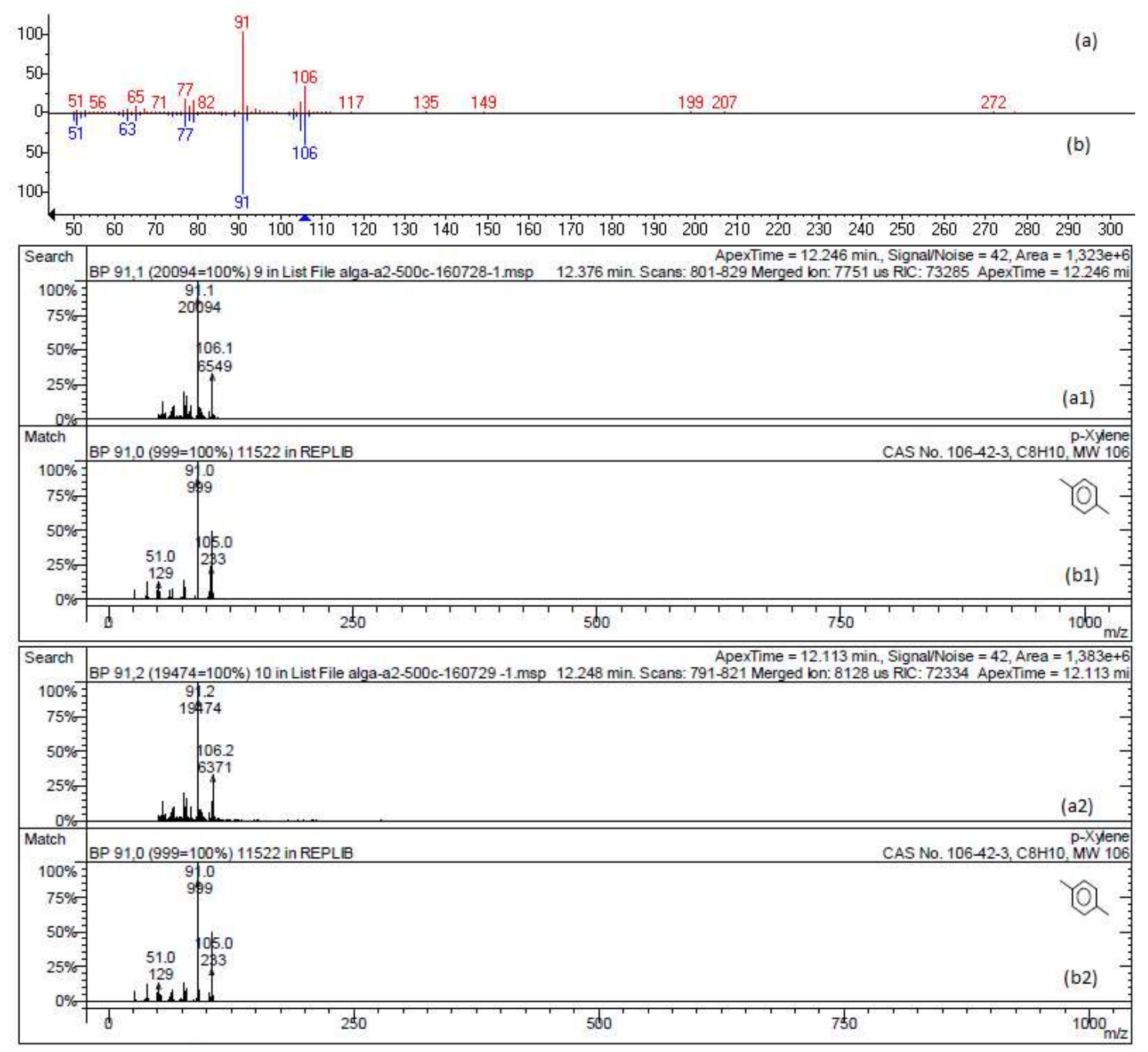




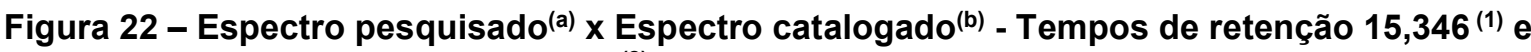
$15,166^{(2)} \mathrm{min}$ - Pirólise a $500^{\circ} \mathrm{C}$

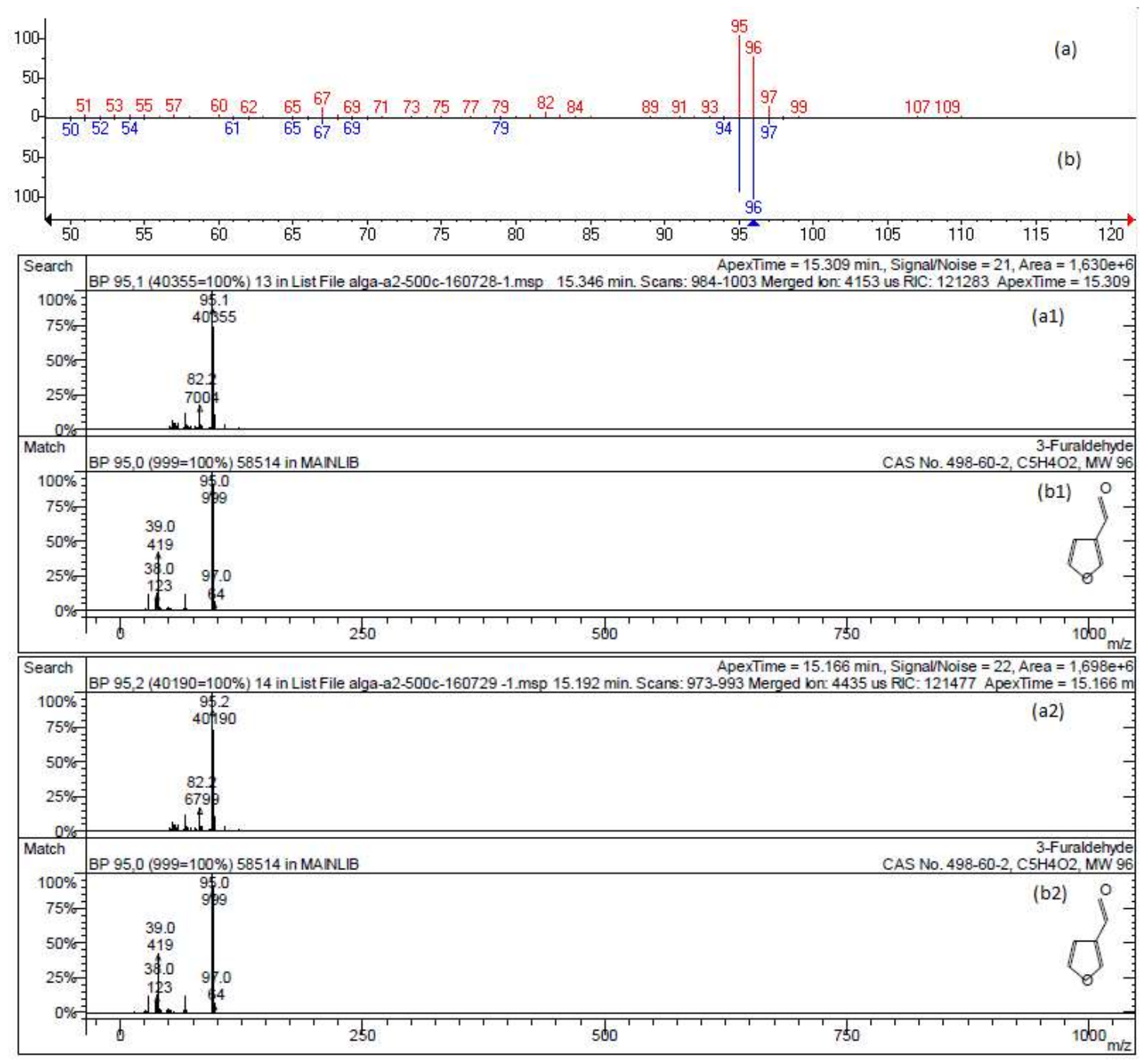


Figura 23 - Espectro pesquisado(a) $x$ Espectro catalogado(b) - Tempos de retenção 17,106(1) e $16,953^{(2)} \mathrm{min}$ - Pirólise a $500{ }^{\circ} \mathrm{C}$

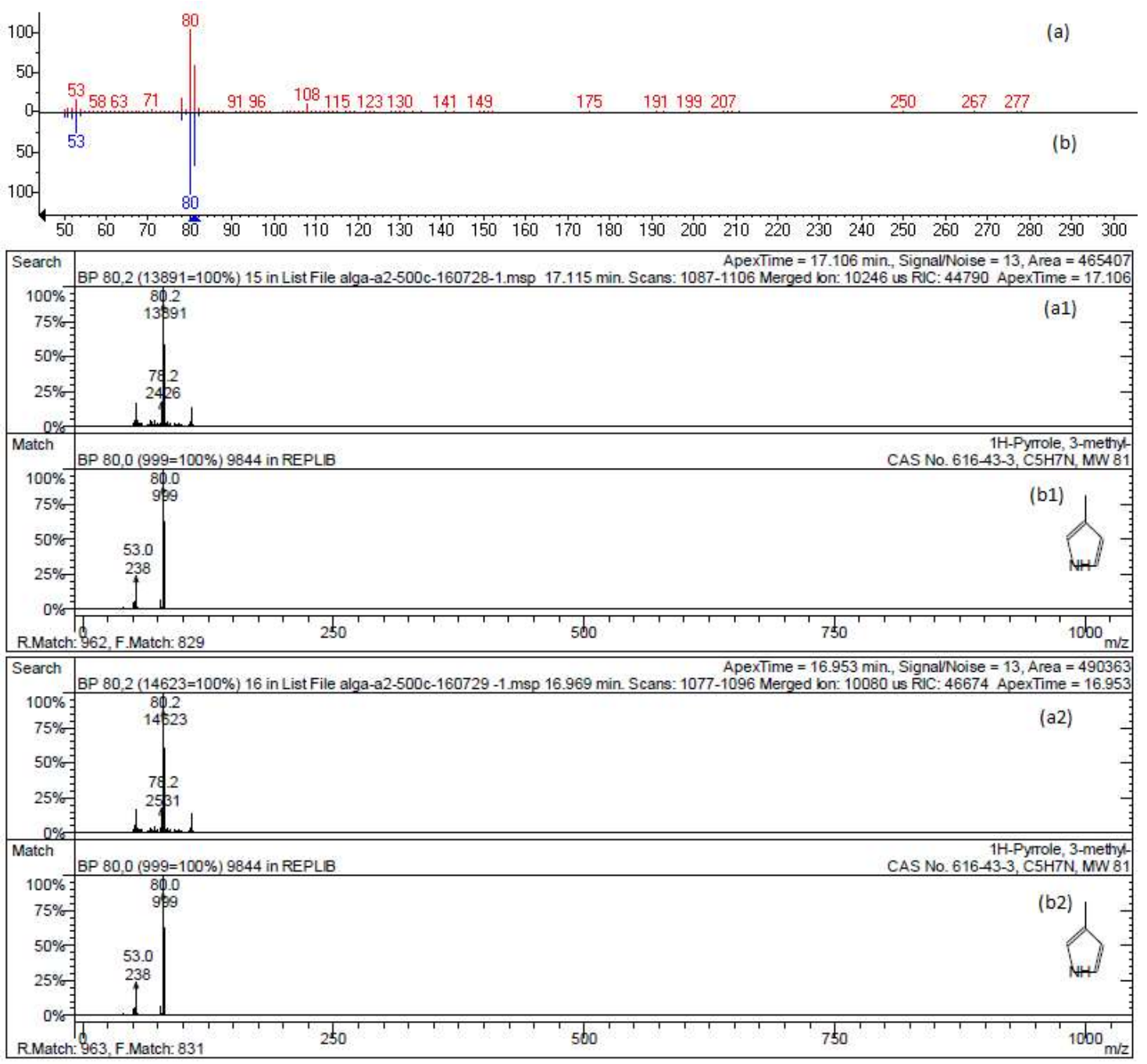


Figura 24 - Espectro pesquisado(a) $x$ Espectro catalogado(b) - Tempos de retenção $18,637^{(1)} e$ $18,490^{(2)} \mathrm{min}$ - Pirólise a $500^{\circ} \mathrm{C}$

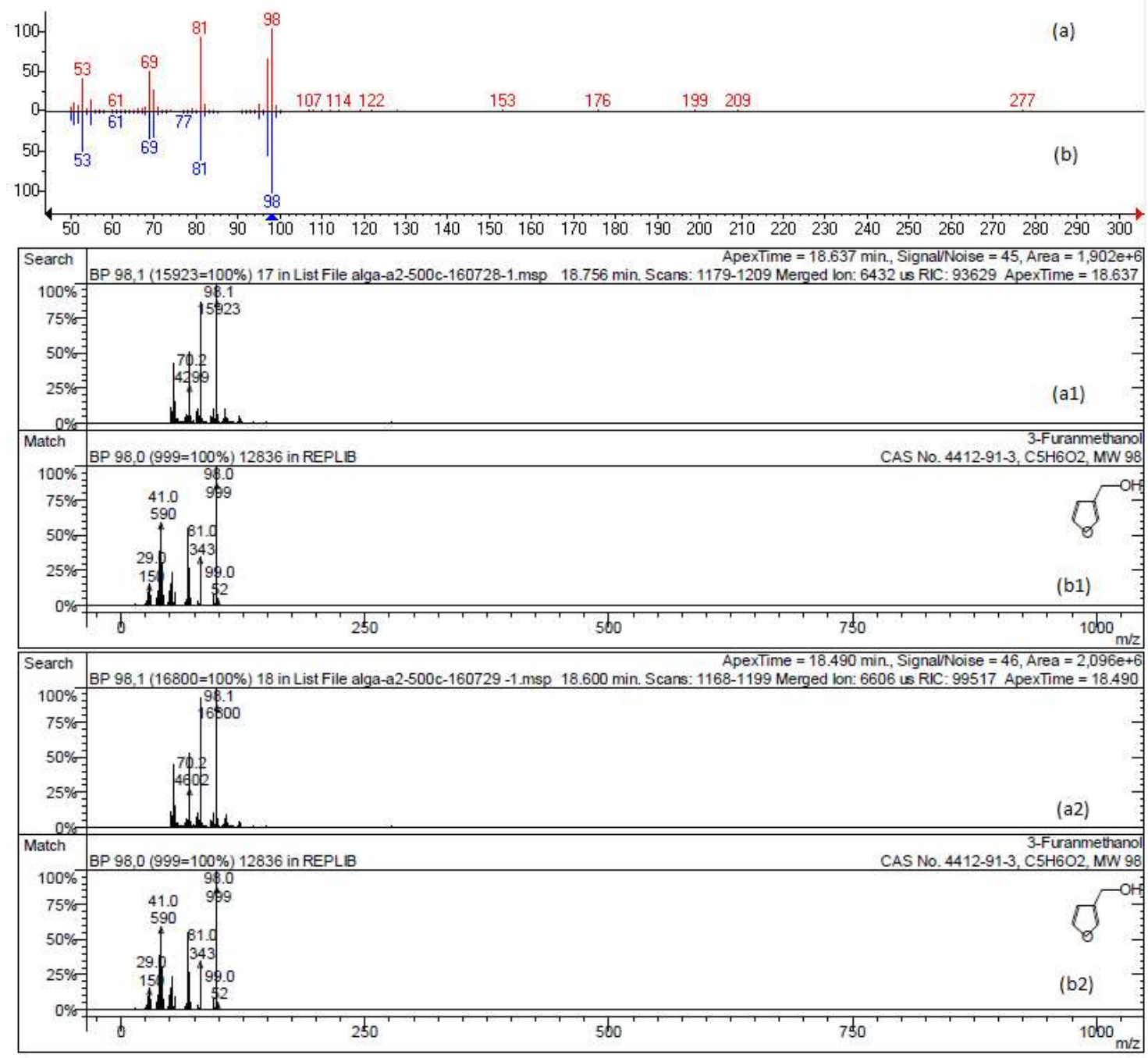

O composto apresentado na Figura 25 foi obtido após um tempo de retenção de aproximadamente 41,9 minutos. O composto sugerido dentre os catalogados apresenta os grupos funcionais de álcool, cetona e éter. O composto pesquisado apresenta um pico de massa $\mathrm{m} / \mathrm{z} 277$, além de outros picos de massa entre $\mathrm{m} / \mathrm{z} 126$ e 156, o que significa que pode se tratar de um composto de massa maior do que o que foi sugerido. A diferença entre os picos m/z 126 e 95 resulta em um fragmento de massa de $\mathrm{m} / \mathrm{z} 31$, que pode ser associado à perda de um radical ${ }^{\circ} \mathrm{OCH}_{3}$ ou ${ }^{\circ} \mathrm{CH}_{2} \mathrm{OH}$, trata-se de um fragmento comum tanto para álcoois, quanto para éteres ou ésteres, caracterizando esta substância como um composto oxigenado. 


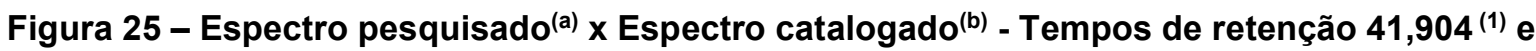
$41,835^{(2)} \mathrm{min}$ - Pirólise a $500{ }^{\circ} \mathrm{C}$

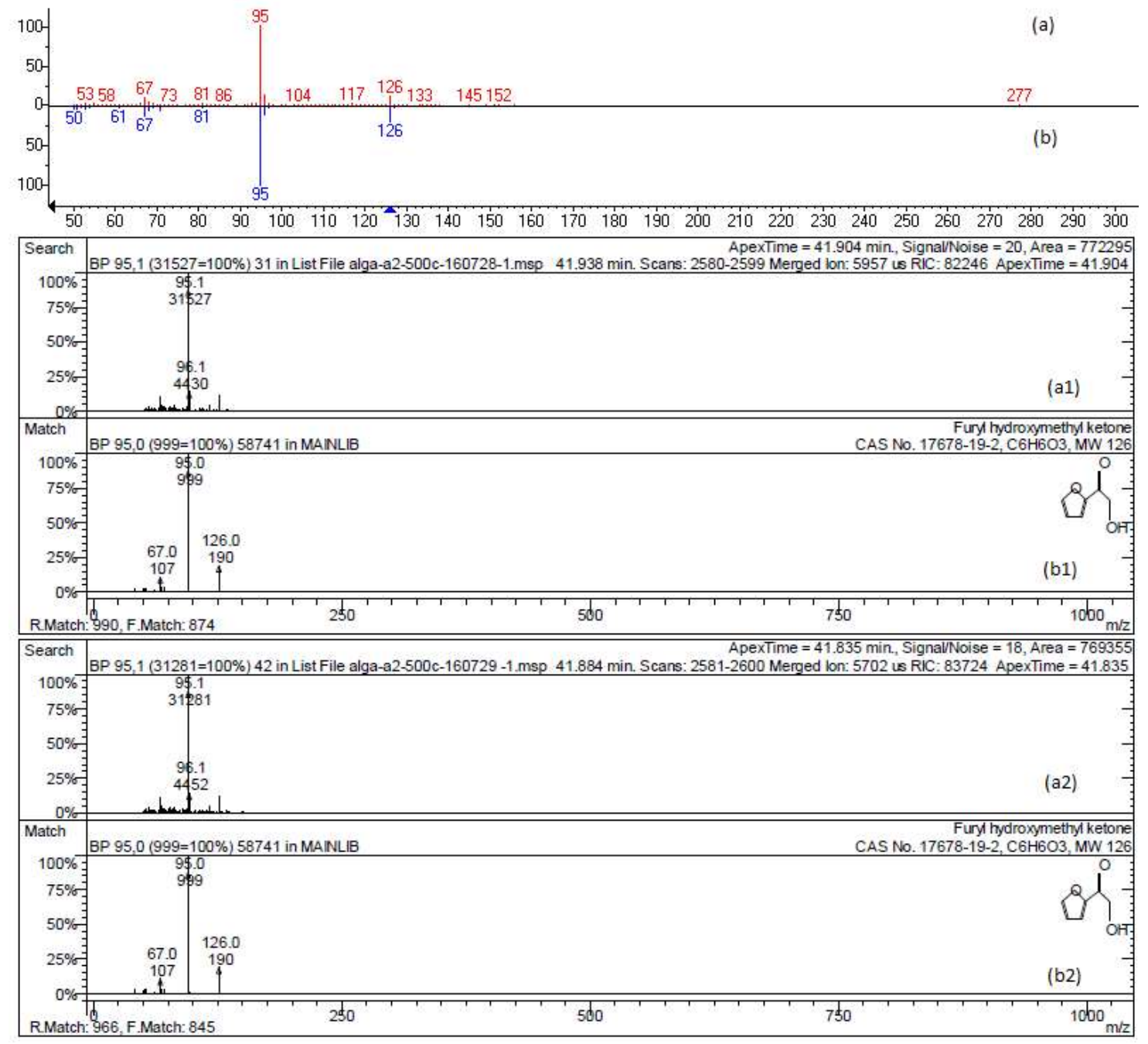

Na Figura 26, os cinco picos de maior abundância, m/z 117, 90, 89, 63 e 118, são os mesmos para os dois compostos e aparecem na mesma sequência nos dois casos, o que indica que a estrutura molecular o indol é parte do composto obtido através da pirólise. 
Figura 26 - Espectro pesquisado(a) $x$ Espectro catalogado(b) - Tempos de retenção $70,943^{(1)} e$ $70,941^{(2)} \mathrm{min}$ - Pirólise a $500{ }^{\circ} \mathrm{C}$

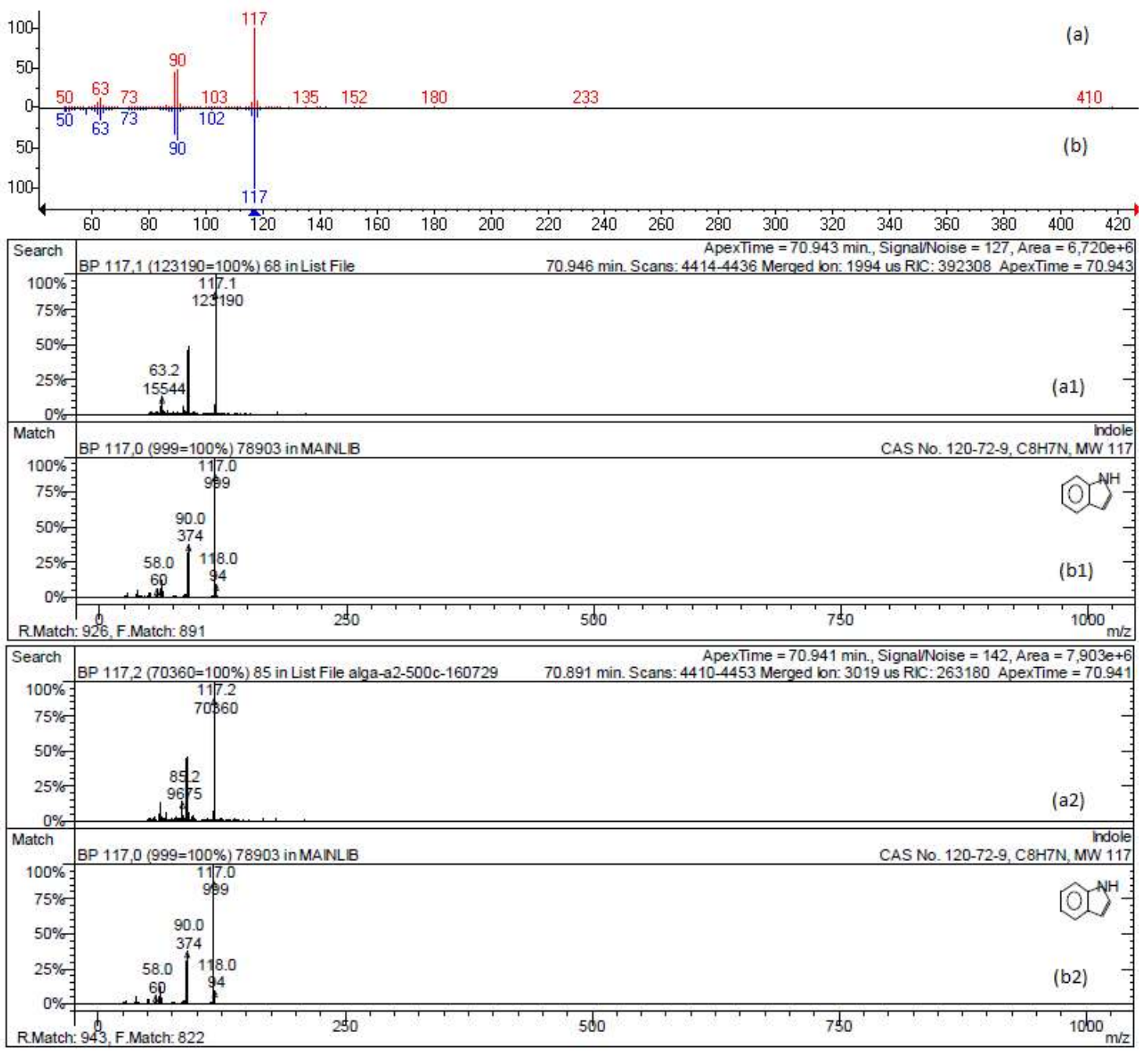

\subsubsection{Reação a $600^{\circ} \mathrm{C}$}

A primeira análise a partir dos produtos da pirólise conduzida a $600{ }^{\circ} \mathrm{C}$ apresentou 579 picos integrados, dos quais 485 apresentaram algum nível de correlação com a biblioteca utilizada como referência. A segunda análise apresentou 346 picos integrados, através dos quais foram registradas 249 correlações. Os compostos que apresentaram maior nível de compatibilidade estão apresentados na Tabela 16. A análise detalhada dos espectros com maior nível de compatibilidade está apresentada no APÊNDICE A. 
Tabela 16 - Lista de compostos com maior compatibilidade entre os espectros pesquisados e os de referência analisados a partir dos produtos de pirólise a $600{ }^{\circ} \mathrm{C}$ - Método 2

\begin{tabular}{cccc}
\hline Corrida & $\begin{array}{c}\text { Tempo de } \\
\text { retenção (mim) }\end{array}$ & Composto compatível & Fórmula \\
\hline $\mathrm{C} 1-\mathrm{C} 2$ & $8,237-8,333$ & tolueno & $\mathrm{C}_{7} \mathrm{H}_{8}$ \\
$\mathrm{C} 1-\mathrm{C} 2$ & $12,391-11,943$ & p-xileno & $\mathrm{C}_{8} \mathrm{H}_{10}$ \\
$\mathrm{C} 1-\mathrm{C} 2$ & $17,288-17,169$ & 3-metil-1H-pirrol & $\mathrm{C}_{5} \mathrm{H}_{7} \mathrm{~N}$ \\
$\mathrm{C} 1$ & 31,882 & N-butil-terc-butilamina & $\mathrm{C}_{8} \mathrm{H}_{19} \mathrm{~N}$ \\
$\mathrm{C} 1-\mathrm{C} 2$ & $34,486-34,226$ & 2-hidroxi-3-metil-2-ciclopentenona, & $\mathrm{C}_{6} \mathrm{H}_{8} \mathrm{O}_{2}$ \\
$\mathrm{C} 1$ & 78,365 & 3-metil-1H-indol & $\mathrm{C}_{9} \mathrm{H}_{9} \mathrm{~N}$ \\
\hline
\end{tabular}

\subsubsection{Reação a $700^{\circ} \mathrm{C}$}

A primeira análise a partir dos produtos da pirólise conduzida a $700{ }^{\circ} \mathrm{C}$ apresentou 577 picos integrados, dos quais 470 apresentaram algum nível de correlação com a biblioteca utilizada como referência. A segunda análise apresentou 376 picos integrados, através dos quais foram registradas 283 correlações. Os compostos que apresentaram maior nível de compatibilidade estão apresentados na Tabela 17. A análise detalhada dos espectros com maior nível de compatibilidade está apresentada no APÊNDICE A.

Tabela 17 - Lista de compostos com maior compatibilidade entre os espectros pesquisados e os de referência analisados a partir dos produtos de pirólise a $700^{\circ} \mathrm{C}$

\begin{tabular}{cccc}
\hline Corrida & $\begin{array}{c}\text { Tempo de retenção } \\
(\mathbf{m i m})\end{array}$ & Composto compatível & Fórmula \\
\hline $\mathrm{C} 1-\mathrm{C} 2$ & $8,050-8,166$ & tolueno & $\mathrm{C}_{7} \mathrm{H}_{8}$ \\
$\mathrm{C} 1-\mathrm{C} 2$ & $12,122-12,334$ & p-xileno & $\mathrm{C}_{8} \mathrm{H}_{10}$ \\
$\mathrm{C} 1-\mathrm{C} 2$ & $16,975-17,192$ & 3-metil-1H-pirrol & $\mathrm{C}_{5} \mathrm{H}_{7} \mathrm{~N}$ \\
$\mathrm{C} 1-\mathrm{C} 2$ & $25,016-25,191$ & 2-etil-1H-pirrol & $\mathrm{C}_{6} \mathrm{H}_{9} \mathrm{~N}$ \\
$\mathrm{C} 1$ & 49,245 & benzilnitrila & $\mathrm{C}_{8} \mathrm{H}_{7} \mathrm{~N}$ \\
$\mathrm{C} 2$ & 49,273 & 1-isociano-2-metil- benzeno & $\mathrm{C}_{8} \mathrm{H}_{7} \mathrm{~N}$ \\
$\mathrm{C} 1-\mathrm{C} 2$ & $71,039-71,028$ & indol & $\mathrm{C}_{8} \mathrm{H}_{7} \mathrm{~N}$ \\
\hline
\end{tabular}




\subsubsection{Reação a $800^{\circ} \mathrm{C}$}

A primeira análise a partir dos produtos da pirólise conduzida a $800{ }^{\circ} \mathrm{C}$ apresentou 358 picos integrados, dos quais 264 apresentaram algum nível de correlação com a biblioteca utilizada como referência. A segunda análise apresentou 399 picos integrados, através dos quais foram registradas 289 correlações. Os compostos que apresentaram maior nível de compatibilidade estão apresentados na Tabela 18. A análise detalhada dos espectros com maior nível de compatibilidade está apresentada no APÊNDICE A.

Tabela 18 - Lista de compostos com maior compatibilidade entre os espectros pesquisados e os de referência analisados a partir dos produtos de pirólise a $800^{\circ} \mathrm{C}$ - Método 2

\begin{tabular}{cccc}
\hline Corrida & $\begin{array}{c}\text { Tempo de } \\
\text { retenção (mim) }\end{array}$ & Composto compatível & Fórmula \\
\hline $\mathrm{C} 1-\mathrm{C} 2$ & $8,031-8,359$ & tolueno & $\mathrm{C}_{7} \mathrm{H}_{8}$ \\
$\mathrm{C} 1$ & 12,099 & o-xileno & $\mathrm{C}_{8} \mathrm{H}_{10}$ \\
C2 & 12,651 & p-xileno & $\mathrm{C}_{8} \mathrm{H}_{10}$ \\
$\mathrm{C} 1-\mathrm{C} 2$ & $16,915-17,532$ & 3-metil-1H-pirrol & $\mathrm{C}_{5} \mathrm{H}_{7} \mathrm{~N}$ \\
$\mathrm{C} 1-\mathrm{C} 2$ & $24,960-25,471$ & 2-etil-1H-pirrol & $\mathrm{C}_{6} \mathrm{H}_{9} \mathrm{~N}$ \\
$\mathrm{C} 1-\mathrm{C} 2$ & $47,438-47,630$ & 3-metil-fenol & $\mathrm{C}_{7} \mathrm{H}_{8} \mathrm{O}$ \\
$\mathrm{C} 1-\mathrm{C} 2$ & $49,220-49,404$ & benzilnitrila & $\mathrm{C}_{8} \mathrm{H}_{7} \mathrm{~N}$ \\
$\mathrm{C} 1-\mathrm{C} 2$ & $78,365-78,423$ & 3-metil-1H-indol & $\mathrm{C}_{9} \mathrm{H}_{9} \mathrm{~N}$ \\
\hline
\end{tabular}

\subsubsection{Reação a $900^{\circ} \mathrm{C}$}

A primeira análise a partir dos produtos da pirólise conduzida a $900{ }^{\circ} \mathrm{C}$ apresentou 396 picos integrados, dos quais 269 apresentaram algum nível de correlação com a biblioteca utilizada como referência. A segunda análise apresentou 406 picos integrados, através dos quais foram registradas 283 correlações. Os compostos que apresentaram maior nível de compatibilidade estão apresentados na Tabela 19. A análise detalhada dos espectros com maior nível de compatibilidade está apresentada no APÊNDICE A. 
Tabela 19 - Lista de compostos com maior compatibilidade entre os espectros pesquisados e os de referência analisados a partir dos produtos de pirólise a $900^{\circ} \mathrm{C}$ - Método 2

\begin{tabular}{cccc}
\hline Corrida & $\begin{array}{c}\text { Tempo de } \\
\text { retenção (mim) }\end{array}$ & Composto compatível & Fórmula \\
\hline $\mathrm{C} 1$ & 8,480 & tolueno & $\mathrm{C}_{7} \mathrm{H}_{8}$ \\
$\mathrm{C} 2$ & 8,484 & 1,3,5-cicloheptatrieno & $\mathrm{C}_{7} \mathrm{H}_{8}$ \\
C1 & 12,827 & o-xileno & $\mathrm{C}_{8} \mathrm{H}_{10}$ \\
C2 & 12,822 & p-xileno & $\mathrm{C}_{8} \mathrm{H}_{10}$ \\
$\mathrm{C} 1-\mathrm{C} 2$ & $17,705-17,698$ & 3-metil-1H-pirrol & $\mathrm{C}_{5} \mathrm{H}_{7} \mathrm{~N}$ \\
$\mathrm{C} 1-\mathrm{C} 2$ & $25,605-25,592$ & 3-etil-1H-pirrol & $\mathrm{C}_{6} \mathrm{H}_{9} \mathrm{~N}$ \\
$\mathrm{C} 1-\mathrm{C} 2$ & $71,076-71,051$ & indol & $\mathrm{C}_{8} \mathrm{H}_{7} \mathrm{~N}$ \\
$\mathrm{C} 1-\mathrm{C} 2$ & $78,409-78,380$ & 3-metil-1H-indol & $\mathrm{C}_{9} \mathrm{H}_{9} \mathrm{~N}$ \\
\hline
\end{tabular}

\subsection{Avaliação das classes dos produtos em diferentes temperaturas}

Através da análise presente no item 5.2 é possível perceber que para um mesmo tempo de retenção existe a coincidência dos compostos obtidos em diferentes temperaturas de reação. A Tabela 20 apresenta uma lista de compostos que são encontrados em diferentes temperaturas de pirólise.

Dentre os compostos identificados, podemos observar uma presença relevante de substâncias derivadas de proteínas, tal qual o tolueno, o fenol, o metil fenol (isómeros), o indol, o 3-metil-1H-indol e compostos pirrólicos. O pirrol e seus derivados são reconhecidos como sendo derivados de hidroxiprolina e glutamina. $\mathrm{O}$ fenol e metil fenol são formados a partir de tirosina. Tolueno é derivado de fenilalamina. Já o indol e metilindol são formados a partir de triptofano. O fitol é um produto derivado da clorofila e o éster metílico do ácido hexadecanóico é derivado de lipídios (KEBELMANN et al., 2013). A benzilnitrila é um composto de alta toxicidade, de tal forma que se torna importante, em estudos posteriores, a avaliação das quantidades produzidas para que sejam tomados os devidos cuidados durante a manipulação dos produtos. 
Tabela 20 - Classes de compostos presentes em diferentes temperaturas - Método 2

\begin{tabular}{|c|c|c|c|c|c|c|c|c|}
\hline \multirow{2}{*}{$\#$} & \multirow{2}{*}{$\begin{array}{l}\text { Tempo de retenção } \\
\text { aproximado (min) }\end{array}$} & \multirow{2}{*}{$\begin{array}{l}\text { Classe orgânica - grupo } \\
\text { funcional predominante }\end{array}$} & \multirow{2}{*}{$\begin{array}{l}\text { Composto de } \\
\text { referência }\end{array}$} & \multicolumn{5}{|c|}{ Presenta na reação à $\left({ }^{\circ} \mathrm{C}\right)$} \\
\hline & & & & 500 & 600 & 700 & 800 & 900 \\
\hline 1 & $8,0-8,5$ & $\begin{array}{l}\text { Hidrocarboneto cíclico e } \\
\text { insaturado - Aromático }\end{array}$ & $\begin{array}{c}\text { Tolueno e } \\
\text { Cicloheptatrieno }\end{array}$ & $X$ & $X$ & $X$ & $X$ & $\mathrm{X}$ \\
\hline 2 & $11,9-12,4$ & Hidrocarboneto aromático & $\begin{array}{l}\text { p-Xileno } \\
\text { (isômeros) }\end{array}$ & $X$ & $X$ & $X$ & $X$ & $x$ \\
\hline 3 & $14,1-14,3$ & $\begin{array}{l}\text { Hidrocarboneto cíclico e } \\
\text { insaturado }\end{array}$ & Ciclooctatetraeno & & $X$ & $X$ & $X$ & \\
\hline 4 & $17,3-17,7$ & $\begin{array}{l}\text { Composto nitrogenado - } \\
\text { Amina }\end{array}$ & $\begin{array}{l}\text { Metil-Pirrol } \\
\text { (isômeros) }\end{array}$ & & $X$ & $X$ & $X$ & $X$ \\
\hline 5 & $18,6-18,8$ & $\begin{array}{c}\text { Composto oxigenado - } \\
\text { éter/álcool }\end{array}$ & $\begin{array}{l}\text { Furanometanol } \\
\text { (isômeros) }\end{array}$ & $X$ & $X$ & $X$ & & \\
\hline 6 & $24,9-25,6$ & $\begin{array}{l}\text { Composto nitrogenado - } \\
\text { Amina }\end{array}$ & $\begin{array}{l}\text { Etil-Pirrol } \\
\text { (isômeros) }\end{array}$ & & & $X$ & $X$ & $X$ \\
\hline 7 & $26,5-26,8$ & $\begin{array}{c}\text { Composto oxigenado - } \\
\text { Éter/aldeído }\end{array}$ & $\begin{array}{l}\text { 5-Metil-2-Furano- } \\
\text { carboxialdeido }\end{array}$ & $X$ & $X$ & $X$ & $X$ & \\
\hline 8 & $34,2-34,6$ & $\begin{array}{l}\text { Composto oxigenado - } \\
\text { cetona/álcool }\end{array}$ & $\begin{array}{l}\text { 2-hidroxi-3-metil- } \\
\text { ciclopentanona } \\
\text { (isômeros) }\end{array}$ & $X$ & $X$ & $X$ & $X$ & $X$ \\
\hline 9 & $38,3-38,6$ & $\begin{array}{l}\text { Composto oxigenado e } \\
\text { aromático - fenol }\end{array}$ & Fenol & $X$ & $X$ & $X$ & $X$ & $X$ \\
\hline 10 & $47,4-47,6$ & $\begin{array}{l}\text { Composto oxigenado e } \\
\text { aromático - fenol }\end{array}$ & $\begin{array}{l}\text { Metil-Fenol } \\
\text { (isômeros) }\end{array}$ & $X$ & $X$ & $X$ & $X$ & $X$ \\
\hline 11 & $49,2-49,4$ & $\begin{array}{l}\text { Composto aromático e } \\
\text { nitrogenado - Nitrila }\end{array}$ & Benzilnitrila & & $X$ & $X$ & $X$ & $X$ \\
\hline 12 & $70,9-71,1$ & $\begin{array}{l}\text { Composto aromático e } \\
\text { nitrogenado - Amina }\end{array}$ & Indol (isômeros) & $X$ & $X$ & $X$ & $X$ & $X$ \\
\hline 13 & $78,3-78,4$ & $\begin{array}{l}\text { Composto aromático e } \\
\text { nitrogenado - Amina }\end{array}$ & $\begin{array}{l}\text { Metil-indol } \\
\text { (isômeros) }\end{array}$ & $X$ & $X$ & $X$ & $X$ & $X$ \\
\hline 14 & $84,8-84,9$ & $\begin{array}{l}\text { Composto aromático e } \\
\text { oxigenado - Fenol }\end{array}$ & $\begin{array}{l}\text { Dimetil-bisfenol } \\
\text { (isômeros) }\end{array}$ & $X$ & $X$ & $X$ & $X$ & $X$ \\
\hline 15 & 110,9 & Ester de ácido carboxílico & $\begin{array}{l}\text { Éster metílico de } \\
\text { ácido } \\
\text { Hexadecanóico }\end{array}$ & $X$ & $X$ & $X$ & $X$ & $X$ \\
\hline 16 & 127,5 & $\begin{array}{l}\text { Composto oxigenado - } \\
\text { álcool }\end{array}$ & Fitol & $X$ & $X$ & $X$ & $X$ & $X$ \\
\hline
\end{tabular}

Estudos anteriores que avaliaram a pirólise da microalga CV a 450 e $500{ }^{\circ} \mathrm{C}$ apresentam compostos como tolueno, metil-pirrol, furanometanol, 5-metil-2-furanocarboxialdeido, fenol, metil-fenol, indol, metil-indol, éster metílico de ácido 
hexadecanóico e fitol como parte dos componentes presentes na corrente de voláteis (KEBELMANN et al., 2013; BABICH et al., 2011). A maioria destes compostos identificados a partir de reações a $500{ }^{\circ} \mathrm{C}$ foram encontrados em reações em temperaturas mais altas, estando presentes inclusive em reações conduzidas a $900^{\circ} \mathrm{C}$.

A presença dos mesmos compostos em diferentes temperaturas de reação é evidente quando os pirogramas são analisados em conjunto, demonstrando que a alteração da temperatura de reação não significa alterações relevantes na composição da corrente de voláteis obtidas através da pirólise do ponto de vista qualitativo. No entanto, apesar da coincidência entre os compostos formados, à medida que a temperatura aumenta é possível identificar que a quantidade de compostos de menor tempo de retenção, que tendem a ter menor peso molecular, aumenta, enquanto que os de maior tempo de retenção diminuem, isso pode ser observado através da Figura 27. Tomemos valores de áreas do pico para o tolueno e o fitol para exemplificar este comportamento. O tolueno (pico 1 , baixo tempo de retenção) apresenta áreas de pico de $2,3 \times 10^{6} \mathrm{e}$ $3,0 \times 10^{7}$ a 500 e $900{ }^{\circ} \mathrm{C}$, respectivamente, enquanto o fitol (pico 16) possui picos de $1,2 \times 10^{7}$ e $4,9 \times 10^{6}$ a 500 e $900{ }^{\circ} \mathrm{C}$. A explicação para o aumento da quantidade relativa de compostos mais voláteis com o aumento da temperatura do meio reacional pode estar associada a clivagens consecutivas sofridas pelas moléculas de maior estrutura quando submetidas a temperaturas mais altas, pois o ambiente de reação dispõe de mais energia para efetivar a quebra sequencial das moléculas.

Pode-se observar uma pequena variação nos tempos de retenção obtidos experimentalmente para uma mesma substância, chegando a uma diferença de 0,7 min para o etil-pirrol. Apesar de não ser comum uma diferença de tempo de retenção dessa amplitude, para uma mesma substância, em uma análise cromatográfica, devemos considerar algumas particularidades do sistema estudado. Nesse caso a injeção dos produtos obtidos através da pirólise não é instantânea, a massa volatilizada é conduzida ao cromatógrafo durante todo o período de reação, que é de 20 segundos, de tal forma que é esperada uma pequena variação no tempo de retenção tendo em vista que não há garantia que em todas as análises o composto analisado seja injetado exatamente no exato instante inicial da corrida cromatográfica. Além disso, o tempo total da corrida é de 166,3 min, o que significa que essa variação 
de 0,7 min não chega a representar sequer $0,5 \%$ do tempo total de análise, de tal forma que pode ser considerada desprezível para o sistema em questão.

Figura 27 - Comparativo dos cromatogramas obtidos a $500^{(a)}, 700^{(b)}$ e $900^{(c)}{ }^{\circ} \mathrm{C}$ pelo Método 2 (Referente a tabela 20)
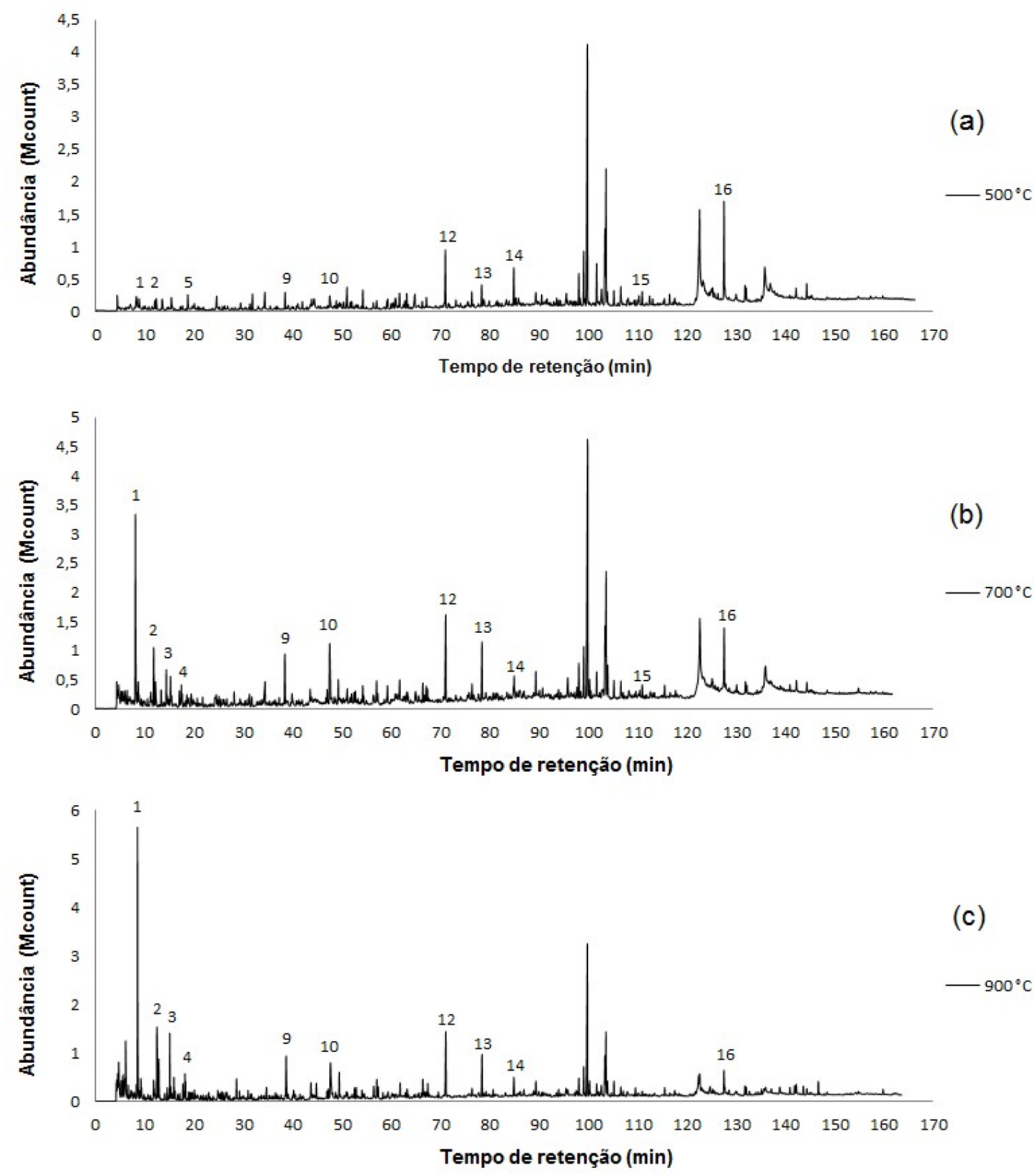


\subsection{Avaliação da taxa de reação - reator de bancada}

Através das medidas da massa da microalga antes e depois da reação foi possível determinar as frações dos produtos voláteis e sólidos para a pirólise em diferentes temperaturas, como mostra a Figura 28. A fração de sólidos é calculada através da diferença entre a fração de voláteis e $100 \%$, e inclui tanto o carbono fixo quanto o teor de cinzas. É possível perceber que à medida que a temperatura de reação aumenta a fração de massa volatilizada também aumenta para um mesmo tempo de reação. $O$ rendimento de produtos voláteis aumenta substancialmente com a temperatura de reação variando de 400 a $600{ }^{\circ} \mathrm{C}(13,5$ a $68,2 \%)$, mas de 600 a $900{ }^{\circ} \mathrm{C}$ observamos uma pequena variação $(68,2$ a $76,3 \%)$. Esse resultado indica que a elevação da temperatura de reação acima de $600{ }^{\circ} \mathrm{C}$ não trará resultados significativos em termos de produção de voláteis.

Figura 28 - Fração dos produtos voláteis de pirólise em diferentes temperaturas para pirólise rápida após 20 segundos de reação

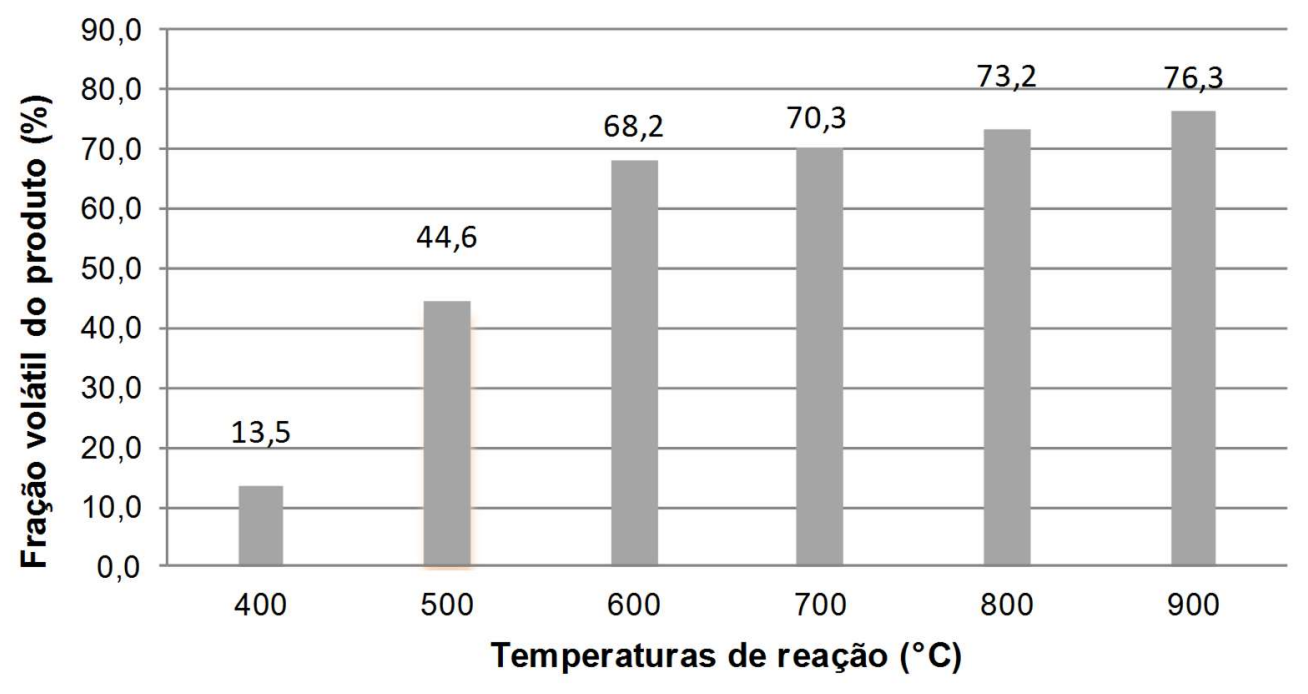

Para uma melhor percepção de como a taxa de reação se comporta com o aumento da temperatura, os valores da variação de massa (obtidos através da pesagem da amostra antes e depois da reação) normalizada pela variação do tempo para cada ensaio de pirólise com o reator de bancada foram calculados a partir da relação $\Delta z / \Delta t$, e estão apresentados na Figura 29 a seguir. Desta forma é possível perceber que quanto maior a temperatura, maior será a taxa de conversão de biomassa em produtos 
voláteis. Os dados relativos à taxa de variação da massa com o tempo de reação apresentaram um desvio padrão médio de $4 \times 10^{-3} \mathrm{~s}^{-1}$, sendo o desvio em termos absolutos mais baixo associado à temperatura de $400^{\circ} \mathrm{C}\left(1,7 \times 10^{-3} \mathrm{~s}^{-1}\right)$ e o mais alto está associado à temperatura de $600{ }^{\circ} \mathrm{C}\left(6,9 \times 10^{-3} \mathrm{~s}^{-1}\right)$. Apesar do valor do desvio absoluto ser baixo, em termos relativos são todos superiores a $10 \%$, pois o valor associado à taxa medida tem ordem de $10^{-2}$, tratando-se, portanto, de uma ordem de grandeza pequena, em que mesmo variações de baixa amplitude tornam-se significativas.

Figura 29 - Taxa de variação da massa no tempo obtida em diferentes temperaturas

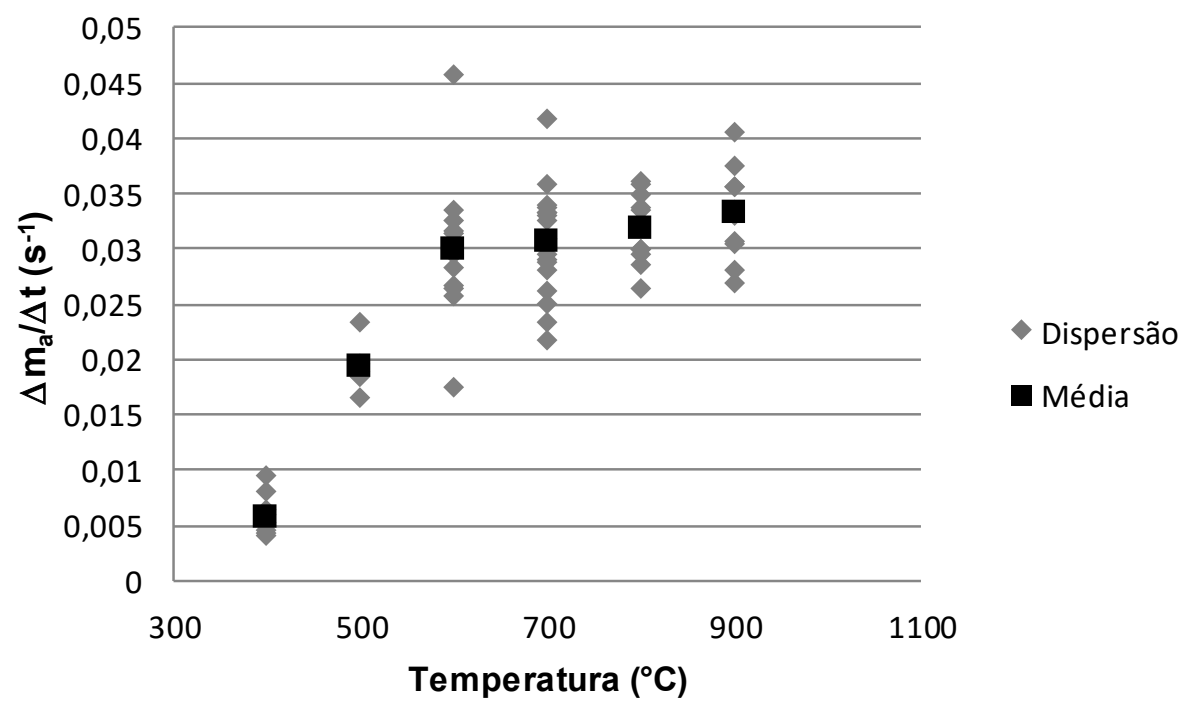

Os experimentos de pirólise foram conduzidos com diferentes vazões do gás de arraste. A Figura 30 apresenta os valores calculados para taxa de reação versus a vazão do gás de arraste em diferentes temperaturas, através da qual pode-se observar que não existe uma correlação entre estas duas variáveis, o que indica que nas condições dessa análise, a variação da vazão do gás de arraste não é um fator preponderante para determinar a fração que reage.

A interferência no tempo em que a biomassa permanecia no reator foi avaliada a $500{ }^{\circ} \mathrm{C}$. A variação na fração de voláteis foi avaliada entre 5 e 20 segundos, e pelos resultados (Figura 31) é possível identificar que a partir de 10 segundos não se percebe alteração na fração volatilizada. Por isso, na determinação dos produtos obtidos a partir da pirólise, o tempo de reação utilizado foi de 20 segundos, de modo a garantir que todos os compostos que poderiam estar na corrente volatilizada foram 
encaminhados para análise no cromatógrafo. Como a taxa de reação aumenta com a temperatura, para temperaturas mais altas, o tempo de 20 segundos também garante que a massa que deveria ser volatilizada foi encaminhada para análise qualitativa de composição.

Figura 30 - Valores médios da taxa de variação da massa no tempo obtida versus a vazão do gás de arraste em diferentes temperaturas

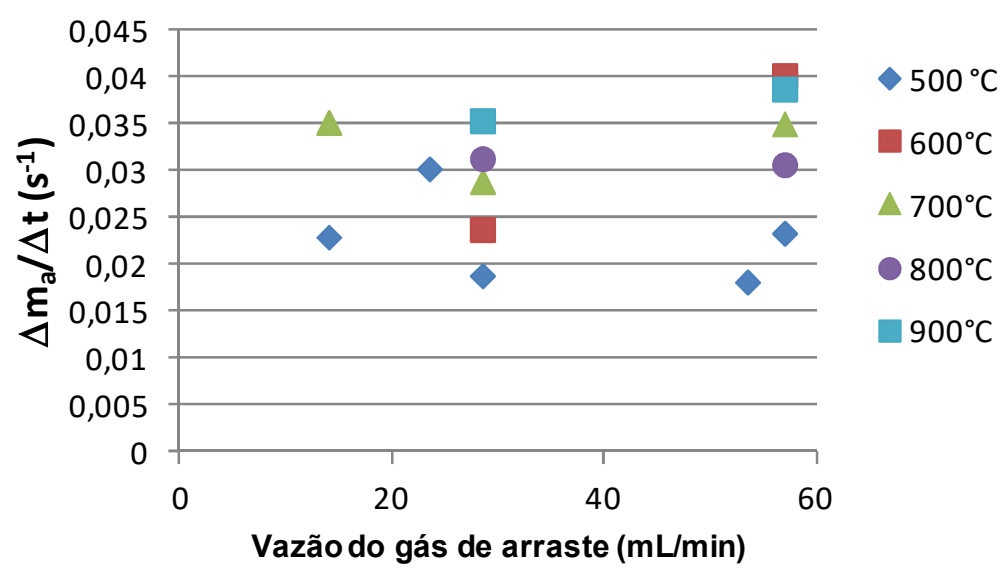

Figura 31 - Avaliação da fração volatilizada variando o tempo de reação a $500{ }^{\circ} \mathrm{C}$

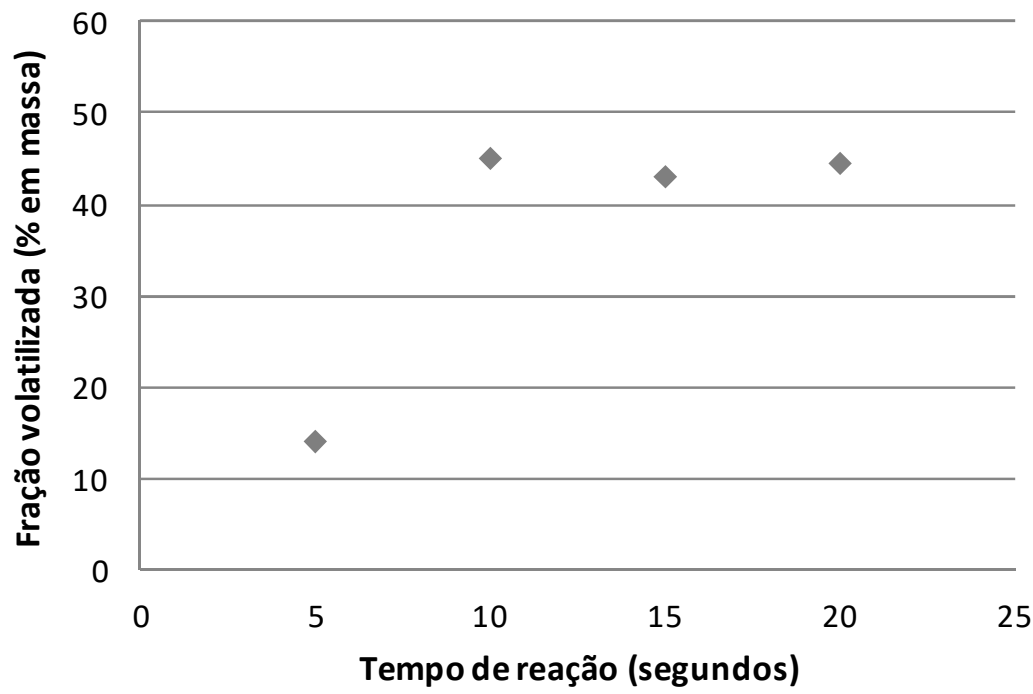




\subsection{Determinação do teor de cinzas}

Existem algumas normas disponíveis para determinação do teor de cinzas nas quais a temperatura final varia entre 450 e $930^{\circ} \mathrm{C}$. De forma geral, o teor de cinzas é mais alto quando uma temperatura final menor é utilizada na análise, devido a combustão incompleta, enquanto que se torna menor quando a temperatura final é mais alta, devido a volatilização do cloro e de alguns metais como o potássio (LIU et al., 2015). Neste estudo, para determinação do teor de cinzas foram realizados ensaios com temperaturas finais de 600 e $800{ }^{\circ} \mathrm{C}$. Os resultados obtidos podem ser visualizados através da Tabela 21.

Tabela 21 - Teor de cinzas

\begin{tabular}{cccc}
\hline $\begin{array}{c}\text { Temperatura } \\
\text { final }\left({ }^{\circ} \mathbf{C}\right)\end{array}$ & $\begin{array}{c}\text { Tempo de manutenção da } \\
\text { temperatura final }(\mathbf{m i n})\end{array}$ & $\begin{array}{c}\text { Taxa de aquecimento } \\
\left({ }^{\circ} \mathbf{C} / \mathbf{m i n}\right)\end{array}$ & $\begin{array}{c}\text { Teor de cinzas } \\
(\%)\end{array}$ \\
\hline 600 & 30 & 20 & $13,0 \pm 0,35$ \\
800 & 20 & 20 & $12,3 \pm 0,89$ \\
\hline
\end{tabular}

A Figura 32 apresenta o aspecto físico da amostra de microalga após a combustão completa a 600 e $800^{\circ} \mathrm{C}$. Pode-se observar que a coloração do produto se altera de acordo com a temperatura final a qual a amostra é submetida, provavelmente devido à volatilização de sais minerais e alguns outros inorgânicos mais voláteis, conforme exposto por Liu et al. (2015).

Figura 32 - Teor de cinzas: Produto a $600^{\circ} \mathrm{C}^{(\mathrm{a})}$ e $800^{\circ} \mathrm{C}^{(\mathrm{b})}$
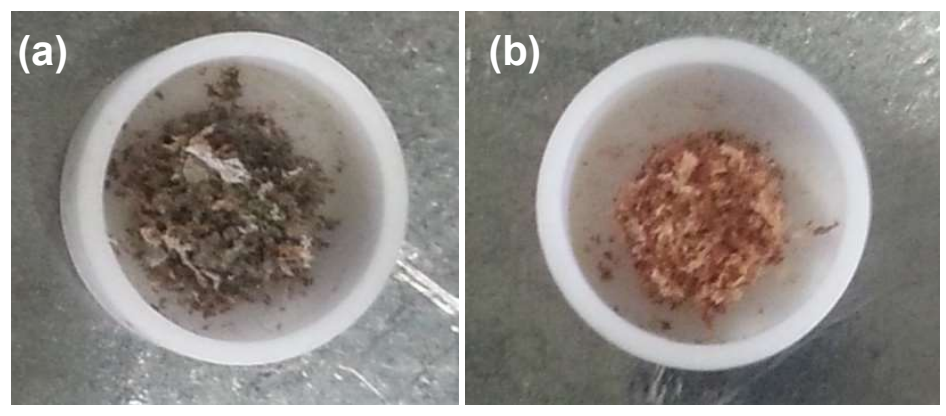

Considerando que os resultados estão próximos e a possível ocorrência de volatilização de inorgânicos em temperaturas mais elevadas, para os cálculos dos parâmetros cinéticos foi estabelecido o valor de 13 \% para o teor de cinzas. 


\subsection{Parâmetros cinéticos da reação de pirólise}

Os parâmetros cinéticos para a reação de pirólise da microalga de estudo foram obtidos através da análise termogravimétrica. Para tal foram realizados ensaios com quatro taxas de aquecimento $\beta(5,10,20$ e $25 \mathrm{~K} / \mathrm{min})$. Para esta análise foi considerado que para as condições analíticas, a resistência à transferência de calor na amostra poderia ser desconsiderada e que a temperatura medida correspondia à temperatura da amostra. As curvas termogravimétricas em diferentes taxas de aquecimento estão apresentadas na Figura 33.

As curvas de termogravimetria diferencial (DTG), apresentadas na Figura 34, demonstram a ocorrência de três fases mais relevantes na decomposição da biomassa analisada. A primeira fase está associada a uma perda de massa devido à desidratação e cobre uma faixa de temperatura entre 50 e $150^{\circ} \mathrm{C}$. A segunda etapa está relacionada com as principais reações de volatilização ou pirólise, onde a maior parte da massa da amostra é perdida como matéria volátil. A temperatura em que se inicia a volatilização principal é cerca de $200^{\circ} \mathrm{C}$ e se estende até $540^{\circ} \mathrm{C}$, tendo seu pico máximo em $315^{\circ} \mathrm{C}$. A terceira fase corresponde a uma decomposição residual que ocorre a partir de $550^{\circ} \mathrm{C}$ até a temperatura final de análise. Esse comportamento é compatível com outros resultados apresentados na literatura com biomassas similares. (ANASTASAKIS et al., 2011; CHEN et al., 2012; RIZZO et al., 2013).

Conforme apresentado na revisão bibliográfica, os parâmetros cinéticos podem ser obtidos a partir da derivação das curvas de termogravimetria. Três modelos matemáticos (K-A-S, Osawa e Freeman-Carroll) foram testados e os resultados estão apresentados a seguir. Nesta análise a umidade da amostra foi determinada através da própria curva termogravimétrica e o teor de cinzas foi determinado a partir de ensaios termogravimétricos em atmosfera oxidante, os quais resultaram em um valor igual a $13,0 \%$. 
Figura 33 - Curvas termogravimétricas

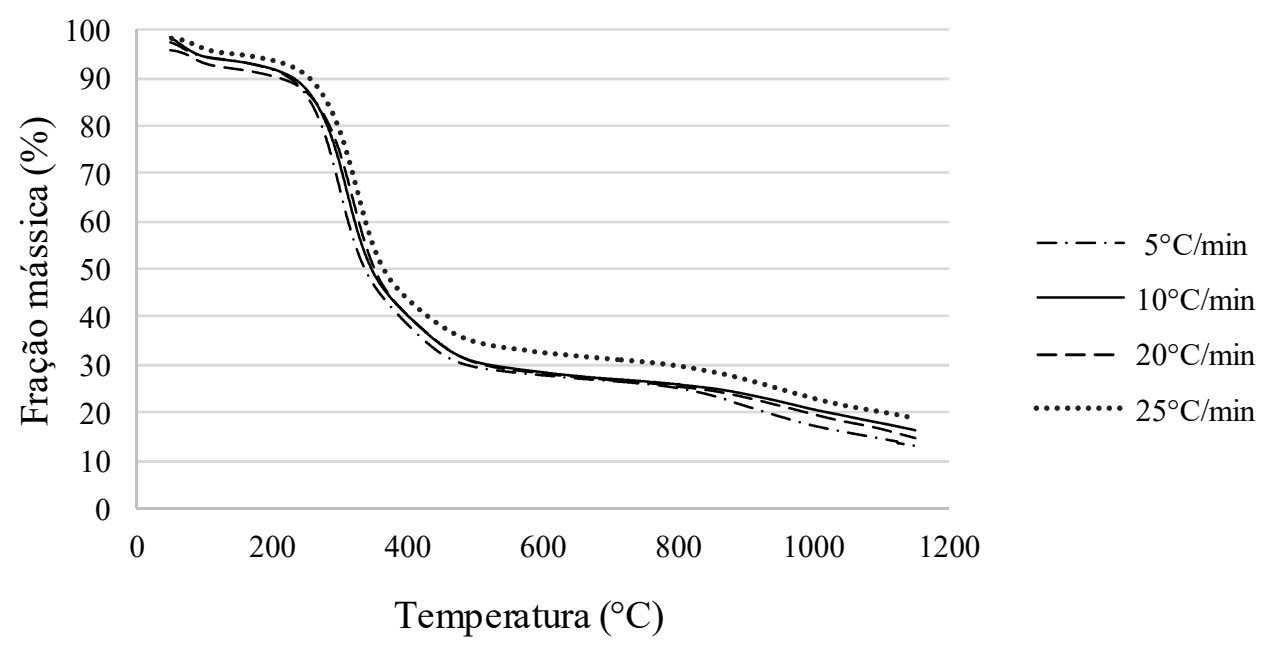

Figura 34 - Curva termogravimétrica diferencial por temperatura ${ }^{(a)}$ e por tempo ${ }^{(b)}$
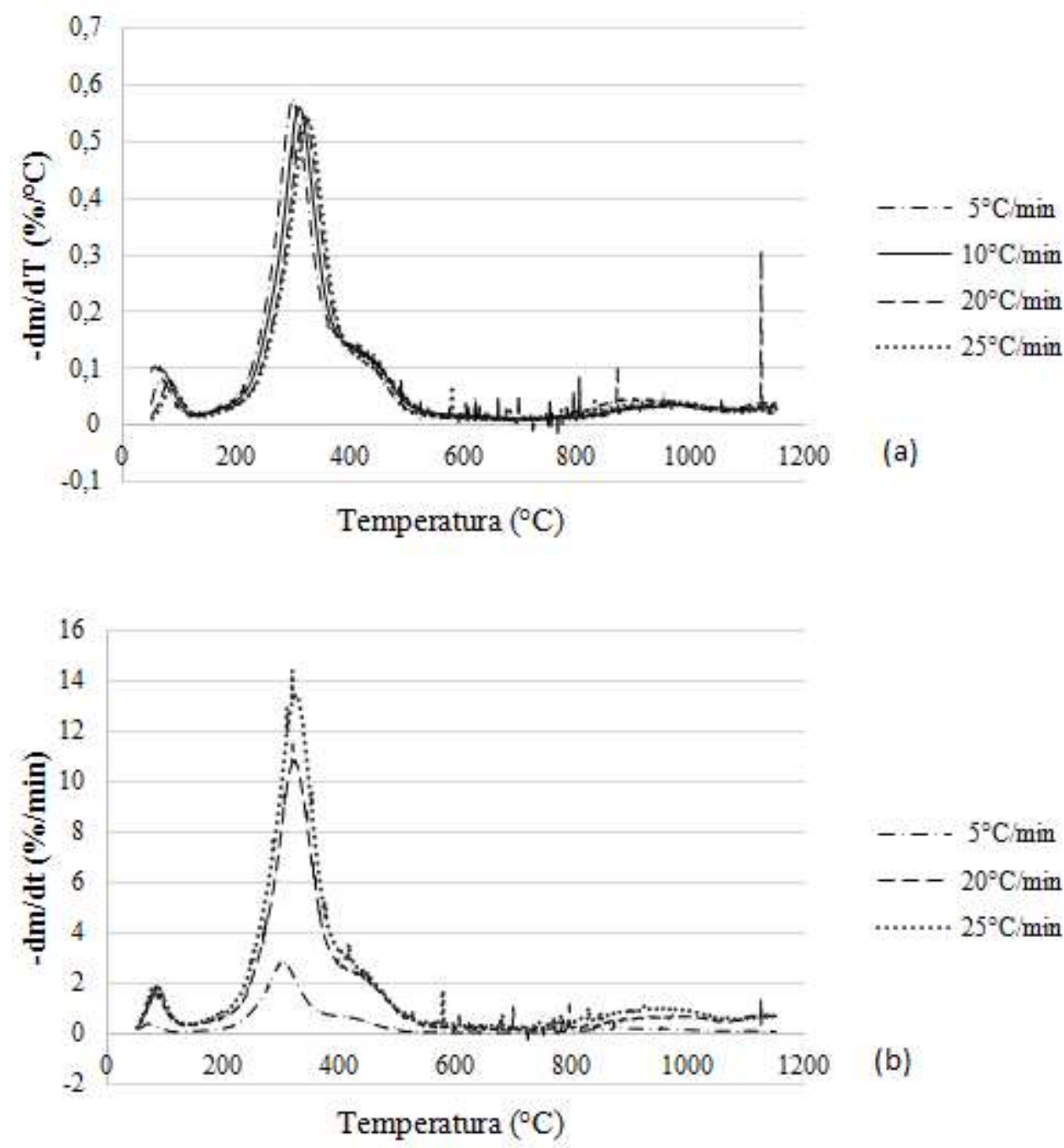

A seguir podem ser visualizados os gráficos resultantes da análise das curvas termogravimétricas. Utilizando-se o modelo conhecido como o K-A-S, pode-se 
determinar a relação $E_{a} / R$, a qual é igual ao coeficiente angular da reta gerada a partir da regressão linear dos pontos obtidos pelo gráfico $\ln \beta / T^{2} \times 1 / T$. Pelo modelo proposto por Osawa, de forma similar ao K-A-S, a energia de ativação é calculada pelo coeficiente angular da reta obtida pelo gráfico log $\beta \times 1 / \mathrm{T}$.

Podemos observar através das Figuras 35 e 36 que as retas obtidas para cada grau de conversão $(\alpha)$ são aproximadamente paralelas, o que resulta em valores similares para energia de ativação. Esse comportamento pode ser associado a uma unificação do mecanismo de múltiplas reações que ocorrem durante o processo de pirólise (YAO et al., 2007).

Figura 35 - Gráfico para cálculo da energia de ativação aparente pelo Método K-A-S

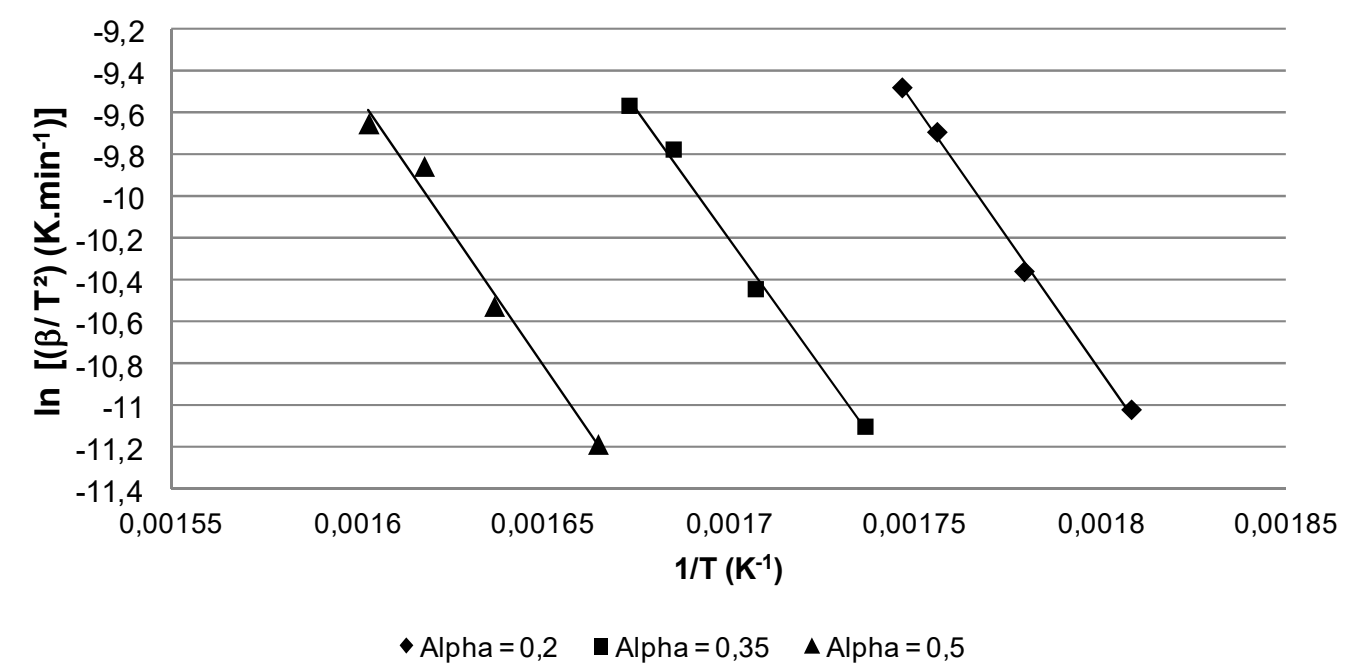

Figura 36 - Gráfico para cálculo da energia de ativação aparente pelo Método Osawa

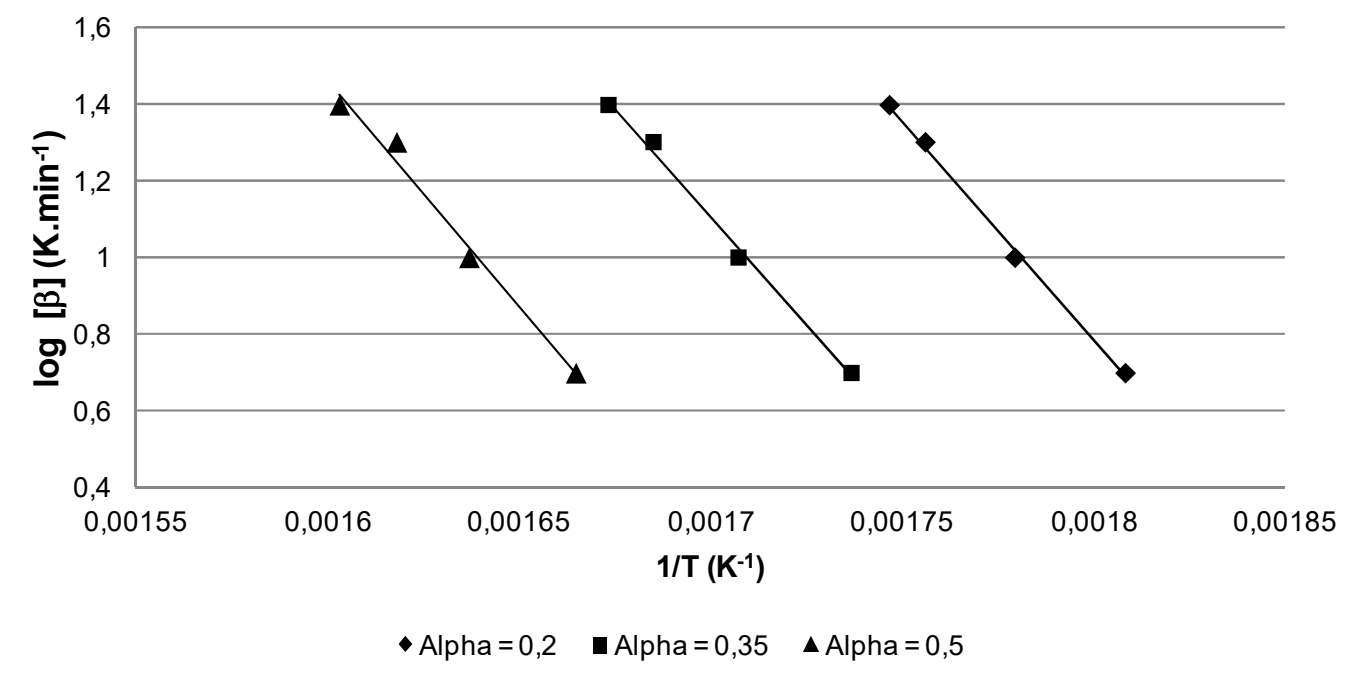


Através do coeficiente angular das retas obtidas a partir da regressão linear dos pontos apresentados nos dois gráficos foi possível chegar aos valores médios de 206 e 205 kJ/mol para energia de ativação (Tabela 22) da reação de pirólise da microalga da espécie Chlorella vulgaris, obtidos a partir dos métodos K-A-S e Osawa, respectivamente.

Tabela 22 - Energia de ativação determinada através dos modelos K-A-S e Osawa

\begin{tabular}{cccccccccc}
\hline \multicolumn{1}{c}{ K-A-S } & \multicolumn{8}{c}{ Osawa } \\
$\alpha$ & Coef. Angular & $\mathbf{R}^{2}$ & $\mathbf{E}_{\mathbf{a}}(\mathbf{k J} / \mathbf{m o l})$ & & $\alpha$ & Coef. Angular & $\mathbf{R}^{2}$ & $\mathbf{E}_{\mathbf{a}}(\mathbf{k J} / \mathbf{m o l})$ \\
\hline 0.2 & -25063 & 0,9880 & 208 & & 0.2 & -11373 & 0,988 & 207 \\
0.35 & -24556 & 0,9839 & 204 & & 0.35 & -11174 & 0,984 & 203 \\
0.5 & -24734 & 0,9423 & 206 & & 0.5 & -11273 & 0,932 & 205 \\
\hline
\end{tabular}

Com a energia de ativação calculada, é possível através de regressão linear, a partir da relação estabelecida pela eq. (20), calcular os valores da ordem de reação $n$ e do fator pré-exponencial para cada um dos modelos utilizados previamente. Os resultados obtidos estão apresentados na Tabela 23 , onde se verifica uma reação de ordem 10.

Tabela 23 - Ordem de reação e fator pré-exponencial determinados através dos modelos K-A-S e Osawa

\begin{tabular}{ccc}
\hline & K-A-S & Osawa \\
\hline$n$ & $10,2 \pm 0,51$ & $10,1 \pm 0,50$ \\
$K_{0}\left(\mathrm{~min}^{-1}\right)$ & $1,25 \mathrm{E} 19 \pm 1,72 \mathrm{E} 18$ & $1,03 \mathrm{E} 19 \pm 1,44 \mathrm{E} 18$ \\
\hline
\end{tabular}

O terceiro modelo (Freeman-Carroll) possui uma proposta diferenciada quando comparada aos dois modelos abordados inicialmente, pois é possível obter o valor da energia de ativação através de ensaios com apenas uma taxa de aquecimento. Além disso, a ordem de reação é determinada ao mesmo tempo em que se determina a energia de ativação aparente. A partir da eq. (6), foi determinado o fator préexponencial $K_{0}$ através dos valores de $E_{a}$ e $n$ previamente determinados por regressão 
linear. As faixas de valores obtidas para cada taxa de aquecimento estão apresentadas na Tabela 24. A energia de ativação apresentou valores variando entre 57 e $80 \mathrm{~kJ} / \mathrm{mol}$ e a ordem de reação variou entre 2 e 3,7.

Tabela 24 - Parâmetros cinéticos determinados pelo modelo Freeman-Carroll adaptado para diferentes taxas de aquecimento

\begin{tabular}{cccc}
\hline $\begin{array}{c}\text { Taxa de } \\
\text { aquecimento } \\
(\mathbf{K} / \mathbf{m i n})\end{array}$ & $\begin{array}{c}\text { Energia de } \\
\text { ativação }-E_{a} \\
(\mathbf{k J} / \mathbf{m o l})\end{array}$ & Ordem de reação $\boldsymbol{n}$ & Fator pré-exponencial $-K_{\boldsymbol{o}}\left(\mathbf{m i n}^{-1}\right)$ \\
\hline 5 & $74,0-80,2$ & $3,43-3,73$ & $5,92 \mathrm{E}+05-2,71 \mathrm{E}+06$ \\
10 & $62,5-67,0$ & $2,53-2,76$ & $5,66 \mathrm{E}+04-1,79 \mathrm{E}+05$ \\
20 & $58,9-61,1$ & $2,09-2,28$ & $3,69-6,28 \mathrm{E}+04$ \\
25 & $57,1-65,2$ & $2,03-3,25$ & $3,12 \mathrm{E}+04-1,49 \mathrm{E}+05$ \\
\hline
\end{tabular}

A Tabela 25 apresenta um comparativo entre os valores determinados pelo modelo Freeman-Carroll através do presente estudo e outros dois disponíveis na literatura, utilizando a Chlorella sp. (RIZZO et al., 2013) e a Chlorella protothecoides (PENG et al., 2001). Os valores determinados no presente estudo são próximos aos valores apresentados na literatura utilizando-se o mesmo modelo matemático para a obtenção dos parâmetros a partir de microalgas diferentes, o que demonstra que os parâmetros cinéticos para diferentes espécies não apresentam variações significativas nos seus valores.

Tabela 25 - Comparação dos valores experimentais e da literatura

\begin{tabular}{|c|c|c|c|c|}
\hline $\begin{array}{l}\text { Parâmetros } \\
\text { cinéticos }\end{array}$ & $\begin{array}{l}\text { Estudo presente } \\
\qquad \beta=10^{\circ} \mathrm{C} / \mathrm{min}\end{array}$ & $\begin{array}{l}\text { Estudo presente } \\
\qquad \beta=20^{\circ} \mathrm{C} / \mathrm{min}\end{array}$ & $\begin{array}{l}\text { Rizzo et al. (2013) } \\
\quad \beta=15^{\circ} \mathrm{C} / \mathrm{min}\end{array}$ & $\begin{array}{l}\text { Peng et al. (2001) } \\
\qquad \beta=15^{\circ} \mathrm{C} / \mathrm{min}\end{array}$ \\
\hline$E_{a}(\mathrm{~kJ} / \mathrm{mol})$ & $62,5-67,0$ & $58,9-61,1$ & $71,3-79,2$ & $52-97$ \\
\hline$K_{0}\left(\min ^{-1}\right)$ & 5,66 E4 - 1,79 E5 & $3,69-6,28 E 4$ & $1,47-1,62 \mathrm{E} 6$ & 1,11 E4 - 9,1 E7 \\
\hline$n$ & $2,53-2,76$ & $2,09-2,28$ & $1,69-2,41$ & $1,88-1,98$ \\
\hline Espécie & Chlorella vulgaris & Chlorella vulgaris & Chlorella sp & $\begin{array}{c}\text { Chlorella } \\
\text { protothecoides }\end{array}$ \\
\hline
\end{tabular}


Os resultados obtidos através dos modelos K-A-S e Osawa foram bastante similares entre si, o que indica que a escolha de um modelo ou outro não traz grande impacto ao resultado final. O valor obtido por Freeman-Carroll é muito inferior aos valores obtidos pelos métodos de Osawa e K-A-S. A Tabela 10 apresenta valores de energia de ativação obtidos de diferentes processos com o gênero Chlorella. Estes valores variam entre 44 e $301 \mathrm{~kJ} / \mathrm{mol}$, considerando as reações de combustão, pirólise e gaseificação. Kassim et al. (2014) relataram um valor de energia de ativação de aproximadamente $300 \mathrm{~kJ} / \mathrm{mol}$ por métodos de Osawa e K-A-S para pirólise de Chlorella sp e Rizzo et al. (2013) apresentaram um intervalo de 71 a 79 kJ/mol pelo método de Freeman-Carroll para a mesma reação e biomassa. Estudos prévios com pirólise de Chlorella vulgaris encontraram valores de energia de ativação entre 44 e $110 \mathrm{~kJ} / \mathrm{mol}$, obtidos pelos métodos Osawa e K-A-S (THANGALAZHY-GOPAKUMAR et al., 2012; RAHEEM et al., 2015). Observamos na literatura que valores associados à energia de ativação da mesma biomassa têm uma variação substancial dependendo do método utilizado, mas não há evidência de que um valor seja mais preciso ou correto do que outro.

A ordem de reação obtida a partir da energia de ativação determinada pelos métodos de Osawa e K-A-S é décima ordem. Os valores obtidos pelo método de FreemanCarroll indicam uma reação entre segunda e terceira ordem. Intuitivamente, tendemos a considerar uma reação de décima ordem como quimicamente incomum. Uma reação de segunda ou terceira ordem parece ser mais adequada para descrever uma realidade física. No entanto, estudos anteriores relataram uma faixa de ordem de reação entre 2,8 e 11,9 para biomassa terrestres (HASHIMOTO et al., 2011) e 1,25 a 2,41 para biomassa proveniente de microalgas (PENG et al., 2001; RIZZO et al., 2013). Portanto, com base na literatura, nenhum valor obtido neste estudo deve ser descartado.

O que podemos observar por esses modelos para determinação dos parâmetros cinéticos é que um valor maior para energia de ativação requer valores mais elevados para a ordem de reação e fator pré-exponencial, de tal forma que o resultado matemático resulte em uma cinética compatível com os dados experimentais. O que nos induz a concluir que para se trabalhar com uma equação cinética coerente é fundamental que todos os parâmetros sejam consistentes entre si, e o fato de utilizar 
parâmetros obtidos por fontes distintas pode conduzir ao erro quando se deseja simular o processo de pirólise.

Comparando-se com algumas biomassas como, por exemplo, a celulose que, segundo Gronli et al. apud Hu et al. (2007), possui uma energia de ativação aparente de $244 \mathrm{~kJ} / \mathrm{mol}$ e fucoidan (carboidrato presente na alga parda) com $247 \mathrm{~kJ} / \mathrm{mol}$ (ANASTASAKIS et al., 2011), a microalga de estudo apresentou um valor inferior. Considerando que valores mais altos associados a energia de ativação podem ser relacionados a uma taxa de reação mais lenta, uma vez que este parâmetro faz parte de um expoente negativo no equacionamento matemático da taxa, este é um indício de que o processamento da CV pode ser mais rápido do que das biomassas baseadas na celulose. Porém, como existem outros parâmetros para a determinação da cinética de reação, esta avaliação não é absoluta. 


\section{CONCLUSÕES}

A microalga de estudo, Chlorella vulgaris, foi pirolisada em um largo range de temperaturas, compreendidas entre 500 e $900^{\circ} \mathrm{C}$. A maior parte dos estudos de pirólise apresentados na literatura avaliam os produtos obtidos a partir da reação entre 350 e $500^{\circ} \mathrm{C}$, de tal forma que esse estudo permite avaliar o comportamento dos produtos obtidos para reações conduzidas em temperaturas superiores a $500^{\circ} \mathrm{C}$, pouco exploradas até hoje pela literatura. Os compostos voláteis identificados são em sua maioria derivados de proteínas, tal qual o tolueno, fenol, metil fenol (isômeros), indol, $1 \mathrm{H}$-indol-3-metil (isômeros) e compostos pirrólicos. Nota-se, portanto, relevante presença de compostos aromáticos e nitrogenados. A maioria dos compostos identificados na corrente de produtos voláteis está presente em todas as temperaturas de reação estudadas. Vários compostos apresentados pela literatura para reação ocorrendo em torno de $500{ }^{\circ} \mathrm{C}$ foram observados dentre os produtos volatilizados em temperaturas superiores, inclusive a $900^{\circ} \mathrm{C}$. Entretanto, a área do pico relativo a compostos com menor tempo de retenção apresentou aumento significativo com o aumento de temperatura, enquanto compostos com maior tempo de retenção, que normalmente estão associados a substâncias de menor volatilidade, apresentaram uma diminuição na área do pico conforme a temperatura de reação aumenta. Assim sendo, pirólise a temperaturas próximas a $900{ }^{\circ} \mathrm{C}$ pode favorecer a produção de compostos de maior volatilidade, como, por exemplo, o tolueno.

Em sua maioria, os estudos relacionados a cinética de pirólise apresentam como resultado apenas a energia de ativação como parâmetro cinético determinado. Neste estudo, os três principais parâmetros cinéticos (energia de ativação, ordem de reação e fator pré-exponencial) para a reação de pirólise da microalga foram determinados por três modelos matemáticos baseados na derivação da curva de termogravimetria, os métodos K-A-S, Osawa e Freeman-Carroll adaptado. Os valores médios associados às energias de ativação foram de 206, 205 e $65 \mathrm{~kJ} / \mathrm{mol}$, respectivamente. A ordem de reação para os dois primeiros modelos foi 10 , e variou entre segunda e terceira ordem quando determinada pelo método Freeman-Carroll. Variações relevantes entre os valores dos parâmetros cinéticos obtidos por metodologias diferentes também foram identificadas na literatura. A partir deste estudo ficou 
evidente que, para projeto e otimização de processos, é fundamental utilizar um conjunto de parâmetros cinéticos consistentes obtidos a partir do mesmo método. 


\section{REFERÊNCIAS}

1. AGRAWAL, A.; CHAKRABORTY, S. Kinetic study of pyrolysis and combustion of microalgae Chlorella vulgaris using thermo-gravimetric analysis. Bioresour. Technol., v. 128, p. 72-80, 2013.

2. ANAND, V.; SUNJEEV, V.; VINU, R. Catalytic fast pyrolysis of Arthrospira platensis (spirulina) algae using zeolites. J. of Analytical and Applied Pyrolysis, v. 118, p. 298-307, 2016.

3. ANASTASAKIS, K.; ROSS, A. B.; JONES, J. M. Pyrolysis behavior of the main carbohydrates of brown macro-algae. Fuel, v. 90, p. 598-607, 2011.

4. ANDRADE, L. M. Produção de microalgas e caracterização de sua composição proteica e lipídica via espectrometria de massas. Tese de doutorado. USP, São Paulo, 2014.

5. ARAÚJO, A. A. S.; MERCURI, L. P.; SEIXAS, S. R. S.; STORPIRTIS, S.; MATOS, J. R. Determinação de teores de umidade e cinzas de amostras comerciais de guaraná utilizando métodos convencionais e análise térmica. Brazilian J. of Pharmaceut. Sciences, v. 42, p. 269-277, 2006.

6. AREY, J. S.; NELSON, R. K.; XU, L.; REDDY, C. M. Using Comprehensive Two-Dimensional Gas Chromatography Retention Indices to Estimate Environmental Partitioning Properties for a Complete Set of Diesel Fuel Hydrocarbons. Anal. Chem., v. 77, p. 7172-7182, 2005.

7. BABICH, I. V.; VAN DER HULST, M.; LEFFERTS, L.; MOULIJN, J. A.; O'CONNOR, P.; SESHAN, K. Catalytic pyrolysis of microalgae to high-quality liquid bio-fuels. Biomass and Bioenergy, v. 35, p. 3199-3207, 2011.

8. BARUPAL, D.; KIND, T.; KOTHARI, S.; LEE, D.; FIEHN, O. Hydrocarbon phenotyping of algal species using pyrolysis-gas chromatography mass spectrometry. BMC Biotechnology, v. 10, p. 40, 2010.

9. BECKER, E. W. Micro-algae as a source of protein. Biotech. Advances, v. 25, p. 207-210, 2007.

10.BROWN, M. R. The amino-acid and sugar composition of 16 species of microalgae used in mariculture. J. Exp. Mar. Biol. Ecol., v. 145, p. 79-99, 1991. 
11. CASONI, A. I.; ZUNINO, J.; PICCOLO, M. C.; VOLPE, M. A. Valorization of Rhizoclonium sp. algae via pyrolysis and catalytic pyrolysis. Bioresour. Technol., v. 216, p. 302-307, 2016.

12. CHEN, C.; MA, X.; LIU, K. Thermogravimetric analysis of microalgae combustion under different oxygen supply concentrations. Appl. Energy, v. 88 p. 3189-3196, 2011.

13. CONTI, R.; PEZZOLESI, L.; PISTOCCHI, R.; TORRI, C.; MASSOLI, P.; FABBRI, D.; Photobioreactor cultivation and catalytic pyrolysis of the microalgae Desmodesmus communis (Chlorophyceae) for hydrocarbons production by HZSM-5 zeolite cracking. Bioresource Technology, v. 222, p. 148155, 2016.

14. CRECESB - CENTRO DE REFERÊNCIA DAS ENERGIAS SOLAR E EÓLICA SÉRGIO BRITO. Energia Solar Fotovoltaica. Disponível em: <http://cresesb.cepel.br/index.php?section=com_content\&cid=321>. Acesso em: 15 jul. 2014.

15. CUNHA, T. H. C. S.; VIDAL, I. C. A; TEIXEIRA, C. C.; SILVA, R. N. A.; FERREIRA, W. B.; FERNANDES, M. S. M. Estudo do cultivo heterotrófico de microalgas com potencial para produção de biodiesel. Anais do Encontro Nacional de Educação, Ciência e Tecnologia UEPB, v. 1, 2012.

16. CZERNIK, S.; BRIDGWATER, A. V. Overview of Applications of Biomass Fast Pyrolysis Oil. Energy Fuels, v. 18, p. 590-598, 2004.

17. DA SILVEIRA, C. A. Modelagem e simulação de reator de cultivo de microalgas tipo "open pond". Tese de doutorado. USP, São Paulo, 2015.

18.DE WAART, J.; TAS, A. C.; LA VOS, G. F.; VAN DER GREEF, J. Characterization of algae by pyrolysis-direct chemical ionization (tandem) mass spectrometry. J. of Anal. and Appl. Pyrolysis, v. 18, p. 245-260, 1991.

19.DU, Z.; HU, B.; MA, X.; CHENG, Y.; LIU, Y.; LIN, X.; WAN, Y.; LEI, H.; CHEN, P.; RUAN, R. Catalytic pyrolysis of microalgae and their three major components: Carbohydrates, proteins, and lipids. Bioresource Technology, v. 130, p.777-782, 2013.

20.DUNNIVANT, F. M.; GINSBACH, J. W. Gas chromatography, liquid chromatography, capillary electrophoresis - Mass spectrometry. Walla Walla: Whitman College, 2011. 
21. EBAH. Energia Eólica. Disponível em: <http://www.ebah.com.br/content/ABAAAgxQUAB/energia-eolica>. Acesso em: 02 ago. 2015.

22. ELLIOTT, D. C.; SCHIEFELBEIN, G. F. Liquid hydrocarbon fuels from biomass. Amer. Chem. Soc., Div. Fuel Chem. Preprints, v. 34, p. 1160-1166, 1989.

23. FATIH DERMIBAS, M., Biofuels from algae for sustainable development. Appl. Energy, v. 88, p. 3473-3480, 2011.

24.FIGUEIRA, C. E.; MOREIRA JR., P. F.; GIUDICI, R. Thermogravimetric analysis of the gasification of microalgae Chlorella vulgaris. Bioresour. Technol., v. 198, p. $717-724,2015$.

25. FREEMAN, E. S.; CARROLL, B. The application of thermoanalytical techniques to reaction kinetics. The thermogravimetric evaluation of the kinetics of decomposition of Calcium Oxalate Monohydrate. J. Phys. Chem., v. 62, p. 394397, 1958.

26. GAI, C.; ZHANG, Y.; CHEN, W.T.; ZHANG, P.; DONG, Y. Thermogravimetric and kinetic analysis of thermal decomposition characteristics of low-lipid microalgae. Bioresour. Technol., v. 150, p. 139-148, 2013.

27. HASHIMOTO, K; HASEGAWA, I; HAYASHI, J; MAE, K. Correlations of kinetic parameters in biomass pyrolysis with solid residue yield and lignin content. Fuel, v. 90, p. 104-112, 2011.

28. HU, M.; CHEN, Z.; GUO, D.; LIU, C.; XIAO, B.; HU, Z.; LIU, S. Thermogravimetric study on pyrolysis kinetics of Chlorella pyrenoidosa and bloom-forming cyanobacteria. Bioresour. Technol., v. 177, p. 41-50, 2015.

29. HU, S.; JESS, A.; XU, M. Kinetic study of Chinese Biomass slow pyrolysis: Comparison of different kinetic models. Fuel, v. 86, p. 2778-2788, 2007.

30. HUBER, G. W.; IBORRA, S.; CORMA, A. Synthesis of Transportation Fuels from Biomass: Chemistry, Catalysts, and Engineering. Chem. Rev., v. 106, p. 4044-4098, 2006.

31. IPCC, 2011: IPCC Special Report on Renewable Energy Sources and Climate Change Mitigation. Prepared by Working Group III of the Intergovernmental Panel on Climate Change [O. Edenhofer, R. Pichs-Madruga, Y. Sokona, K. Seyboth, P. Matschoss, S. Kadner, T. Zwickel, P. Eickemeier, G. Hansen, S. 
Schlömer, C. von Stechow (eds)]. Cambridge University Press, Cambridge, United Kingdom and New York, NY, USA, 1075 pp.

32. KASSIM, M.A.; KIRTANIA, K.; DE LA CRUZ, D.; CURA, N.; SRIVATSA, S.C.; BHATTACHARYA, S. Thermogravimetric analysis and kinetic characterization of lipid-extracted Tetraselmis suecica and Chlorella sp. Algal Res., v. 6, p. 3945, 2014.

33. KEBELMANN, K. Intermediate pyrolysis studies of aquatic biomass and potential applications in the BtVB-process. Doctoral Theses, Aston University, Birmingham, 2013.

34. KEBELMANN, K., HORNUNG, A., KARSTEN, U., GRIFFITHS, G. Intermediate pyrolysis and product identification by TGA and Py-GC/MS of green microalgae and their extracted protein and lipid components. Biomass and Bioenergy, v. 49, p. 38-48, 2013.

35. KIRTANIA, K.; BHATTACHARYA, S. Application of the distributed activation energy model to the kinetic study of pyrolysis of the fresh water algae Chlorococcum humicola. Bioresour. Technol., v. 107, p. 476-481, 2012.

36. KLASS, D. L. Biomass for renewable energy, fuels and chemicals. San Diego: Academic Press, 1998.

37. LANÇAS, F. M.; MCNAIR, H. M. Cromatografia em fase gasosa - 1. Teoria elementar. Química Nova, v. 6, p. 6-13, 1983.

38. LEE, D. H.; YANG, H.; YAN, R.; LIANG, D. T. Prediction of gaseous products from biomass pyrolysis through combined kinetic and thermodynamic simulations. Fuel, v. 86, p. 410-417, 2007.

39. LI, D.; CHEN, L.; ZHANG, X.; YE, N.; XING, F. Pyrolytic characteristics and kinetic studies of three kinds of red algae. Biomass Bioenergy, v. 35, p. 1765$1772,2011$.

40.LIU, J.; PAN, Y.; YAO, C.; WANG, H.; CAO, X.; XUE, S. Determination of ash content and concomitant acquisition of cell compositions in microalgae via thermogravimetric (TG) analysis. Algal Research, v. 12, p. 149-155, 2015.

41. MAHER, K. D.; BRESSLER, D. C. Pyrolysis of triglyceride materials for the production of renewable fuels and chemicals. Bioresour. Technol., v. 98, p. 2351-2368, 2007. 
42. MANSARAY, K. G.; GHALY, A. E. Thermal degradation of rice husks in nitrogen atmosphere. Biores. Technol., v. 65, p. 13-20, 1998.

43. MIAO, X.; WU, Q., High yield bio-oil production from fast pyrolysis by metabolic controlling of Chlorella protothecoides. J. Biotechnol., v. 110, p. 85-93, 2004.

44. MIAO, X.; WU, Q.; YANG, C., Fast pyrolysis of microalgae to produce renewable fuels. J. Anal. Appl. Pyrol., v. 71, p. 855-863, 2004.

45. MME - Ministério de Minas e Energia. Boletim de Energia Solar - Brasil e Mundo - ano ref. 2015, 2016.

46. MOHAN, D.; PITTMAN, C. U.; STEELE, P. H. Pyrolysis of Wood/Biomass for Bio-oil: A Critical Review. Energy Fuels, v. 20, p. 848-889, 2006.

47. MUHLEN, C. V. Índices de retenção em cromatografia gasosa bidimensional abrangente. Scientia chromatographica, v. 1, n 3, p. 21-29, 2009.

48. NICHOLS, P.; HOLMAN, R. Pyrolysis of saturated triglycerides. Lipids, v. 7, p. 773-779, 1972.

49. OSAWA, T. A new method of analyzing thermogravimetric data. Chem. Soc. Jpn., v. 38 (11), p. 1881-1886, 1965.

50.PANWAR, N.L.; KAUSHIK, S.C.; KOTHARI, S. Role of renewable energy sources in environmental protection: A review. Renewable and Sustainable Energy Reviews, v. 15, p. 1513-1524, 2011.

51.PATWARDHAN, P. R.; SATRIO, J. A.; BROWN, R. C.; SHANKS, B. L. Product Distribution from Fast Pyrolysis of Glucose-based Carbohydrates. J. Anal. Appl. Pyrol., v. 86, p. 323-330, 2009.

52.PENG, W.; WU, Q.; TU, P., Effects of temperature and holding time on production of renewable fuels from pyrolysis of Chlorella protothecoides. J. Appl. Phycol., v. 12, p.147-152, 2000.

53.PENG, W; QINGYU, W; PINGGUAN, T; NANMING, Z. Pyrolytic characteristics of microalgae as renewable energy source determined by thermogravimetric analysis. Bioresource Technology, v. 80, p. 1-7, 2001.

54.PESSOA, J. C. Cromatografia - Técnicas experimentais. Química - Boletim da Sociedade Portuguesa de Química, v. 50, p. 57-62, 1993.

55.PHUKAN, M. M.; CHUTIA, S. R.; KONWAR, K. B.; KATAKI, R. Microalgae Chlorella as a potential bio-energy feedstock. Applied Energy, v. 88, p. 33073312, 2011. 
56.RAHEEM, A.; SIVASANGAR, S.; AZLINA, W.A.K.G. W.; YAP, Y.H. T.; DANQUAH, M. K.; HARUN, R. Thermogravimetric study of Chlorella vulgaris for syngas production. Algal Research, v. 12, p. 52-59, 2015.

57. RATCLIFF, M. A.; MEDLEY, E. E.; SIMMONDS, P. G. Pyrolysis of amino acids. Mechanistic considerations. J. Org. Chem., v. 39, p. 1481-1490, 1974.

58. RIZZO, A. M.; PRUSSI, M.; BETTUCCI, L.; LIBELLI, I. M.; CHIARAMONTI, D. Characterization of microalga Chlorella as a fuel and its thermogravimetric behavior. Applied Energy, v. 102, p. 24-31, 2013.

59. ROSS, A. B.; ANASTASAKIS, K.; KUBACKI, M.; JONES, J. M. Investigation of the pyrolysis behavior of brown algae before and after pre-treatment using $P Y$ GC/MS and TGA. J. of Anal. and Appl. Pyrolysis, v. 85, p. 3-10, 2009.

60.SAIZ-JIMENEZ, C.; DE LEEUW, J. F. Lignin Pyrolysis Products: Their Structures and Their Significance as Biomarkers. Adv. Org. Geochem., v. 10, p. 869-876, 1985.

61.SANCHEZ-SILVA, L.; LÓPEZ-GONZÁLEZ, D.; VILLASEÑOR, J.; SANCHEZ, P.; VALVERDE, J.L. Thermogravimetric-mass spectrometric analysis of lignocellulosic and marine biomass pyrolysis. Bioresour. Technol., v. 109, p. 163-172, 2012.

62. SCHULTEN, H. R.; GLEIXNER, G. Analytical pyrolysis of humic substances and dissolved organic matter in aquatic systems: structure and origin. Water Research, v. 33, p. 2489-2498, 1999.

63. SHUPING, Z.; YULONG, W.; MINGDE, Y.; CHUN, L.; JUNMAO, T. Pyrolysis characteristics and kinetics of the marine microalgae Dunaliella tertiolecta using thermogravimetric analyzer. Bioresour. Technol., v. 101, p. 359-365, 2010.

64. SMITH, W. T.; HARRIS, T. B.; PATTERSON, J. M. Pyrolysis of Soybean Protein and an Amino Acid Mixture Having the Same Amino Acid Composition. J. Agric. Food Chem., v. 22, p. 480-483, 1974.

65. SONOBE, T.; WORASUWANNARAK, N. Kinetic analyses of biomass pyrolysis using the distributed activation energy model. Fuel, v. 87, p. 414-421, 2008.

66.SPOLAORE, P.; JOANNIS-CASSAN, C.; DURAN, E.; ISAMBERT, A. Commercial applications of microalgae. J. of Biosc. And Bioeng., v. 101, p. 8796, 2006. 
67.TAHMASEBI, A.; KASSIM, M.A.; YU, J.; BHATTACHARYA, S. Thermogravimetric study of the combustion of Tetraselmis suecica microalgae and its blend with a Victorian brown coal in $\mathrm{O}_{2} / \mathrm{N}_{2}$ and $\mathrm{O}_{2} / \mathrm{CO}_{2}$ atmospheres. Bioresour. Technol., v. 150, p. 15-27, 2013.

68. THANGALAZHY-GOPAKUMAR, S.; ADHIKARI, S.; CHATTANATHAN, S. A.; GUPTA, R. B. Catalytic pyrolysis of green algae for hydrocarbon production using H+ZSM-5catalyst. Bioresource Technology, v. 118, p.150-157, 2012.

69.WANG, K; BROWN, R.C. Catalytic pyrolysis of microalgae for production of aromatics and ammonia. Green Chem., v. 15, p. 675-681, 2013.

70.WEBER, R. Extractingmathematically exact kinetic parameters from experimental data on combustion and pyrolysis of solid fuels. J Energy Inst, v. 81, p. 226-33, 2008.

71.WEC - WORLD ENERGY COUNCIL. World Energy Resources: 2013 Survey. 2013.

72.WILLIAMS, P. T.; BESLER, S. The pyrolysis of rice husks in a thermogravimetric analyzer and static batch reactor. Fuel, v. 72, p. 151-159, 1993.

73.WU, Q.; ZHANG, B.; GRANT, N. High yield of hydrocarbon gases resulting from pyrolysis of yellow heterotrophic and bacterially degraded Chlorella protothecoides. J. Appl. Phycol., v. 8, p. 181-184, 1996.

74. YAO, F., WU, Q., LEI, Y., GUO, W., XU, Y. Thermal decomposition kinetics of natural fibers: Activation energy with dynamic thermogravimetric analysis. Polym. Degrad. Stab., v. 93, p. 90-98, 2007. 


\section{APÊNDICE A - Análise detalhada dos espectros de massa com maior nível de correlação para reações entre 600 e $900^{\circ} \mathrm{C}$}

\section{A-1 Reação a $600{ }^{\circ} \mathrm{C}$}

Assim como na análise dos produtos obtidos através da reação a $500^{\circ} \mathrm{C}$, a amostra com os produtos obtidos a $600^{\circ} \mathrm{C}$, teve como resultado para um tempo de retenção de aproximadamente 8,2 minutos, cujo espectro de massa está apresentado na Figura 37, um composto que apresenta picos relevantes para fragmentos $\mathrm{m} / \mathrm{z} 91$ e 65 , os quais são característicos de compostos que apresentam anel aromático.

Figura 37 - Espectro pesquisado ${ }^{(a)} \times$ Espectro catalogado(b) - Tempos de retenção $8,237^{(1)}$ e $8,333^{(2)} \mathrm{min}$ - Pirólise a $600{ }^{\circ} \mathrm{C}$

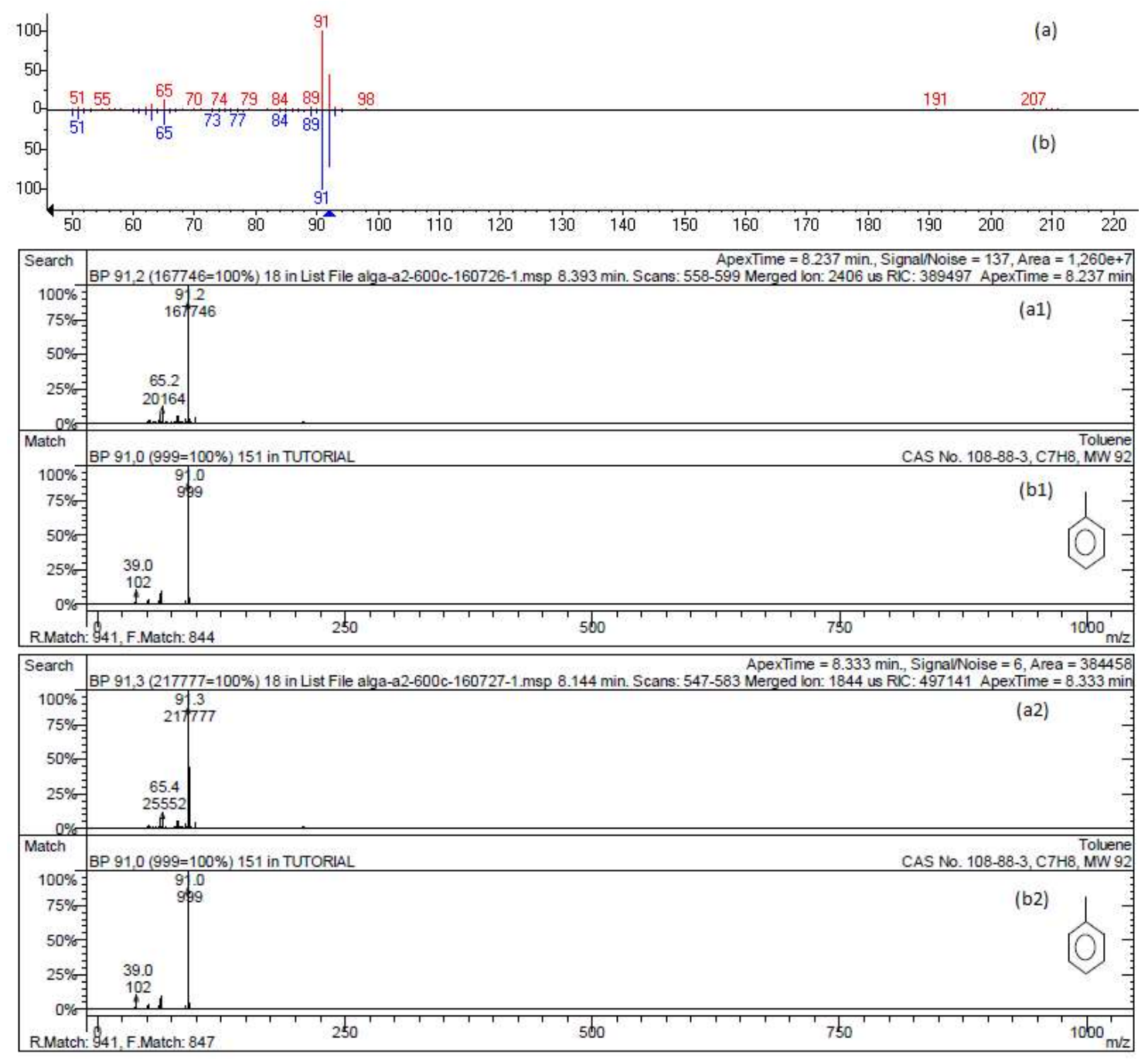


O composto com tempo de retenção próximo a 12 minutos (Figura 38) apresenta fragmentos de massa relevantes em m/z 91 e 65, caracterizando que possui um anel aromático. A diferença entre as massas m/z 106 e 91, resulta em um fragmento $\mathrm{m} / \mathrm{z}$ 15 , que pode ser associado a perda de um radical ${ }^{\circ} \mathrm{CH}_{3}$, a diferença entre os fragmentos m/z 91 e 77 e os fragmentos m/z 79 e 65 resulta em m/z 14, que frequentemente está associado a perda de $\mathrm{CH}_{2}$ em uma cadeia alifática, o que mostra que o anel aromático possui ramificações.

Figura 38 - Espectro pesquisado(a) $x$ Espectro catalogado(b) - Tempos de retenção $12,391^{(1)}$ e $11,943^{(2)} \mathrm{min}$ - Pirólise a $600^{\circ} \mathrm{C}$

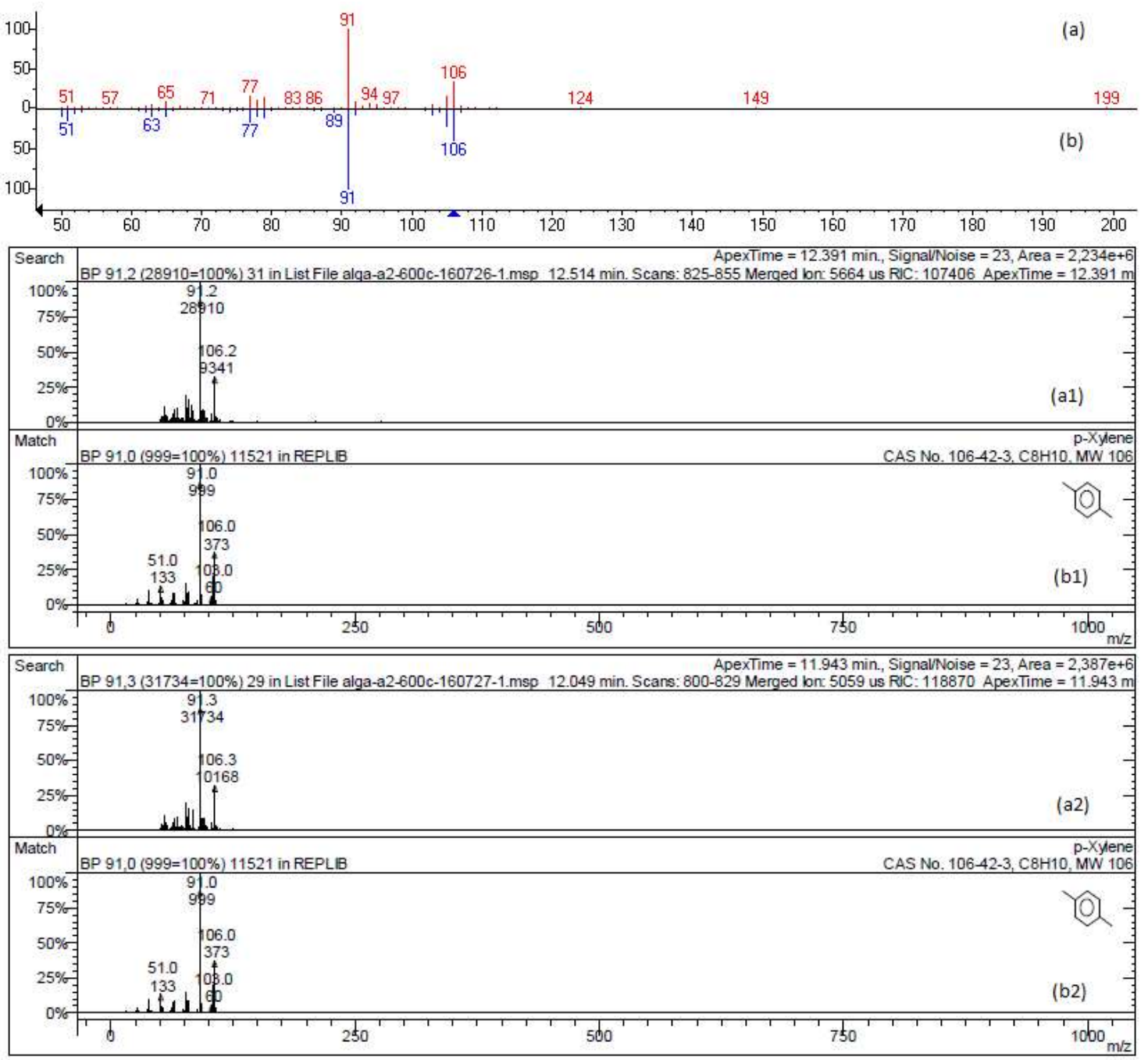


A Figura 39 apresenta o composto com tempo de retenção de aproximadamente 17 minutos. A presença de diversos fragmentos de massa maiores do que $\mathrm{m} / \mathrm{z} 82$ pode indicar que o composto pesquisado possui massa molecular superior à do 3-metil-1Hpirrol. Os 5 fragmentos de massa mais abundantes para os dois compostos são $\mathrm{m} / \mathrm{z}$ $80,81,78,53$ e 52 , o que é um indício de que a molécula sugerida é parte do composto pesquisado.

Figura 39 - Espectro pesquisado(a) $x$ Espectro catalogado(b) - Tempos de retenção $17,265^{(1)} e$ $16,759^{(2)} \mathrm{min}$ - Pirólise a $600{ }^{\circ} \mathrm{C}$

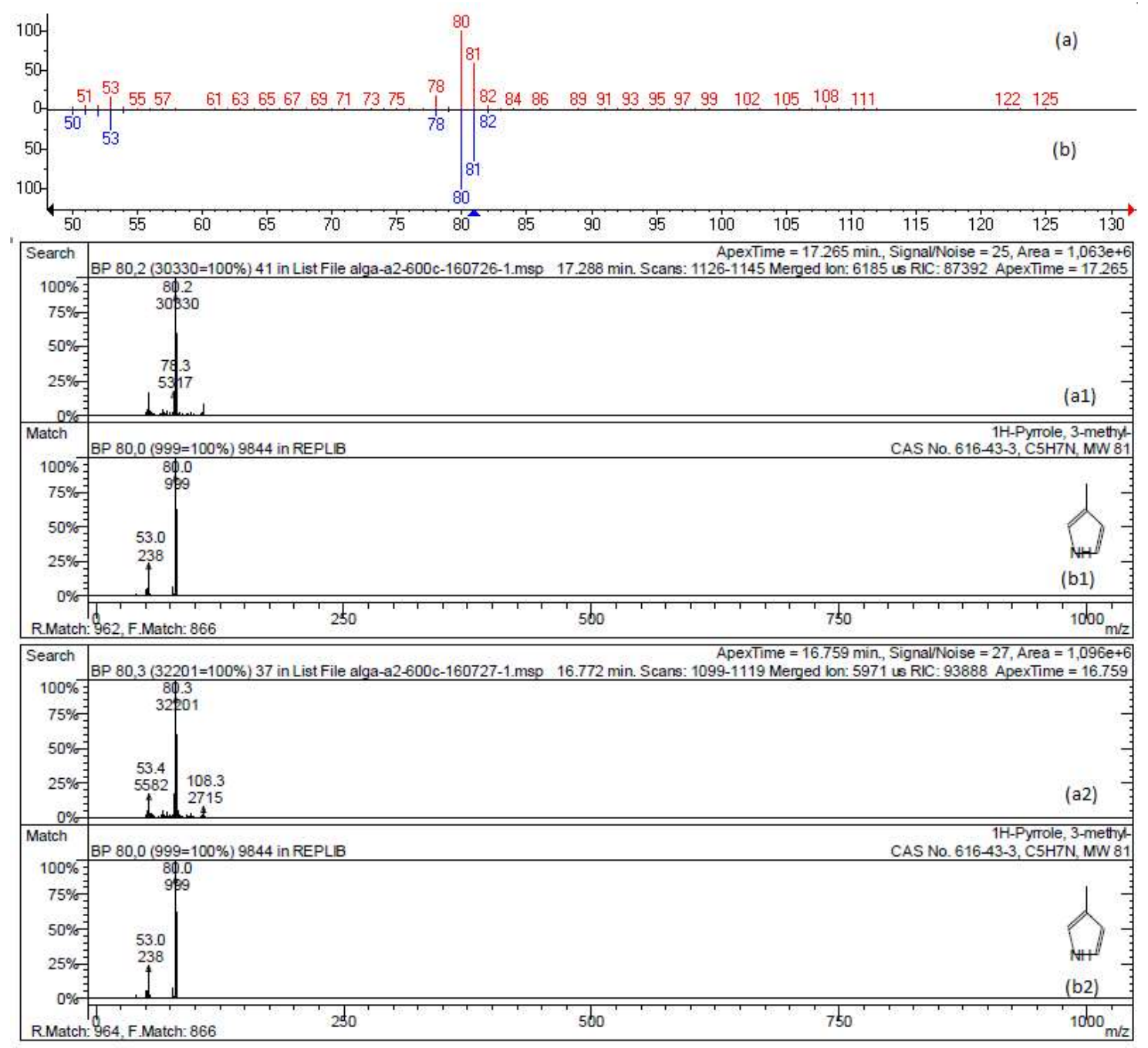

O composto pesquisado presente na Figura 40 apresenta o pico m/z 58 como o segundo mais abundante, este é um fragmento de massa característico de aminas alifáticas, indicando a presença do grupo funcional amina neste composto. O 
composto sugerido no espectro "b2" sugere a presença de um grupo funcional de um éter, porém não foi possível identificar no espectro da substância proveniente nenhum pico ou fragmento de massa característico de um éter, indicando que é mais provável o composto pesquisado ser apenas uma amina alifática.

Figura 40 - Espectro pesquisado(a) $x$ Espectro catalogado(b) - Tempos de retenção $31,882^{(1)} e$ $31,563^{(2)} \mathrm{min}$ - Pirólise a $600^{\circ} \mathrm{C}$

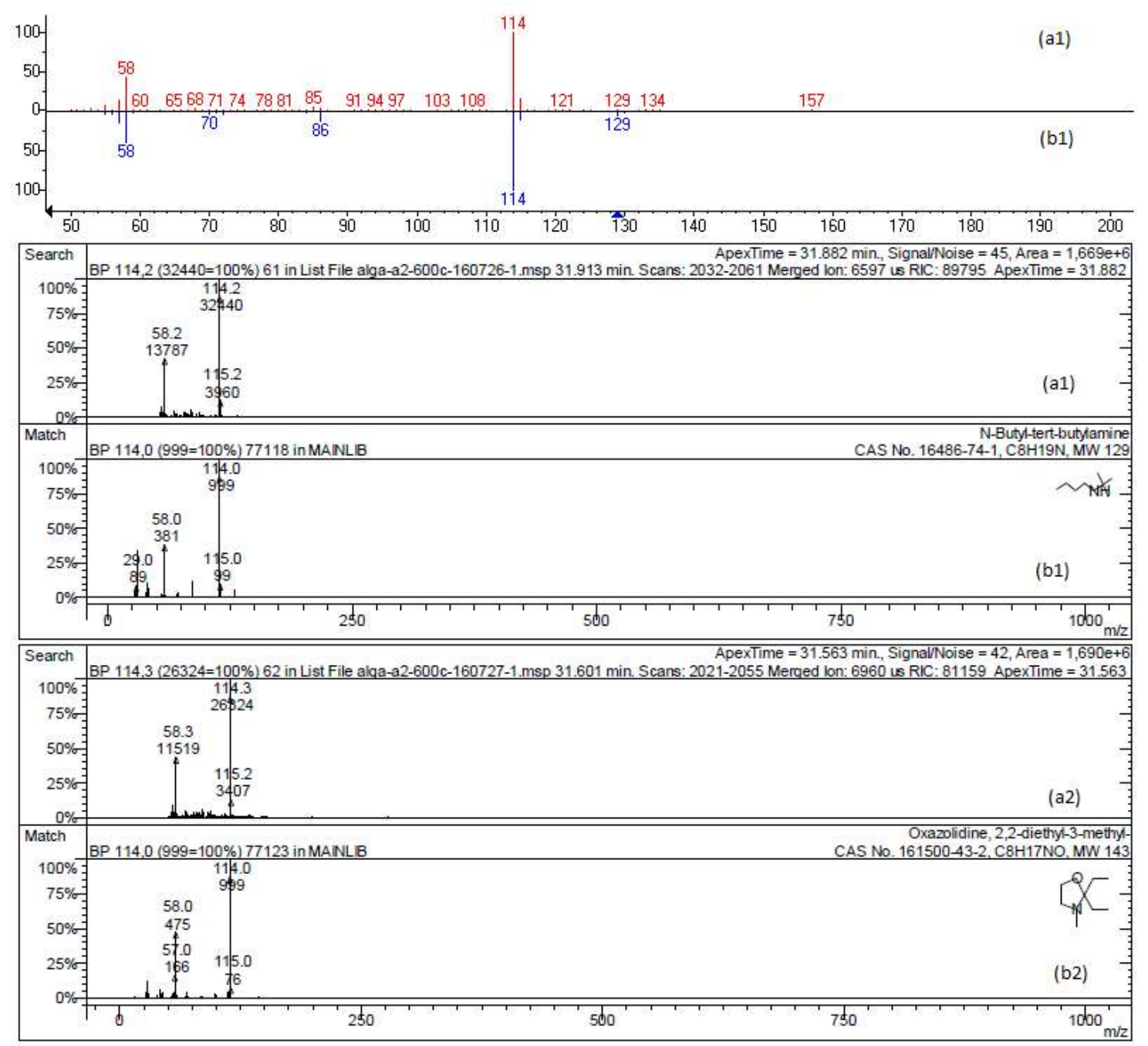

A diferença entre os fragmentos m/z 112 e 83, presentes no espectro "a" da Figura 41 , que resulta em um fragmento $\mathrm{m} / \mathrm{z} 29$ pode ser associado a perda de um radical - $\mathrm{CHO}$, o qual caracterizaria um aldeído, assim como a diferença entre os fragmentos 
$\mathrm{m} / \mathrm{z} 112$ e 69 resultam em um fragmento $\mathrm{m} / \mathrm{z} 43$, o qual pode estar associado a um radical ${ }^{\circ} \mathrm{CH}_{3} \mathrm{CO}$, caracterizando o grupo funcional de uma cetona. Não foram apresentados quebras ou picos que caracterizem o grupo funcional de um álcool, porém a substância pesquisada provavelmente é um composto oxigenado com o grupo cetona.

Figura 41 - Espectro pesquisado(a) $x$ Espectro catalogado(b) - Tempos de retenção $34,486^{(1)}$ e $34,226^{(2)} \mathrm{min}$ - Pirólise a $600{ }^{\circ} \mathrm{C}$

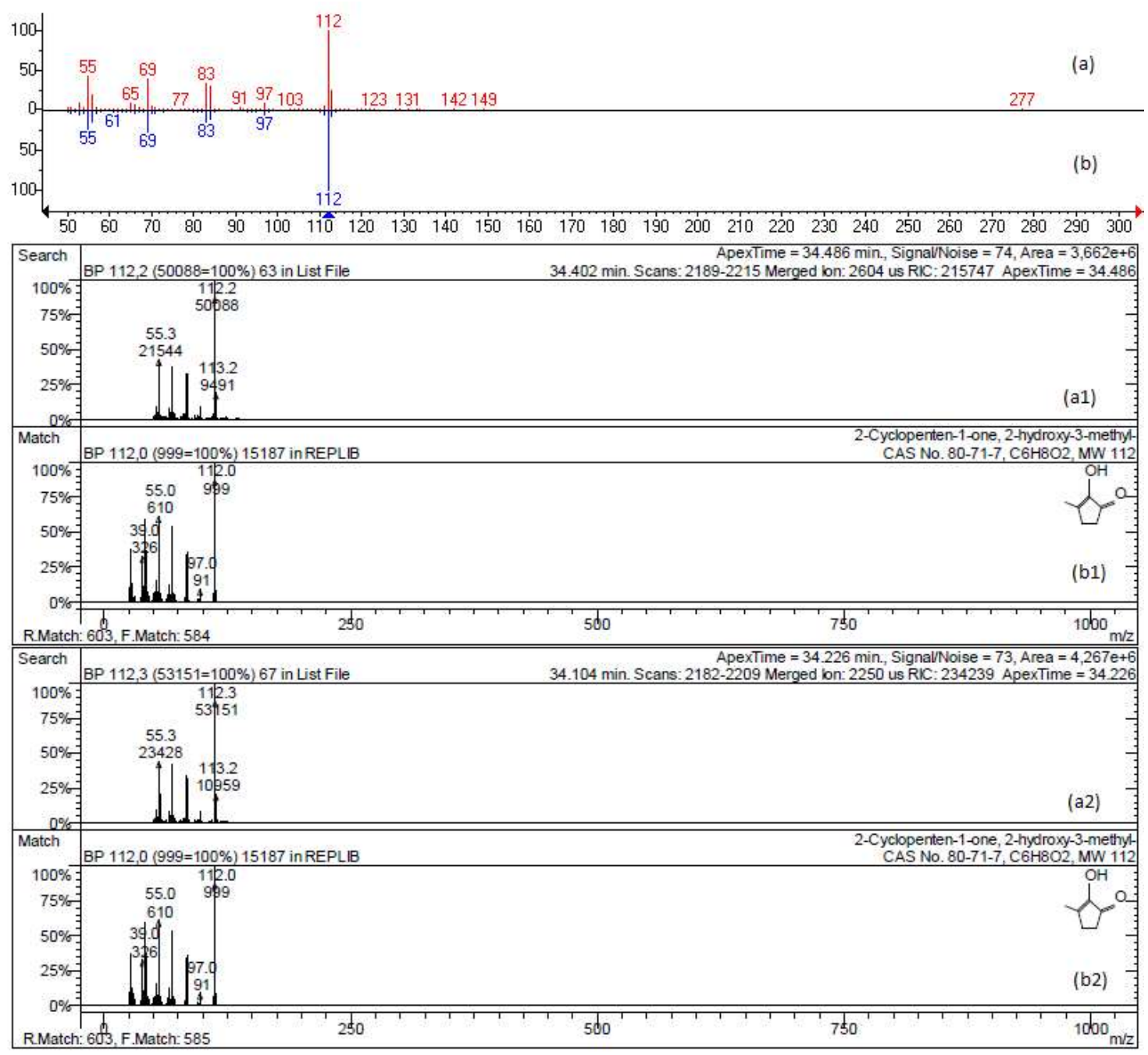

O espectro, apresentado na Figura 42, possui como picos principais os fragmentos $\mathrm{m} / \mathrm{z}$ 130, 103 e 77 . A diferença entre os fragmentos $\mathrm{m} / \mathrm{z} 130$ e 103, e entre os fragmentos m/z 103 e 77 resultam respectivamente em fragmentos $\mathrm{m} / \mathrm{z} 27$ e 26 , o quais estão relacionados a perda de uma molécula neutra $\mathrm{HCN}$ e de um radical ${ }^{\circ} \mathrm{CN}$, caracterizando esta substância como um composto nitrogenado. A coincidência entre 
os quatro fragmentos com picos mais abundantes, m/z 130, 131, 77 e 103 na mesma ordem, indica que o 3-metil-1H-indol ou um dos seus isômeros de posição é parte ou é o composto pesquisado.

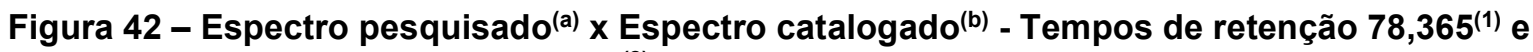
$78,336^{(2)} \mathrm{min}$ - Pirólise a $600{ }^{\circ} \mathrm{C}$

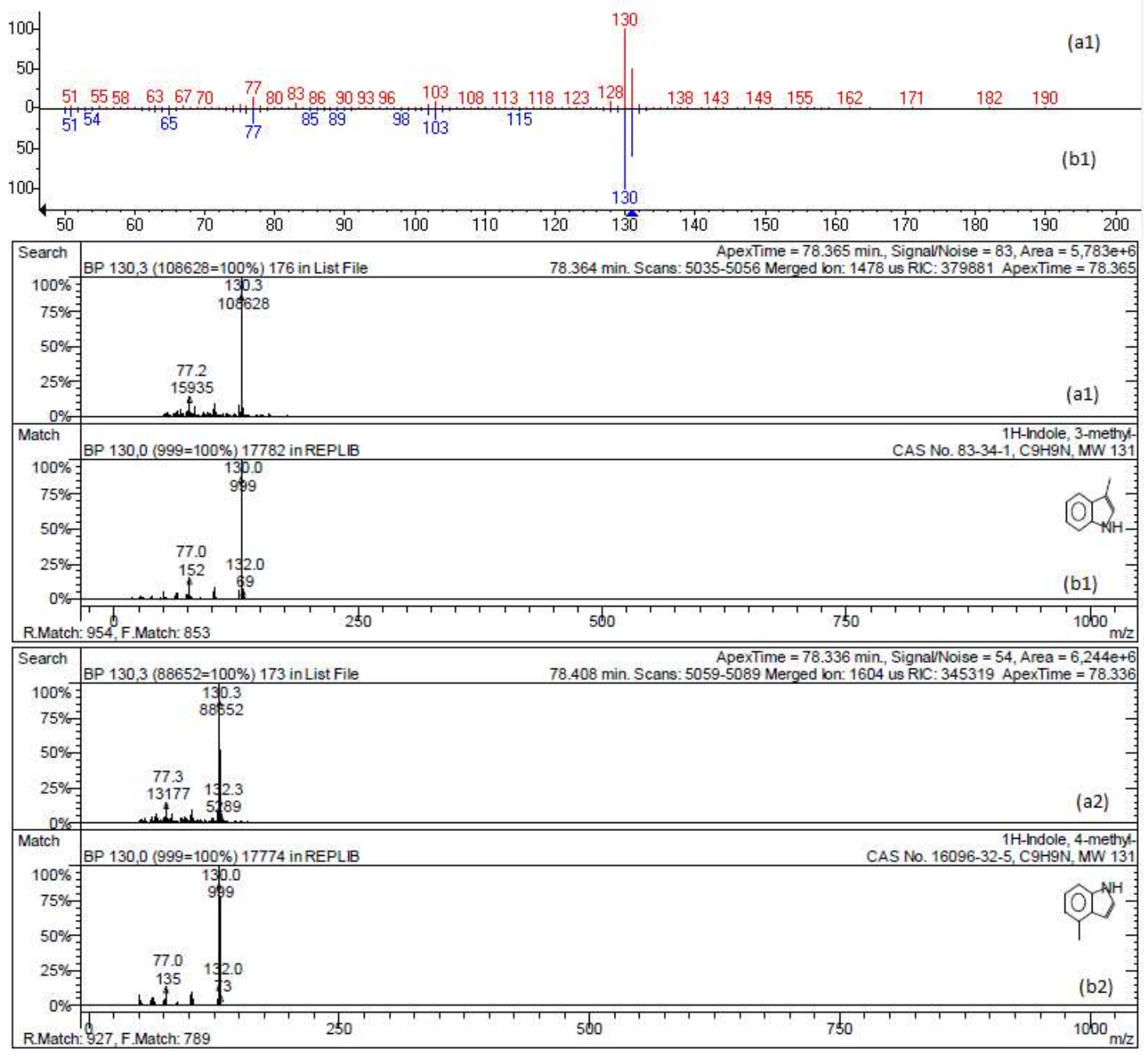




\section{A-2 Reação a $700^{\circ} \mathrm{C}$}

A presença dos picos m/z 91 e 65 como os mais abundantes do espectro presente na Figura 43 identifica este composto como possuindo um anel aromático e a presença de fragmentos maiores do que $\mathrm{m} / \mathrm{z} 92$ indicam que o composto pesquisado pode possuir estrutura maior do que o tolueno.

Figura 43 - Espectro pesquisado ${ }^{(a)} \times$ Espectro catalogado(b) - Tempos de retenção $8,050^{(1)} e$ $8,166^{(2)} \mathrm{min}$ - Pirólise a $700{ }^{\circ} \mathrm{C}$

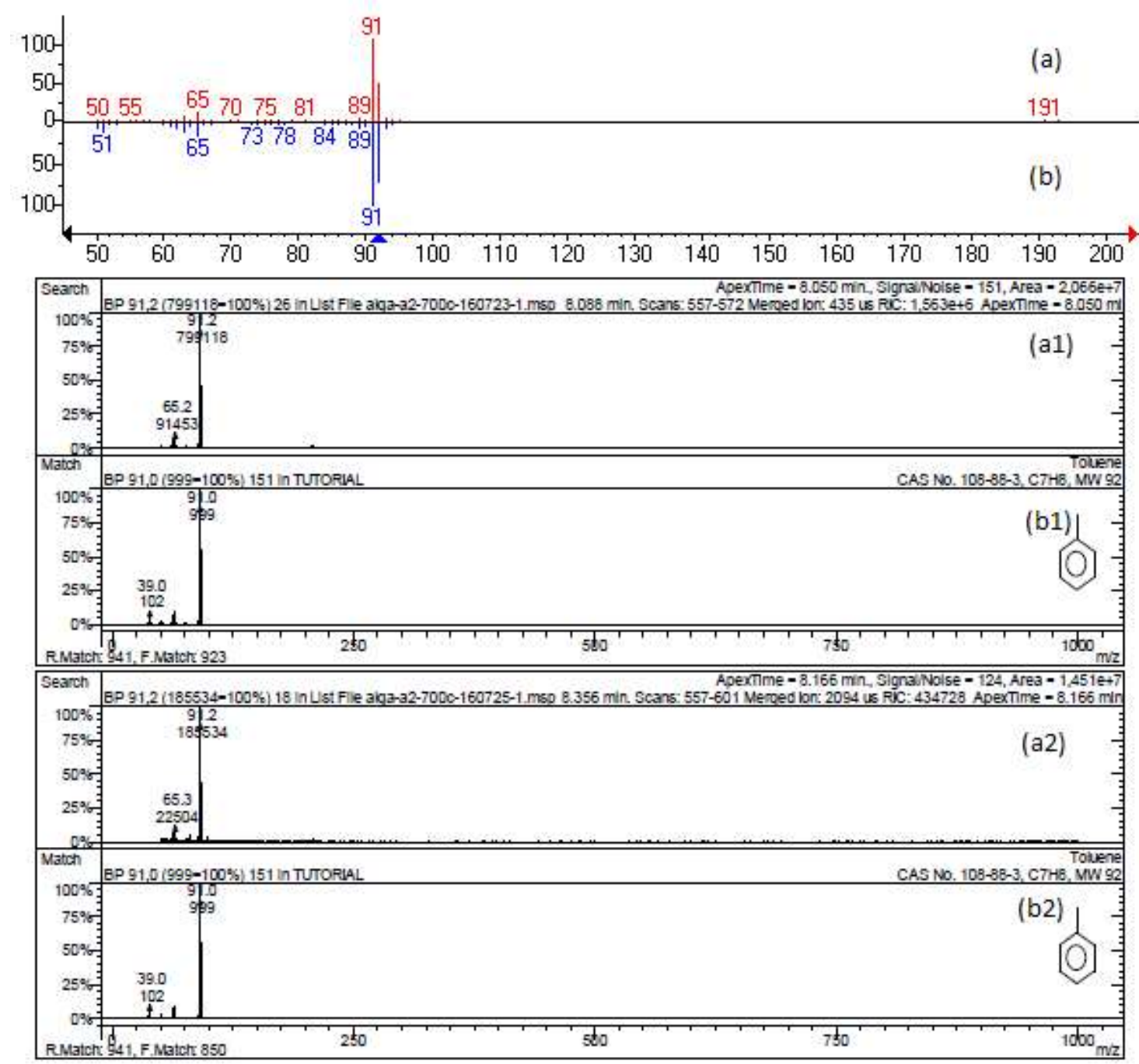


O espectro de massa obtido com um tempo de retenção de aproximadamente 12 minutos pode ser visualizado através da Figura 44. Ele apresenta fragmentos de massa relevantes em m/z 91 e 65, caracterizando que possui um anel aromático. Este espectro apresenta a diferença entre as massas m/z 106 e 91, que resulta em um fragmento $\mathrm{m} / \mathrm{z} 15$ e pode ser associado a perda de um radical ${ }^{\circ} \mathrm{CH}_{3}$, assim como a diferença entre os fragmentos m/z 91 e 77 e os fragmentos m/z 79 e 65 resulta em $\mathrm{m} / \mathrm{z} 14$, que frequentemente está associado a perda de $\mathrm{CH}_{2}$ em uma cadeia alifática, o que mostra que o anel aromático possui ramificações.

Figura 44 - Espectro pesquisado(a) $x$ Espectro catalogado(b) - Tempos de retenção $12,122^{(1)}$ e $12,334^{(2)} \mathrm{min}$ - Pirólise a $700^{\circ} \mathrm{C}$

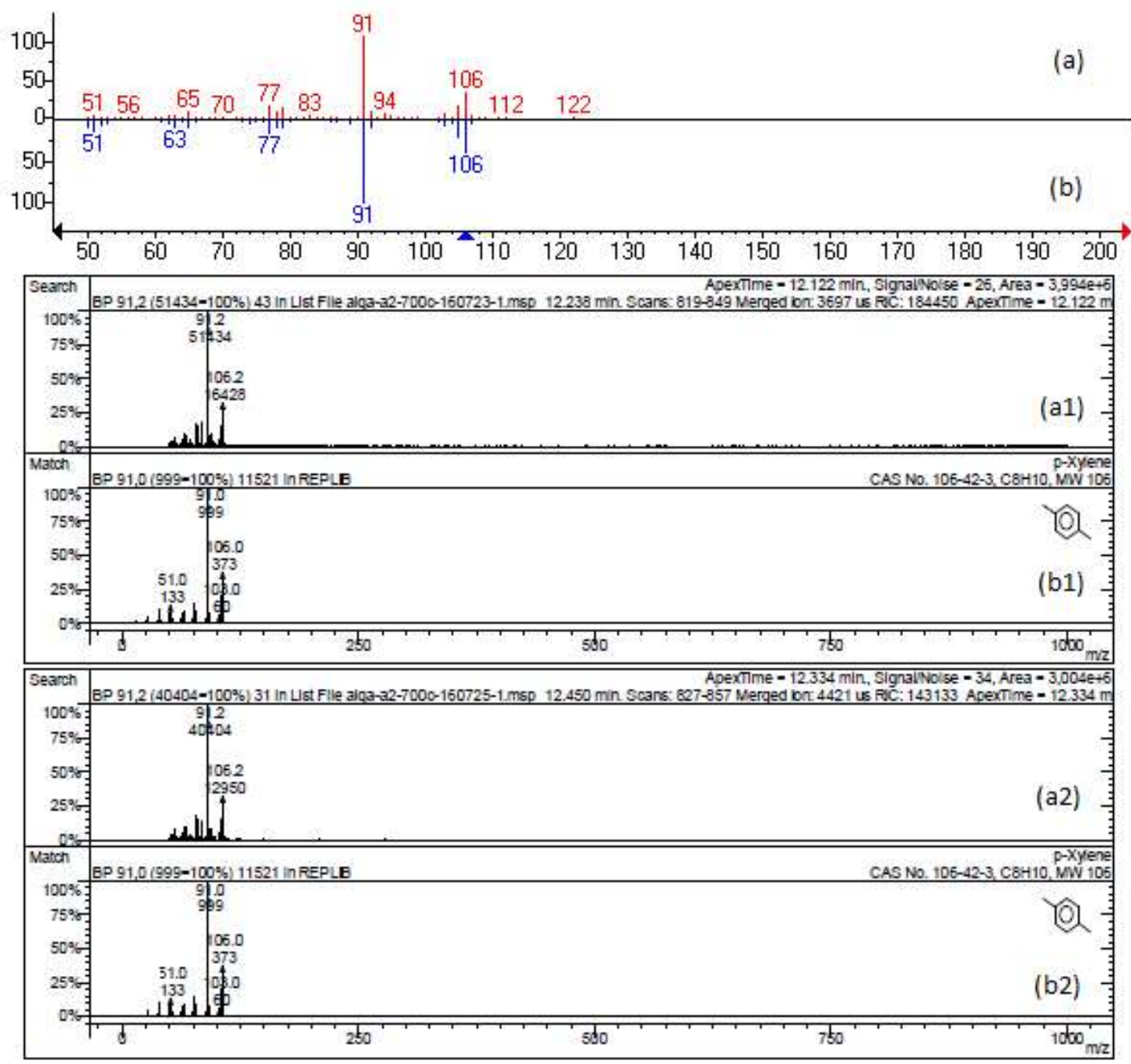


No espectro apresentado na Figura 45, relativo ao tempo de retenção de aproximadamente 17 minutos, podemos verificar que os 5 fragmentos de massa mais abundantes para os dois compostos são $\mathrm{m} / \mathrm{z} 80,81,78,53$ e 52, sugerindo-se que se trata de uma amina, provavelmente o 3-metil-pirrol.

Figura 45 - Espectro pesquisado(a) $x$ Espectro catalogado(b) - Tempos de retenção $16,975^{(1)} e$ $17,192^{(2)} \mathrm{min}$ - Pirólise a $700^{\circ} \mathrm{C}$

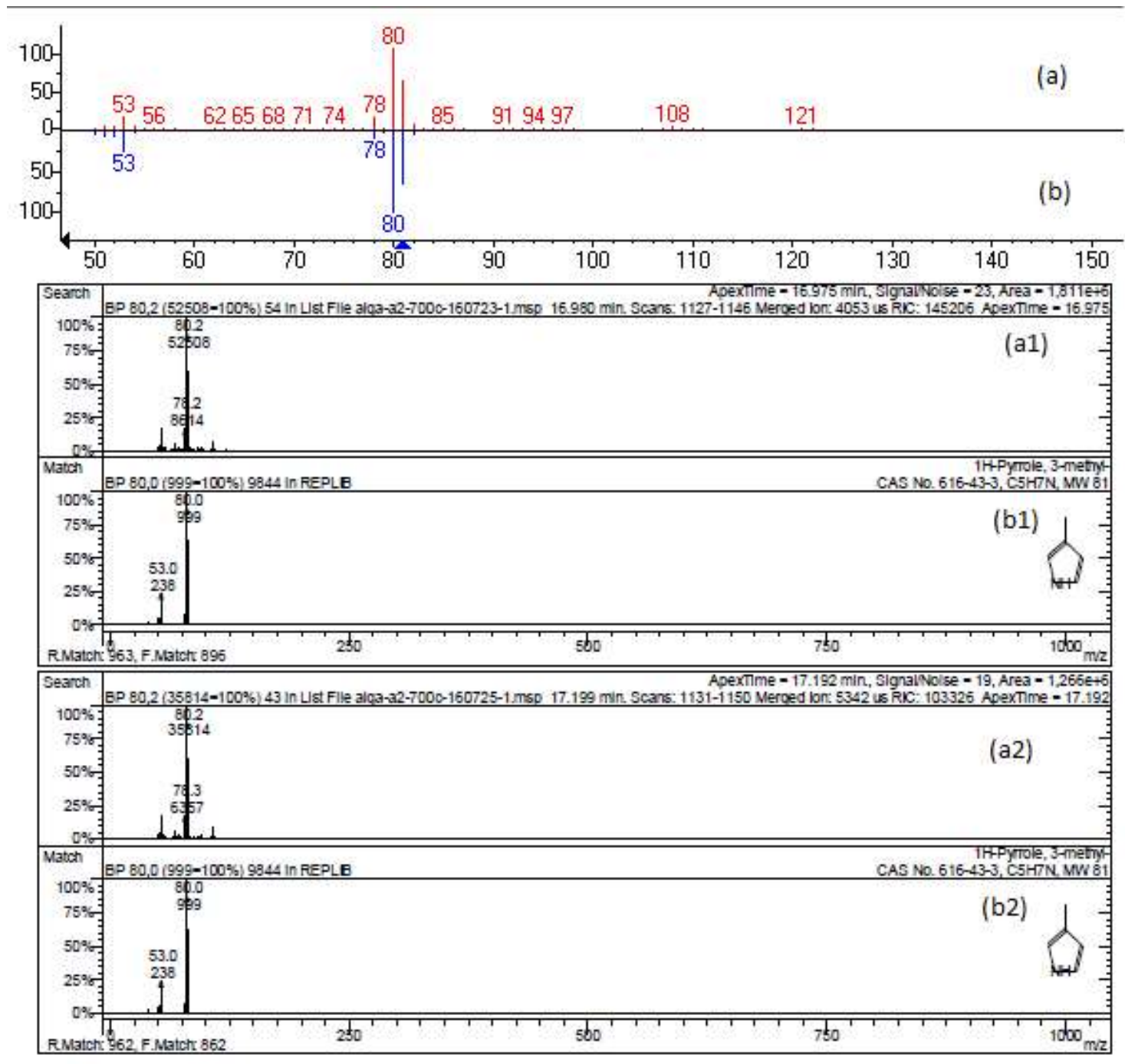

De forma similar, com tempo de retenção de aproximadamente 25 minutos, o espectro apresentado na Figura 46 possui como picos de maior abundância m/z 80, 95, 94, 53 
e 67, os quais coincidem com os picos de maior abundância do composto sugerido como mais provável, indicando que o 2-etil-pirrol, ou um isômero de posição, faz parte da estrutura do composto pesquisado, tratando-se, assim, de uma amina.

Figura 46 - Espectro pesquisado(a) $x$ Espectro catalogado(b) - Tempos de retenção $25,016^{(1)} e$ $25,191^{(2)} \mathrm{min}$ - Pirólise a $700{ }^{\circ} \mathrm{C}$
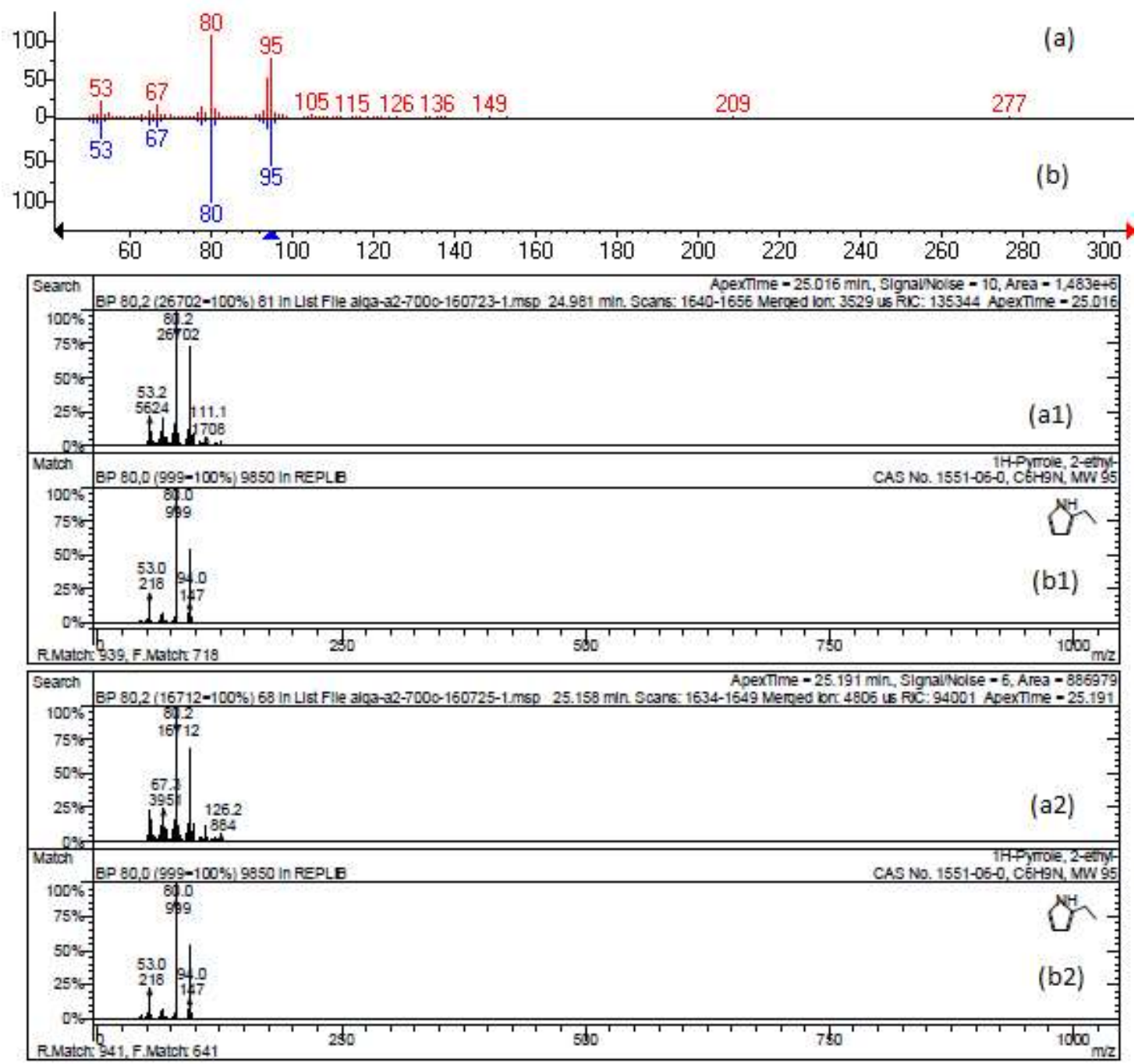

A Figura 47 apresenta o espectro relativo ao composto com tempo de retenção de aproximadamente 49 minutos. A diferença entre os dois picos mais abundantes $\mathrm{m} / \mathrm{z}$ 117 e 90 resulta em um fragmento de massa $\mathrm{m} / \mathrm{z} 27$, o qual pode ser associado a perda de uma molécula neutra de $\mathrm{HCN}$, indicando que se trata de um composto nitrogenado. Os quatro fragmentos de massa mais abundantes no espectro do composto analisado, m/z 117, 90, 89 e 116, são coincidentes com os picos mais 
abundantes do composto sugerido como mais provável, o que indica que o anel benzênico e o grupo nitrila provavelmente fazem parte do composto pesquisado.

Figura 47 - Espectro pesquisado(a) $x$ Espectro catalogado(b) - Tempos de retenção 49,245 ${ }^{(1)}$ e $49,273^{(2)} \mathrm{min}$ - Pirólise a $700{ }^{\circ} \mathrm{C}$
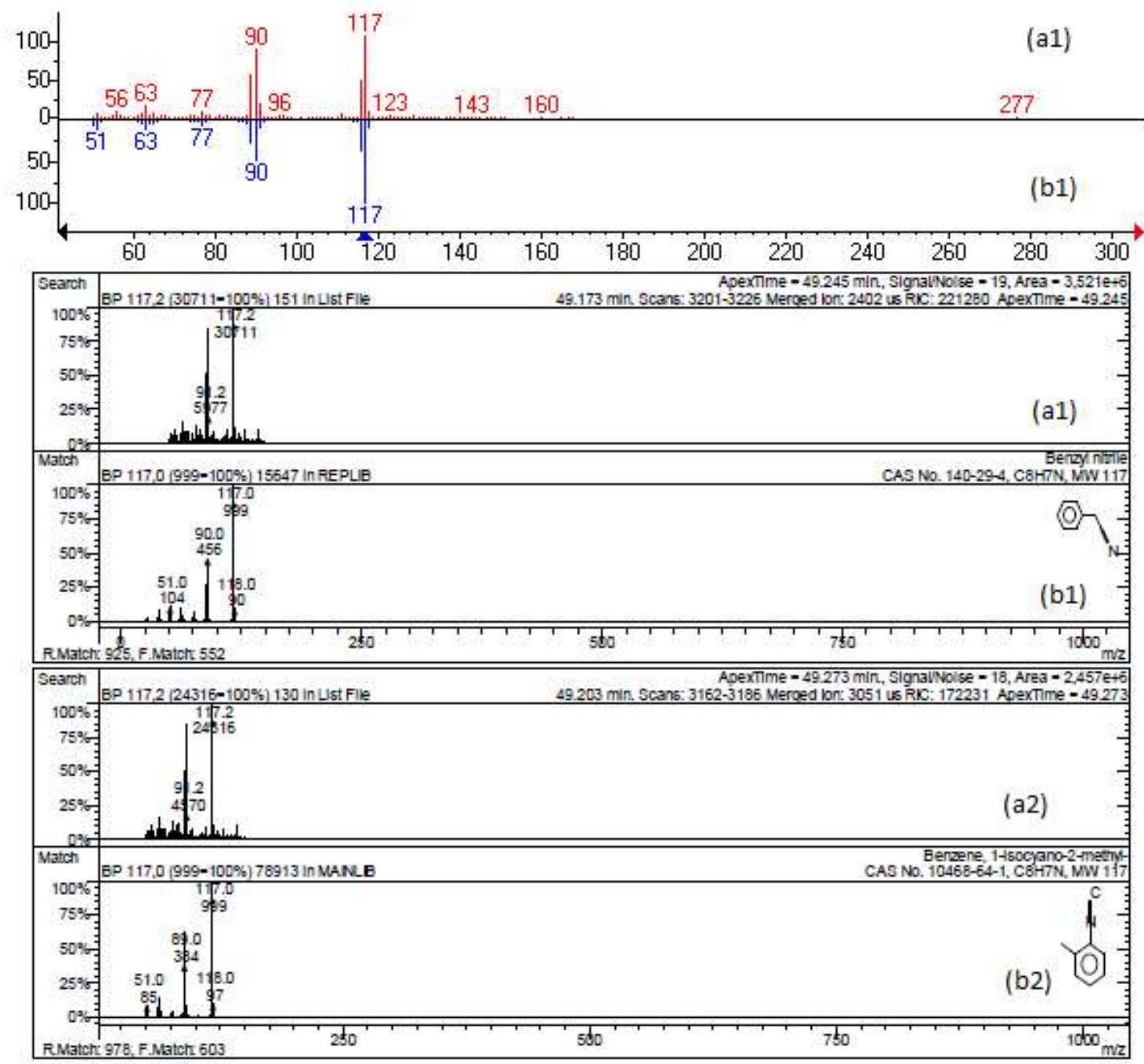

A Figura 48 apresenta um espectro pesquisado cujo cinco picos de maior abundância, $\mathrm{m} / \mathrm{z} 117,90,89,63$ e 118, são os mesmos que o indol, o que indica que a estrutura molecular o indol é provavelmente coincidente com composto obtido através da pirólise. 
Figura 48 - Espectro pesquisado(a) $x$ Espectro catalogado(b) - Tempos de retenção $71,058^{(1)} e$ $71,026^{(2)} \mathrm{min}$ - Pirólise a $700^{\circ} \mathrm{C}$
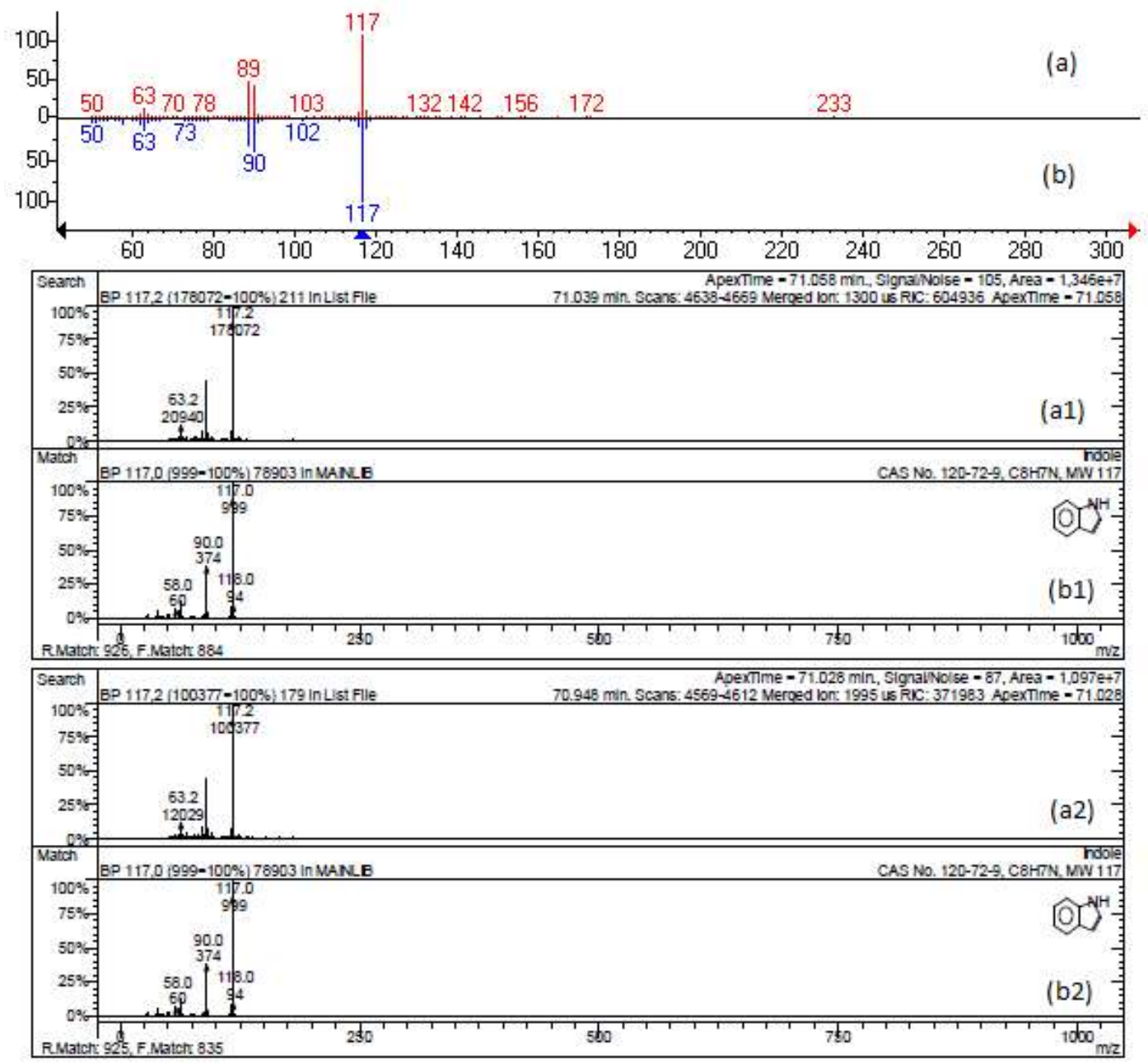


\section{A-3 Reação a $800^{\circ} \mathrm{C}$}

A presença dos picos m/z 91 e 65 como dois dos mais abundantes do espectro presente na Figura 49 identifica este composto como possuindo um anel aromático.

Figura 49 - Espectro pesquisado ${ }^{(a)} \times$ Espectro catalogado(b) - Tempos de retenção $8,031^{(1)} \mathrm{e}$ $8,359^{(2)} \mathrm{min}$ - Pirólise a $800{ }^{\circ} \mathrm{C}$

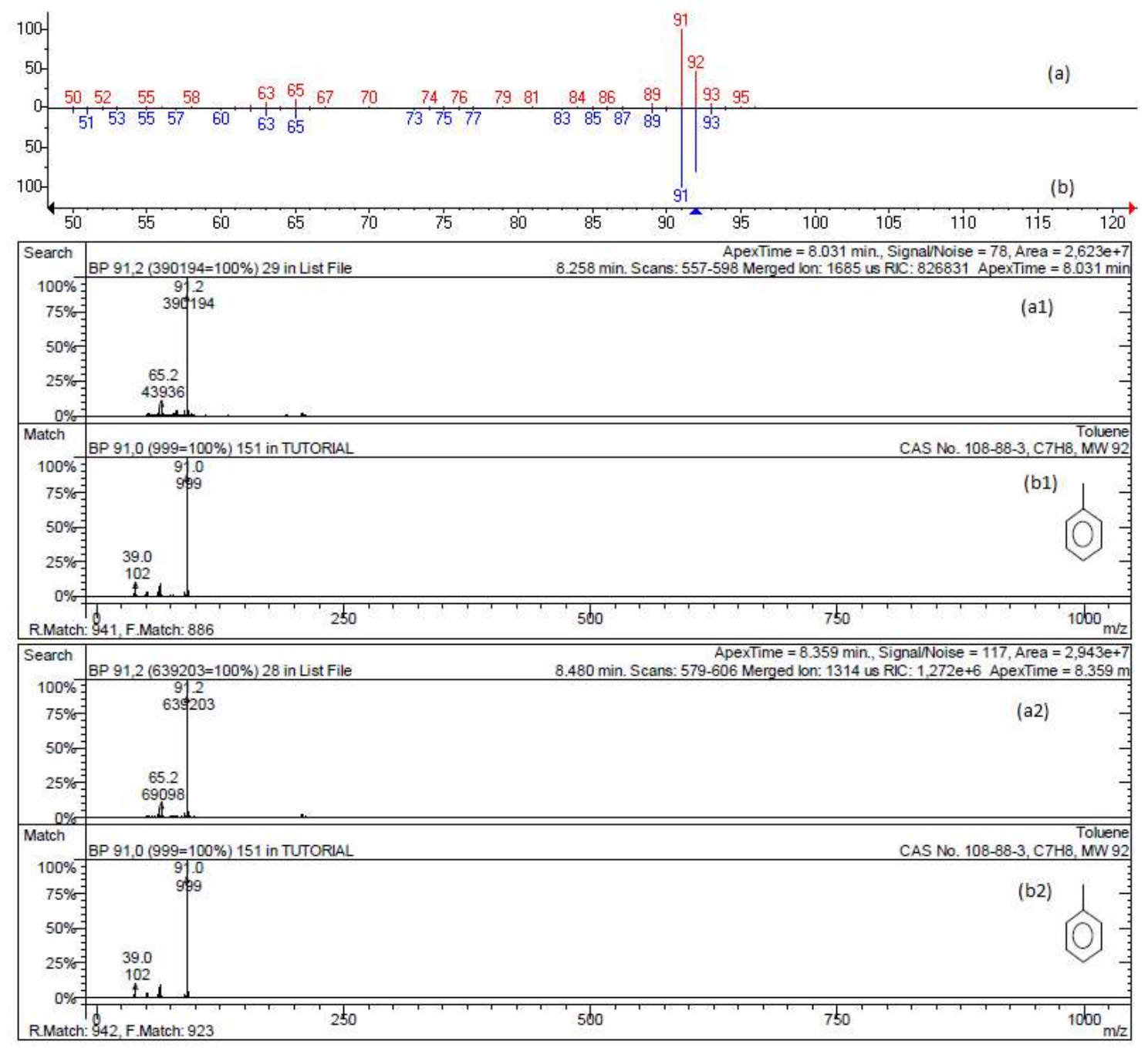


Da mesma forma, o espectro apresentado na Figura 50 evidencia uma presença relevante dos fragmentos $\mathrm{m} / \mathrm{z} 91$ e 65 , indicando a presença de um aromático. A diferença entre as massas m/z 106 e 91, resulta em um fragmento m/z 15, que pode ser associado a perda de um radical ${ }^{\circ} \mathrm{CH}_{3}$, e a diferença entre os fragmentos $\mathrm{m} / \mathrm{z} 91$ e 77 e os fragmentos m/z 79 e 65 resulta em m/z 14, que frequentemente está associado a perda de $\mathrm{CH}_{2}$, o que mostra que o anel aromático possui ramificações, compatíveis com o xileno, sejam as ramificações na posição "orto" ou "para".

Figura 50 - Espectro pesquisado(a) $x$ Espectro catalogado(b) - Tempos de retenção $12,099^{(1)} e$ $12,651^{(2)} \mathrm{min}$ - Pirólise a $800^{\circ} \mathrm{C}$

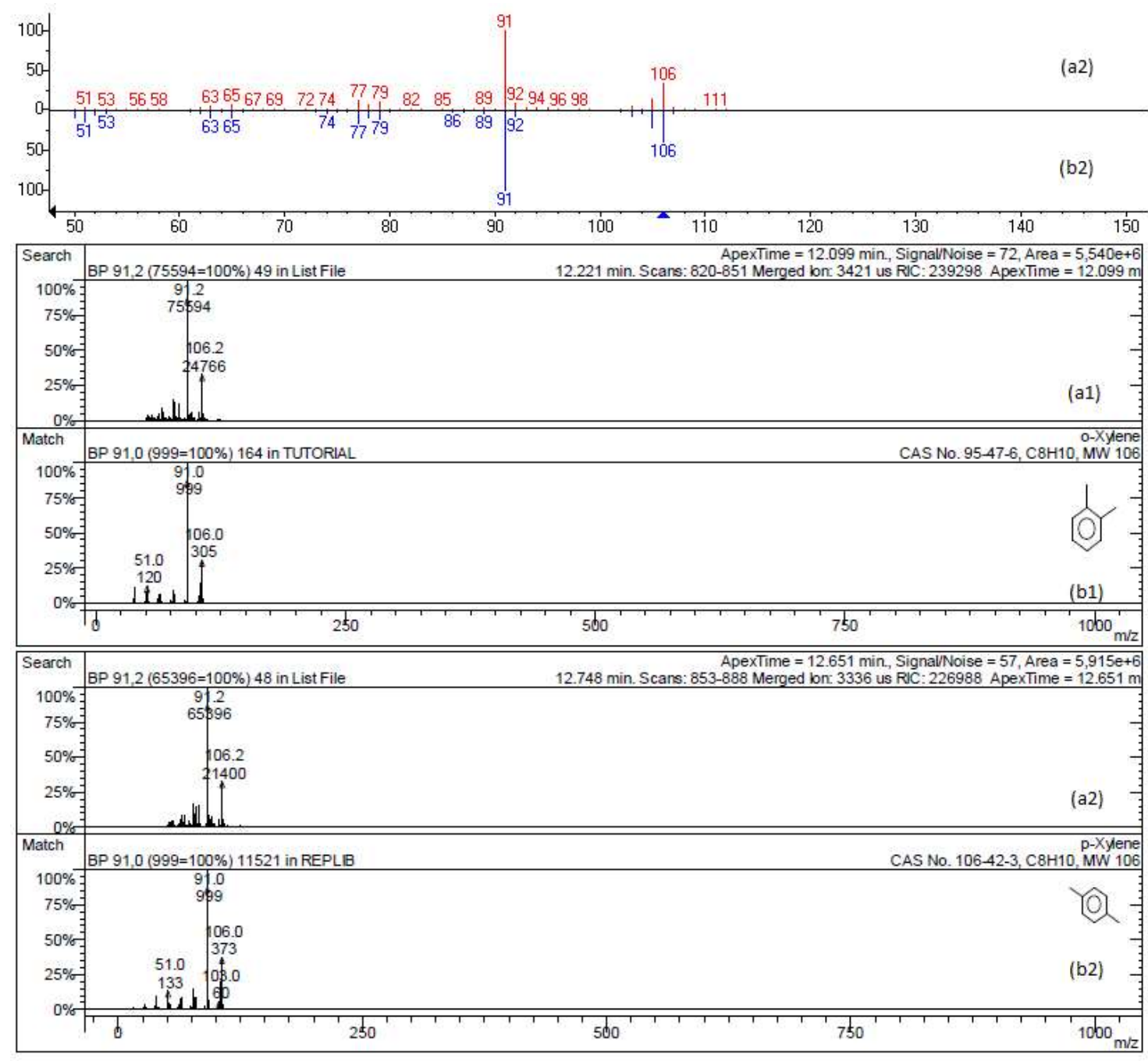


A Figura 51 apresenta o espectro relativo ao tempo de retenção de aproximadamente 17 minutos. A coincidência entre os fragmentos de massa mais abundantes para os dois compostos, que são $\mathrm{m} / \mathrm{z} 80,81,53,78$ e 52 , é um indicativo de que a molécula pesquisada é compatível com o 3-metil-1H-pirrol, tratando-se, portanto, de uma amina.

Figura 51 - Espectro pesquisado(a) $x$ Espectro catalogado(b) - Tempos de retenção $16,915^{(1)}$ e $17,532^{(2)} \mathrm{min}$ - Pirólise a $800^{\circ} \mathrm{C}$

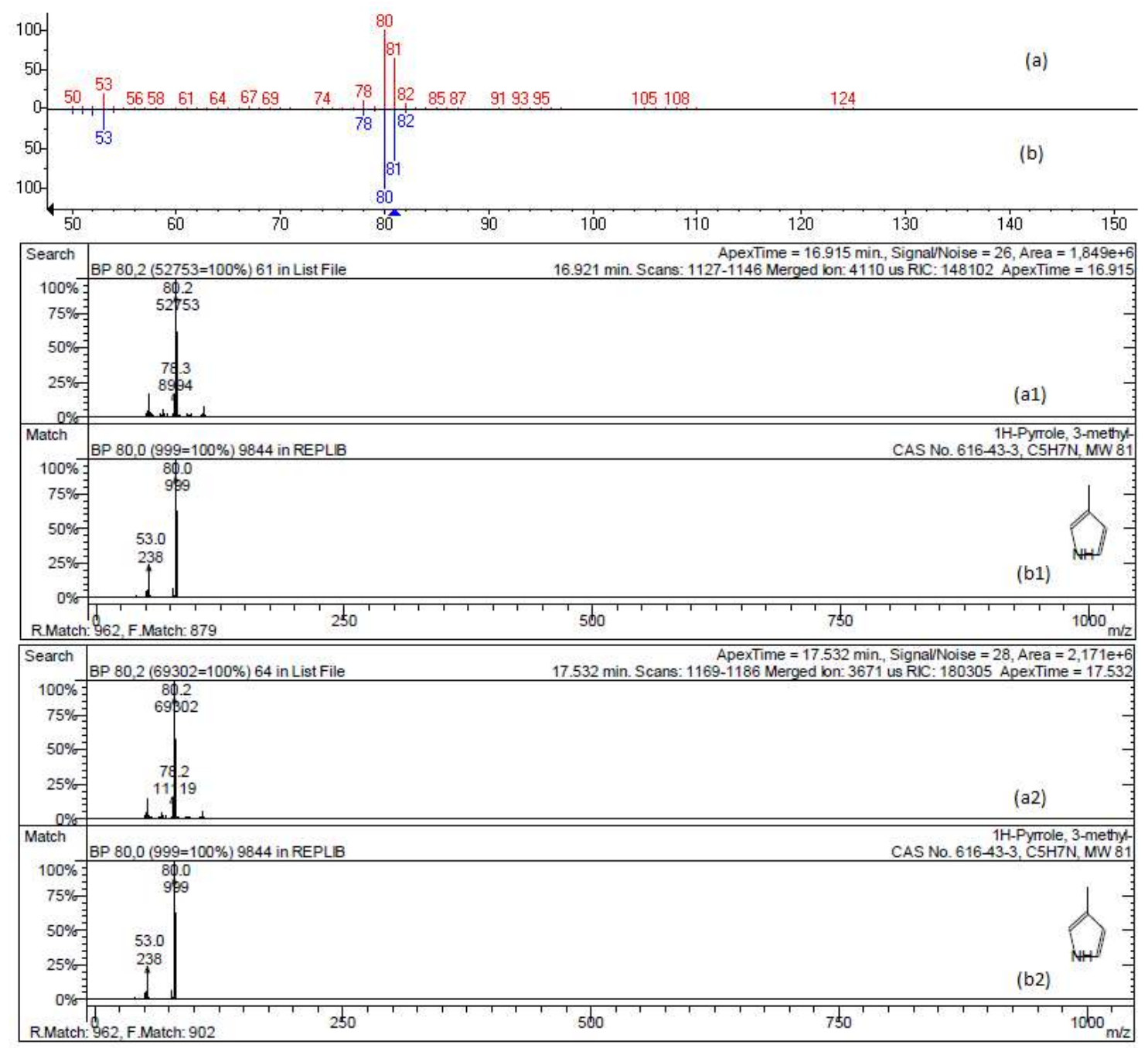


Analogamente, com tempo de retenção de aproximadamente 25 minutos, o espectro apresentado na Figura 52 possui como picos de maior abundância m/z 80, 95, 94, 53 e 67, os quais coincidem com os picos de maior abundância do composto sugerido como mais provável, indicando que o 2-etil-pirrol, ou um isômero de posição, faz parte da estrutura do composto pesquisado, tratando-se, assim, de uma amina.

Figura 52 - Espectro pesquisado(a) $x$ Espectro catalogado(b) - Tempos de retenção $24,960^{(1)}$ e $25,471^{(2)} \mathrm{min}$ - Pirólise a $800^{\circ} \mathrm{C}$

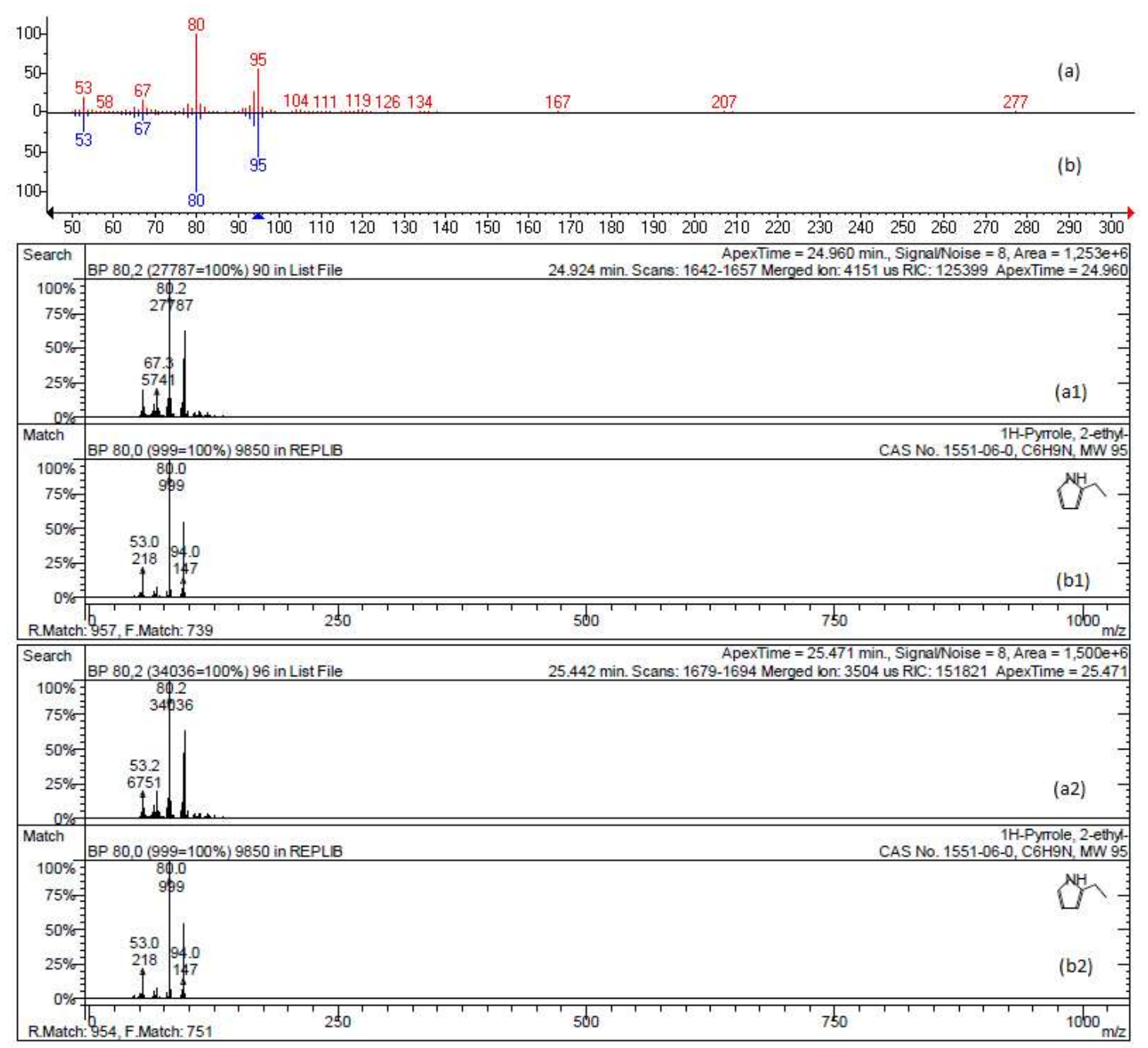


O composto com tempo de retenção de aproximadamente 47 minutos tem seu espectro de massa apresentado na Figura 53. A diferença entre os fragmentos de massa m/z 108 e 77 resulta em um fragmento $\mathrm{m} / \mathrm{z} 31$, o qual pode ser associado a perda de um radical ${ }^{\circ} \mathrm{CH}_{2} \mathrm{OH}$. Da mesma forma, a diferença entre os picos $\mathrm{m} / \mathrm{z} 107 \mathrm{e}$ 90 resulta em um fragmento $\mathrm{m} / \mathrm{z} 17$ que corresponde a perda de um radical $\bullet \mathrm{OH}$, identificando que o grupo funcional de um álcool está presente nesta molécula. A semelhança entre os quatro picos de maior intensidade, m/z 107, 108, 77 e 79, presentes tanto na molécula pesquisada quanto na molécula sugerida indicam que o metil-fenol é compatível com a molécula pesquisada.

Figura 53 - Espectro pesquisado ${ }^{(a)} \times$ Espectro catalogado ${ }^{(b)}$ - Tempos de retenção $47,438^{(1)}$ e $47,630^{(2)} \mathrm{min}$ - Pirólise a $800^{\circ} \mathrm{C}$

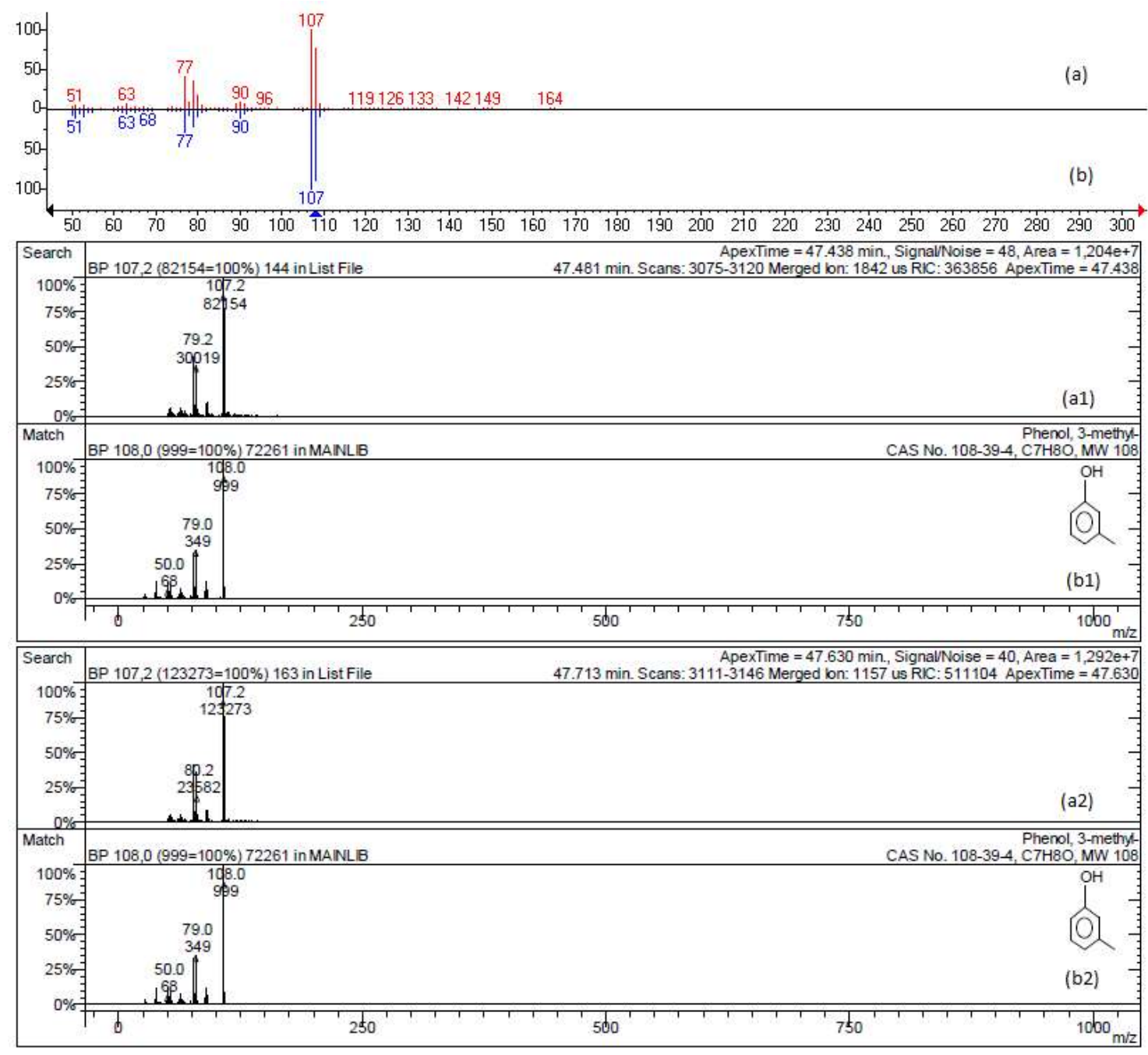


A Figura 54 apresenta o espectro relativo ao composto com tempo de retenção de aproximadamente 49 minutos. A diferença entre os fragmentos m/z 117 e 90, que são os mais abundantes, resulta em um fragmento de massa $\mathrm{m} / \mathrm{z} 27$, o qual pode ser associado a perda de uma molécula neutra de $\mathrm{HCN}$, indicando que se trata de um composto nitrogenado. Os quatro fragmentos de massas mais abundantes no espectro do composto analisado, $\mathrm{m} / \mathrm{z}$ 117, 90, 89 e 116, são coincidentes com os picos mais abundantes do composto sugerido como mais provável, a benzilnitrila, indicando que essa estrutura provavelmente faz parte do composto pesquisado.

Figura 54 - Espectro pesquisado(a) $x$ Espectro catalogado(b) - Tempos de retenção $49,220^{(1)}$ e $49,904^{(2)} \mathrm{min}$ - Pirólise a $800^{\circ} \mathrm{C}$

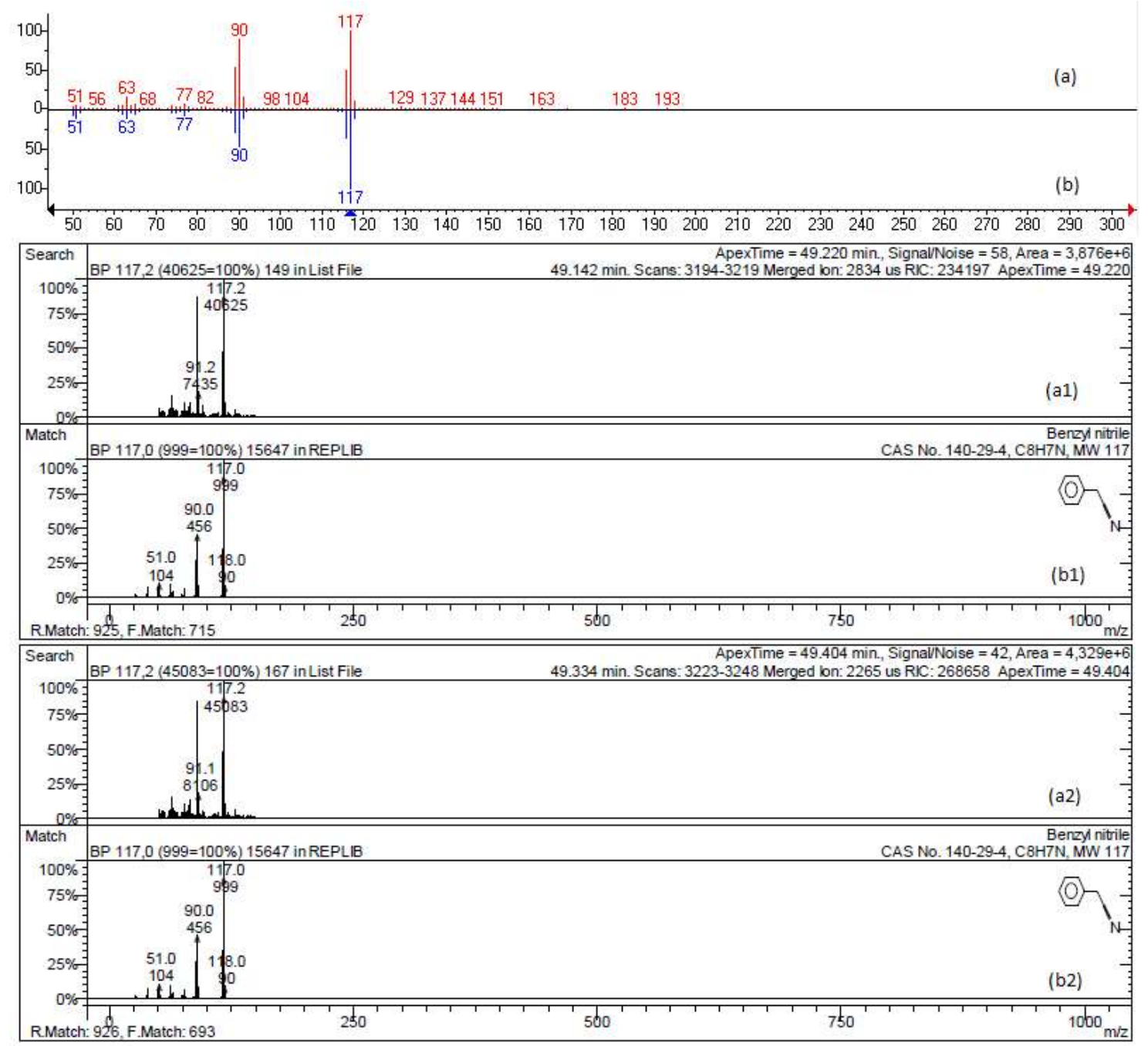


O espectro relativo ao composto com tempo de retenção de aproximadamente 78 minutos (Figura 55) possui como picos principais os fragmentos $\mathrm{m} / \mathrm{z}$ 130, 103 e 77 . A diferença entre os fragmentos m/z 130 e 103, e dos fragmentos m/z 103 e 77 resultam respectivamente em fragmentos $\mathrm{m} / \mathrm{z} 27$, que pode ser relacionado à perda de uma molécula neutra $\mathrm{HCN}$, e $\mathrm{m} / \mathrm{z} 26$, relacionado à perda de um radical ${ }^{\circ} \mathrm{CN}$, caracterizando esta substância como um composto nitrogenado. A coincidência entre estre os quatro fragmentos com picos mais abundantes, m/z 130, 131, 77 e 103 na mesma ordem, indica que o 3-metil-1H-indol ou um dos seus isômeros de posição é compatível com o composto pesquisado.

Figura 55 - Espectro pesquisado(a) $x$ Espectro catalogado(b) - Tempos de retenção $78,365^{(1)}$ e $78,423^{(2)} \mathrm{min}$ - Pirólise a $800^{\circ} \mathrm{C}$

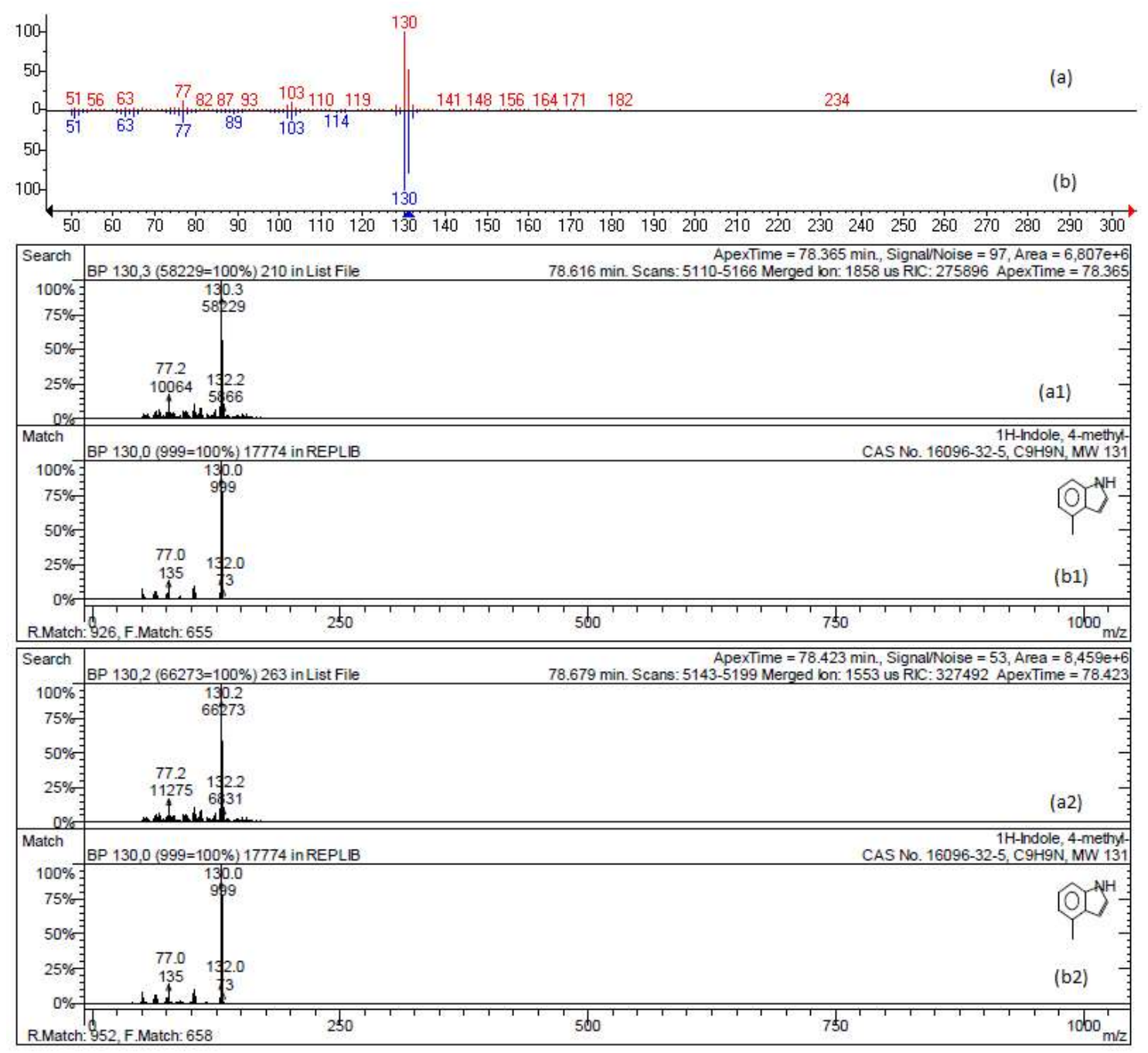




\section{A-4 Reação a $900^{\circ} \mathrm{C}$}

Os espectros apresentados na Figura 56 são relativos ao composto que deixa a coluna cromatográfica após aproximadamente 8,5 minutos de análise. Apesar dos espectros serem similares, para cada uma das corridas foi sugerido um tipo de composto diferente, conforme mostram os espectros "b1" e "b2".

Figura 56 - Espectro pesquisado(a) $x$ Espectro catalogado ${ }^{(b)}-$ Tempos de retenção $8,480^{(1)}$ e $8,464^{(2)} \mathrm{min}$ - Pirólise a $900^{\circ} \mathrm{C}$

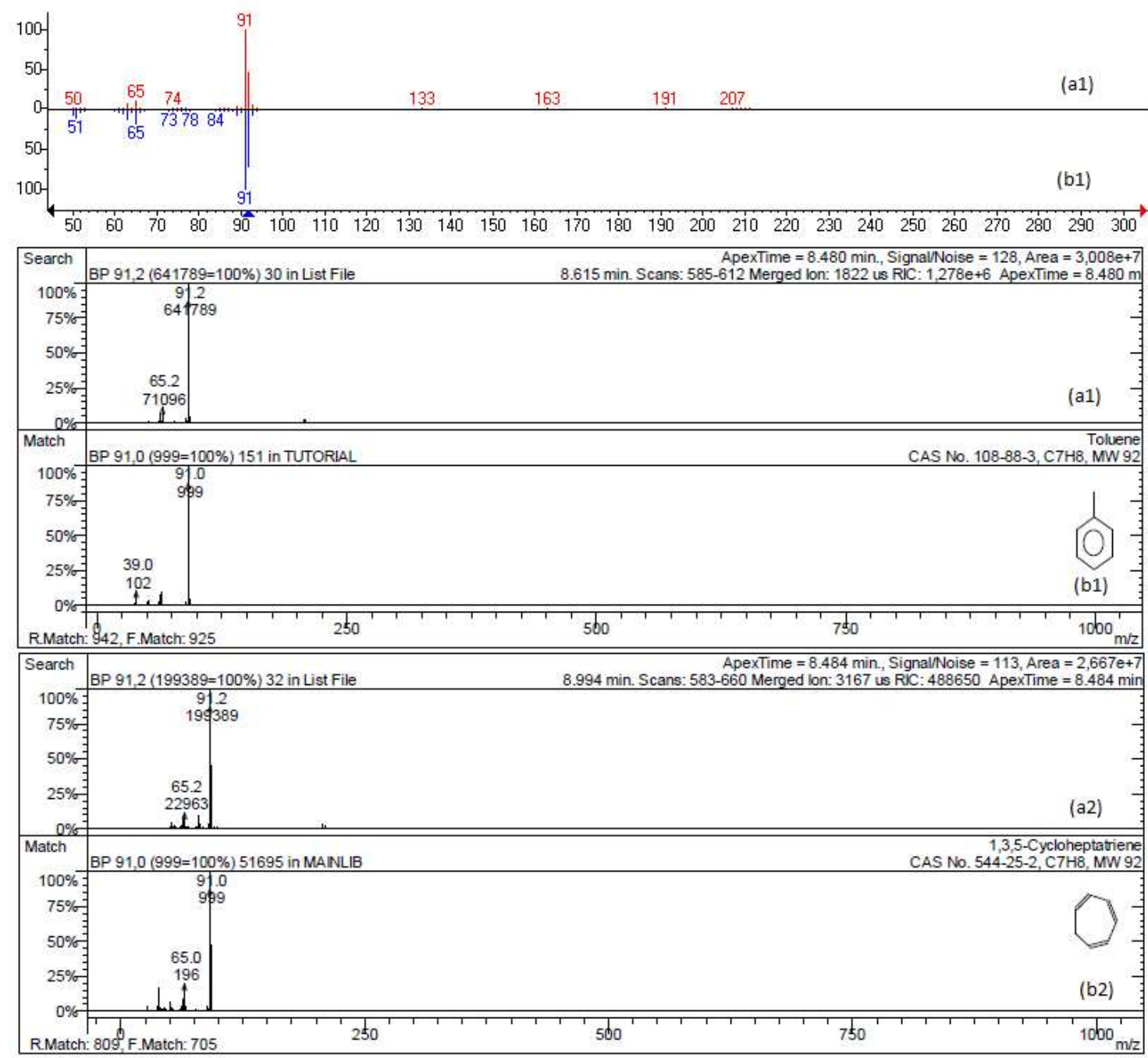

O composto procurado apresenta dois picos característicos de compostos aromáticos, sendo eles o m/z 91, que está relacionado ao íon tropílio e o m/z 65 que corresponde à perda de uma molécula de acetileno pelo íon tropílio. Estes dois picos com intensidade relevante no espectro de massas indicam a presença de um anel 
aromático em um hidrocarboneto ou que se trata de um hidrocarboneto cíclico e insaturado.

O espectro apresentado na Figura 57 evidencia uma presença relevante dos fragmentos m/z 91 e 65, indicando a presença de um aromático. Conforme já foi discutido nos itens anteriores, a diferença entre as massas m/z 106 e 91, resulta em um fragmento $\mathrm{m} / \mathrm{z} 15$, que pode ser associado a perda de um radical ${ }^{\circ} \mathrm{CH}_{3}$, e a diferença entre os fragmentos m/z 91 e 77 e os fragmentos m/z 79 e 65 resulta em $\mathrm{m} / \mathrm{z} 14$, que frequentemente está associado a perda de $\mathrm{CH}_{2}$, o que mostra que o anel aromático possui ramificações compatíveis com o xileno, sejam as ramificações na posição "orto" ou "para".

Figura 57 - Espectro pesquisado(a) $x$ Espectro catalogado(b) - Tempos de retenção 12,827 ${ }^{(1)}$ e $12,822^{(2)} \mathrm{min}$ - Pirólise a $900{ }^{\circ} \mathrm{C}$

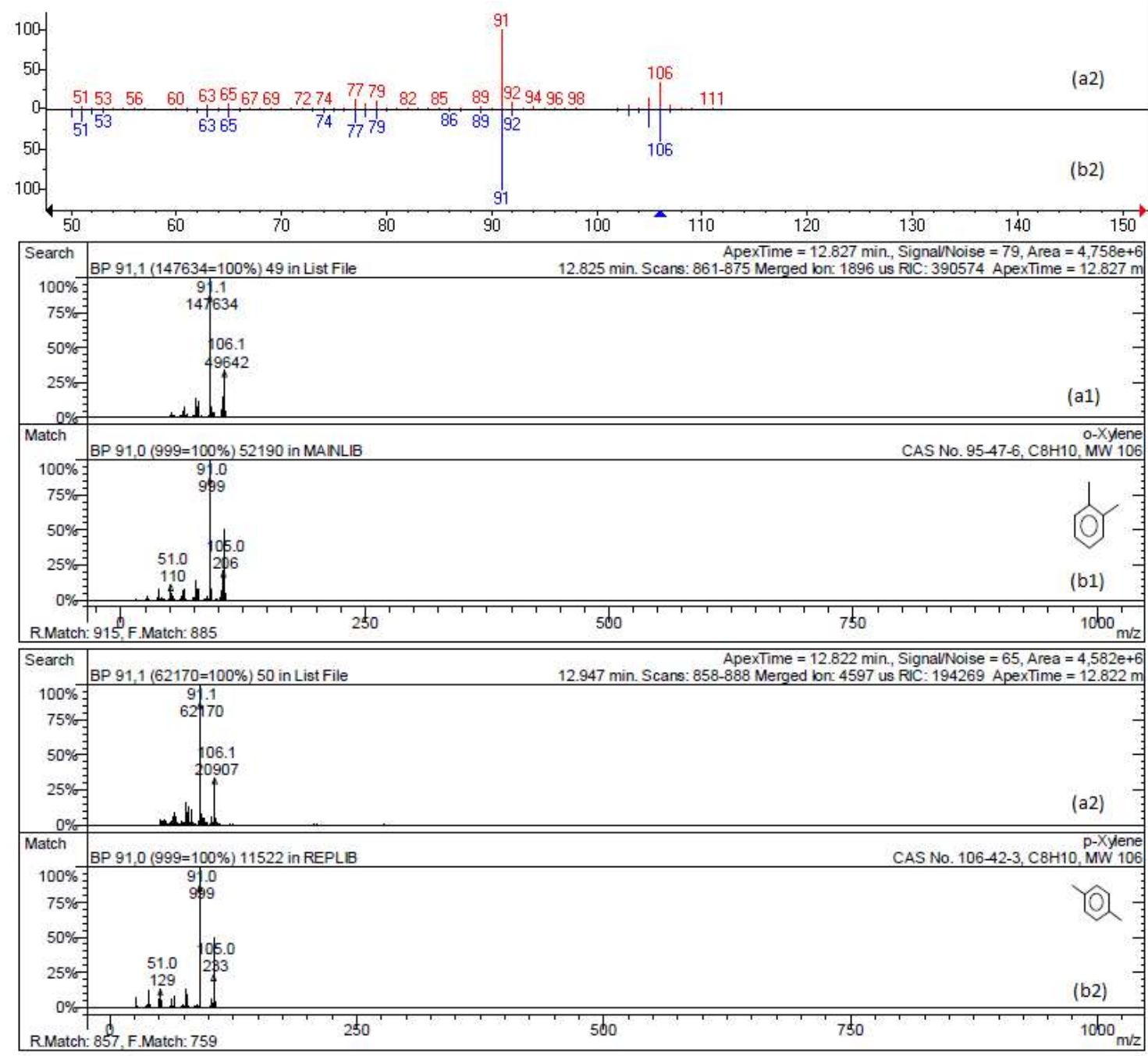


A Figura 58 apresenta o espectro relativo ao tempo de retenção de aproximadamente 17,7 minutos. A coincidência entre os fragmentos de massa mais abundantes para o composto pesquisado e o 3-metil-pirrol, que são $\mathrm{m} / \mathrm{z} 80,81,53,78$ e 52, é um indicativo de que a molécula sugerida é compatível com o composto pesquisado, tratando-se, portanto, de uma amina.

Figura 58 - Espectro pesquisado(a) $x$ Espectro catalogado(b) - Tempos de retenção $17,705^{(1)} e$ $17,698^{(2)} \mathrm{min}$ - Pirólise a $900^{\circ} \mathrm{C}$

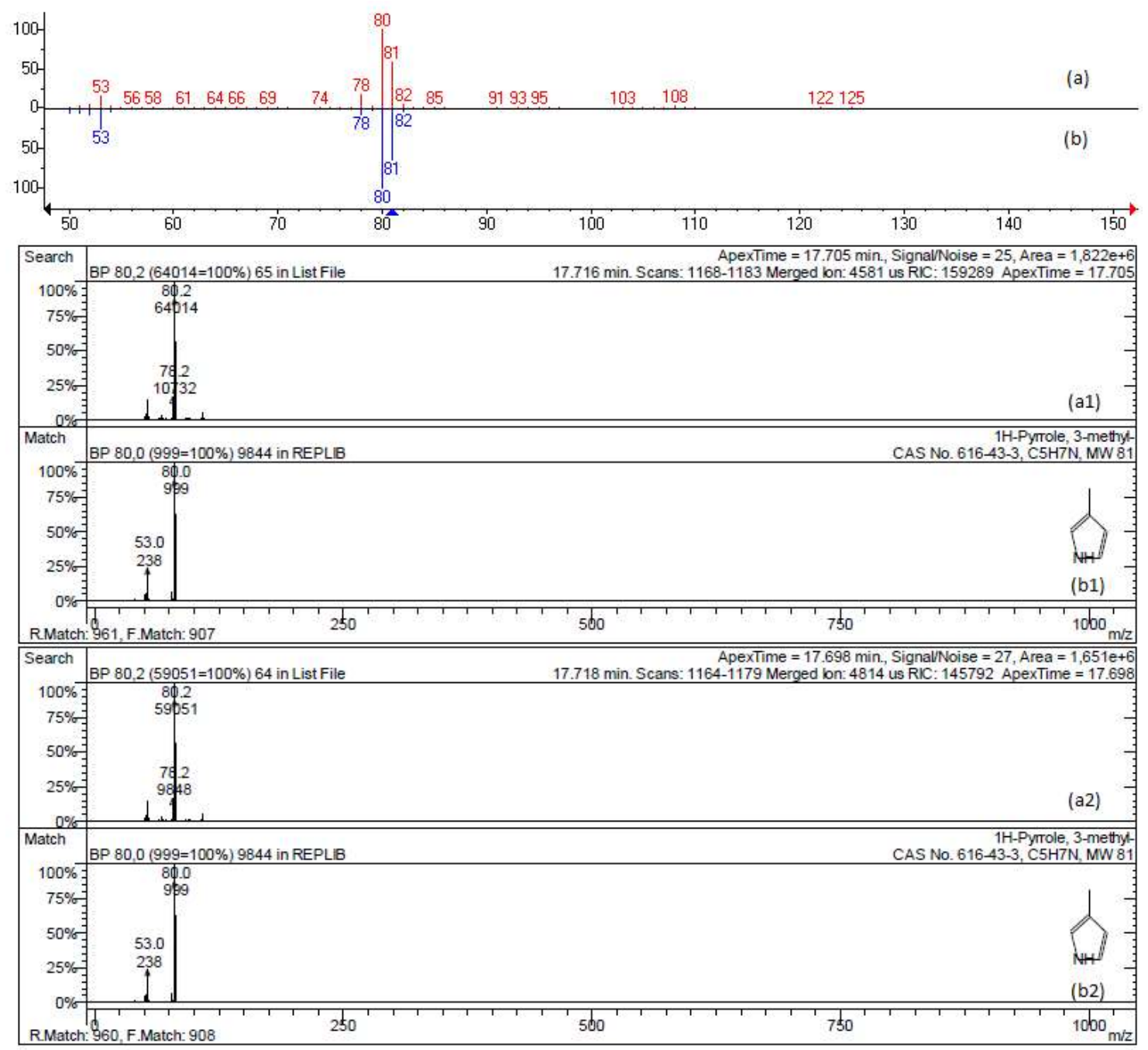


Analogamente, com tempo de retenção de aproximadamente 25,5 minutos, o espectro apresentado na Figura 59 possui como picos de maior abundância m/z 80, 95, 94, 53 e 67, os quais coincidem com os picos de maior abundância do composto sugerido como mais provável, indicando que o 2-etil-pirrol, ou um isômero de posição, faz parte da estrutura ou é o composto pesquisado, tratando-se novamente de uma amina.

Figura 59 - Espectro pesquisado(a) $x$ Espectro catalogado(b) - Tempos de retenção 25,605(1) e $25,592^{(2)} \mathrm{min}$ - Pirólise a $900{ }^{\circ} \mathrm{C}$

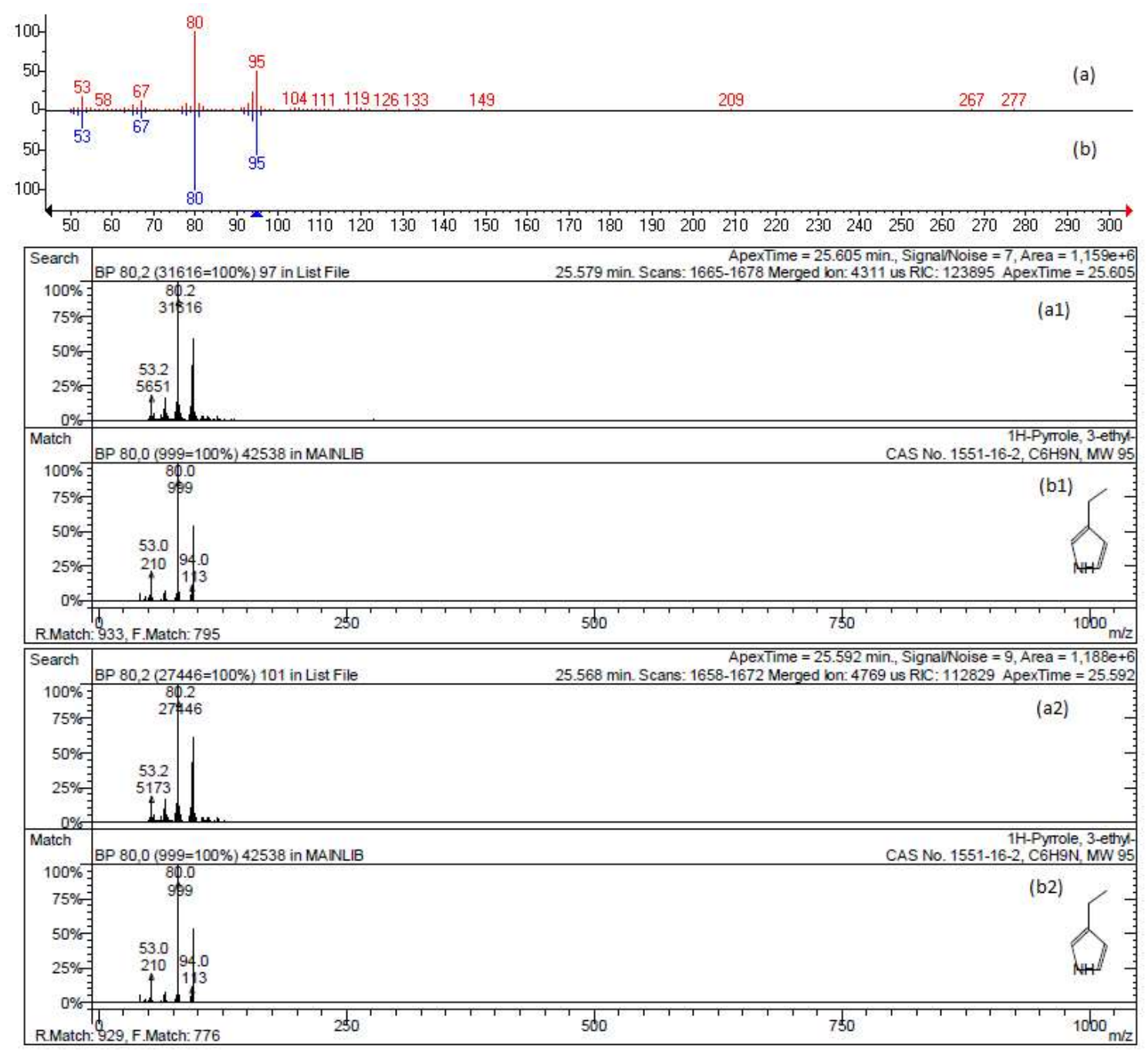


Na Figura 60, o espectro pesquisado possui fragmentos de massa compatíveis com o indol. Sendo os cinco picos de maior abundância, m/z 117, 90, 89, 63 e 118, os mesmos para os dois compostos e aparecem na mesma sequência nos dois casos.

Figura 60 - Espectro pesquisado(a) $x$ Espectro catalogado(b) - Tempos de retenção $71,076^{(1)} e$ $71,051^{(2)} \mathrm{min}$ - Pirólise a $900{ }^{\circ} \mathrm{C}$

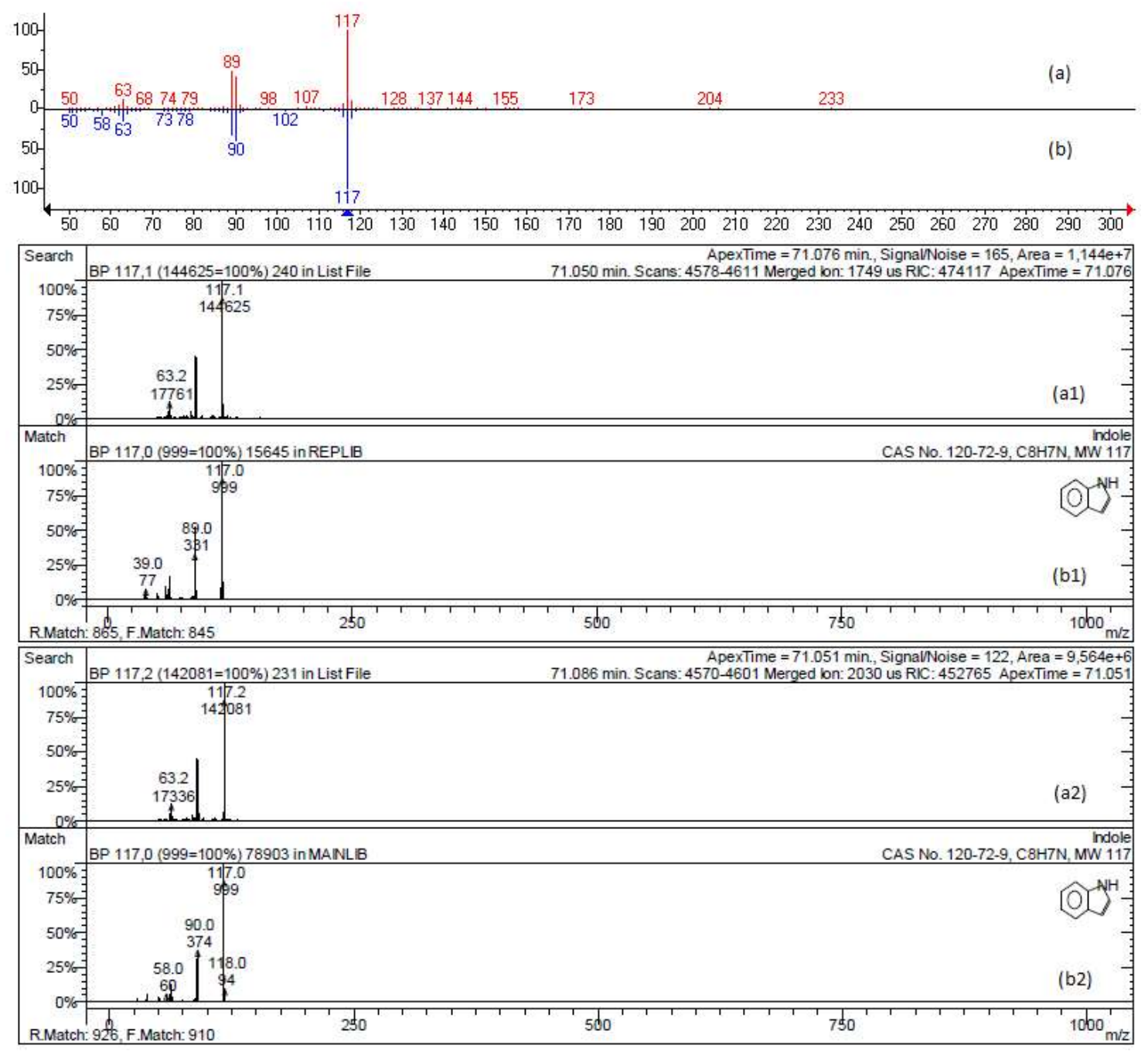


O espectro relativo ao composto com tempo de retenção de aproximadamente 78 minutos, apresentado na Figura 61, possui como picos principais os fragmentos $\mathrm{m} / \mathrm{z}$ 130, 103 e 77. A diferença entre os fragmentos m/z 130 e 103, e dos fragmentos m/z 103 e 77 resultam respectivamente em fragmentos $\mathrm{m} / \mathrm{z} 27$, que pode ser relacionado à perda de uma molécula neutra $\mathrm{HCN}$, e $\mathrm{m} / \mathrm{z} 26$, relacionado à perda de um radical - $\mathrm{CN}$, caracterizando esta substância como um composto nitrogenado. A coincidência entre estre os quatro fragmentos com picos mais abundantes, m/z 130, 131, 77 e 103 na mesma ordem, indica que o 3-metil-indol ou um dos seus isômeros de posição faz parte do composto pesquisado.

Figura 61 - Espectro pesquisado(a) $x$ Espectro catalogado(b) - Tempos de retenção $78,409^{(1)} e$ $78,380^{(2)} \mathrm{min}$ - Pirólise a $900^{\circ} \mathrm{C}$

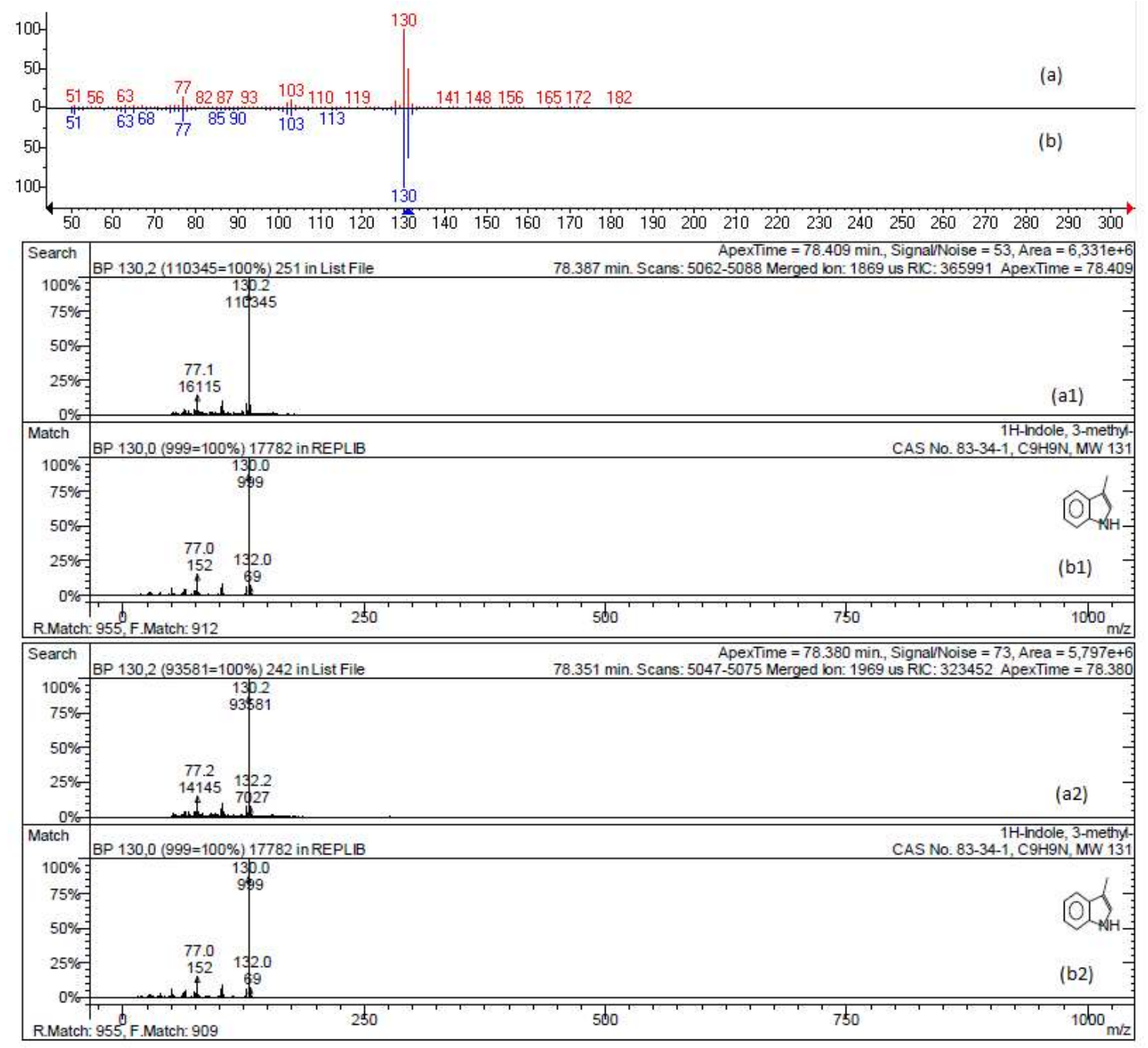

